\title{
Dietary nitrate and sports performance
}

Citation for published version (APA):

Jonvik, K. L. (2018). Dietary nitrate and sports performance. [Doctoral Thesis, Maastricht University]. Datawyse / Universitaire Pers Maastricht. https://doi.org/10.26481/dis.20180913kj

Document status and date:

Published: 01/01/2018

DOI:

10.26481/dis.20180913kj

Document Version:

Publisher's PDF, also known as Version of record

\section{Please check the document version of this publication:}

- A submitted manuscript is the version of the article upon submission and before peer-review. There can be important differences between the submitted version and the official published version of record.

People interested in the research are advised to contact the author for the final version of the publication, or visit the DOI to the publisher's website.

- The final author version and the galley proof are versions of the publication after peer review.

- The final published version features the final layout of the paper including the volume, issue and page numbers.

Link to publication

\footnotetext{
General rights rights.

- You may freely distribute the URL identifying the publication in the public portal. please follow below link for the End User Agreement:

www.umlib.nl/taverne-license

Take down policy

If you believe that this document breaches copyright please contact us at:

repository@maastrichtuniversity.nl

providing details and we will investigate your claim.
}

Copyright and moral rights for the publications made accessible in the public portal are retained by the authors and/or other copyright owners and it is a condition of accessing publications that users recognise and abide by the legal requirements associated with these

- Users may download and print one copy of any publication from the public portal for the purpose of private study or research.

- You may not further distribute the material or use it for any profit-making activity or commercial gain

If the publication is distributed under the terms of Article $25 \mathrm{fa}$ of the Dutch Copyright Act, indicated by the "Taverne" license above, 


\section{Dietary nitrate and sports performance}




\section{e्Nutrim}

The studies presented in this thesis were performed within School of Nutrition and Translational Research in Metabolism. The project was financially supported through a grant from the Dutch Technology Foundation STW (Beet-ing your competitors, project number 12877), and was performed in collaboration between Maastricht University and HAN University of Applied Sciences in a joint consortium with NOC*NSF, Sports Centre Papendal, Kenniscentrum Suiker \& Voeding, and NIZO Food Research.

Cover design: Hensen Trenning, Karin Lambrechtse and Kristin Lundanes Jonvik Layout: Hensen Trenning, Karin Lambrechtse and Kristin Lundanes Jonvik Printed by: Datawyse, Universitaire Pers Maastricht ISBN 978-94-93019-04-1

(c) Copyright Kristin Lundanes Jonvik, Maastricht 2018

All rights reserved. No part of this thesis may be reproduced, distributed, or transmitted in any form or by any means, including photocopying, recording, or other electronic or mechanical methods, without the prior written permission of the author or publisher, except in the case of brief quotations embodied in critical reviews and certain other noncommercial uses permitted by copyright law. 


\section{Dietary nitrate and sports performance}

\section{DISSERTATION}

To obtain the degree of Doctor at Maastricht University, on the authority of the Rector Magnificus, Prof. Dr. Rianne M. Letschert in accordance with the decision of the Board of Deans, to be defended in public on Thursday 13 September 2018, at 16:00 hours

by

Kristin Lundanes Jonvik

Born on 24-09-1987 
PROMOTOR

Prof. dr. L.J.C. van Loon

CO-PROMOTOR

Dr. L.B. Verdijk

\section{ASSESSMENT COMMITTEE}

Prof. dr. A.M.W.J. Schols (chair)

Prof. dr. F. Brouns

Prof. dr. A. Jones (University of Exeter, United Kingdom)

Prof. dr. R. Meeusen (Vrije Universiteit Brussel, Belgium)

Prof. dr. M. Poeze 
Niet de hoeveelheid overwinningen, maar het aantal foute passes, gemiste kansen en bloedneuzen die daaraan vooraf gingen bepalen hoe succesvol je bent

De 'Wall of failure' in...

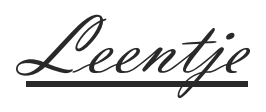





\section{Table of contents}

CHAPTER 1 General introduction

CHAPTER 2 Can elite athletes benefit from dietary nitrate 27 supplementation?

CHAPTER 3 No effect of acute and 6-day nitrate supplementation on $\mathrm{VO}_{2}$ and time-trial performance in highly-trained cyclists

CHAPTER 4 Nitrate-rich vegetables increase plasma nitrate and nitrite concentrations and lower blood pressure in healthy adults

CHAPTER 5 Habitual dietary nitrate intake in highly trained athletes

CHAPTER 6 Repeated-sprint performance and plasma responses following beetroot juice supplementation do not differ between recreational, competitive and elite sprint athletes

CHAPTER 7 The effect of beetroot juice supplementation on dynamic apnea and intermittent sprint performance in elite female water polo players

CHAPTER 8 Sucrose but not nitrate ingestion reduces high-intensity exercise-induced gut injury

CHAPTER 9 General discussion

Summary

Valorization

Dankwoord

Curriculum Vitae

List of Publications 



\section{Chapter}

General introduction

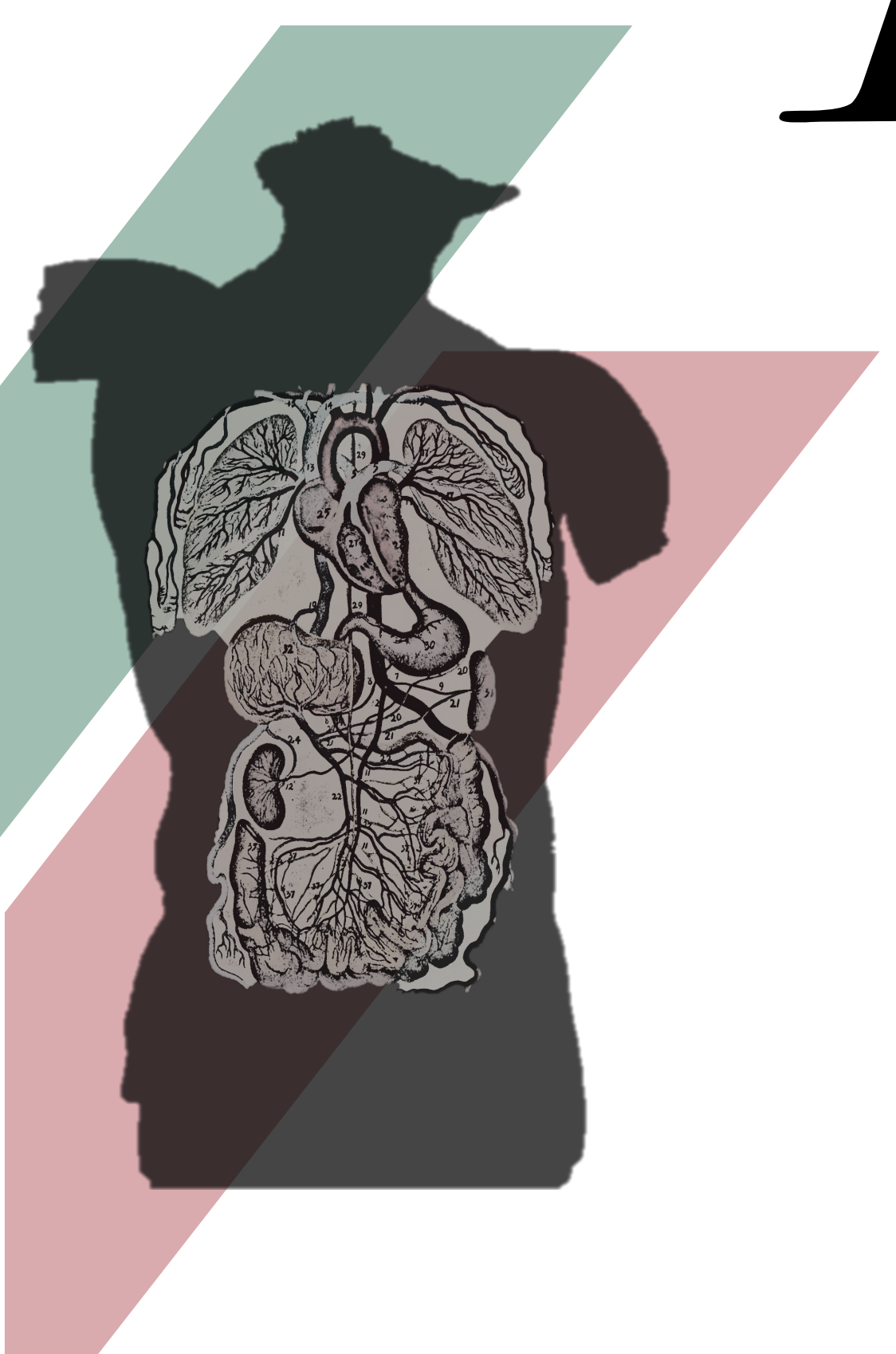




\section{Chapter 1}

"Sports nutrition involves the application of eating strategies to promote good health and adaptation to the training program, to recover quickly after each exercise session and to perform optimally during competition" (1). The science of nutrition in relation to sports performance has progressed from empirical studies in the 1960s, on the effects of dietary manipulations, to the direct investigation of the physiological mechanisms of the specific nutritional demands of exercise (2). Within the last decade, there has been an explosion of publications and consensus statements related to sports nutrition. Especially the use of sports supplements to enhance exercise performance has received more attention. Sports supplements represent an ever-growing industry, and the prevalence of supplement use by athletes internationally has been estimated to range between $40-90 \%$, with greater prevalence reported among elite athletes (3).

One of the supplements becoming progressively popular amongst athletes is dietary nitrate, due to its proposed beneficial effects on health and performance. Since Larsen et al. in 2007 (4) reported reduced oxygen demands during exercise and thereby more efficient energy use following nitrate supplementation, research on nitrate in athletes has expanded. Even though there is great diversity in the results of studies on nitrate and performance, nitrate-rich beetroot juice is now considered one of the top-5 ergogenic aids (5). As a result, many athletes are currently using beetroot juice as a performance-enhancing supplement. Next to being a popular supplement, nitrate is a component of our habitual diet, and is found in considerable amounts in beetroot and green leafy vegetables, such as rocket salad, spinach and lettuce (6). The beneficial effects of dietary nitrate are related to its ability to increase the bioavailability of nitric oxide in the human body (7).

\section{Dietary nitrate and nitric oxide}

Nitric oxide (NO) represents a key regulator of several physiological functions (Figure 1.1), including vasodilation, muscle contractility, cell cycle regulation, mitochondrial respiration, glucose and calcium homeostasis $(8,9)$; all of which represent important factors in determining exercise and performance capacity. NO was originally believed to be generated solely through the oxidation of L-arginine in a reaction catalyzed by nitric oxide synthase (NOS), with nitrite $\left(\mathrm{NO}_{2}^{-}\right)$and nitrate $\left(\mathrm{NO}_{3}{ }^{-}\right)$considered to be inert by-products of this process. However, in the 1990s a reverse pathway was shown, whereby nitrate and nitrite can be reduced back to NO $(10,11)$. There is now a general consensus that dietary nitrate ingestion can strongly increase plasma nitrate and nitrite concentrations. 

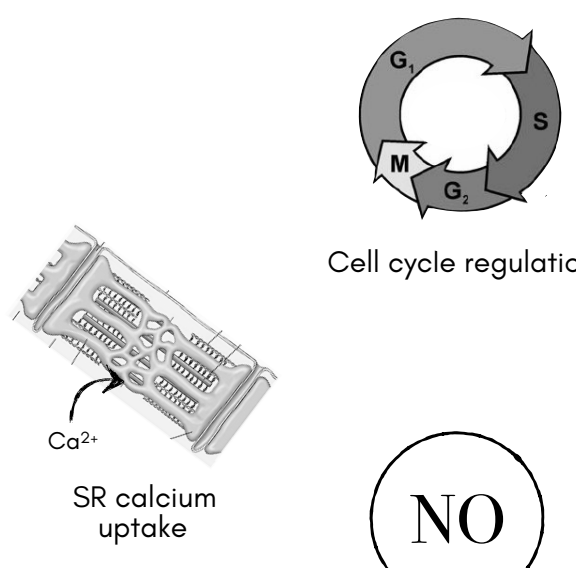

Cell cycle regulation

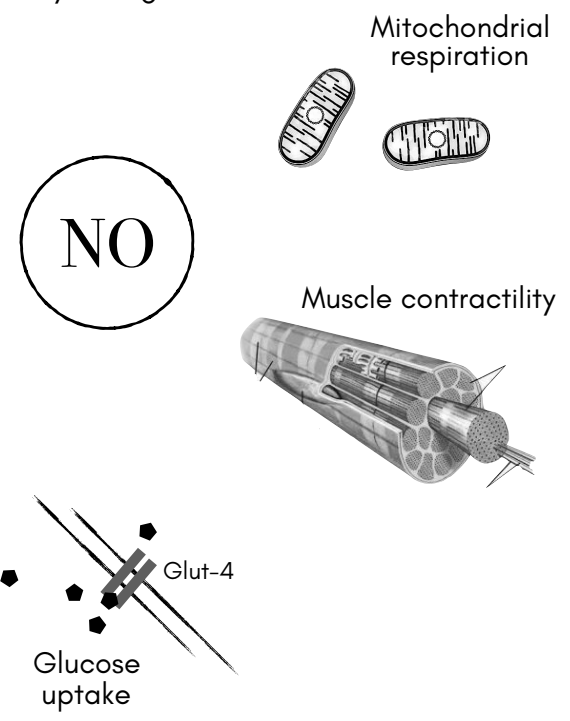

Figure 1.1: Key regulating physiological functions of nitric oxide (NO). NO is important for the regulation of vasodilation, muscle contractility, cell cycle regulation, mitochondrial respiration, glucose uptake and sarcoplasmic reticulum (SR) calcium uptake.

Once ingested, inorganic nitrate from dietary sources is readily converted to nitrite by bacteria present in the oral cavity (12). Nitrite is then swallowed with saliva whereof some is reduced to NO in the acidic environment of the stomach. However, a substantial amount of nitrite enters the circulation, elevating plasma nitrite concentrations. Plasma nitrite is subsequently reduced to $\mathrm{NO}$ through several enzymatic reactions in blood and other tissues $(8,12)$. The nitrate-nitrite-NO pathway (Figure 1.2) may be important as a means to increase NO production under circumstances when NO synthesis by the NOS enzymes is impaired. While the NOS pathway is highly oxygen dependent, the nitrate-nitrite-NO pathway is stimulated under conditions of low pH and low oxygen availability (13). As such, the nitratenitrite-NO pathway is likely to be activated when oxygen is a limiting factor, such as under 'local hypoxia' in skeletal muscle tissue during high-intensity intermittent type exercise or under 'systemic hypoxia' such as at high altitude or under water. 


\section{Chapter 1}

Once produced, NO has a half-life of $\sim 1 \mathrm{~s}$ and is quickly oxidized to e.g. nitrite and nitrate (14). Therefore, NO is not sufficiently stable to be measured in plasma. Instead plasma nitrite is used as an indirect measure of increases in NO via the nitrate-nitrite-NO pathway, due to its low background concentrations and relatively stable nature (15). While plasma nitrite has an in vivo half-life of 20-45 min, orally ingested nitrate reaches peak plasma nitrate concentrations within 2-3 hours and has a half-life of 5-8 hours (16-18). Plasma nitrate and nitrite concentrations are used to determine the respective uptake and bioconversion of orally ingested nitrate (12).

\section{DIET}

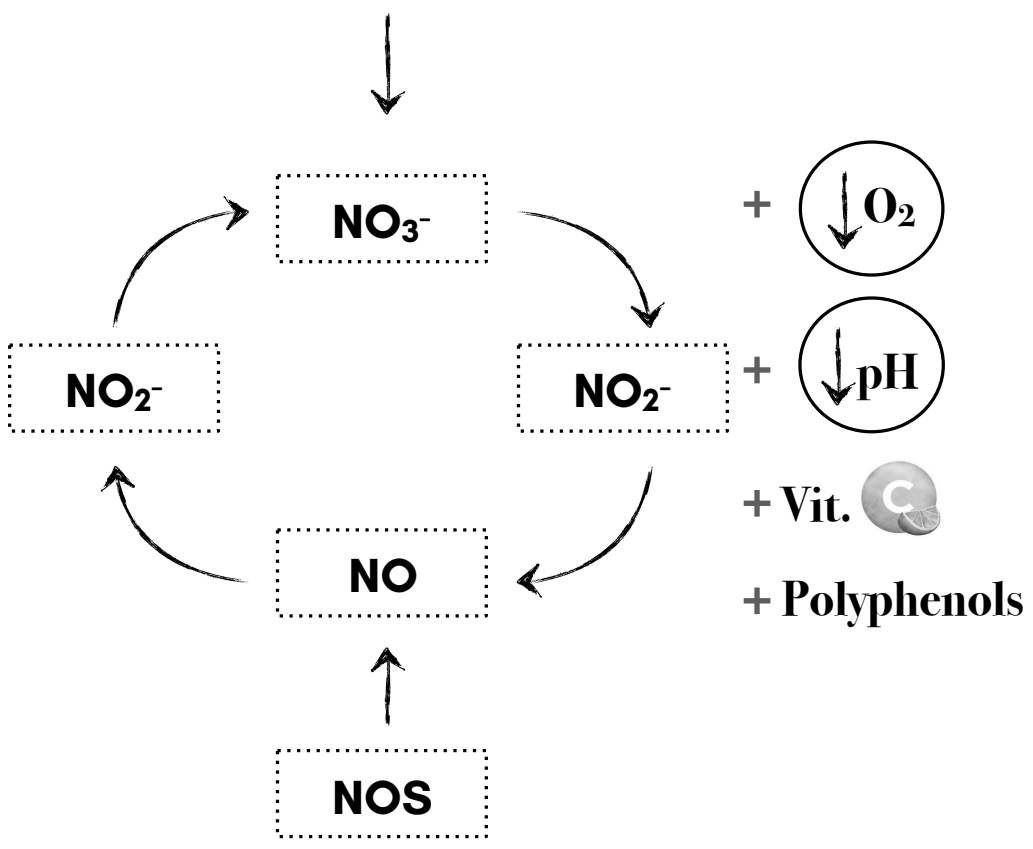

Figure 1.2: The nitrate-nitrite-NO pathway. The bioactivity of NO is acutely terminated by its rapid oxidation to nitrite $\left(\mathrm{NO}_{2}^{-}\right)$and nitrate $\left(\mathrm{NO}_{3}^{-}\right)$. Nitrate, which also can be supplied from the diet, can undergo reduction to nitrite by bacteria in the oral cavity and by xanthine oxidase and possibly other enzymes in tissues. In blood and tissues nitrite can be further metabolized to nitric oxide (NO), catalyzed by various enzymatic and non-enzymatic pathways, most of which are greatly enhanced under conditions of low oxygen availability and low $\mathrm{pH}$. Vitamin $\mathrm{C}$ and polyphenols have been shown to stimulate the nitrate-nitrite-NO pathway. 


\section{Dietary nitrate affects oxygen requirements of exercise and vasodilation}

Since dietary nitrate was established as a NO donor (19), the potential physiological impact of dietary nitrate supplementation on metabolic, circulatory, and performance parameters in populations ranging from well-trained athletes to specific patient groups have been extensively investigated (20). Larsen et al. (4) reported that three days of sodium nitrate supplementation increased plasma nitrite concentrations and reduced the oxygen consumption during submaximal cycling exercise by $\sim 5 \%$. These findings were surprising because the oxygen consumption during exercise at a given submaximal power output has always been regarded as a constant value. Similar effects have also been found when beetroot juice was used as the provided nitrate source (21). By reducing the oxygen consumption of exercise, nitrate can improve muscle and oxygen efficiency.

The rationale for a lower oxygen consumption of exercise at the same power output could be: 1) Improved muscle contractile efficiency by a lower adenosine triphosphate (ATP) cost of muscle contraction for the same force production, or 2) Improved mitochondrial metabolic efficiency by a lower oxygen consumption for the same rate of oxidative ATP resynthesis (22). Bailey et al. (23) investigated the first rationale, reporting lower ATP cost of muscle contraction during both low- and high-intensity exercise following beetroot juice supplementation. They suggested that the decreased ATP turnover rate in the contracting muscle cells could be caused by a reduction of the enzyme activity of the two main ATP pathways actomyosin ATPase and/or $\mathrm{Ca}^{2+}$-ATPase. The second rationale considering enhancement of mitochondrial efficiency has been investigated by Larsen et al. (24). They reported an increased mitochondrial ATP production for each oxygen molecule used (increased $\mathrm{P} / \mathrm{O}$ ratio) following sodium nitrate supplementation, which was correlated with a reduction in whole body oxygen use during exercise. As a potential mechanism they also reported a decreased proton leakage of the mitochondrial membrane following nitrate supplementation, which could explain the proposed increase in the efficiency of the mitochondria to produce ATP.

The effects of nitrate supplementation on muscular and mitochondrial efficiency are still under discussion, as some studies report no improvements while other studies do. The most established physiological effect of dietary nitrate however, is its ability to improve tissue perfusion. By increasing the bioavailability of $\mathrm{NO}$, which is the most potent vasodilator we know, nitrate can regulate blood flow. As a consequence, dietary nitrate supplementation has been associated with several cardiovascular benefits such as a reduction in blood pressure $(25,26)$ and an improved revascularization in chronic ischemia (27). As such, nitrate supplementation is not only advantageous to the athlete, improving skeletal muscle 


\section{Chapter 1}

blood flow during exercise, but its benefits also apply to clinical settings, e.g., enhanced exercise performance following nitrate supplementation in patients with peripheral arterial disease (28). Therapeutic opportunities for dietary nitrate supplementation could be reduction in blood pressure, tissue protection in ischemia-reperfusion injury, and protection against gastric ulcers (13). Such findings underline the potential benefits of dietary nitrate supplementation in a sports setting as well as in more clinical conditions.

\section{Ergogenic properties of dietary nitrate}

All of the above-mentioned physiological effects of nitrate could potentially augment exercise performance, and an increasing body of evidence supports the beneficial effects of nitrate supplementation during exercise. In general, a more profound effect of dietary nitrate is found in maximal exhaustion testing, while smaller and more unclear effects are found for time-trial performance (29). Several studies using time to exhaustion or incremental tests have found improvements in exercise tolerance following nitrate supplementation (21, 30-35). However, an exhaustion test is very sensitive to variation, as a small change in the athlete's power results in a large change in endurance time. In other words, an exhaustion test 'amplifies' the potential performance benefits of a given intervention. It has been suggested that an intervention that extends time-to-exhaustion at a fixed work rate by about $15 \%$ would be expected to improve time-trial performance by a much smaller, though still practically meaningful $1 \%(36)$. Exhaustion tests reflect exercise capacity rather than exercise performance, and time-trial protocols have been suggested to be more appropriate and reliable to evaluate the impact of an intervention on endurance exercise performance in 'real-life' (37). The effect of nitrate supplementation on time-trial performance is less clear. A number of studies have found improvements in time-trial performance following nitrate supplementation (38-42), while others found no effects of nitrate on performance (43-51). A meta-analysis clustering nitrate and exercise studies from year 2007 to 2012 (52), stated that nitrate supplementation has "a small but insignificant effect on performance for time trials". However, this conclusion was based on merely nine time-trial studies, and more data are needed to clarify the effects of nitrate supplementation on exercise performance.

Next to differences between exhaustion testing and time-trial performance, the variability in the findings in nitrate supplementation studies may be related to the variation in other aspects of the study design. The efficacy of nitrate supplementation to improve exercise performance likely depends on factors 
such as supplementation protocol, habitual dietary nitrate intake, exercise conditions, sex and training status of the athlete.

\section{Dietary nitrate supplementation protocol}

So far, there is no consensus regarding how to supplement nitrate to maximize its proposed beneficial effects on exercise performance. It remains to be established what the preferred duration of nitrate supplementation, daily nitrate dose, and nitrate source should be to maximize its potential as an ergogenic aid. As a consequence, the nitrate supplementation protocols deviate greatly between studies, which makes it difficult to compare their results. It has been suggested that larger doses and longer duration of supplementation are more beneficial than smaller doses and acute ingestion, at least in recreational athletes competing in exercise tasks that last between 5 and $30 \mathrm{~min}(30,33,34)$.

With the present knowledge, both the use of an acute dose and a severalday loading protocol can be justified to enhance exercise performance. Following acute nitrate supplementation, vasodilation has been reported, which during exercise may translate to increased blood supply and enhanced oxygen availability to the working muscle (22). By increasing the bioavailability of NO, a single dose of nitrate can provide systemic vasodilation and significantly reduce systolic and diastolic blood pressure 2.5-3 h following ingestion (53). On the contrary, the potential effects of nitrate on muscular and mitochondrial efficiency might require a several days supplementation protocol. Larsen et al. (9) found decreased use of oxygen and increased $\mathrm{P} / \mathrm{O}$ ratio during exercise, indicating that improved exercise efficiency is taking place at the mitochondrial level after 3 days of nitrate supplementation. They argue that acute nitrate supplementation is unlikely to induce changes in mitochondrial and contractile protein expression and, as such, to influence exercise performance. A more prolonged supplementation period of 3 days or more could be sufficient to allow such changes to occur. However, it could be speculated that an even longer supplementation period might be advantageous. Vanhatalo et al. (54) reported decreased oxygen consumption during submaximal exercise following acute, 5 and 15 days of nitrate supplementation. Furthermore, only the 15-day supplementation protocol led to improved peak power of an exhaustion test. Whether even longer-term (i.e., beyond 2 weeks) nitrate supplementation protocols may augment or even hinder the physiological adaptations to training is currently unknown (55). Based on the present literature, 3-6 days of nitrate supplementation seem to more often lead to a reduction in oxygen use during submaximal exercise and to improved exercise performance than acute supplementation (55), while an acute protocol could be sufficient if vasodilation per se is the purpose of nitrate ingestion. More studies comparing the 


\section{Chapter 1}

ergogenic effects following different durations of nitrate supplementation are needed before specific recommendations about the duration of nitrate supplementation to enhance sports performance can be provided.

Next to differences in duration of nitrate supplementation protocols, there is also a great range in the daily amount of nitrate consumed between studies. Only one study has investigated the effects of different doses of nitrate on plasma nitrate and nitrite responses and exercise performance (34). Wylie et al. reported a clear dose-dependent relationship for the increase in both plasma nitrate and nitrite concentrations following ingestion of $4.2,8.4$, and $16.8 \mathrm{mmol}$ of nitrate, respectively. This implies that for these amounts of nitrate supplementation, there is an effective uptake and bioconversion in blood, which likely increases the NO availability and does not plateau at the highest intake level. Furthermore, Wylie et al. reported that both 8.4 and $16.8 \mathrm{mmol}$ of dietary nitrate decreased the oxygen consumption of submaximal exercise and improved the time-to-task failure to a similar extent, while there was no effect of ingesting $4.2 \mathrm{mmol}$ of nitrate. As such, even though plasma nitrate and nitrite concentrations continue to increase when ingesting larger doses, the physiological effects of nitrate supplementation seem to plateau, indicating that there is no further benefit of ingesting nitrate doses beyond this level. Based on this dose-response study and studies reporting physiological and performance benefits of nitrate supplementation, a minimal dose of 300-600 mg ( 5-10 mmol) of nitrate seems to be required to enhance exercise performance $(34,52,56)$. The nitrate dose at which the effects on exercise performance plateaus however, is more speculative. Most studies tend to use a dose higher than $8.4 \mathrm{mmol}$ of nitrate, as this was the lowest dose improving oxygen efficiency and increasing performance in the above-mentioned dose-response study. The optimal dose of nitrate to enhance performance may be dependent on the characteristics of the study population. For instance, most studies do not take the habitual dietary nitrate intake of the study participants into account. As such, while nitrate supplementation is standardized, the total nitrate consumption including diet and supplementation could vary greatly between individuals. This variation may affect the daily dose of nitrate required to obtain performance benefits.

Similarly to the lack of consensus regarding the amount and duration, it is also under debate which source of nitrate is most effective to enhance exercise performance. While nitrate salts such as sodium/potassium nitrate dominated the early nitrate research, most studies are currently using beetroot juice as the source of nitrate. By using nitrate salts, unknown interactions with other interventional compounds in the solution do not have to be accounted for. On the other side, when beetroot juice or other vegetable nitrate sources are used, other nutrients 
could potentially either strengthen or attenuate the effects of nitrate on exercise performance. For instance, beetroot juice might be regarded more advantageous to increase NO availability compared with nitrate salts, as vitamin C and polyphenols in beetroot juice have been suggested to potentiate the nitrate-nitriteNO pathway (57-59). Whether greater increases in NO availability following nitrate supplementation from vegetable sources compared with nitrate salts translate to greater improvements in oxygen efficiency and exercise performance still needs to be investigated. However, if their ergogenic potential is similar, it could be argued that natural food sources should always be preferred above artificial products. Nitrate and nitrite salts are among the key components of fertilizers and food preservatives. Since it was recognized that nitrate theoretically could be transformed into potentially carcinogenic $N$-nitrosamines $(60,61)$, the use of nitrate and nitrite salts in food production has been under critical observation. There is an ongoing debate on potential health risks of long-term exposure to high nitrite and nitrate (62), and the current Acceptable Daily Intake (ADI) level set by the Joint Food and Agricultural Organization/WHO (62) is $3.7 \mathrm{mg}$ nitrate per kg bodyweight. However, no observational epidemiological studies have directly associated the intake of nitrate or nitrite through diet or drinking water with cancer in humans (6365). On the other side, it is currently speculated that the cardioprotective effects of the Mediterranean Diet may be, at least partly, attributed to the high nitrate intake from vegetable consumption $(6,66)$. In fact, the cardiovascular benefits of dietary nitrate have been suggested to by far outweigh the small risk of harmful effects (56). Although the exact long-term effects of chronic nitrate intake are yet to be fully investigated, Hord et al. (6) previously reported the contradicting fact that an individual following a DASH dietary pattern (Dietary Approaches to Stop Hypertension), with high nitrate vegetable and fruit choices, would exceed the ADI for nitrate by $550 \%$. Irrespective of their nitrate content, it is generally accepted that vegetables do play an important role in a healthy diet. Furthermore, nitraterich vegetables are directly available to the general public, which is not per se the case for nitrate salts. While beetroot juice has been frequently used, studies on the ergogenic effects of nitrate-rich vegetables are still limited $(67,68)$. Before recommendations can be made on the preferred source of nitrate supplementation, more studies are needed to determine whether nitrate-rich vegetables could elicit similar effects on exercise performance as nitrate salts and beetroot juice supplementation.

Aside from the nitrate supplementation protocol and habitual nitrate intake, other athletes' characteristics may be of importance for the ergogenic properties of dietary nitrate. Factors such as body weight, sex, training status of the 


\section{Chapter 1}

athletes, and the intensity of the competitive exercise may all interact to determine the effectiveness of nitrate supplementation on exercise performance (22).

\section{Exercise conditions}

It is evident that the ergogenic properties of nitrate supplementation may depend on the physiological demands of the exercise task. Whereas most research on the performance effects of dietary nitrate supplementation has been on endurance type exercise tasks, the focus is currently shifting towards intermittent and/or very high-intensity sports. This shift is caused by the increasing knowledge about the mechanisms behind the beneficial effects of dietary nitrate. During high-intensity exercise, oxygen availability is decreased and metabolic by-products accumulate and cause acidosis, creating a state of low $\mathrm{pH}$ (69). The low oxygen tension and low $\mathrm{pH}$ in the muscle promotes the nitrite to $\mathrm{NO}$ conversion (13). It has been suggested that under the hypoxic conditions occurring during high-intensity exercise, prior nitrate supplementation may be more effective in eliciting its ergogenic potential (70), whereas low-intensity endurance type exercise, in which the skeletal muscle remains well oxygenated and $\mathrm{pH}$ does not fall significantly, would presumably not stimulate NO production from nitrite to the same extent (55).

Thus, the potential effect of dietary nitrate on the oxygen cost of exercise is likely more apparent in a context where oxygen availability is the limiting factor for performance. As such, nitrate supplementation may be particularly effective at improving physiological and functional responses in type II (fast-twitch) muscle fibers, where the oxygen availability is lower than in type I muscle fibers (71). In rodents, 5-7 days of nitrate supplementation have been found to enhance contractility $(72)$ and blood flow $(73,74)$ specifically in type II muscle fibers. Based on these findings, it could be suggested that the ergogenic effects of nitrate supplementation are most profound for activities that (mainly) recruit type II muscle fibers, i.e., repeated bouts of high-intensity exercise of short duration (75). The stimulation of the nitrate-nitrite-NO pathway during high-intensity exercise may improve local muscle perfusion, fatigue resistance, muscle fiber contractility, and ultimately whole body performance (75). The increased muscle fiber contractility is likely caused by increased intracellular release of calcium in the muscle (76). Increased intracellular calcium levels have been suggested to elicit the greatest impact during the initial phase of contraction where the calcium saturation normally is incomplete (77). Haider et al. reported enhanced force production, especially during the explosive/rising phase of contraction, following nitrate supplementation in humans (77). As such, nitrate supplementation could be of interest for athletes competing in sports where the ability to produce a great concentric power and to generate high velocity during acceleration is the key to success. This would be the 
case for sprint- and short distance maximal effort disciplines (78), but also for highintensity intermittent type exercise based field sports (79). Despite the increasing interest in the ergogenic effects of nitrate supplementation for these types of sport, there is only a limited amount of studies investigating nitrate supplementation and (repeated) sprint ability. Nitrate supplementation has been reported to improve repeated-sprint performance in recreational team sport athletes (30), while no improvements were observed in repeated-sprint performance in moderately trained team sport athletes (51) or trained kayak athletes (80). These studies vary greatly, not only in supplementation protocol and type of exercise, but also in the training status of the participating athletes. Many studies are currently ongoing to establish the impact of dietary nitrate supplementation on performance during sport disciplines where intermittent high intensity exercise is the key exercise modality.

\section{Recreational versus elite athletes}

Based upon the reported ergogenic properties of nitrate and beetroot juice supplementation and concomitant attention in the media, many athletes have started to use beetroot juice or other nitrate-rich foods as dietary supplements to improve their sport performance. As explained in the previous sections, the efficacy of dietary nitrate supplementation depends on the type of exercise and the supplementation protocol used. However, there may also be differences in the efficacy of nitrate supplementation on sports performance, depending on whether the athlete using the product is either a recreational athlete or a world-class, elite athlete (43). Due to genetic selection as well as a lifelong intense training regimen, elite athletes are likely to show a different adaptive response to training and, as such, also differences in the response to dietary nitrate supplementation. It has been proposed that highly trained athletes are less responsive to the ergogenic properties of nitrate supplementation than recreational athletes (43). So far, only one study has compared the effects of nitrate supplementation on plasma nitrate and nitrite responses, submaximal oxygen consumption and time-trial performance between athletes of low, moderate, and high fitness level (42). Porcelli et al. reported inverse correlations between athletes' training status and the reduction in oxygen cost of exercise as well as the improvements in performance during a $3 \mathrm{~km}$ time-trial, suggesting that individual aerobic fitness level affects the ergogenic benefits induced by nitrate supplementation. They explained their findings by an accordingly attenuated increase in plasma nitrate and nitrite concentrations following dietary nitrate supplementation in the more highly trained subjects. A possible explanation for an attenuated response in more highly trained athletes could be a greater NO availability, potentially caused by greater dietary nitrate intakes or higher NOS capacity $(43,46)$. As such, an already improved ability to 


\section{Chapter 1}

release and utilize NO could render additional nitrate supplementation ineffective in highly trained athletes. The study by Porcelli et al. however, merely included six highly trained subjects (i.e., $\mathrm{VO}_{2 \max }>60 \mathrm{~mL} / \mathrm{kg} / \mathrm{min}$ ) who were not of world-class or elite level.

So far there are few studies that investigate the impact of nitrate supplementation in world-class, elite athletes $(41,45,46,48,81)$. Four of the five studies, in cross-country skiers $(45,81)$, cyclists $(46)$, and 1,500 m runners $(48)$, were unable to detect improvements in exercise performance following nitrate supplementation. In contrast, Peeling et al. (41) observed a small, but significant decline in oxygen consumption during exercise and an improvement in time-trial performance in elite kayakers. Clearly, more work is needed to define the efficacy of nitrate supplementation to improve performance in elite athletes. However, this is more difficult than it seems, as elite athletes are (by definition) scarce. Consequently, it is difficult to design and perform well-powered studies. In support, the above-mentioned nitrate supplementation studies in elite athletes $(41,45,46$, $48,81)$ included merely 10 or less athletes. In addition to the potential reduced responsiveness of elite athletes to dietary nitrate supplementation, such small study cohorts lower the ability to detect small but relevant effects of dietary nitrate on performance. While the lack of any effect could be, at least partly, a methodological issue, the absolute effect is likely small. Of course, it should be noted that in an elite competitive setting, even small effects that are hardly detectable may still be highly relevant for the outcome of a sports event. As such, further studies on the effects of nitrate supplementation in the elite athlete are needed to establish its ergogenic potential, taking into account that it is difficult to detect small differences in performance in such small groups of athletes (82). 


\section{Thesis outline}

The aim of this thesis is to gain further insight into dietary nitrate supplementation as a means to enhance sports performance, with focus on elite athletes from a broad range of sports. In chapter 2 we address the key questions concerning the proposed ergogenic effects of nitrate supplementation in elite athletes. Based on these questions, we investigated different aspects of nitrate supplementation in several athlete populations. In chapter 3 we first investigated the impact of acute and 6 days of sodium nitrate supplementation on oxygen consumption during submaximal exercise and on $10 \mathrm{~km}$ time-trial performance in highly trained cyclists. As we were unable to detect any ergogenic benefits of sodium nitrate ingestion, we questioned whether the source of nitrate is of importance for its proposed ergogenic properties. In chapter $\mathbf{4}$ we compared four different nitrate sources with regard to nitrate uptake, bioconversion, and physiological response. Based on the finding that nitrate-rich vegetables can serve as an alternative strategy for nitrate supplementation, we investigated the habitual dietary nitrate and vegetable intake in a large population of highly trained athletes (chapter 5). As recent research suggests that nitrate supplementation is more effective for recreational athletes and during high-intensity exercise, we compared the metabolic and functional responses to beetroot juice between recreational, competitive and elite athletes, completing the exact same repeated-sprints protocol (chapter 6). Next to the 'local hypoxic' aspect of high-intensity and intermittent type exercise, athletes competing under conditions creating 'systemic hypoxia', such as dynamic apnea under water, are also likely to benefit from nitrate supplementation. We investigated the effects of beetroot juice on underwater swimming capacity and high-intensity exercise performance in elite water polo players (chapter 7). Besides direct performance enhancement, the vasodilatory properties of nitrate might provide other beneficial effects during exercise. Many athletes suffer from gastrointestinal (GI) complaints during high-intensity exercise, likely related to a reduction in $\mathrm{GI}$ blood flow, resulting in gut injury. As nitrate supplementation may attenuate the impact of exercise-induced hypoperfusion of the gut, we investigated the effects of nitrate ingestion and sucrose ingestion on $\mathrm{Gl}$ blood flow and gut injury during high-intensity exercise (chapter 8). Finally, in chapter 9, the outcomes of chapters 2 through 8 are discussed and general conclusions are provided. 


\section{References}

1. Burke L. Nutrition for sport. Getting the most out of training. Aust Fam Physician. 1999;28(6):561-7.

2. Brotherhood JR. Nutrition and sports performance. Sports Med. 1984;1(5):350-89.

3. Thomas DT, Erdman KA, Burke LM. American College of Sports Medicine Joint Position Statement. Nutrition and Athletic Performance. Med Sci Sports Exerc. 2016;48(3):543-68.

4. Larsen FJ, Weitzberg E, Lundberg JO, Ekblom B. Effects of dietary nitrate on oxygen cost during exercise. Acta Physiol. 2007;191(1):59-66.

5. Burke LM. Practical Issues in Evidence-Based Use of Performance Supplements: Supplement Interactions, Repeated Use and Individual Responses. Sports Med. 2017;47(Suppl 1):79-100.

6. Hord NG, Tang Y, Bryan NS. Food sources of nitrates and nitrites: the physiologic context for potential health benefits. Am J Clin Nutr. 2009;90:1-10.

7. Lundberg JO, Gladwin MT, Ahluwalia A, Benjamin N, Bryan NS, Butler A, et al. Nitrate and nitrite in biology, nutrition and therapeutics. Nat Chem Biol. 2009;5(12):865-9.

8. Dejam A, Hunter CJ, Schechter AN, Gladwin MT. Emerging role of nitrite in human biology. Blood Cells Mol Dis. 2004;32:423-9.

9. Larsen FJ, Schiffer TA, Borniquel S, Sahlin K, Ekblom Br, Lundberg JO, et al. Article: Dietary Inorganic Nitrate Improves Mitochondrial Efficiency in Humans. Cell Metab. 2011;13:149-59.

10. Benjamin N, O'Driscoll F, Dougall H, Duncan C, Smith L, Golden M, et al. Stomach NO synthesis. Nature. 1994;368(6471):502.

11. Lundberg JO, Weitzberg E, Lundberg JM, Alving K. Intragastric nitric oxide production in humans: measurements in expelled air. Gut. 1994;35(11):1543-6.

12. Lundberg JO, Govoni M. Inorganic nitrate is a possible source for systemic generation of nitric oxide. Free Radic Biol Med. 2004;37:395-400.

13. Lundberg JO, Weitzberg E, Gladwin MT. The nitrate-nitrite-nitric oxide pathway in physiology and therapeutics. Nat Rev Drug Discov. 2008;7:156-67.

14. Kelm M. Nitric oxide metabolism and breakdown. Biochim Biophys Acta. 1999;1411(2-3):273-89.

15. Allen JD, Stabler T, Kenjale A, Ham KL, Robbins JL, Duscha BD, et al. Plasma nitrite flux predicts exercise performance in peripheral arterial disease after 3months of exercise training. Free Radic Biol Med. 2010;49(6):1138-44.

16. Dejam A, Hunter CJ, Tremonti C, Pluta RM, Hon YY, Grimes G, et al. Nitrite infusion in humans and nonhuman primates: endocrine effects, pharmacokinetics, and tolerance formation. Circulation. 2007;116(16):1821-31.

17. McKnight GM, Smith LM, Drummond RS, Duncan CW, Golden M, Benjamin N. Chemical synthesis of nitric oxide in the stomach from dietary nitrate in humans. Gut. 1997;40(2):211-4.

18. Hunault CC, van Velzen AG, Sips AJ, Schothorst RC, Meulenbelt J. Bioavailability of sodium nitrite from an aqueous solution in healthy adults. Toxicol Lett. 2009;190(1):48-53.

19. Duncan C, Dougall H, Johnston P, Green S, Brogan R, Leifert C, et al. Chemical generation of nitric oxide in the mouth from the enterosalivary circulation of dietary nitrate. Nat Med. 1995;1(6):546-51.

20. Clements WT, Lee S-R, Bloomer RJ. Nitrate ingestion: a review of the health and physical performance effects. Nutrients. 2014;6(11):5224-64.

21. Bailey SJ, Winyard P, Vanhatalo A, Blackwell JR, Dimenna FJ, Wilkerson DP, et al. Dietary nitrate supplementation reduces the $\mathrm{O} 2$ cost of low-intensity exercise and enhances tolerance to high-intensity exercise in humans. J Appl Physiol. 2009;107:1144-55.

22. Jones AM. Influence of dietary nitrate on the physiological determinants of exercise performance: a critical review. Appl Physiol Nutr Metab. 2014;39(9):1019-28.

23. Bailey SJ, Fulford J, Vanhatalo A, Winyard PG, Blackwell JR, DiMenna FJ, et al. Dietary nitrate supplementation enhances muscle contractile efficiency during knee-extensor exercise in humans. J Appl Physiol. 2010;109:135-48.

24. Larsen FJ, Schiffer TA, Borniquel S, Sahlin K, Ekblom B, Lundberg JO, et al. Dietary inorganic nitrate improves mitochondrial efficiency in humans. Cell Metab. 2011;13:149-59.

25. Hobbs DA, Kaffa N, George TW, Methven L, Lovegrove JA. Blood pressure-lowering effects of beetroot juice and novel beetroot-enriched bread products in normotensive male subjects. $\mathrm{Br} \mathrm{J}$ Nutr. 2012;108:2066-74. 
26. Larsen FJ, Ekblom Br, Sahlin K, Lundberg JO, Weitzberg E. Effects of dietary nitrate on blood pressure in healthy volunteers. N Engl J Med. 2006;355(26):2792-3.

27. Hendgen-Cotta UB, Luedike $P$, Totzeck $M$, Kropp $M$, Schicho $A$, Stock $P$, et al. Dietary nitrate supplementation improves revascularization in chronic ischemia. Circulation. 2012;126(16):1983-92.

28. Kenjale AA, Ham KL, Stabler T, Robbins JL, Johnson JL, Vanbruggen M, et al. Dietary nitrate supplementation enhances exercise performance in peripheral arterial disease. J Appl Physiol (1985). 2011;110(6):1582-91.

29. McMahon NF, Leveritt MD, Pavey TG. The Effect of Dietary Nitrate Supplementation on Endurance Exercise Performance in Healthy Adults: A Systematic Review and Meta-Analysis. Sports Med. 2017;47(4):735-56.

30. Wylie L, Mohr M, Krustrup P, Jackman SR, Ermiotadis G, Kelly J, et al. Dietary nitrate supplementation improves team sport-specific intense intermittent exercise performance. Eur J Appl Physiol. 2013;113:1673-84.

31. Lansley KE, Winyard P, Fulford J, Vanhatalo A, Bailey S, Blackwell JR, et al. Dietary nitrate supplementation reduces the $\mathrm{O} 2$ cost of walking and running: a placebo-controlled study. J Appl Physiol (1985). 2011;110:591-600.

32. Breese BC, McNarry MA, Marwood S, Blackwell JR, Bailey SJ, Jones AM. Beetroot juice supplementation speeds $\mathrm{O} 2$ uptake kinetics and improves exercise tolerance during severe-intensity exercise initiated from an elevated baseline. Am J Physiol Regul Integr Comp Physiol. 2013;15;305(12):R1441-50.

33. Kelly J, Vanhatalo A, Wilkerson DP, Wylie L, Jones AM. Effects of Nitrate on the Power-Duration Relationship for Severe-Intensity Exercise. Med Sci Sports Exerc. 2013; 45(9):1798-806.

34. Wylie LJ, Kelly J, Bailey SJ, Blackwell JR, Skiba PF, Winyard PG, et al. Beetroot juice and exercise: pharmacodynamic and dose-response relationships. J Appl Physiol (1985). 2013;115:325-36.

35. Aucouturier J, Boissiere J, Pawlak-Chaouch M, Cuvelier G, Gamelin FX. Effect of dietary nitrate supplementation on tolerance to supramaximal intensity intermittent exercise. Nitric Oxide. 2015;49:16-25.

36. Hopkins WG, Hawley JA, Burke LM. Design and analysis of research on sport performance enhancement. Med Sci Sports Exerc. 1999;31(3):472-85.

37. Amann M, Hopkins WG, Marcora SM. Similar sensitivity of time to exhaustion and time-trial time to changes in endurance. Med Sci Sports Exerc. 2008;40(3):574-8.

38. Lansley KE, Winyard PG, Bailey SJ, Vanhatalo A, Wilkerson DP, Blackwell JR, et al. Acute dietary nitrate supplementation improves cycling time trial performance. Med Sci Sports Exerc. 2011;43:1125-31.

39. Cermak NM, Gibala MJ, van Loon LC. Nitrate Supplementation's Improvement of 10-km Time-Trial Performance in Trained Cyclists. Int J Sport Nutr Exerc Metabol. 2012;22(1):64-71.

40. Muggeridge DJ, Howe CC, Spendiff O, Pedlar C, James PE, Easton C. A Single Dose of Beetroot Juice Enhances Cycling Performance in Simulated Altitude. Med Sci Sports Exerc. 2014; 46(1):143-50.

41. Peeling P, Cox GR, Bullock N, Burke LM. Beetroot Juice Improves on-Water $500 \mathrm{~m}$ Time-Trial Performance, and Laboratory-Based Paddling Economy in National and International-Level Kayak Athletes. Int J Sport Nutr Exerc Metab. 2015; 25(3):278-84.

42. Porcelli S, Ramaglia M, Bellistri G, Pavei G, Pugliese L, Montorsi M, et al. Aerobic Fitness Affects the Exercise Performance Responses to Nitrate Supplementation. MedSci SportsExerc. 2015;47(8):1643-51.

43. Wilkerson DP, Hayward GM, Bailey SJ, Vanhatalo A, Blackwell JR, Jones AM. Influence of acute dietary nitrate supplementation on 50 mile time trial performance in well-trained cyclists. Eur J Appl Physiol. 2012;112:4127-34.

44. Cermak NM, Res P, Stinkens R, Lundberg JO, Gibala MJ, van Loon L. No improvement in endurance performance after a single dose of beetroot juice. Int J Sport Nutr Exerc Metab. 2012;22:470-8.

45. Peacock $O$, Tjonna $A E$, James $P$, Wisloff $U$, Welde $B$, Bohlke $N$, et al. Dietary nitrate does not enhance running performance in elite cross-country skiers. Med Sci Sports Exerc. 2012;44:2213-9.

46. Christensen PM, Nyberg M, Bangsbo J. Influence of nitrate supplementation on VO(2) kinetics and endurance of elite cyclists. Scand J Med Sci Sports. 2013;23:e21-31.

47. Bescos RI, Ferrer-Roca V, Galilea PA, Roig A, Drobnic F, Sureda A, et al. Sodium nitrate supplementation does not enhance performance of endurance athletes. Med Sci Sports Exerc. 2012;44(12):2400-9.

48. Boorsma RK, Whitfield J, Spriet LL. Beetroot Juice Supplementation Does Not Improve Performance in Elite 1500-m Runners. Med Sci Sports Exerc. 2014; 46(12):2326-34. 


\section{Chapter 1}

49. Hoon MW, Hopkins WG, Jones AM, Martin DT, Halson SL, West NP, et al. Nitrate supplementation and high-intensity performance in competitive cyclists. Appl Physiol Nutr Metab. 2014;39(9):1043-9.

50. Arnold JT, Oliver SJ, Lewis-Jones TM, Wylie LJ, Macdonald JH. Beetroot juice does not enhance altitude running performance in well-trained athletes. Appl Physiol Nutr Metab. 2015;40(6):590-5.

51. Martin K, Smee D, Thompson KG, Rattray B. No improvement of repeated-sprint performance with dietary nitrate. Int J Sports Physiol Perform. 2014;9:845-50.

52. Hoon MW, Johnson NA, Chapman PG, Burke LM. The effect of nitrate supplementation on exercise performance in healthy individuals: a systematic review and meta-analysis. Int J Sport Nutr Exerc Metab. 2013;23:522-32.

53. Webb AJ, Patel N, Loukogeorgakis S, Okorie M, Aboud Z, Misra S, et al. Acute blood pressure lowering, vasoprotective, and antiplatelet properties of dietary nitrate via bioconversion to nitrite. Hypertension. 2008;51:784-90.

54. Vanhatalo A, Bailey S, Blackwell J, DiMenna F, Pavey TG, Wilkerson DP, et al. Acute and chronic effects of dietary nitrate supplementation on blood pressure and the physiological responses to moderateintensity and incremental exercise. Am J Physiol Regul Integr Comp Physiol. 2010;299:1121-31.

55. Jones A. Dietary Nitrate Supplementation and Exercise Performance. Sports Medicine. 2014;44:35-45.

56. Bryan NS, Ivy JL. Inorganic nitrite and nitrate: evidence to support consideration as dietary nutrients. Nutr Res. 2015;35(8):643-54.

57. Peri L, Pietraforte D, Scorza G, Napolitano A, Fogliano V, Minetti M. Original Contribution: Apples increase nitric oxide production by human saliva at the acidic $\mathrm{pH}$ of the stomach: $\mathrm{A}$ new biological function for polyphenols with a catechol group? Free Radic Biol Med. 2005;39:668-81.

58. Gago B, Lundberg JO, Barbosa RM, Laranjinha Jo. Original Contribution: Red wine-dependent reduction of nitrite to nitric oxide in the stomach. Free Radic Biol Med. 2007;43:1233-42.

59. Weitzberg E, Lundberg JO. Nonenzymatic nitric oxide production in humans. Nitric Oxide. 1998;2(1):17.

60. Spiegelhalder B, Eisenbrand G, Preussmann R. Influence of dietary nitrate on nitrite content of human saliva: possible relevance to in vivo formation of $\mathrm{N}$-nitroso compounds. Food Cosmet Toxicol. 1976;14(6):545-8.

61. Tannenbaum SR, Weisman M, Fett D. The effect of nitrate intake on nitrite formation in human saliva. Food Cosmet Toxicol. 1976;14(6):549-52.

62. Alexander J, Benford D, Cockburn A, Cravedi JP, Dogliotti E, Di Domenico A, et al. Nitrate in vegetables Scientific Opinion of the Panel on Contaminants in the Food chain. European Food Safety Authority Journal. 2008;689:1-79.

63. Powlson DS, Addiscott TM, Benjamin N, Cassman KG, de Kok TM, van Grinsven H, et al. When does nitrate become a risk for humans? J Environ Qual. 2008;37:291-5.

64. Katan MB. Nitrate in foods: harmful or healthy? Am J Clin Nutr. 2009;90:11-2.

65. Sindelar JJ, Milkowski AL. Human safety controversies surrounding nitrate and nitrite in the diet. Nitric Oxide. 2012;26:259-66.

66. Lundberg JO, Feelisch M, Bjorne H, Jansson EA, Weitzberg E. Cardioprotective effects of vegetables: is nitrate the answer? Nitric Oxide. 2006;15(4):359-62.

67. Porcelli S, Pugliese L, Rejc E, Pavei G, Bonato M, Montorsi M, et al. Effects of a Short-Term High-Nitrate Diet on Exercise Performance. Nutrients. 2016;8(9).

68. Bondonno CP, Blekkenhorst LC, Liu AH, Bondonno NP, Ward NC, Croft KD, et al. Vegetable-derived bioactive nitrate and cardiovascular health. Mol Aspects Med. 2017; pii: S0098-2997(17)30061-4.

69. Krustrup P, Mohr M, Amstrup T, Rysgaard T, Johansen J, Steensberg A, et al. The yo-yo intermittent recovery test: physiological response, reliability, and validity. Med Sci Sports Exerc. 2003;35(4):697-705.

70. Wylie LJ, Bailey SJ, Kelly J, Blackwell JR, Vanhatalo A, Jones AM. Influence of beetroot juice supplementation on intermittent exercise performance. Eur J Appl Physiol. 2016;116(2):415-25.

71. Bailey SJ, Varnham RL, DiMenna FJ, Breese BC, Wylie LJ, Jones AM. Inorganic nitrate supplementation improves muscle oxygenation, $\mathrm{O}(2)$ uptake kinetics, and exercise tolerance at high but not low pedal rates. J Appl Physiol (1985). 2015;118(11):1396-405.

72. Hernandez A, Schiffer TA, Ivarsson N, Cheng AJ, Bruton JD, Lundberg JO, et al. Dietary nitrate increases tetanic [Ca2+]i and contractile force in mouse fast-twitch muscle. J Physiol. 2012;590(15):3575-83. 
73. Ferguson SK, Hirai DM, Copp SW, Holdsworth CT, Allen JD, Jones AM, et al. Impact of dietary nitrate supplementation via beetroot juice on exercising muscle vascular control in rats. J Physiol. 2013;591:547-57.

74. Ferguson SK, Holdsworth CT, Wright JL, Fees AJ, Allen JD, Jones AM, et al. Microvascular oxygen pressures in muscles comprised of different fiber types: Impact of dietary nitrate supplementation. Nitric Oxide. 2015; 48:38-43.

75. Jones AM, Ferguson SK, Bailey SJ, Vanhatalo A, Poole DC. Fiber Type-Specific Effects of Dietary Nitrate. Exerc Sport Sci Rev. 2016;44(2):53-60.

76. Stamler JS, Meissner G. Physiology of nitric oxide in skeletal muscle. Physiol Rev. 2001;81(1):209-37.

77. Haider G, Folland JP. Nitrate supplementation enhances the contractile properties of human skeletal muscle. Med Sci Sports Exerc. 2014;46(12):2234-43.

78. Mero A, Komi PV, Gregor RJ. Biomechanics of sprint running. A review. Sports Med. 1992;13(6):376-92.

79. Lockie RG, Murphy AJ, Knight TJ, Janse de Jonge XA. Factors that differentiate acceleration ability in field sport athletes. J Strength Cond Res. 2011;25(10):2704-14.

80. Muggeridge DJ, Howe CC, Spendiff O, Pedlar C, James PE, Easton C. The effects of a single dose of concentrated beetroot juice on performance in trained flatwater kayakers. Int J Sport Nutr Exerc Metab. 2013;23:498-506.

81. Sandbakk SB, Sandbakk O, Peacock O, James P, Welde B, Stokes K, et al. Effects of acute supplementation of L-arginine and nitrate on endurance and sprint performance in elite athletes. Nitric Oxide. 2015; 48:10-5.

82. Hopkins WG, Schabort EJ, Hawley JA. Reliability of power in physical performance tests. Sports Med. 2001;31(3):211-34. 



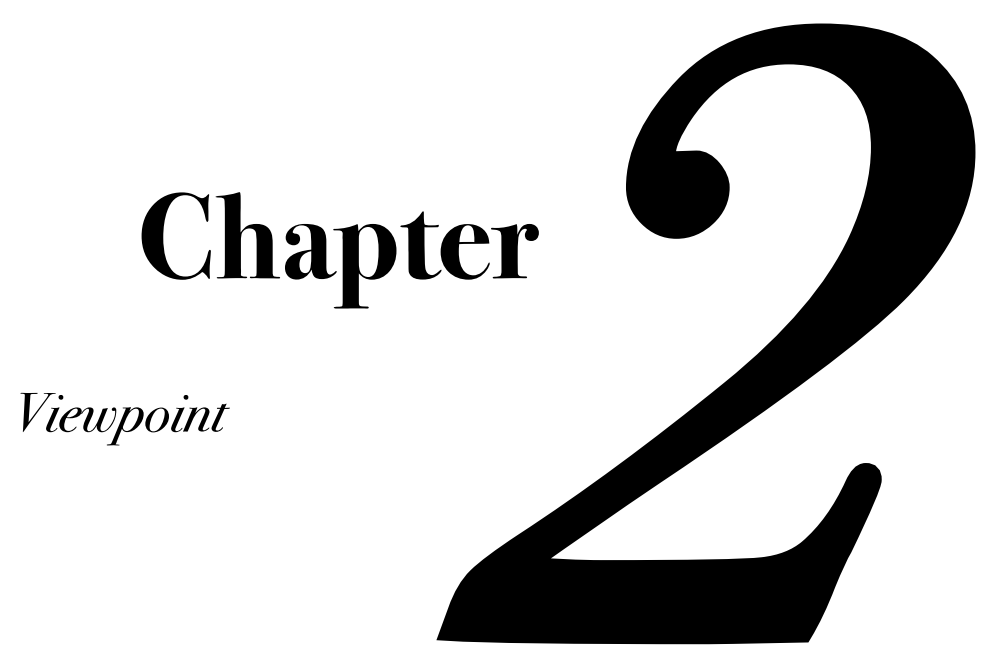

Can elite athletes benefit from dietary nitrate supplementation?

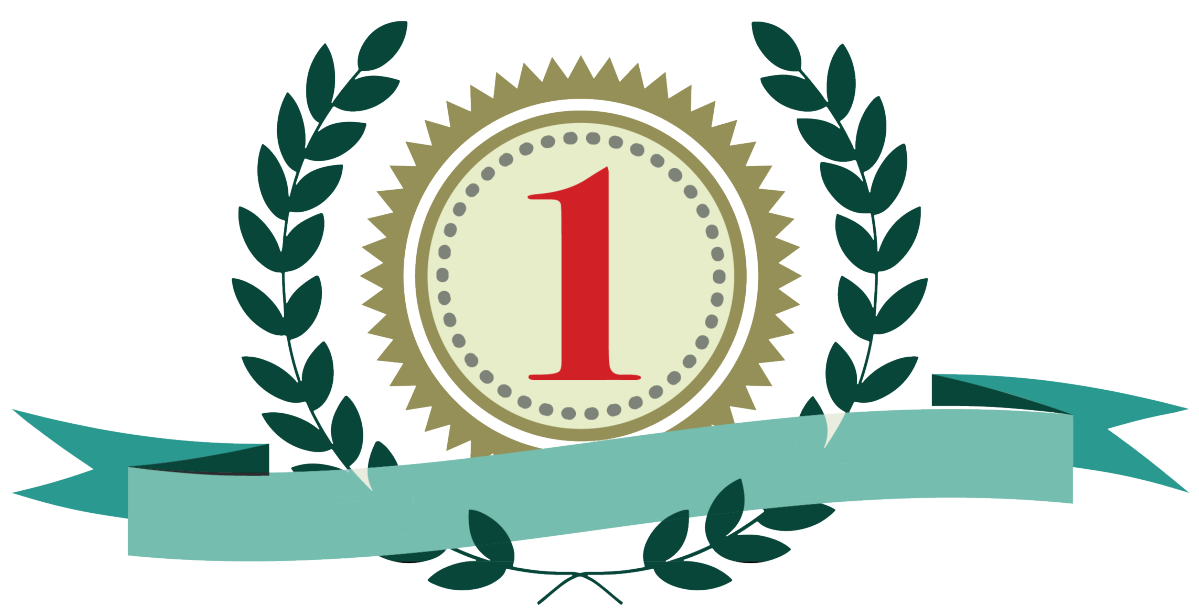

Kristin L. Jonvik Jean Nyakayiru Luc J.C. van Loon Lex B. Verdijk 
Nitrate rich beetroot juice has become a popular sports supplement due to its proposed ergogenic properties. The effects of dietary nitrate supplementation on exercise performance have been attributed to its capacity to increase nitric oxide (NO) bioavailability. NO modulates many processes that are essential to exercise performance, such as regulation of blood flow, muscle contractility, myocyte differentiation and glucose and calcium homeostasis (9). Recent evidence indicates that NO bioavailability can be enhanced by supplementing inorganic nitrate by consuming more leafy green vegetables and beetroot juice $(2,26,27)$ or by ingesting nitrate salt (e.g. sodium nitrate; $\left.\mathrm{NaNO}_{3}\right)(18,20)$. Larsen et al. (18) were the first to report lower oxygen requirements during exercise following three days of $\mathrm{NaNO}_{3}$ supplementation. In a follow-up study (19) the same authors attributed this to improvements in mitochondrial efficiency during exercise, with less oxygen being used to produce a given amount of ATP. Beetroot juice is a product rich in nitrate and is being used by many athletes as a source of nitrate supplementation. Several studies $(1,2,7,17,26)$ have confirmed nitrate's oxygen-saving effects following beetroot juice supplementation as previously observed for $\mathrm{NaNO}_{3}$. Moreover, using beetroot juice, Bailey et al. (2) were the first to study the effect of nitrate supplementation on exercise performance. They and others have now consistently shown that nitrate supplementation can increase the time to exhaustion and improve time-trial performance in trained athletes $(2,4,7,15-17,21$, $26,30)$. As a consequence, numerous athletes have started to use beetroot juice as an ergogenic aid, including many elite athletes during the London 2012 Olympic Games. Could any of the gold medals won in London be (partially) attributed to the use of beetroot juice?

Whereas several studies have reported increased performance following nitrate supplementation in well-trained athletes $(4,7,16,30)$, others have been unable to confirm those findings $(3,6)$. Only few studies have investigated the impact of nitrate supplementation in elite, professional athletes $(5,8,22,23)$. One of these studies observed a small, but significant decline in oxygen uptake during exercise and an improvement in time trial performance in kayakers (23). However, the three other studies failed to observe changes in either $\mathrm{VO}_{2}$ kinetics and/or exercise performance following nitrate supplementation in cross-country skiers (22), cyclists (8) and 1500 m runners (5). Based on these findings it has become a topic of debate on whether the ergogenic benefits of beetroot juice may be dependent on the training status of the athletes recruited in these studies. It has been hypothesized that highly trained, elite athletes are less responsive to the ergogenic properties of nitrate when compared with recreational athletes (28). 
In the present viewpoint we will address the physiological and methodological rationale that could explain the proposed absence of ergogenic properties of beetroot juice supplementation in elite athletes.

\section{Metabolic adaptations}

So far, there is little evidence to assume that the elite athlete does not benefit from the ergogenic properties of nitrate supplementation. However, a recent study reports that fitness level affects the impact of nitrate supplementation on reducing oxygen consumption during exercise and increasing exercise performance, suggesting that elite athletes are less likely to benefit from nitrate supplementation (24). As recently reviewed by Jones et al. (14), there are some factors that may restrict the ergogenic properties of nitrate supplementation in the elite athlete. The intense exercise training routine in the elite athlete strongly increases daily energy expenditure and is matched by a $50-100 \%$ greater daily energy intake when compared with the recreational athlete. When consuming a well balanced diet, dietary nitrate consumption will be increased accordingly. In line, higher baseline nitrite levels have been reported in more highly trained athletes (25). It could be speculated that greater NO bioavailability in the elite athlete, both through higher nitrate intake and through greater eNOS/nNOS-dependent NO synthesis capacities, renders additional nitrate supplementation ineffective $(8,28)$. Though it has been suggested that a dose-response relationship exists between nitrate intake and the ergogenic properties (29), the dose of nitrate required to improve performance may differ with training status, exercise mode, or supplementation period. Also, many years or even decades of intense exercise training in the elite may have induced reconditioning responses on cardiovascular function, skeletal muscle vascularization and mitochondrial efficiency, resulting in greater metabolic and mechanical efficiency (13). Such extensive adaptive responses may negate the impact of nitrate supplementation on mitochondrial efficiency and contractile function and make those effects less relevant for the elite athlete Furthermore, it should be noted that an elite athlete is elite in a specific sport. Most research so far has focused on submaximal endurance type activities in (highly) trained athletes, during which oxygen delivery rarely restricts performance. Nitrate supplementation may be of greater benefit to those athletes involved in exercise activities performed at both a higher relative as well as absolute workload (28). The greater dependency on type II muscle fiber recruitment and non-oxidative energy provision may provide a setting where greater NO bioavailability could improve contractile function and increase performance (11), as supported by the type II muscle fiber-specific increase in microvascular $\mathrm{O}_{2}$ pressure with nitrate (10). 


\section{Methodological complications}

It is difficult to answer the question whether the effects of nitrate supplementation are the same for the elite athlete competing at the highest international level, when compared with the recreational athlete. Research in elite athletes has been limited by their busy schedules and conflicting priorities. However, the main problem is that elite athletes are, by definition, scarce. Furthermore, to evaluate the impact of nitrate on elite exercise performance, it will be required to test the athlete in an exercise protocol appropriate to the specific sport and preferably performed in a competitive setting. A performance enhancement of less than $1 \%$ generally represents the difference between gold and not even reaching the podium, but such small differences in performance can be difficult to detect in a laboratory setting (12). To detect small, but relevant, effects of nitrate supplementation on an elite athlete's performance it may be preferred to assess performance repetitively in the same athlete as opposed to the evaluation of performance in a more traditional group-based comparison. Interestingly, some of the 'negative' elite studies actually identified a number of individual subjects that seemed to respond very positively to nitrate supplementation $(5,8)$. As such, the use of a double blinded randomized multiple crossover $n=1$ design may be more appropriate to evaluate whether nitrate supplementation can improve performance in the true elite athlete.

\section{Conclusion}

Recent data tend to suggest that the ergogenic properties of nitrate supplementation are restricted to the recreational athlete and not evident in the highly trained, elite athlete. The absence of any measurable ergogenic effect of nitrate supplementation in the elite athlete may be attributed to their greater habitual dietary nitrate intake and/or extensive exercise training reconditioning that negate any further benefit of nitrate supplementation. Additionally, methodological limitations prevent detection of small, but relevant, increases in performance capacity in the elite athlete. Alternative methodologies such as case studies on the true elite athlete, and further development of sport-specific testing should be prioritized. Even though performance benefits of nitrate supplementation may be of a lesser magnitude in the elite athlete, a minimal increase in speed, strength or endurance will be of a much greater relevance in an elite, competitive setting. 


\section{References}

1. Bailey SJ, Fulford J, Vanhatalo A, Winyard PG, Blackwell JR, DiMenna FJ, Wilkerson DP, Benjamin N and Jones AM. Dietary nitrate supplementation enhances muscle contractile efficiency during knee-extensor exercise in humans. J Appl Physiol 109: 135-148, 2010.

2. Bailey SJ, Winyard P, Vanhatalo A, Blackwell JR, DiMenna FJ, Wilkerson DP, Tarr J, Benjamin N and Jones AM. Dietary nitrate supplementation reduces the 0-2 cost of low-intensity exercise and enhances tolerance to high-intensity exercise in humans. J Appl Physiol 107: 1144-1155, 2009.

3. Bescós R, Ferrer-Roca V, Galilea PA, Roig A, Drobnic F, Sureda A, Martorell M, Cordova A, Tur JA and Pons A. Sodium nitrate supplementation does not enhance performance of endurance athletes. Med $\mathrm{Sci}$ Sports Exerc 44: 2400-2409, 2012.

4. Bond $\mathrm{H}$, Morton $\mathrm{L}$ and Braakhuis AJ. Dietary nitrate supplementation improves rowing performance in well-trained rowers. Int J Sport Nutr Exerc Metab 22: 251-256, 2012.

5. Boorsma RK, Whitfield J and Spriet LL. Beetroot juice supplementation does not improve performance of elite 1500-m runners. Med Sci Sports Exerc 46: 2326-2334, 2014.

6. Cermak NM, Res P, Stinkens R, Lundberg JO, Gibala MJ and van Loon L. No Improvement in Endurance Performance After a Single Dose of Beetroot Juice. Int J Sport Nutr Exerc Metab 22: 470-478, 2012.

7. Cermak NM, Gibala MJ and van Loon L,J.C. Nitrate supplementation's improvement of $10-\mathrm{km}$ time-trial performance in trained cyclists. Int J Sport Nutr Exerc Metab 22: 64-71, 2012.

8. Christensen PM, Nyberg $\mathrm{M}$ and Bangsbo J. Influence of nitrate supplementation on $\mathrm{VO}_{2}$, kinetics and endurance of elite cyclists. Scand J Med Sci Sports 23: e21-e31, 2013.

9. Dejam A, Hunter CJ, Schechter AN and Gladwin MT. Emerging role of nitrite in human biology. Blood Cells, Molecules and Diseases 32: 423-429, 2004.

10. Ferguson SK, Holdsworth CT, Wright JL, Fees AJ, Allen JD, Jones AM, Musch TI and Poole DC. Microvascular oxygen pressures in muscles comprised of different fiber types: Impact of dietary nitrate supplementation. Nitric Oxide: in press, 2014.

11. Hernández A, Schiffer TA, Ivarsson N, Cheng AJ, Bruton JD, Lundberg JO, Weitzberg E and Westerblad H. Dietary nitrate increases tetanic [Ca2+]i and contractile force in mouse fast-twitch muscle. J Physio/ 590: 3575-3583, 2012.

12. Hopkins WG, Schabort EJ and Hawley JA. Reliability of power in physical performance tests. Sports Med 31: 211-234, 2001.

13. Jensen L, Bangsbo $J$ and Hellsten Y. Effect of high intensity training on capillarization and presence of angiogenic factors in human skeletal muscle. J Physiol 557: 571-582, 2004.

14. Jones A. Dietary Nitrate Supplementation and Exercise Performance. Sports Med 44: 35-45, 2014.

15. Kelly J, Vanhatalo A, Wilkerson DP, Wylie LJ and Jones AM. Effects of nitrate on the power-duration relationship for severe-intensity exercise. Med Sci Sports Exerc 45: 1798-1806, 2013.

16. Lansley KE, Winyard PG, Bailey SJ, Vanhatalo A, Wilkerson DP, Blackwell JR, Gilchrist M, Benjamin N and Jones AM. Acute Dietary Nitrate Supplementation Improves Cycling Time Trial Performance. Med Sci Sports Exerc 43: 1125-1131, 2011.

17. Lansley KE, Winyard PG, Fulford J, Vanhatalo A, Bailey SJ, Blackwell JR, DiMenna FJ, Gilchrist M, Benjamin $\mathrm{N}$ and Jones $\mathrm{AM}$. Dietary nitrate supplementation reduces the $\mathrm{O}-2$ cost of walking and running: a placebo-controlled study. J Appl Physiol 110: 591-600, 2011.

18. Larsen FJ, Weitzberg E, Lundberg JO and Ekblom B. Effects of dietary nitrate on oxygen cost during exercise. Acta Physiologica 191: 59-66, 2007.

19. Larsen FJ, Schiffer TA, Borniquel S, Sahlin K, Ekblom B, Lundberg JO and Weitzberg E. Article: Dietary Inorganic Nitrate Improves Mitochondrial Efficiency in Humans. Cell Metabolism 13: 149-159, 2011.

20. Larsen FJ, Weitzberg E, Lundberg JO and Ekblom B. Dietary nitrate reduces maximal oxygen consumption while maintaining work performance in maximal exercise. Free Radic Biol Med 48: 342-347, 2010.

21. Muggeridge DJ, Howe C, Spendiff O, Pedlar C, James PE and Easton C. The Effects of a Single Dose of Concentrated Beetroot Juice on Performance in Trained Flatwater Kayakers. Int J Sport Nutr Exerc Metab 23: 498-506, 2013.

22. Peacock O, Tjønna AE, James P, Wisløff U, Welde B, Böhlke N, Smith A, Stokes K, Cook C and Sandbakk O. Dietary nitrate does not enhance running performance in elite cross-country skiers. Med Sci Sports Exerc 44: 2213-2219, 2012. 


\section{Chapter 2}

23. Peeling $\mathrm{P}$, Cox GR, Bullock $\mathrm{N}$ and Burke LM. Beetroot Juice Improves on-Water $500 \mathrm{~m}$ Time-Trial Performance, and Laboratory-Based Paddling Economy in National and International-Level Kayak Athletes. Int J Sport Nutr Exerc Metab 25(3): 278-84, 2015.

24. Porcelli S, Ramaglia M, Bellistri G, Pavei G, Pugliese L, Montorsi M, Rasica L and Marzorati M. Aerobic Fitness Affects the Exercise Performance Responses to Nitrate Supplementation. Med Sci Sports Exerc 47(8): 1643-51, 2015.

25. Totzeck M, Hendgen-Cotta U, Rammos C, Frommke L, Knackstedt C, Predel H, Kelm M and Rassaf T. Higher endogenous nitrite levels are associated with superior exercise capacity in highly trained athletes. Nitric Oxide 27: 75-81, 2012.

26. Vanhatalo A, Bailey SJ, Blackwell JR, DiMenna FJ, Pavey TG, Wilkerson DP, Benjamin N, Winyard PG and Jones AM. Acute and chronic effects of dietary nitrate supplementation on blood pressure and the physiological responses to moderate-intensity and incremental exercise. Am J Physiol Regul Integr Comp Physiol 299: R1121-R1131, 2010.

27. Webb AJ, Patel N, Loukogeorgakis S, Okorie M, Aboud Z, Misra S, Rashid R, Miall P, Deanfield J, Benjamin $\mathrm{N}$, MacAllister R, Hobbs AJ and Ahluwalia A. Acute blood pressure lowering, vasoprotective, and antiplatelet properties of dietary nitrate via bioconversion to nitrite. Hypertension 51: 784-790, 2008.

28. Wilkerson DP, Hayward GM, Bailey SJ, Vanhatalo A, Blackwell JR and Jones AM. Influence of acute dietary nitrate supplementation on 50 mile time trial performance in well-trained cyclists. Eur J Appl Physiol 112: 4127-4134, 2012.

29. Wylie L, Kelly J, Bailey SJ, Blackwell JR, Skiba PF, Winyard PG, Jeukendrup AE, Vanhatalo A and Jones AM. Beetroot juice and exercise: pharmacodynamic and dose-response relationships. J Appl Physiol 115: 325-336, 2013.

30. Wylie LJ, Mohr M, Krustrup P, Jackman SR, Ermidis G, Kelly J, Black MI, Bailey SJ, Vanhatalo A and Jones AM. Dietary nitrate supplementation improves team sport-specific intense intermittent exercise performance. Eur J Appl Physiol 113: 1673-1684, 2013. 


\title{
Chapter
}

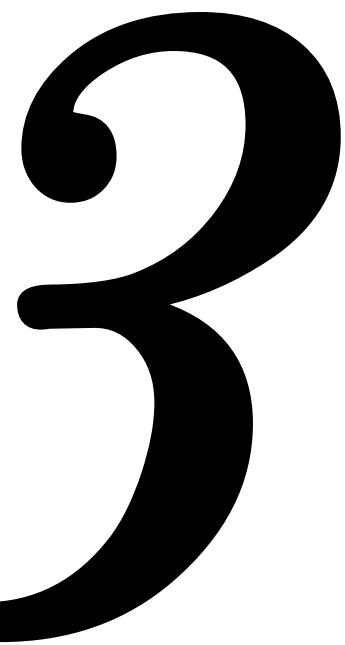

No Effect of Acute and 6-Day Nitrate Supplementation on $\mathrm{VO}_{2}$ and Time-Trial Performance in Highly-Trained Cyclists

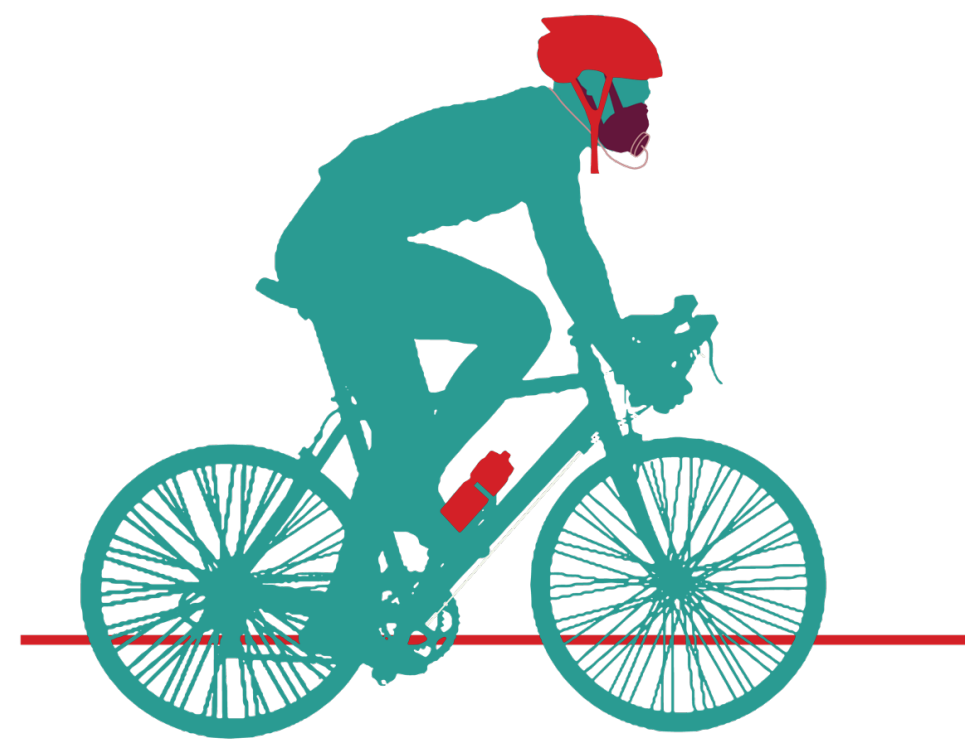

\author{
Jean Nyakayiru \\ Kristin L. Jonvik \\ Philippe J.M. Pinckaers \\ Joan M.G. Senden \\ Luc J.C. van Loon \\ Lex B. Verdijk
}




\section{ABSTRACT}

Background: While the majority of studies reporting ergogenic effects of dietary nitrate have used a multiday supplementation protocol, some studies suggest that a single dose of dietary nitrate prior to exercise can also improve subsequent performance. We aimed to compare the impact of acute and 6-day sodium nitrate supplementation on oxygen uptake $\left(\mathrm{V}_{2}\right)$ and time-trial performance in trained cyclists.

Methods: Using a randomized, double blind, cross-over design, 17 male cyclists $\left(25 \pm 4\right.$ y, $\left.\dot{V} O_{2 \text { peak }} 65 \pm 4 \mathrm{~mL} \cdot \mathrm{kg}^{-1} \cdot \mathrm{min}^{-1}, \mathrm{~W}_{\max } 411 \pm 35 \mathrm{~W}\right)$ were subjected to 3 different trials; 5 days placebo and 1 day sodium nitrate supplementation (1-DAY); 6 days sodium nitrate supplementation (6-DAY); 6 days placebo supplementation (PLA). Nitrate was administered as $1097 \mathrm{mg}$ sodium nitrate providing $800 \mathrm{mg}$ ( 12.9 mmol) nitrate per day. Three hours after ingestion of the last supplemental bolus, indirect calorimetry was performed while subjects performed $30 \mathrm{~min}$ of exercise at $45 \%$ $\mathrm{W}_{\max }$ and $30 \mathrm{~min}$ at $65 \% \mathrm{~W}_{\max }$ on a cycle ergometer, followed by a $10 \mathrm{~km}$ time-trial.

Results: Immediately prior to exercise, plasma [nitrate] and [nitrite] increased to a similar extent during the 6-DAY and 1-DAY trial, but not with PLA (plasma nitrite: $501 \pm 205,553 \pm 278$, and $239 \pm 74 \mathrm{nM}$, respectively; $P<0.001)$. No differences were observed between interventions in $\dot{V}_{2}$ during submaximal exercise, or in time to complete the time-trial (6-DAY: $1004 \pm 61$, 1-DAY: 1022 $\pm 72, \mathrm{PLA}: 1017 \pm 71 \mathrm{~s} ; P=0.28$ ).

Conclusion: Both acute and 6-days of sodium nitrate supplementation do not alter $\dot{\mathrm{V}}_{2}$ during submaximal exercise or improve time-trial performance in highly-trained cyclists, despite increasing plasma [nitrate] and [nitrite]. 


\section{Introduction}

An increasing body of evidence suggests that inorganic nitrate supplementation can have beneficial effects on exercise performance (1-5). Previous studies reported reduced oxygen uptake $\left(\mathrm{V}_{2}\right)$ during submaximal exercise (1-3), enhanced exercise tolerance $(1,6)$, and improved time-trial performance $(2,5)$, following ingestion of dietary nitrate in humans. A reduction of the ingested nitrate by facultative bacteria in the oral cavity into nitrite, can eventually lead to an increased bio-availability of nitric oxide (NO) (7). This increased NO bio-availability has been associated with reduced $\mathrm{VO}_{2}$ during submaximal exercise and increased blood flow during exercise $(8,9)$.

Larsen et al. (3) were the first to study the effects of dietary nitrate supplementation on $\dot{\mathrm{V}}_{2}$ during exercise. They observed a lower $\dot{\mathrm{V}}_{2}$ during submaximal cycling exercise following 3 days of sodium nitrate ingestion. These findings were later confirmed in studies that used beetroot juice as the nitrate source $(1,2)$. Interestingly, the ingestion of nitrate-rich beetroot juice for 6 consecutive days did not only result in a reduced $\mathrm{V}_{2}$ during submaximal cycling exercise, but also increased time to exhaustion during constant work high-intensity cycling (1). In an attempt to determine whether the observed effects translate to functional performance benefits, we previously assessed the effect of nitrate on time-trial performance (2). We showed that 6 days of beetroot juice supplementation resulted in a $1.2 \%$ improvement in cycling time-trial performance compared to a nitrate-depleted placebo.

Whereas most of the earlier studies used a multi-day ( $\geq 3$ days) supplementation protocol to elicit the ergogenic effects of dietary nitrate $(1,2)$, other studies adopted a so-called 'acute' supplementation regimen (10, 11). Vanhatalo et al. (11) reported reduced $\mathrm{VO}_{2}$ during submaximal exercise following the acute (i.e. $2.5 \mathrm{~h}$ prior to exercise) ingestion of beetroot juice. This effect persisted when nitrate supplementation was continued for 5 and 15 days. Likewise, acute nitrate supplementation was observed to improve functional performance during a simulated 4- and 16-km cycling time-trial (5). These observations suggest that a single nitrate dose might be as effective in improving performance as a multiday supplementation protocol. However, multi-day nitrate supplementation has been shown to induce beneficial structural adaptations at the myocellular level which are unlikely to manifest within 1-3 $\mathrm{h}$ after ingestion of a single nitrate bolus $(8,12)$. As such, a multiday regimen might be necessary to obtain the full ergogenic benefits of nitrate supplementation. In accordance, improvements in exercise performance after acute nitrate supplementation have been observed by some (5, $6)$, but certainly not all studies (10, 13-15). Interestingly, recent work also suggests minimal to no performance enhancing effects of dietary nitrate in highly- 
trained/elite athletes, with most of the studies adopting an acute supplementation protocol $(10,16-18)$. Since there are no studies that have comprehensively compared the effects of acute and chronic nitrate supplementation in trained cyclists, it is currently unknown whether a longer supplementation protocol would be more beneficial than ingestion of a single dose of dietary nitrate. Therefore, the aim of the present study was to determine the effect of acute and 6-day dietary nitrate supplementation on $\mathrm{VO}_{2}$ during submaximal exercise, and time-trial performance in highly-trained cyclists. We hypothesized that 6 days of nitrate ingestion would lower $\mathrm{VO}_{2}$ during submaximal exercise and improve time trial performance.

\section{Methods}

\section{Subjects}

Twenty male competitive cyclists/triathletes participated in this study that was approved by the medical ethical committee of the Maastricht University Medical Centre, the Netherlands. After explanation of the protocol, all subjects provided written informed consent. Three subjects failed to complete the study because of injury $(n=1)$, or personal time constraints $(n=2)$. Subjects' characteristics of the remaining 17 subjects are provided in Table 3.1.

\section{Study design}

In this double-blind, randomized, placebo controlled cross-over study, subjects engaged in 3 experimental test-days to study the effects of acute and 6-day supplementation of a dietary sodium nitrate solution $\left(\mathrm{NaNO}_{3}\right)$ in comparison to a placebo $(\mathrm{NaCl})$. On each test-day, $\mathrm{V}_{2}$ during submaximal cycling, and time-trial performance were assessed. After screening (visit 1), subjects visited the laboratory 1 week prior to the first trial for familiarization of the full protocol, including $2 \times 30$ min submaximal cycling exercise and the $10-\mathrm{km}$ time-trial (visit 2). Subsequently, the three test-days (visits 3-5) were each preceded by the subjects consuming a supplemental bolus for 5 consecutive days. The last $\left(6^{\text {th }}\right)$ bolus was consumed in the laboratory on the test-day, $3 \mathrm{~h}$ prior to the exercise tests. The supplementation periods were interspaced by 8 days of wash-out.

\section{Pre-testing}

Baseline characteristics were determined during screening (Table 3.1). Subjects' peak power output $\left(\mathrm{W}_{\text {max }}\right)$ and peak oxygen consumption $\left(\dot{\mathrm{V}}_{2 \text { peak }}\right)$ were determined while performing a stepwise exercise test to exhaustion on an electronically braked cycle ergometer (Lode Excalibur, Groningen, The Netherlands), using an online 
gas-collection system (Omnical, Maastricht University, The Netherlands). After a 5min warm-up at $150 \mathrm{~W}$, the workload was increased by $50 \mathrm{~W}$ every 2.5 min until exhaustion. $\dot{\mathrm{V}} \mathrm{O}_{2 \text { peak }}$ was defined as the median of the highest consecutive $\mathrm{V}_{2}$ values over $30 \mathrm{~s}$. $W_{\max }$ was calculated as follows: $W_{\text {max }}=W_{\text {completed }}+t_{\text {uncompleted }} / 150$ (s) $x 50$ (19). The $W_{\text {completed }}$ was the power output at the last completed step, and the $t_{\text {uncompleted }}$ was the time (s) spent in the last uncompleted step.

Table 3.1 Subjects' characteristics

\begin{tabular}{ll}
\hline \hline Age $(\mathrm{y})$ & $25 \pm 4$ \\
$\mathrm{BMI}\left(\mathrm{kg} / \mathrm{m}^{2}\right)$ & $21.8 \pm 1.8$ \\
Cycling experience $(\mathrm{y})$ & $9.6 \pm 5.1$ \\
Cycling $\mathrm{h} / \mathrm{wk}$ & $9.7 \pm 3.7$ \\
$\dot{\mathrm{VO}}$ 2peak $\left(\mathrm{mL} \cdot \mathrm{kg}^{-1} \cdot \mathrm{min}^{-1}\right)$ & $65 \pm 4$ \\
$\mathrm{~W}_{\max }(\mathrm{W})$ & $411 \pm 35$ \\
\hline All values are means $\pm \mathrm{SD}(n=17)$. &
\end{tabular}

\section{Supplementation protocol}

In the five days leading up to the test-days (visits 3-5), subjects either consumed a daily dose of sodium nitrate ( $\mathrm{NaNO}_{3}$ [BASF, Ludwigshafen, Germany]) or an equal amount of $\mathrm{NaCl}$ (Frisia Zout BV, Harlingen, The Netherlands) dissolved in $140 \mathrm{~mL}$ of water after breakfast. The 6-day nitrate supplementation period (6-DAY) consisted of 6 days of $1097 \mathrm{mg} \mathrm{NaNO}$ ingestion, providing $800 \mathrm{mg}(\sim 12.9 \mathrm{mmol})$ nitrate/day. As the placebo intervention (PLA), subjects ingested $1097 \mathrm{mg} /$ day $\mathrm{NaCl}$ for 6 days. The acute nitrate trial (1-DAY) consisted of a $1097 \mathrm{mg} \mathrm{NaNO} 3$ bolus that was ingested on the test-day (day 6), preceded by 5 days of $\mathrm{NaCl}$ ingestion.

\section{Experimental test-days}

On the morning of the final $\left(6^{\text {th }}\right)$ day of each supplemental period, subjects reported to the laboratory after an overnight fast. Following a 10 -min rest period, blood pressure was measured with subjects in the supine position using an automated blood pressure monitor (Omron Healthcare Inc, Field Court Lake Forest, USA), and a catheter was inserted into an antecubital vein. After obtaining a fasted blood sample, subjects consumed a standardized breakfast, immediately followed by their last $\left(6^{\text {th }}\right)$ supplemental beverage. During the subsequent 3-h rest period, repeated blood draws were performed at 90, 150, 180, 240, and $270 \mathrm{~min}$ and a second blood pressure measurement was performed $2.5 \mathrm{~h}$ post-ingestion of the last supplement. After the 3-h rest period, subjects performed a 1-h submaximal exercise test on a cycle ergometer at $45 \% \mathrm{~W}_{\max }(30 \mathrm{~min})$ and $65 \% \mathrm{~W}_{\max }(30 \mathrm{~min})$. Measurements of $\mathrm{V}_{2}$ 
and $\mathrm{CO}_{2}$ production were obtained through the use of a respiratory facemask, connected to a gas-collection system (2). Respiratory data and heart-rate (HR) (Polar, Finland) were collected continuously for 5-7 min at 5, 20, 35, and 50 min into the submaximal exercise test, and the last 3-min were averaged.

Following the submaximal test, subjects performed a simulated $\sim 10-\mathrm{km}$ cycling time-trial. The amount of work to be performed was calculated as follows: total amount of work $(\mathrm{J})=0.85 * W_{\max } * 900(\mathrm{~s})(20)$. The ergometer was set in linearmode so that $85 \% W_{\max }$ was achieved when subjects cycled at their preferred pedaling rate of $85 \pm 7 \mathrm{rpm}$, as determined during familiarization. Subjects received no verbal or physiological feedback during the time-trial, and were only aware of the absolute $(\mathrm{kJ})$ and relative (\%) amount of work performed. Ratings of perceived exertion (RPE) were assessed after each 30-min submaximal exercise test and after the time-trial using the Borg 6-20 scale (21). All testing was performed under standardized conditions $\left(18.3 \pm 0.1^{\circ} \mathrm{C}, 58 \pm 1 \%\right.$ humidity) on the same time of day, and the same day in the week.

\section{Physical activity and dietary standardization}

Subjects recorded their dietary intake and physical activity for three days prior to the first test-day (visit 3), and refrained from strenuous activity for $48 \mathrm{~h}$ prior to the test. Subjects replicated their dietary intake and activities in the days prior to the following two test-days. Subjects did not consume caffeine (12 h) or alcohol (24 h) prior to each visit. To prevent attenuation in the reduction of nitrate to nitrite, subjects refrained from using antibacterial mouthwash/toothpaste during the 6day supplementation period (22). No restrictions were set for the intake of nitraterich foods. However, subjects were provided with a standardized dinner for the evening before ( $41 \mathrm{mg}$ nitrate), and a standardized breakfast ( $7 \mathrm{mg}$ nitrate) on each test-day, which was adapted to their bodyweight as described previously (2). The ad libitum amount of water consumed during the first test-day was replicated during the second and third test-day.

\section{Plasma analysis}

Blood samples were collected in S-Monovette ${ }^{\circledR}$ Lithium-Heparin containing tubes (Sarstedt, Nümbrecht, Germany) and immediately centrifuged at 1,000 g for $5 \mathrm{~min}$, at $4{ }^{\circ} \mathrm{C}$. Aliquots of plasma were frozen in liquid nitrogen, and stored at $-80^{\circ} \mathrm{C}$ for subsequent analysis of plasma [nitrate] and [nitrite] using chemiluminescence, as described previously (13). 


\section{Statistical analysis}

Performance data from the time-trials as well as $\mathrm{VO}_{2}$ data were analyzed by oneway repeated measures ANOVA with treatment (PLA vs 1-DAY vs 6-DAY) as factor. Statistical analysis of all plasma data was performed using two-way repeated measures ANOVA with time and treatment as within subject factors. Statistical significance was set at $P<0.05$, and any interaction or main effect was subsequently analyzed using Bonferroni post-hoc test. All data were analyzed using SPSS 21.0 (SPSS Inc, USA), and are presented as means \pm SD.

\section{Results}

\section{Plasma [nitrate] and [nitrite]}

Plasma concentrations at baseline $(t=0)$ were higher in the 6-DAY trial when compared with 1-DAY and PLA trials $(160 \pm 53$ vs $74 \pm 26$ and $71 \pm 16 \mu \mathrm{M}$, respectively; $P<0.001)$. Following ingestion of the final bolus, plasma [nitrate] increased to the same extent in the 6-DAY $(+316 \pm 136 \mu \mathrm{M})$ and 1-DAY trial $(+360 \pm 150 \mu \mathrm{M})$ and remained elevated throughout the exercise protocol ( $t=180 \mathrm{~min}$ and beyond), while no changes were observed during the PLA trial (Figure 3.1A). In contrast to plasma [nitrate], plasma [nitrite] was not different between trials at baseline (Figure 3.1B). Following ingestion of the final bolus, plasma [nitrite] increased 2 -fold prior to exercise ( $t=180 \mathrm{~min}$ ) during the 6-DAY (from $263 \pm 104$ to $501 \pm 206 \mathrm{nM} ; P<0.001$ ) and the 1-DAY trial (from $216 \pm 81$ to $553 \pm 278 \mathrm{nM} ; P<0.001$ ), whereas no changes were observed during the PLA trial (from $229 \pm 76$ to $239 \pm 74 \mathrm{nM} ; P=0.49$; Figure 3.1B). Plasma [nitrite] did not differ between the 1-DAY and 6-DAY trial at any time point.

\section{Submaximal cycling exercise}

Mean $\mathrm{V}_{2}$ was not different between the 6-DAY, 1-DAY and PLA trial while cycling at $45 \% \mathrm{~W}_{\max }\left(P=0.60\right.$; Figure 3.2). After adjusting the workload to $65 \% \mathrm{~W}_{\text {max }}, \dot{\mathrm{V}} \mathrm{O}_{2}$ increased in all 3 trials, but no differences were observed in mean $\mathrm{V}_{2}$ between trials $(P=0.89)$. Similarly, no differences were observed between trials for RER (data not shown), average HR and RPE during both the $45 \% \mathrm{~W}_{\max }$, and $65 \% \mathrm{~W}_{\max }$ workload (Table 3.2; all P 0.20). 

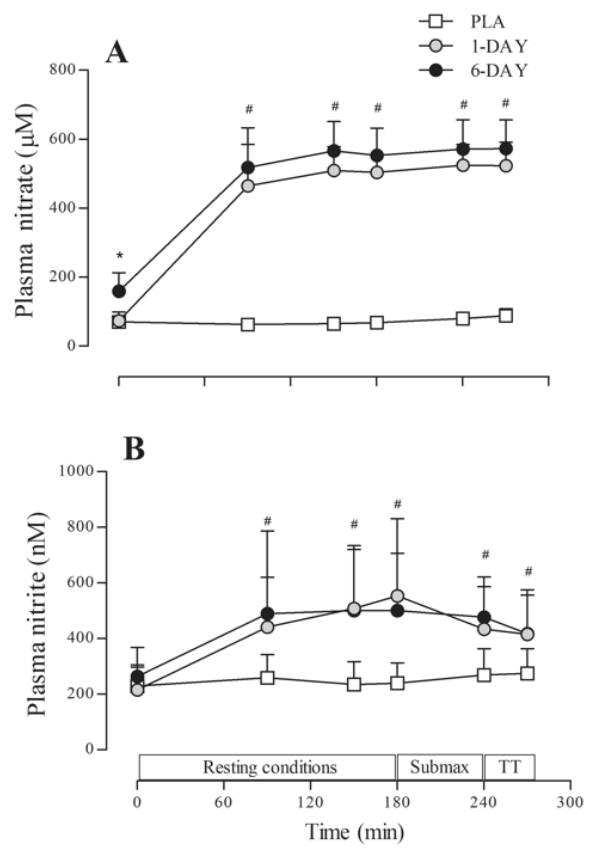

Figure 3.1. Mean plasma nitrate (A) and nitrite (B) concentrations on trial days during resting conditions and during the submaximal cycling test (Submax) and the 10-km time-trial (TT) for the placebo (PLA), the acute nitrate (1-DAY) and the 6-day nitrate (6-DAY) intervention. *6DAY significantly different from 1-DAY and PLA. \#1-DAY and 6-DAY significantly different from $t=0$ min (within treatment) and different from PLA (between treatments). Data are means $\pm \operatorname{SD}(n=17)$.

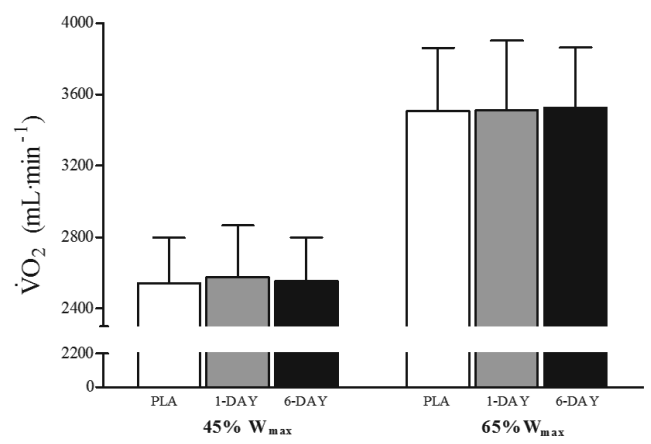

Figure 3.2. Mean oxygen uptake $\left(\mathrm{V}_{2}\right)$ during submaximal cycling at $45 \%$ and $65 \%$ of maximal power output (Wmax) for the placebo (PLA), the acute nitrate (1-DAY) and the 6-day nitrate (6-DAY) trial. No differences were observed between experimental trials. Data are means $\pm S D(n=17)$. 


\section{Time Trial performance}

The average time to complete the $10-\mathrm{km}$ time-trial was $1004 \pm 61 \mathrm{~s}(6-\mathrm{DAY}), 1022 \pm 72$ $\mathrm{s}(1-D A Y)$, and $1017 \pm 71 \mathrm{~s}$ (PLA), with no apparent differences between the interventions ( $P=0.28$; Figure 3.3A). In accordance, no differences were observed in average power output during the time-trial between the 3 interventions $(P=0.33$; Figure 3.3B), nor for the power output at every $10 \%$ stage of the time trial $(P=0.54$, data not shown). For both RPE and HR, no differences were observed between interventions (Table 3.2).
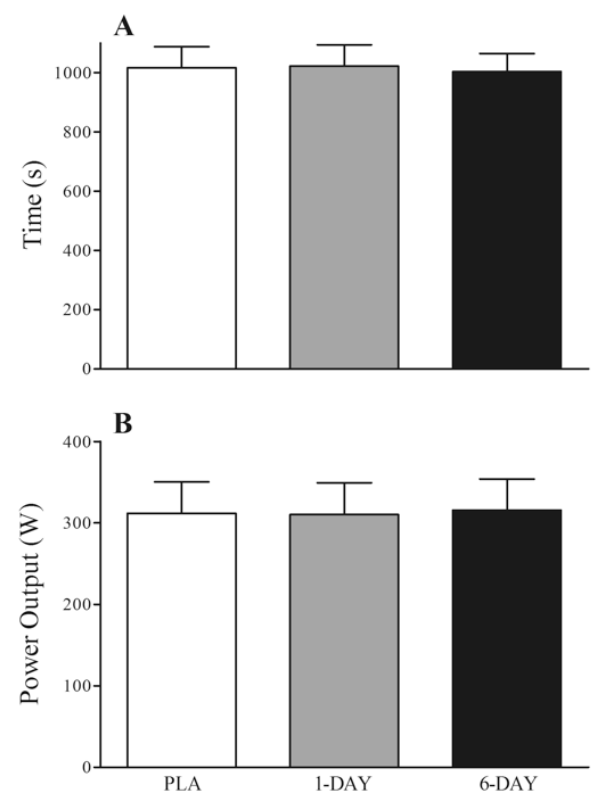

Figure 3.3. Time to complete the time trial $(A)$ and mean power output (B) during the $\sim 10-\mathrm{km}$ time trial for the placebo (PLA), the acute nitrate (1-DAY) and the 6-day nitrate (6-DAY) trial. No differences were observed between experimental trials. Data are means $\pm \operatorname{SD}(n=17)$.

Blood pressure and Gastro-intestinal (Gl) discomfort

Both systolic and diastolic blood pressure did not differ between interventions at baseline, and did not change following ingestion of the final bolus (Table 3.2). None of the subjects reported any Gl complaints during the experiments. 
Table 3.2: Blood pressure and heart rate data

\begin{tabular}{|c|c|c|c|}
\hline & PLA & 1-DAY & 6-DAY \\
\hline Blood pressure SYS ( $t=0 \mathrm{~h})(\mathrm{mmHg})$ & $121 \pm 8$ & $122 \pm 5$ & $120 \pm 8$ \\
\hline Blood pressure SYS ( $t=2.5 \mathrm{~h})(\mathrm{mmHg})$ & $121 \pm 6$ & $122 \pm 7$ & $122 \pm 9$ \\
\hline Blood pressure DIA $(t=0 h)(\mathrm{mmHg})$ & $65 \pm 7$ & $64 \pm 7$ & $64 \pm 8$ \\
\hline Blood pressure DIA $(t=2.5 \mathrm{~h})(\mathrm{mmHg})$ & $61 \pm 9$ & $62 \pm 7$ & $61 \pm 6$ \\
\hline Mean Heart rate $45 \% \mathrm{~W}_{\max }$ (beats $/ \mathrm{min}$ ) & $133 \pm 10$ & $134 \pm 11$ & $131 \pm 9$ \\
\hline Mean Heart rate $65 \% W_{\max }$ (beats $/ \mathrm{min}$ ) & $166 \pm 13$ & $168 \pm 10$ & $166 \pm 10$ \\
\hline Mean Heart rate TT (beats/min) & $178 \pm 6$ & $177 \pm 6$ & $175 \pm 7$ \\
\hline Peak Heart rate TT (beats/min) & $187 \pm 7$ & $187 \pm 7$ & $183 \pm 8^{1}$ \\
\hline RPE after $45 \% W_{\max }$ & $11 \pm 1$ & $11 \pm 1$ & $11 \pm 1$ \\
\hline RPE after $65 \% W_{\max }$ & $16 \pm 2$ & $16 \pm 2$ & $16 \pm 2$ \\
\hline RPE after TT & $19 \pm 1$ & $19 \pm 1$ & $19 \pm 1$ \\
\hline
\end{tabular}

All values are means $\pm \mathrm{SD}(\mathrm{n}=17)$. Placebo (PLA), acute nitrate (1-DAY), 6-day nitrate (6-DAY), systolic (SYS), diastolic (DIA), peak power output (Wmax), time-trial (TT) and Rate of perceived exertion (RPE). No differences over time or between interventions were observed for blood pressure. There was a main effect for peak heart rate, which tended to be lower for 6-DAY vs 1-DAY $\left({ }^{\prime} P=0.10\right)$.

\section{Discussion}

In the present study, we demonstrated that nitrate supplementation with an acute or 6-day supplementation protocol resulted in similar increases in plasma [nitrate] and [nitrite]. However, acute as well as 6-day dietary nitrate supplementation did not alter $\dot{\mathrm{V}}_{2}$ during submaximal exercise or improve time-trial performance in highly-trained cyclists.

Nitrate-rich supplements have become increasingly popular among both elite and recreational athletes over the past years. Following the first studies reporting reduced $\mathrm{VO}_{2}$ during submaximal exercise and improved exercise performance $(1-3,5)$, a plethora of different supplementation regimens have been used to explore the ergogenic effects of nitrate. Whereas the majority of studies in this area showed ergogenic effects following multiple days of nitrate supplementation, some suggest that ingestion of a single dose of nitrate prior to exercise can also improve performance $(5,6)$. However, fundamental work exploring the underlying mechanisms of nitrate's ergogenic properties has shown that improved mitochondrial efficiency and contractile function following chronic nitrate supplementation are associated with reduced expression of ANT (8) and increased expression of calcium-handling proteins (12). Such changes are unlikely to occur after the acute ingestion of dietary nitrate. Hence, we speculated that greater benefits can be expected from multi-day supplementation than from acute supplementation. The present study is the first to assess the effects of both acute 
and 6-days of nitrate supplementation on $\mathrm{VO}_{2}$ and time-trial performance within the same group of highly-trained cyclists. We found that supplementation with 800 mg nitrate, provided both acutely and successively for 6 days, resulted in a 6 -fold increase in plasma [nitrate] and a 2 -fold increase in plasma [nitrite], in comparison to a placebo (Figure 3.1). Interestingly, in line with previous work by Vanhatalo et al. (11), the elevated plasma [nitrate] and [nitrite] in the hours following ingestion of the final bolus did not differ between acute and 6-day nitrate supplementation. Therefore, potential differences in ergogenic effects between acute and prolonged nitrate supplementation would more likely be attributed to an adaptive response to nitrate availability, rather than circulating (peak) [nitrate] or [nitrite].

Despite the substantially elevated plasma [nitrate] and [nitrite] after acute and 6-days of nitrate supplementation, we did not observe any ergogenic or pharmacodynamic effects in the highly-trained cyclists in the present study. Given the time required for structural myocellular adaptations to occur (8), we expected the 6-DAY protocol to be more beneficial than the 1-DAY protocol. In contrast to our hypothesis, $\dot{\mathrm{V}}{ }_{2}$ during submaximal cycling did not differ between interventions, and no differences were observed in time-trial performance (Figures 3.2 and 3.3). These findings do not match our previous observations of ergogenic effects following 6-day supplementation in moderately trained athletes with a $\mathrm{VO}_{2 \text { peak }}$ of $58 \mathrm{~mL} \cdot \mathrm{kg}^{-1} \cdot \mathrm{min}^{-1}(2)$. However, the lack of ergogenic effects observed in the present study with better trained subjects $\left(\mathrm{VO}_{2 \text { peak }} \sim 65 \mathrm{~mL} \cdot \mathrm{kg}^{-1} \cdot \mathrm{min}^{-1}\right)$ is in line with recent literature on highly-trained and elite athletes $(14,17,23,24)$. Indeed, $\dot{\mathrm{V}} \mathrm{O}_{2}$ and timetrial performance remained unchanged following nitrate supplementation in highlytrained cross-country skiers (17) and middle-distance runners (14). Although the exact reason for the impaired response to nitrate in trained individuals is still unclear, some viable explanations have emerged in recent literature. For example, two animal studies reported that nitrate preferably exerts its effects through type II muscle fibers $(9,12)$. Endurance-trained athletes, such as those included in the current study, likely have a low proportion of these fibers (25), possibly limiting their ability to fully benefit from the effects of nitrate supplementation. In addition, previous observations suggest that regular (endurance-type) exercise results in structural adaptations in various tissues, most likely in response to elevated NOS activity (26). These physiological changes are believed to account for the attenuated response to elevations in NO-bioavailability in elite athletes (27). A recent study elegantly illustrated this difference in responsiveness, between individuals with different levels of aerobic capacity (24). Whereas low and moderately trained athletes were shown to improve running time-trial performance after 7 days of sodium nitrate supplementation, the highly-trained group $\left(\mathrm{V}_{2 \text { peak }}\right.$ 


\section{Chapter 3}

$\sim 72 \mathrm{~mL} \cdot \mathrm{kg}^{-1} \cdot \mathrm{min}^{-1}$ ) did not show any improvements when compared to the placebo condition (24). Although we cannot exclude potential benefits from extending the supplementation period beyond 6 days (in line with Vanhatalo et al., (11)), the present study supports current literature by showing no changes in $\mathrm{V}_{2}$ or time-trial performance after both acute or 6-day nitrate supplementation in highly-trained athletes.

Interestingly, despite not detecting ergogenic effects at the group level, some studies have suggested that there may be specific nitrate 'responders' within the group of highly-trained athletes $(14,16)$. Wilkerson et al. (16) identified 5 of the 8 highly-trained cyclists in their study as possible 'responders' based on increases in plasma [nitrite] $(+45 \%)$, and improvements in time-trial performance ( $2 \%$ faster). In the present study, all subjects showed substantial increases in plasma [nitrite] averaging $+287 \pm 216 \mathrm{nM}$ (range 94-881 nM); or $+162 \pm 152 \%$. However, no performance improvements were observed at the group level. This seems to suggest that measuring increases in plasma [nitrite] following nitrate ingestion does not suffice when identifying potential 'responders' to the ergogenic properties of nitrate supplements. Alternatively, other studies defined 'responders' solely based on improvements in time-trial performance and/or changes in $\dot{\mathrm{V}}_{2}(14,28)$. Although we did not observe any changes in $\dot{\mathrm{V}}_{2}$, six subjects did show a faster time to complete the time-trial with both the 1-DAY $(4.5 \pm 2.4 \%$ faster $)$ and the 6DAY $(5.4 \pm 2.9 \%$ faster $)$ protocols. Interestingly, the differences in time trial performance between trials were less pronounced $(2.3 \pm 3.5 \%)$, in subjects in which time-trial performance was better following ingestion of PLA or with only one of the nitrate interventions (1-DAY or 6-DAY). However, as we previously suggested, a more robust scientific approach is needed to quantify the responsiveness to nitrate supplementation in individual athletes (29). As such, caution should be taken when speculating on potential 'responders' and 'non-responders' to nitrate supplementation based on our data.

We conclude that both acute and 6-day nitrate supplementation result in similar increases in plasma [nitrate] and [nitrite]. However, $800 \mathrm{mg}$ sodium nitrate supplementation, acutely or successively for 6 days does not lower oxygen requirements during submaximal exercise or improve time-trial performance in highly-trained cyclists. 


\section{References}

1. Bailey SJ, Winyard P, Vanhatalo A, Blackwell JR, Dimenna FJ, Wilkerson DP, et al. Dietary nitrate supplementation reduces the $\mathrm{O} 2$ cost of low-intensity exercise and enhances tolerance to high-intensity exercise in humans. J Appl Physiol (1985). 2009;107(4):1144-55.

2. Cermak N, Gibala M, van Loon L. Nitrate supplementation improves $10 \mathrm{~km}$ time trial performance in trained cyclists. Int J Sport Nutr Exerc Metab. 2011;22(1):64-71.

3. Larsen FJ, Weitzberg E, Lundberg JO, Ekblom B. Effects of dietary nitrate on oxygen cost during exercise. Acta Physiol (Oxf). 2007;191(1):59-66.

4. Bond H, Morton L, Braakhuis AJ. Dietary nitrate supplementation improves rowing performance in welltrained rowers. Int J Sport Nutr Exerc Metab. 2012;22(4):251-6.

5. Lansley, Winyard P, Bailey S, Vanhatalo A, Wilkerson D, Blackwell J, et al. Acute dietary nitrate supplementation improves cycling time trial performance. Med Sci Sports Exerc. 2011;43(6):1125-31.

6. Wylie LJ, Kelly J, Bailey SJ, Blackwell JR, Skiba PF, Winyard PG, et al. Beetroot juice and exercise: pharmacodynamic and dose-response relationships. J Appl Physiol (1985). 2013;115(3):325-36.

7. Weitzberg E, Lundberg JO. Novel aspects of dietary nitrate and human health. Annu Rev Nutr. 2013;33:129-59.

8. Larsen FJ, Schiffer TA, Borniquel S, Sahlin K, Ekblom B, Lundberg JO, et al. Dietary inorganic nitrate improves mitochondrial efficiency in humans. Cell Metab. 2011;13(2):149-59.

9. Ferguson SK, Hirai DM, Copp SW, Holdsworth CT, Allen JD, Jones AM, et al. Impact of dietary nitrate supplementation via beetroot juice on exercising muscle vascular control in rats. J Physiol. 2013;591(Pt 2):547-57.

10. Bescos $R$, Rodriguez FA, Iglesias $X$, Ferrer MD, Iborra E, Pons A. Acute administration of inorganic nitrate reduces VO(2peak) in endurance athletes. Med Sci Sports Exerc. 2011;43(10):1979-86.

11. Vanhatalo A, Bailey S, Blackwell J, DiMenna F, Pavey T, Wilkerson D, et al. Acute and chronic effects of dietary nitrate supplementation on blood pressure and the physiological responses to moderateintensity and incremental exercise. Am J Physiol Regul Integr Comp Physiol. 2010;299(4):1121-31.

12. Hernandez A, Schiffer TA, Ivarsson N, Cheng AJ, Bruton JD, Lundberg JO, et al. Dietary nitrate increases tetanic [Ca2+]i and contractile force in mouse fast-twitch muscle. J Physiol. 2012;590(Pt 15):3575-83.

13. Cermak NM, Res P, Stinkens R, Lundberg JO, Gibala MJ, van Loon LJ. No improvement in endurance performance after a single dose of beetroot juice. Int J Sport Nutr Exerc Metab. 2012;22(6):470-8.

14. Boorsma RK, Whitfield J, Spriet LL. Beetroot juice supplementation does not improve performance of elite 1500-m runners. Med Sci Sports Exerc. 2014;46(12):2326-34.

15. Lane SC, Hawley JA, Desbrow B, Jones AM, Blackwell JR, Ross ML, et al. Single and combined effects of beetroot juice and caffeine supplementation on cycling time trial performance. Appl Physiol Nutr Metab. 2014;39(9):1050-7.

16. Wilkerson DP, Hayward GM, Bailey SJ, Vanhatalo A, Blackwell JR, Jones AM. Influence of acute dietary nitrate supplementation on 50 mile time trial performance in well-trained cyclists. European journal of applied physiology. 2012;112(12):4127-34.

17. Peacock O, Tjonna AE, James P, Wisloff $U$, Welde B, Bohlke N, et al. Dietary nitrate does not enhance running performance in elite cross-country skiers. Med Sci Sports Exerc. 2012;44(11):2213-9.

18. Sandbakk SB, Sandbakk O, Peacock O, James P, Welde B, Stokes K, et al. Effects of acute supplementation of $\mathrm{L}$-arginine and nitrate on endurance and sprint performance in elite athletes. Nitric Oxide. 2015;48:105.

19. Kuipers H, Verstappen FT, Keizer HA, Geurten P, van Kranenburg G. Variability of aerobic performance in the laboratory and its physiologic correlates. Int J Sports Med. 1985;6(4):197-201.

20. Jeukendrup A, Saris WH, Brouns F, Kester AD. A new validated endurance performance test. Med Sci Sports Exerc. 1996;28(2):266-70.

21. Borg GA. Psychophysical bases of perceived exertion. Med Sci Sports Exerc. 1982;14(5):377-81.

22. Govoni $M$, Jansson $E$, Weitzberg $E$, Lundberg J. The increase in plasma nitrite after a dietary nitrate load is markedly attenuated by an antibacterial mouthwash. Nitric Oxide. 2008;19(4):333-7.

23. Bescos R, Ferrer-Roca V, Galilea PA, Roig A, Drobnic F, Sureda A, et al. Sodium nitrate supplementation does not enhance performance of endurance athletes. Med Sci Sports Exerc. 2012;44(12):2400-9.

24. Porcelli S, Ramaglia M, Bellistri G, Pavei G, Pugliese L, Montorsi M, et al. Aerobic Fitness Affects the Exercise Performance Responses to Nitrate Supplementation. Med Sci Sports Exerc. 2015;47(8):1643-51. 
25. Lucia A, Hoyos J, Chicharro JL. Physiology of professional road cycling. Sports medicine. 2001;31(5):32537.

26. Maiorana A, O'Driscoll G, Taylor R, Green D. Exercise and the nitric oxide vasodilator system. Sports medicine. 2003;33(14):1013-35.

27. Green DJ, Rowley N, Spence A, Carter H, Whyte G, George K, et al. Why isn't flow-mediated dilation enhanced in athletes? Med Sci Sports Exerc. 2013;45(1):75-82.

28. Christensen PM, Nyberg M, Bangsbo J. Influence of nitrate supplementation on $\mathrm{VO}(2)$ kinetics and endurance of elite cyclists. Scandinavian journal of medicine \& science in sports. 2013;23(1):e21-31.

29. Jonvik KL, Nyakayiru J, van Loon LJ, Verdijk LB. Can elite athletes benefit from dietary nitrate supplementation? J Appl Physiol (1985). 2015;119(6):759-61. 


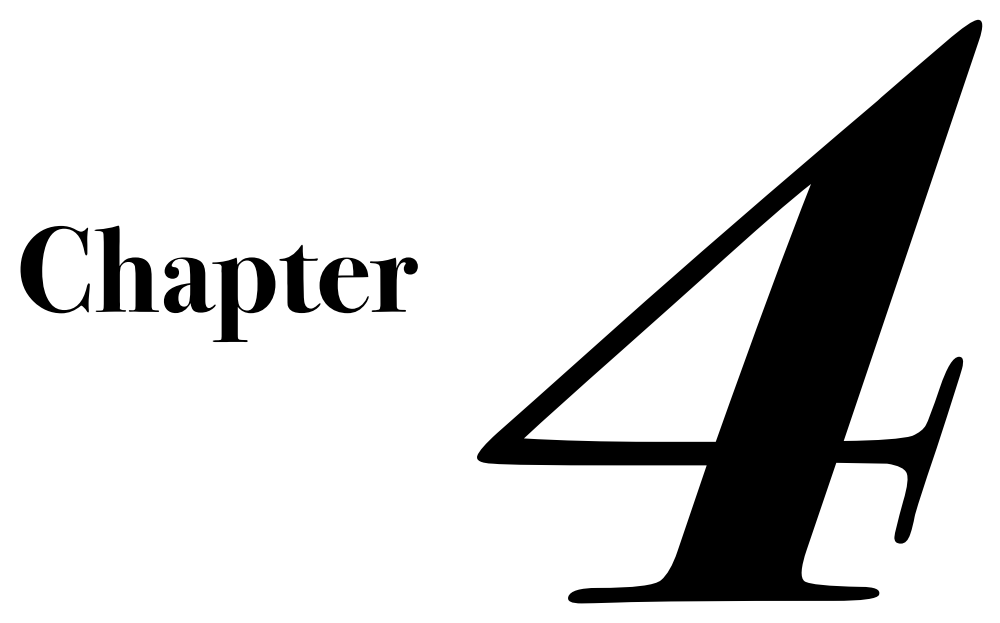

Nitrate-rich vegetables increase plasma nitrate and nitrite concentrations and lower blood pressure in healthy adults
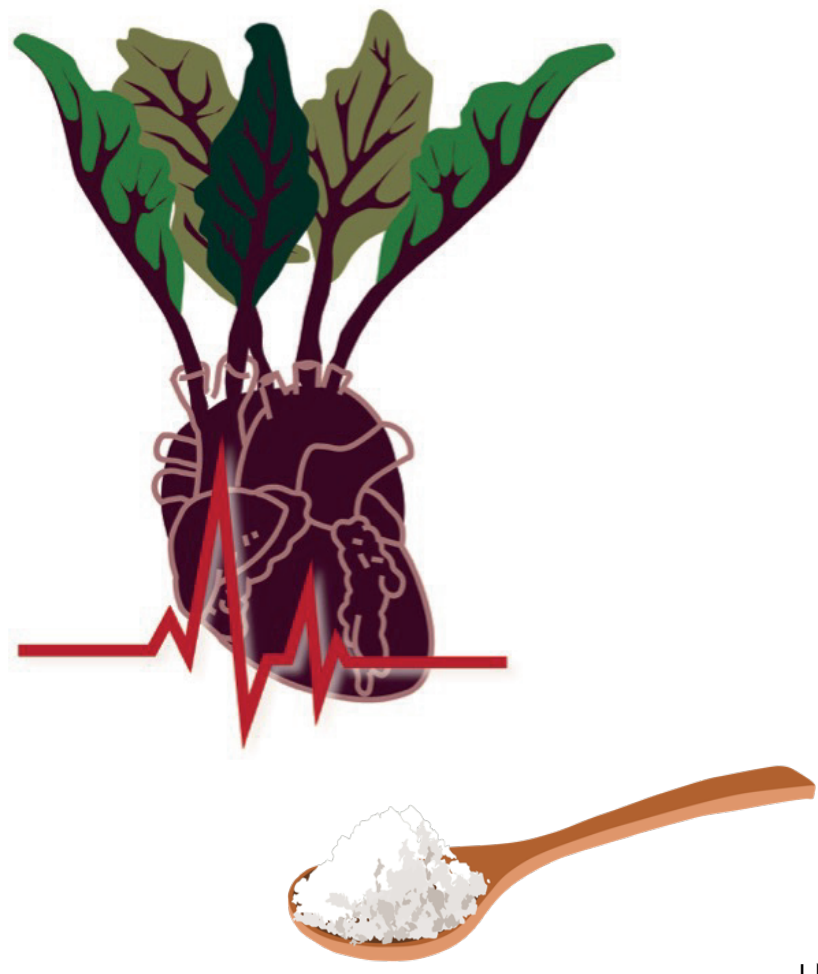

Kristin L. Jonvik Jean Nyakayiru Philippe J.M. Pinckaers Joan M.G. Senden Luc J.C. van Loon Lex B. Verdijk

J Nutr. 2016 May;146(5):986-93. 


\section{ABSTRACT}

Background: Dietary nitrate is receiving increased attention due to its reported ergogenic and cardioprotective properties. It is currently unknown to what extent ingestion of various nitrate-rich vegetables increases post-prandial plasma nitrate and nitrite concentrations and lowers blood pressure. We aimed to assess the impact of ingesting different nitrate-rich vegetables on subsequent plasma nitrate and nitrite concentrations and resting blood pressure in healthy normotensive individuals.

Methods: Using a semi-randomized cross-over design, 11 males and 7 females (28 11 $y, B M l 23 \pm 1 \mathrm{~kg} / \mathrm{m} 2$, exercise 1-10 h/wk) ingested 4 different beverages, each providing $800 \mathrm{mg}(\sim 12.9 \mathrm{mmol})$ nitrate: sodium nitrate (NaNO3), concentrated beetroot juice, a rocket salad beverage, and a spinach beverage. Plasma nitrate and nitrite concentrations and blood pressure were determined before and up to 300 min after beverage ingestion. Data were analyzed using repeated-measures ANOVA.

Results: Plasma nitrate and nitrite concentrations increased after ingestion of all 4 beverages $(P<0.001)$. Peak plasma nitrate concentrations were similar for all treatments ( $\left.\mathrm{NaNO}_{3}: 583 \pm 29, \mathrm{BR}: 597 \pm 23, \mathrm{RS}: 584 \pm 24, \mathrm{SP}: 584 \pm 23 \mu \mathrm{mol} / \mathrm{L}\right)$. Peak plasma nitrite concentrations were different between treatments $\left(\mathrm{NaNO}_{3}: 580 \pm 58\right.$, BR: $557 \pm 57$, RS: $643 \pm 63, \mathrm{SP}: 980 \pm 160 \mathrm{nmol} / \mathrm{L}, P=0.016)$. Compared to baseline, systolic blood pressure declined 150 min after ingestion of BR (from 118 \pm 2 to $113 \pm 2$ $\mathrm{mmHg} ; P<0.001$ ) and RS (from 122 \pm 3 to $116 \pm 2 \mathrm{mmHg} ; P=0.007$ ), and 300 min after ingestion of SP (from $118 \pm 2$ to $111 \pm 3 \mathrm{mmHg} ; P<0.001$ ), but did not change with $\mathrm{NaNO}_{3}$. Diastolic blood pressure declined $150 \mathrm{~min}$ after ingestion of all beverages $(P<0.05)$, and remained lower at 300 min after ingestion of RS ( $P=0.045)$ and $\operatorname{SP}(P=0.001)$.

Conclusion: Ingestion of nitrate-rich beetroot juice, rocket salad and spinach effectively increase plasma nitrate and nitrite concentrations, and lower blood pressure to a greater extent than sodium nitrate. These findings show that nitraterich vegetables can be used as dietary nitrate supplements. 


\section{Introduction}

Dietary nitrate, often consumed with beetroot juice as its carrier, has become a popular supplement due to its reported ergogenic (1-5) and cardioprotective (6-8) properties. These beneficial effects of dietary nitrate have been attributed to its capacity to increase the bioavailability of nitric oxide (NO). NO represents an important signaling molecule in the human body and plays a key role in several physiological processes by regulating blood flow, muscle contractility, glucose and calcium homeostasis, and mitochondrial respiration and biogenesis (9). Nitrate and nitrite have traditionally been viewed as inactive by-products of $\mathrm{NO}$ metabolism through the nitric oxide synthase (NOS) dependent pathway. However, research from the 1990s showed that a reverse pathway exists whereby nitrate and nitrite can be reduced back into NO $(10,11)$. There is now a general consensus that dietary nitrate ingestion can strongly increase plasma nitrate concentrations. Circulating nitrate is subsequently actively taken up by the salivary glands and concentrated in the saliva, where it can be reduced to nitrite by facultative anaerobic bacteria in the oral cavity. After swallowing, nitrite enters the circulation and can be further reduced to NO via various pathways (12-14).

Multiple studies have reported increased plasma nitrate and nitrite concentrations after ingestion of nitrate in the form of sodium nitrate $(4,5,15-17)$. Similar effects have been reported using (concentrated) beetroot juice $(1,2,18-23)$. Whereas there are several other nitrate-rich food sources, including green leafy and root vegetables (24), research on the pharmacokinetic and physiological effects of nitrate supplementation has mainly applied either sodium nitrate or beetroot juice as a nitrate donor. One of the consequences of the post-prandial increase in plasma nitrate and nitrite availability is a decrease in resting blood pressure, which has been reported after ingestion of both sodium nitrate (7) and beetroot juice (6, 8). As of yet there is little research on the optimal way of supplementing dietary nitrate. Literature has reported a dose-response relationship between the amount of dietary nitrate ingested and the rise in plasma nitrate and nitrite concentrations, as well as the reduction in oxygen cost of submaximal exercise (18) and the reduction in blood pressure (25). Apart from the dose of nitrate ingested, it is unknown which other factors influence the bioavailability of nitrate and nitrite, and subsequent performance and clinical outcomes (26). While various nitrate-rich sources are available, no studies have directly compared to what extent the actual source of dietary nitrate may affect the pharmacokinetic and physiological effects upon ingestion.

In the present study we assessed the acute pharmacokinetic and blood pressure lowering effects of ingesting various nitrate-rich sources. Therefore, recreationally active participants ingested $800 \mathrm{mg}$ nitrate provided as sodium 
nitrate, concentrated beetroot juice, rocket salad, and spinach, after which plasma nitrate and nitrite concentrations and resting blood pressure were determined for up to 300 min after ingestion.

\section{Materials and methods}

\section{Participants and ethical approval}

Twenty-two healthy, adult, and non-hypertensive participants were recruited to take part in this study, which was conducted between September and December 2014. Exclusion criteria were as follows: current or recent smoking (<6 mo), current or recent beetroot juice (or other nitrate) supplementation $(<1 \mathrm{mo})$, resting blood pressure $>140 / 90 \mathrm{mmHg}, \mathrm{BMl}<18$ or $>30 \mathrm{~kg} / \mathrm{m}^{2}$, age $<18$ or $>45 \mathrm{y}$, and consumption of chronic medications. To exclude the possible confounding effect of either extremely high or low training status on NO metabolism, recreationally active participants (exercise 1-10 h/wk) were recruited. This study was approved by the medical ethical committee of the Maastricht University Medical Centre, Maastricht, the Netherlands, followed the principles of the Declaration of Helsinki, and was registered at clinicaltrials.gov as NCT02271633. After being informed about the purpose and potential risks of the study, all participants provided written informed consent.

\section{Study design}

Using a semirandomized crossover design, we investigated the impact of ingesting $800 \mathrm{mg}$ dietary nitrate provided in 4 different sources on subsequent plasma nitrate and nitrite concentrations and resting blood pressure. Over a 5-wk period, participants were required to report to the laboratory on 5 occasions, consisting of a screening session (visit 1 ) and 4 experimental test days (visits 2-5). The 4 sources all contained $800 \mathrm{mg}(\sim 12.9 \mathrm{mmol})$ nitrate, and were provided as: sodium nitrate $\left(\mathrm{NaNO}_{3}\right)$, concentrated beetroot juice, a rocket salad (arugula) beverage, and a spinach beverage. In order to expose all participants to vegetable beverages from the same batch, a single test day was performed for the rocket salad treatment (all participants on $1 \mathrm{~d}$ ) and also a single test day was performed for the spinach treatment (all participants on 1d). As such, we could only randomize the order of the other 2 treatments, and defined this procedure as 'semi-randomized'. Thus, the $\mathrm{NaNO}_{3}$ and beetroot juice treatments were randomly administered before and/or after the rocket salad and spinach beverage treatments (random number generator). The test days were interspaced by a 7-d washout period. 


\section{Experimental protocol}

During a screening session, eligibility for participation in the study was assessed. Standard medical questionnaires were administered, and blood pressure was determined to rule out hypertension. After a $10 \mathrm{~min}$ rest period, blood pressure was measured 4 times using an automated cuff (Omron Healthcare Inc, Field Court Lake Forest, USA), with the last 3 measurements being averaged to obtain mean blood pressure. Body mass (digital balance scale; accuracy $0.1 \mathrm{~kg}$ ) and height (wallmounted stadiometer; accuracy $0.1 \mathrm{~cm}$ ) were measured with participants standing barefoot and dressed lightly.

On the 4 experimental test days, the participants arrived in the morning after an overnight fast. After a $10 \mathrm{~min}$ rest period, blood pressure was measured as described above. Subsequently, a catheter was inserted into an antecubital vein for repeated venous blood draws. After a baseline blood sample was obtained, participants consumed a standardized breakfast, immediately followed by the treatment beverage. Repeated blood draws were performed at 30, 60, 120, 150, 180,240 , and 300 min after the ingestion of the beverages. $300 \mathrm{~min}$ was chosen to capture the peak and the subsequent begin of decline in plasma nitrate and nitrite concentrations (26), without the need for subsequent additional food intake (i.e., lunch time). Resting blood pressure was also measured at $150 \mathrm{~min}$ and $300 \mathrm{~min}$ after beverage ingestion. In addition, a gastrointestinal tolerance questionnaire was administered at baseline and at $150 \mathrm{~min}$ after beverage ingestion. To limit any effect of circadian blood pressure fluctuation throughout the day (27), all test days were performed at the exact same time of the day for each participant (all participants starting between 0800 and 0900).

\section{Study treatments}

With previous work suggesting a minimally required dose of $\sim 500 \mathrm{mg}$ nitrate to induce acute blood pressure lowering effects $(6,7,15,25,28,29)$, and doseresponse relations observed for the improvement in blood pressure (25) and other physiological parameters (18), we applied a treatment dose of $800 \mathrm{mg}$ nitrate to optimize the chance of detecting effects on blood pressure. Though above the current Acceptable Daily Intake (ADI) level of $3.7 \mathrm{mg} / \mathrm{kg} / \mathrm{d}$ (30), this dose falls well within the range that was used previously in acute and multi-day nitrate supplementation trials (including the above-mentioned studies), providing 496-1488 mg.

The 4 beverages were sodium nitrate ( $\mathrm{NaNO}_{3}$ dissolved in water), concentrated beetroot juice (Beet It, James White Drinks Ltd., Ipswich, UK), a fresh rocket salad (arugula) beverage, and a fresh spinach beverage. The beetroot juice, rocket salad, and spinach beverages were analyzed for nitrate content using 
chemiluminesence as described below for plasma analysis to ascertain that an exact dose of $800 \mathrm{mg}$ nitrate was provided for each treatment. Beetroot juice was diluted 2000 times in distilled water (18 $M \Omega$ ) before being analyzed for nitrate content. Both rocket salad and spinach beverages were blended into a smoothielike beverage upon arrival from the store. Adapted from a previously described method (31), the vegetable beverages were extracted for nitrate and nitrite analysis. $500 \mathrm{mg}$ of beverage was weighed accurately in a screw cap glass tube. Then $5 \mathrm{~mL}$ distilled water and $5 \mathrm{~mL}$ methanol were added, and the tube was capped and shaken vigorously for $15 \mathrm{~min}$, before being centrifuged $\left(4^{\circ} \mathrm{C}\right)$ for $5 \mathrm{~min}$ at 1,000 g. The supernatant was filtered through a PVDF filter $(0.22 \mu \mathrm{m})$, and the filtrate was diluted in distilled water until the concentrations fell within the measurement range, before being analyzed for nitrate and nitrite content. Beetroot juice, rocket salad, and spinach beverages were analyzed for nitrate content in duplicate within $3 \%$ variance, and calculations were performed to determine the exact amount of beverage providing $800 \mathrm{mg}$ of nitrate. This resulted in an amount of $1.1 \mathrm{~g} \mathrm{NaNO}_{3}$ $(140 \mathrm{~mL}), 116 \mathrm{~g}$ beetroot juice $(106 \mathrm{~mL}), 196 \mathrm{~g}$ rocket salad beverage $(225 \mathrm{~mL})$, and $365 \mathrm{~g}$ spinach beverage $(400 \mathrm{~mL})$. The beverages were stored at $4{ }^{\circ} \mathrm{C}$ and provided to the participants within $24 \mathrm{~h}$ after analysis for nitrate content. Nutritional composition of the treatments is provided in Supplemental Table 4.1.

Supplemental Table 4.1: Nutritional content of the 4 nitrate beverages

\begin{tabular}{|c|c|c|c|c|}
\hline & Sodium nitrate & Beetroot juice & Rocket salad & Spinach \\
\hline Weight, $g$ & 1.1 & 116 & 196 & 365 \\
\hline Volume, $m L$ & 140 & 106 & 225 & 400 \\
\hline Energy, kJ & 0 & 490 & 192 & 394 \\
\hline Energy, kcal & 0 & 115 & 45 & 95 \\
\hline Protein, $g$ & 0 & 4.1 & 6.9 & 11.7 \\
\hline Carbohydrate, $g$ & 0 & 24.2 & 0.2 & 3.3 \\
\hline Fat, $g$ & 0 & 0.2 & 1.0 & 2.2 \\
\hline Fiber, $g$ & 0 & $<0.5$ & 4.3 & 7.3 \\
\hline Calcium, mg & 0 & 9.6 & 531.2 & 383.3 \\
\hline Iron, mg & 0 & 0.4 & 5.1 & 7.3 \\
\hline Potassium, mg & 0 & 1073 & 894 & 1967 \\
\hline Vitamin C, mg & 0 & 1.0 & 3.9 & 3.7 \\
\hline Sodium, $m g$ & 300 & 133 & 49 & 47 \\
\hline Nitrate, $m g$ & 800 & 800 & 800 & 800 \\
\hline
\end{tabular}

Values for Beetroot juice are based on analytical report of Beet It Sports Shot (James White Drinks Ltd, Ipswich, UK). Values for Rocket salad and Spinach are adapted from the Dutch Food Composition Database 'NEVO'. 


\section{Physical activity and dietary standardization}

In the $48 \mathrm{~h}$ leading up to the first experimental test day (visit 2), participants recorded their dietary intake and physical activity and refrained from strenuous exercise or labor. Participants replicated their diet and physical activities in the 48 $\mathrm{h}$ before the following 3 test days (visits 3-5). Participants avoided caffeine and alcohol for 12 and $24 \mathrm{~h}$ before each test day, respectively. To prevent any attenuation in the reduction of nitrate to nitrite in the oral cavity by commensal bacteria, participants refrained from using any antibacterial mouthwash/ toothpaste and chewing gum, and avoided tongue-scraping during the intervention period (14). No restrictions were set for the intake of nitrate-rich foods $(21,23)$ during the intervention period. On the evening before each test day, all participants consumed a standardized dinner that was adapted to their bodyweight $(53 \mathrm{~kJ} / \mathrm{kg}$, providing $57 \%$ of energy from carbohydrate, $27 \%$ from fat, and $16 \%$ from protein, composed of a mixed meal of potato, chicken and vegetables, orange juice, crackers and yoghurt). Furthermore, all participants received the same standardized breakfast (39 kJ/kg, providing 68\% from carbohydrate, $18 \%$ from fat, and $14 \%$ from protein, composed of bread, butter, cheese, jam, crackers and orange juice) on the morning of each test day before ingestion of the beverage. The ad libitum consumption of water was registered during the first test day (visit 2), and replicated during the subsequent test days (visits 3-5).

\section{Plasma analysis}

Blood samples were collected in Lithium-Heparin containing tubes for plasma nitrate and nitrite analysis, and centrifuged immediately at 1,000 $\mathrm{g}$ for $5 \mathrm{~min}$, at 4 ${ }^{\circ} \mathrm{C}$. Aliquots of plasma were frozen and stored at $-80^{\circ} \mathrm{C}$ for subsequent analysis. Determination of plasma nitrate and nitrite concentrations was performed using the chemiluminescence technique, which has been described previously (32). In short, plasma nitrate and nitrite concentrations are determined by their reduction to NO. The spectral emission of electronically excited nitrogen dioxide, from the NO reaction with ozone, is detected by a thermoelectrically cooled, red-sensitive photomultiplier tube, housed in a Sievers gas-phase chemiluminescence NO analyzer (NOA; Sievers NOA 280i; Analytix, Durham, UK). Inter- and intra-assay CVs were $4.2 \%$ and $1.1 \%$ for plasma nitrate, and $4.9 \%$ and $4.7 \%$ for plasma nitrite.

\section{Statistical methods}

For the power calculation we used a difference in plasma nitrite concentrations of $50 \mathrm{nmol} / \mathrm{L}$ as primary outcome. With a crossover design, sample size was calculated with a power of $95 \%$, a significance level of 0.008 (to adjust for Bonferroni corrected post-hoc testing), and a drop-out rate of $10 \%$. The final number of 
participants to be included after screening was calculated to be 22. Plasma nitrate and nitrite concentrations and resting blood pressure were analyzed using a 2factor (time $\times$ treatment) repeated measures analysis of variance (ANOVA). Additionally, 1-factor repeated-measures ANOVA was used to determine differences in peak concentrations, time to peak values and incremental area under the curve (iAUC) for both plasma nitrate and nitrite concentrations, between the different treatments. For each treatment, peak concentrations were defined as the highest measured values at any time point for each individual. Time to peak was defined as the time point where the individual reached the highest plasma nitrate and nitrite concentrations. iAUC was calculated by multiplying each time period (i.e., 30 or $60 \mathrm{~min}$ ) by the average increase above baseline for that period, summing all time periods. This was done for each individual and each treatment separately. Although we did not specifically aim to study any sex effects on the response to dietary nitrate ingestion, the individual plasma nitrate and nitrite graphs appeared substantially different between men and women upon visual inspection. Therefore, as a secondary analysis, we included sex as a between-subjects factor in the ANOVA analyses described above. As another secondary analysis, the change in blood pressure from baseline was compared between groups using 1-factor repeated measures ANOVA. For all analyses, statistical significance was set at $P<0.05$, and any interaction or main effect was subsequently analyzed using a Bonferroni's corrected post hoc test. All data were analyzed using SPSS 22.0 (SPSS Inc., USA), and are presented as means \pm SEMs.

\section{Results}

Four of the 22 participants dropped out during the study due to failure to comply with the protocol (incomplete ingestion of 1 of the beverages, within the given timeframe of $15 \mathrm{~min})$. General characteristics of the remaining 18 participants are reported in Table 4.1.

Table 4.1: Participants' characteristics of healthy adults who ingested 4 different nitrate sources ${ }^{1}$

\begin{tabular}{llll}
\hline & All & Men & Women \\
\hline $\mathrm{n}$ & 18 & 11 & 7 \\
Age, $y$ & $28 \pm 1$ & $29 \pm 2$ & $26 \pm 2$ \\
Height, $\mathrm{cm}$ & $181 \pm 2$ & $185 \pm 2$ & $174 \pm 3$ \\
Body mass, $\mathrm{kg}$ & $76 \pm 3$ & $82 \pm 3$ & $66 \pm 4$ \\
$\mathrm{BMl}, \mathrm{kg} / \mathrm{m}^{2}$ & $23 \pm 1$ & $24 \pm 1$ & $22 \pm 1$ \\
\hline
\end{tabular}

'Values are means \pm SEM. BMl: body mass index. 


\section{Plasma nitrate}

Plasma nitrate concentrations at different time points are presented in Figure 4.1A. Baseline plasma nitrate concentrations were similar for all 4 treatments $\left(\mathrm{NaNO}_{3}\right.$ : $66 \pm 6 \mu \mathrm{mol} / \mathrm{L}$, beetroot juice: $61 \pm 5 \mu \mathrm{mol} / \mathrm{L}$, rocket salad beverage: $63 \pm 6 \mu \mathrm{mol} / \mathrm{L}$, and spinach beverage: $69 \pm 6 \mu \mathrm{mol} / L, P=0.56)$. A significant time $\mathrm{x}$ treatment interaction $(P<0.001)$ was observed; although plasma nitrate increased to similar peak concentrations after ingestion of all 4 beverages $\left(\mathrm{NaNO}_{3}: 583 \pm 29 \mu \mathrm{mol} / \mathrm{L}\right.$, beetroot juice: $597 \pm 23 \mu \mathrm{mol} / \mathrm{L}$, rocket salad beverage: $584 \pm 24 \mu \mathrm{mol} / \mathrm{L}$, and spinach beverage: $584 \pm 23 \mu \mathrm{mol} / \mathrm{L}, P=0.65)$, differences in nitrate concentrations were observed at specific time points ( $t=30,60,120,240$, and $300 \mathrm{~min}$; Figure 4.1A). Furthermore, there was a significant treatment effect for time to peak $(P<0.001$; Figure 4.1B), and post hoc analysis showed that after ingestion of rocket salad and spinach beverages, time to peak was later compared to both $\mathrm{NaNO}_{3}$ and beetroot juice (all $P<0.001$ ). As a result, the iAUC was significantly different between the treatments $(P<0.001$; Figure $4.1 \mathrm{C})$. Post hoc analysis showed that the iAUC for plasma nitrate concentrations after ingestion of $\mathrm{NaNO}_{3}$ was smaller than beetroot juice $(P=0.038)$, greater than rocket salad beverage $(P=0.007)$, but not different from spinach beverage $(P=0.082)$. Moreover, iAUC for plasma nitrate after ingestion of beetroot juice was higher than both rocket salad and spinach beverages (both $P<0.001)$.

\section{Plasma nitrite}

Plasma nitrite concentrations at different time points are presented in Figure 4.2A. Baseline plasma nitrite concentrations were similar for all 4 treatments $\left(\mathrm{NaNO}_{3}\right.$ : $131 \pm 24 \mathrm{nmol} / \mathrm{L}$, beetroot juice: $135 \pm 20 \mathrm{nmol} / \mathrm{L}$, rocket salad beverage: $115 \pm 14$ $\mathrm{nmol} / \mathrm{L}$, and spinach beverage: $155 \pm 25 \mathrm{nmol} / \mathrm{L}, P=0.37)$. A significant time $\mathrm{x}$ treatment interaction ( $P=0.001$ ) showed that although plasma nitrite increased after ingestion of all 4 beverages (all $P<0.001$ ), differences in nitrite concentrations were observed at specific time points $(t=30,60,120,150$, and $180 \mathrm{~min}$; Figure 2A). There were no significant differences in time to peak between the treatments $(P=0.077$; Figure 4.2B). However, there was a significant treatment effect for peak nitrite concentrations ( $\mathrm{NaNO}_{3}: 580 \pm 58 \mathrm{nmol} / \mathrm{L}$, beetroot juice: $557 \pm 57 \mathrm{nmol} / \mathrm{L}$, rocket salad beverage: $643 \pm 63 \mathrm{nmol} / \mathrm{L}$, and spinach beverage: $980 \pm 160 \mathrm{nmol} / \mathrm{L}, P=0.016)$. Although peak nitrite concentration was numerically greater for the spinach beverage, differences were not significant in the post hoc test $(P=0.084, P=0.122$, and $P=0.197$, for spinach beverage compared with beetroot juice, $\mathrm{NaNO}_{3}$, and rocket salad beverage, respectively). The iAUC for plasma nitrite concentrations was significantly different between treatments ( $P=0.003$; Figure 4.2C), and was higher afteingestion of spinach beverage compared with $\mathrm{NaNO}_{3}(P=0.025)$, 
beetroot juice $(P=0.035)$ and rocket salad beverage $(P=0.046)$, with no differences between $\mathrm{NaNO}_{3}$, beetroot juice, and rocket salad beverage.

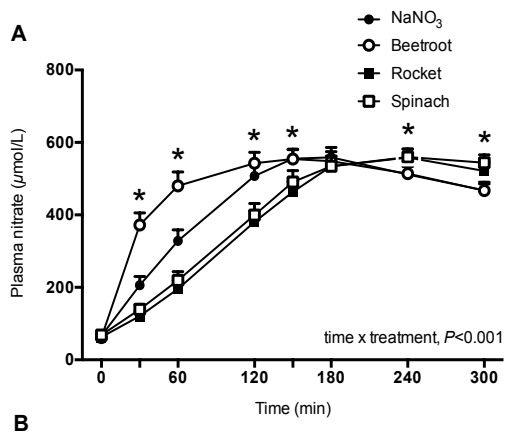

B

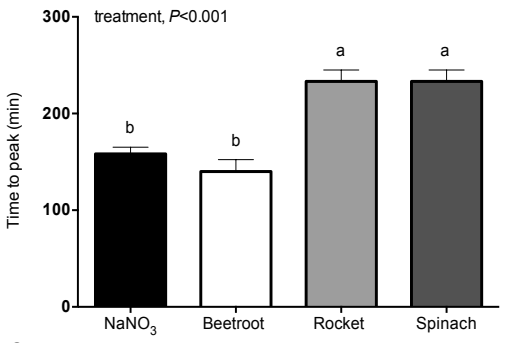

C

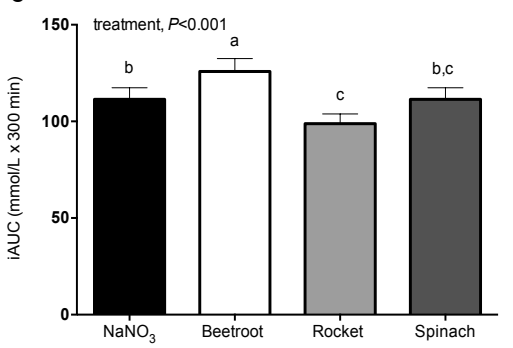

Figure 4.1: Plasma nitrate concentrations (A), time to peak plasma nitrate concentrations (B), and incremental area under curve (iAUC) for plasma nitrate concentrations (C) in 18 healthy adults ingesting 4 different nitrate sources. Values are means \pm SEM. A: *Significant difference between treatments, $P<0.05$. B-C: $a>b>c$ : labeled means without a common letter differ, $P<0.05$.
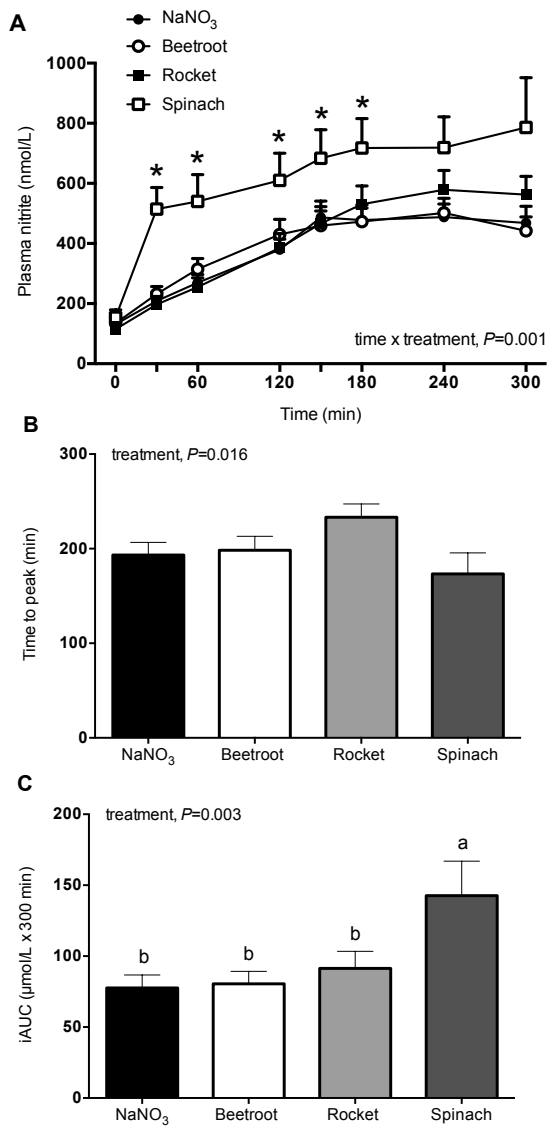

Figure 4.2: Plasma nitrite concentrations (A), time to peak plasma nitrite concentrations (B), and incremental area under curve (iAUC) for plasma nitrite concentrations (C) in 18 healthy adults ingesting 4 different nitrate sources. Values are means \pm SEM. A: *Significant difference between treatments, $P<0.05$. B-C: $a>b$ : labeled means without a common letter differ, $P<0.05$. 


\section{Blood pressure}

A significant time $\mathrm{x}$ treatment interaction was observed for both systolic $(P=0.017$; Figure 4.3A) and diastolic ( $P=0.010$; Figure 4.3B) blood pressure Separate analyses showed a decrease in systolic blood pressure from baseline to $150 \mathrm{~min}$ following ingestion of both beetroot juice $(P<0.001)$ and rocket salad $(P=0.007 ; 4$. 3C). After ingestion of spinach beverage, systolic blood pressure was significantly lower at 300 min compared to baseline values $(P<0.001$; Figure $4.3 \mathrm{C})$. In contrast, no changes in systolic blood pressure were observed after ingestion of $\mathrm{NaNO}_{3}(P=0.11$, Figure 4.3C). The change in systolic blood pressure from baseline to $150 \mathrm{~min}$ (Figure 4.3C) was significantly different between treatments $(P=0.022)$, with post-hoc analysis showing a significant difference for $\mathrm{NaNO}_{3}$ compared with beetroot juice $(P=0.022)$ and $\mathrm{NaNO}_{3}$ compared with rocket salad beverage $(P=0.001)$. No differences were observed in the change in systolic blood pressure from baseline to $300 \mathrm{~min}$ between treatments $(P=0.21)$, despite the strong reduction for the spinach beverage treatment only (Figure $4.3 \mathrm{C}$ ).

For diastolic blood pressure, separate analyses showed a decrease from baseline to $150 \mathrm{~min}$ following ingestion of all beverages ( $\mathrm{NaNO}_{3} ; P=0.022$, beetroot juice and rocket salad beverage; $P<0.001$, and spinach beverage; $P=0.002$; Figure 4.3D). However, at $300 \mathrm{~min}$ after ingestion, diastolic blood pressure only remained significantly lower compared to baseline values in the rocket salad beverage $(P=0.045)$ and spinach beverage $(P=0.001$; Figure 4.3D) treatments. Despite these observations, no differences were observed in the actual change in diastolic blood pressure from baseline to 150 and 300 min between treatments $(P=0.12$ and $P=0.23$, respectively). 
A

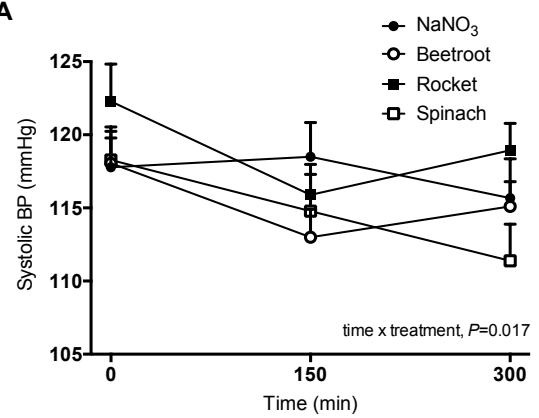

C

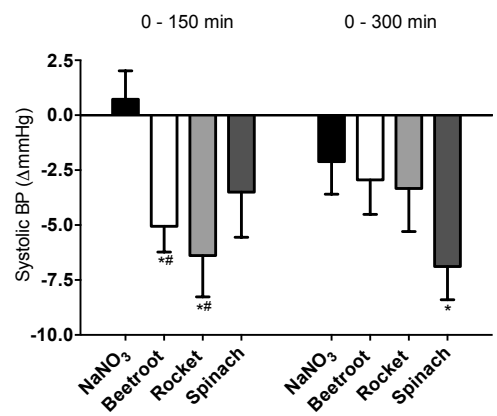

B

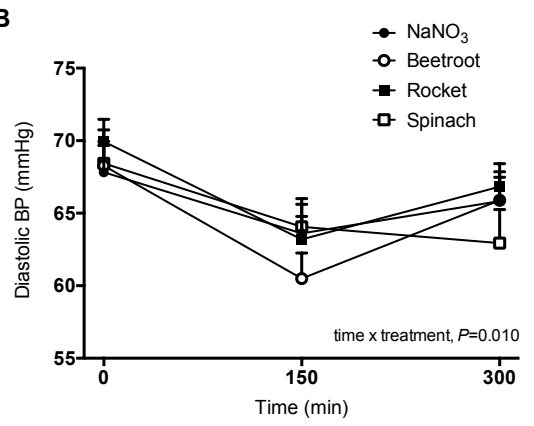

D

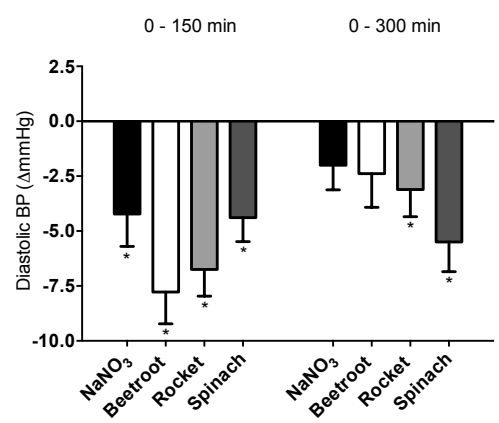

Figure 4.3: Blood pressure reported as absolute systolic (A), absolute diastolic (B), change in systolic from baseline (C) and change in diastolic from baseline (D) in 18 healthy adults ingesting 4 different nitrate sources. Values are means \pm SEM. For reasons of clarity, treatment differences are only displayed in panels C-D. *Significant change from baseline within treatment, $P<0.05$. "Change from baseline significantly different compared to $\mathrm{NaNO}_{3}, P<0.05$.

\section{Sex}

Plasma nitrate and nitrite concentrations and iAUC for men and women separately are presented in Supplemental Figure 4.1 and Supplemental Figure 4.2. Subanalysis including sex as a between-subjects factor showed that the baseline $(P=0.020)$, the peak value $(P<0.001)$, and the iAUC $(P=0.005)$ for plasma nitrate concentrations were higher in the women compared to men for all 4 treatments. For plasma nitrite concentrations, no sex differences were observed at baseline. Although peak values and iAUC for plasma nitrite concentrations appeared higher in the women than the men, this difference reached statistical significance for only the spinach beverage treatment ( $P=0.010$ and $P=0.016$, respectively). Despite these sex differences in the plasma nitrate and nitrite responses, no differences in blood pressure responses to nitrate ingestion were observed between men and women. 


\section{Side effects}

No serious adverse events were reported. Ingestion of the 4 beverages was well tolerated by most of the participants. Four participants (1 man and 3 women) did not manage to ingest the total volume of the rocket salad or the spinach beverage within the given timeframe of $15 \mathrm{~min}$, and were therefore excluded from the study. Gastrointestinal complaints were reported by 2 participants after the rocket salad beverage, and by 1 participant after the spinach beverage. No gastrointestinal complaints were reported for the $\mathrm{NaNO}_{3}$ and beetroot juice beverages, respectively. One participant reported headache at baseline and throughout the test day after ingestion of the spinach beverage.
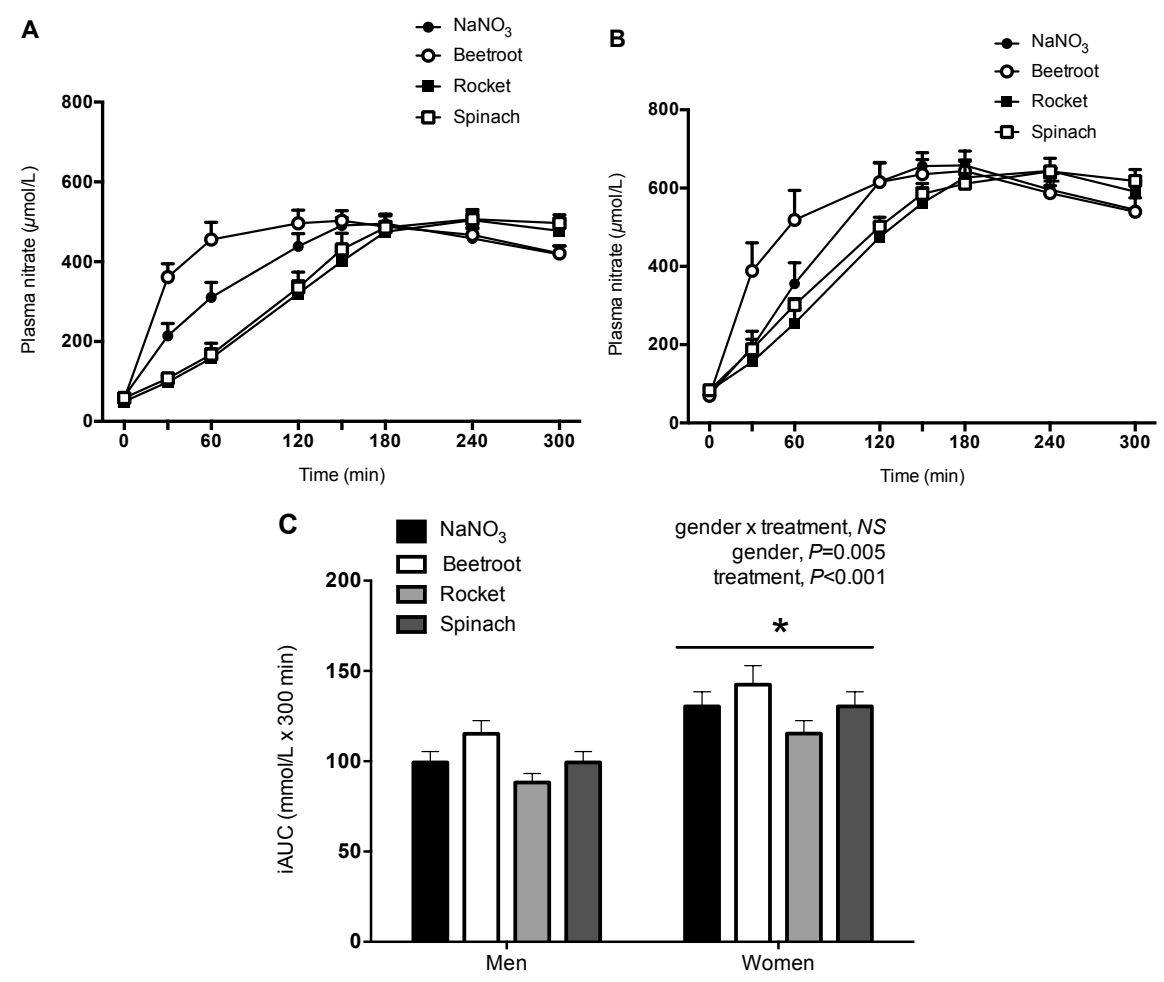

Supplemental Figure 4.1: Plasma nitrate concentrations before and up to 300 min after ingestion of 4 different nitrate sources in men $(n=11, A)$ and women $(n=7, B)$, and iAUC for plasma nitrate in men vs women (C). Values are means \pm SEM. * Significantly different from men. For post-hoc analysis of the treatment effect, see Figure 4.1C. 
A

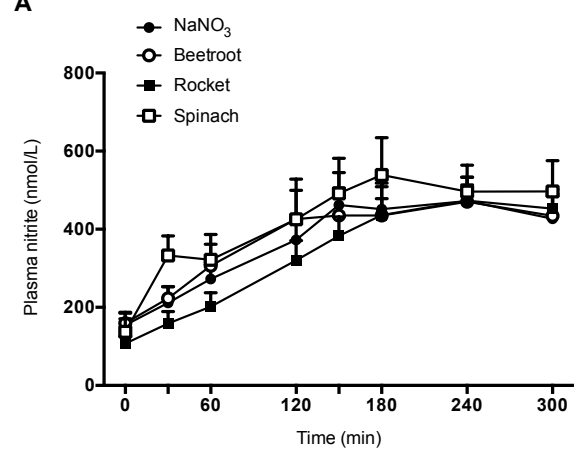

C

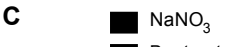

300 $\square$ Beetroot
B

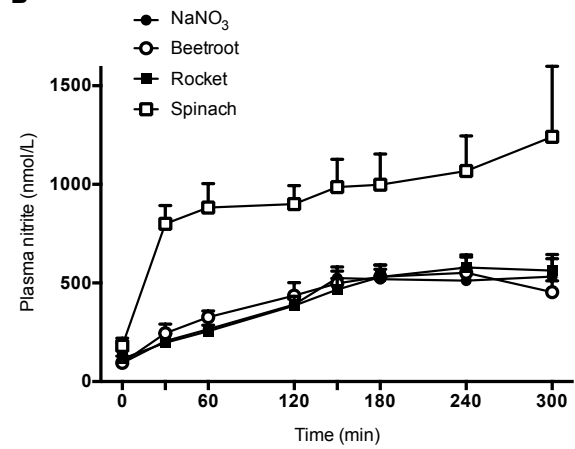

gender $\mathrm{x}$ treatment, $P<0.001$

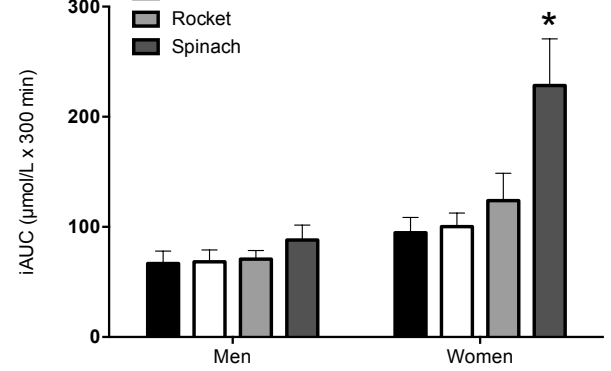

Supplemental Figure 4.2: Plasma nitrite concentrations before and up to 300 min after ingestion of 4 different nitrate sources in men $(n=11, A)$ and women $(n=7, B)$, and iAUC for plasma nitrite in men vs women (C). Values are means \pm SEM. * Significantly different from men. For post-hoc analysis of the treatment effect, see Figure 4.2C.

\section{Discussion}

The present study demonstrated that acute ingestion of $800 \mathrm{mg}$ nitrate from beetroot juice, rocket salad and spinach elevated plasma nitrate concentrations to the same extent ( $\rightarrow$ fold) as the ingestion of an identical dose from sodium nitrate. Although ingestion of all 4 nitrate sources led to substantial increases in plasma nitrite concentrations, the increase was greater ( 6 fold vs $\sim 4$ fold) after ingestion of spinach compared to the ingestion of the other nitrate sources. In contrast to the ingestion of sodium nitrate, ingestion of beetroot juice, rocket salad and spinach resulted in a significant lowering of both systolic and diastolic blood pressure in this group of healthy, normotensive individuals.

Over the past decade, beetroot juice has become an increasingly popular dietary supplement due to its high nitrate content, and the associated ergogenic and cardioprotective properties. Research in this area has mainly utilized the ingestion of beetroot juice and sodium nitrate as dietary intervention. Both sources have been shown to substantially increase plasma nitrate and nitrite 
concentrations, improve exercise performance (1-5), and lower blood pressure (68 ) in healthy individuals. However, it remains unclear whether differences exist in the pharmacokinetic and physiological responses to the ingestion of different dietary nitrate sources. We assessed the acute effects of ingesting various nitraterich sources on plasma nitrate and nitrite concentrations and resting blood pressure. In our study, ingestion of exactly $800 \mathrm{mg}$ of nitrate from all 4 sources led to similar increases ( $~ 9$ fold) in plasma nitrate concentrations (Figure 4.1A). Our data lend further support to the suggestion by Van Velzen et al. (33) that dietary nitrate from different vegetable sources can be effectively absorbed, reaching $100 \%$ bioavailability in the circulation. The time to peak plasma nitrate concentrations after sodium nitrate and beetroot juice ingestion (Figure 4.1B) was similar to that shown in earlier studies using these sources $(18,32)$. The longer time needed to reach peak plasma nitrate concentrations after ingestion of rocket salad and spinach may be related to their higher fiber content and the larger volume ingested (Supplemental Table 4.1), likely resulting in a slower gastric emptying (34). Hence, the optimal timing of supplementation may slightly differ between various nitrate sources. More importantly though, ingestion of dietary nitrate from all 4 sources seemed to be equally effective in increasing plasma nitrate concentrations.

In line with the data on plasma nitrate concentrations, substantial increases in plasma nitrite concentrations were observed after ingestion of all 4 beverages (Figure 4.2A). Both the increases in plasma nitrite concentrations ( 4 fold) and time to reach peak values ( $180-240 \mathrm{~min})$ are in agreement with previous work supplementing $~ 500-1000 \mathrm{mg}$ nitrate in the form of sodium nitrate (15) or beetroot juice $(2,20-22)$. In contrast with the plasma nitrate concentrations, time to reach peak plasma nitrite concentrations did not differ between treatments (Figure 4.2B). This could imply that the speed of bioconversion of nitrate to nitrite is not merely driven by the rate at which nitrate appears in the circulation. Furthermore, the total release of nitrite into the blood may be affected by the composition of the specific nitrate source. In this context, we observed a remarkable initial increase in plasma nitrite concentrations after ingestion of spinach (Figure 4.2A), which was much stronger compared to the other beverages. This substantial increase in plasma nitrite ( 4 fold within $30 \mathrm{~min}$ ) is unlikely to be completely explained by the endogenous conversion of dietary nitrate (32). Alternatively, the initial increase in plasma nitrite after spinach ingestion may be attributed to the higher nitrite content found in spinach compared to other vegetables (35). In agreement, analysis of the 4 provided beverages for nitrite content revealed substantially greater nitrite content in the spinach beverage $(\sim 100 \mu \mathrm{g})$ compared to the rocket salad beverage $(\sim 20 \mu \mathrm{g})$, beetroot juice $(<1 \mu \mathrm{g})$ and sodium nitrate $(<1 \mu \mathrm{g})$. Though this may partly explain the greater initial increase in plasma nitrite concentrations after ingestion 


\section{Chapter 4}

of the spinach, plasma nitrite concentrations continued to increase throughout the test day. In fact, the increase in plasma nitrite concentrations from 30 min after ingestion to peak values was similar for all 4 beverages (Figure 4.2A). As such, our findings are the first to show that the effective uptake of dietary nitrate and the total bioconversion of the ingested nitrate into nitrite do not seem to depend on the source of dietary nitrate.

Plasma nitrite represents a precursor for the NOS-independent formation of NO, which can then act as a vasodilatory agent thereby lowering blood pressure (6). Previous work in healthy populations has shown reductions in blood pressure after acute beetroot juice $(6,8,20,22,29)$, several-day beetroot juice $(1,2,23)$ or acute spinach $(36,37)$ ingestion. The blood pressure lowering effects of sodium nitrate have been studied less extensively. We are the first to compare the blood pressure lowering effects after ingestion of various nitrate-rich vegetable sources and sodium nitrate, using identical nitrate doses. We observed a more pronounced decrease in blood pressure after ingestion of the vegetable beverages (systolic $~ 5$ $7 \mathrm{mmHg}$, diastolic $4-8 \mathrm{mmHg}$; Figure 4.3C and 4.3D) compared to sodium nitrate (only diastolic, $\sim 2-4 \mathrm{mmHg}$ ). In line with our findings, previous work reported that despite substantial increases in plasma nitrate and nitrite concentrations, sodium nitrate only decreased diastolic blood pressure while systolic blood pressure remained unaffected $(7,15)$. It has been speculated that other compounds in vegetables (such as vitamin $C$, potassium and polyphenols) may contribute and/or act synergistically with nitrate, enhancing its blood pressure lowering effects. For example, it has been shown that vitamin $\mathrm{C}$ increases the reduction of nitrite to NO $(38,39)$, which may potentiate the blood pressure lowering effects at a given nitrate/nitrite concentration. Additionally, 2 studies using potassium nitrate observed positive effects on both systolic and diastolic blood pressure $(25,28)$, suggesting that the combination of potassium and nitrate may be more effective than sodium and nitrate. Obviously, all vegetable beverages in the present study contained substantial amounts of macro- and micronutrients that were not present in the sodium nitrate beverage (Supplemental Table 1). As such, the principle of a synergistic effect between nitrate and other nutritional compounds may explain why the vegetable beverages are more effective than sodium nitrate in lowering blood pressure, despite similar increases in plasma nitrate and nitrite concentrations. Yet, it remains to be established what specific mechanisms may underlie a potentially more effective conversion of nitrite into bio-active NO, thereby explaining the more pronounced blood pressure lowering effects following ingestion of different nitrate-rich vegetables.

A discordance between changes in plasma nitrite concentrations and subsequent physiological effects was recently also observed by Larsen et al. (17). 
Despite a substantial increase in plasma nitrite concentrations, intravenous nitrite infusion did not lead to a decreased resting metabolic rate as observed after ingestion of dietary nitrate (17). In accordance, the initial high plasma nitrite concentrations after spinach ingestion did not translate into any additional reduction in blood pressure in the present study (Figure 4.3C). Overall, it appears that plasma nitrite per se is not the key driver, nor the key indicator of the physiological effects induced through the nitrate-nitrite-NO pathway. Though nitrite represents an important intermediate, Larsen et al. (17) suggest that nitratederived bioactive nitrogen oxides other than nitrite could be the final mediators of the observed effects. Ultimately, it is the actual bio-availability of NO that is likely driving any physiological effects (32). In this respect, cyclic guanosine monophosphate (cGMP) has been suggested to be the most sensitive indicator of NO bio-activity (25). As such, cGMP should be included in future studies investigating the effects of dietary nitrate, including potential differences between various dietary nitrate sources.

The major strength of the present study lies in the within-subject comparison of the 4 treatments, providing exactly $800 \mathrm{mg}$ of nitrate with each treatment, under fully standardized conditions. By testing each participant at the same time of day for all 4 treatments, we bypassed the effects of circadian fluctuation of blood pressure, ensuring a valid comparison between treatments. However, since blood pressure is known to rise throughout the morning (27), we cannot rule out the possibility that we may have overlooked (in the case of sodium nitrate) or simply underestimated the blood pressure lowering effect of each treatment. We chose not to burden the participants with a control trial since our primary aim was to study the pharmacokinetics of plasma nitrate and nitrite. It is clearly established that plasma nitrate and nitrite do not change upon placebo ingestion $(20,22,40,41)$. As a further limitation, we did not power to investigate any potential sex differences. However, sub-analysis of the data indicated higher plasma nitrate and nitrite concentrations in women compared with men (Supplemental Figures 4.1-4.2). Of note, these sex differences did not translate to any differences in the blood pressure lowering effects after nitrate ingestion. The sex differences in plasma nitrate and nitrite concentrations could partly be explained by differences in body mass and/or distribution volume of plasma. Previous studies have also reported higher plasma nitrate and/or nitrite responses in women versus men, while a subsequent reduction in platelet reactivity and increase in platelet cGMP (42), as well as a reduction in blood pressure (25) was more pronounced in men versus women. As a potential explanation, it has been suggested that there may be sex differences in the bacterial colonization of the tongue, likely affecting nitrate reductase activity (25). Again, it appears that not 


\section{Chapter 4}

nitrate/nitrite per se, but rather the effective bioconversion into NO is the final mediator of any physiological effects. As such, sex differences in the response to dietary nitrate ingestion, including $c G M P$, may represent a key target for future research.

The present work clearly shows that various natural food sources, here provided as vegetable beverages, can be used effectively as dietary nitrate donors, with no differences in post-prandial plasma nitrate and nitrite concentrations. Furthermore, all vegetable beverages induced a substantial reduction in blood pressure, despite the recruitment of healthy, normotensive individuals. Our findings are relevant for the development of nutritional strategies to increase dietary nitrate intake either to enhance sports performance or facilitate clinical and/or health benefits (43). Obviously, the minimal nitrate dose needed to achieve beneficial effects should be investigated. We provided a dose exceeding the recommended $\mathrm{ADI}$ of $3.7 \mathrm{mg} / \mathrm{kg} / \mathrm{d}(30)$, but well within the range used in studies showing blood pressure lowering effects $(6,7,15,25,28,29)$. There is an ongoing debate on potential health risks of long-term exposure to high nitrite and nitrate, especially with regard to the formation of low-molecular-weight $\mathrm{N}$-nitrosamines, and associated cancer risk. Given the 'acute' setting in the present study (i.e., determining plasma and blood pressure responses up to $300 \mathrm{~min}$ after a single nitrate dose), we chose not to burden our participants with multiple 24-hour urine collections to measure nitroso-compound formation. Furthermore, previous work suggests that there is no relevance of measuring nitroso formation in plasma after acute nitrate supplementation (32). Though the risk of long-term exposure to nitrite and nitrate and developing cancers is weak at best, and the cardiovascular benefits have been suggested to outweigh the risks (43), any potential risk still needs to be carefully considered. Therefore, we propose that future work investigating (longterm) exposure to high nitrate intakes should include measurements of nitrosocompound formation. In the present study, we did not observe any acute serious adverse effects. A few participants reported minor gastrointestinal complaints after ingestion of the rocket salad or spinach beverage, likely related to the total volume to be ingested rather than the nitrate dose. For practical use of various nitrate sources, future studies should focus on optimizing the volume, consistency and palatability of various nitrate sources.

In conclusion, ingestion of $800 \mathrm{mg}$ nitrate provided as sodium nitrate, beetroot juice, rocket salad, and spinach substantially increases plasma nitrate and nitrite concentrations. Ingestion of nitrate from beetroot juice, rocket salad and spinach lowers blood pressure to a greater extent than ingestion of the same amount of nitrate provided as sodium nitrate. These findings imply that nitrate-rich vegetables can be used as dietary nitrate supplements. 


\section{References}

1. Bailey SJ, Fulford J, Vanhatalo A, Winyard PG, Blackwell JR, DiMenna FJ, Wilkerson DP, Benjamin N, Jones AM. Dietary nitrate supplementation enhances muscle contractile efficiency during knee-extensor exercise in humans. J Appl Physiol 2010;109:135-48.

2. Bailey SJ, Winyard P, Vanhatalo A, Blackwell JR, Dimenna FJ, Wilkerson DP, Tarr J, Benjamin N, Jones AM. Dietary nitrate supplementation reduces the $\mathrm{O} 2$ cost of low-intensity exercise and enhances tolerance to high-intensity exercise in humans. J Appl Physiol 2009;107:1144-55.

3. Cermak NM, Gibala MJ, van Loon LJC. Nitrate Supplementation's Improvement of 10-km Time-Trial Performance in Trained Cyclists. Int J Sport Nutr Exerc Metab 2012;22(1):64-71.

4. Larsen FJ, Schiffer TA, Borniquel S, Sahlin K, Ekblom B, Lundberg JO, Weitzberg E. Dietary inorganic nitrate improves mitochondrial efficiency in humans. Cell Metab 2011;13:149-59.

5. Larsen FJ, Weitzberg E, Lundberg JO, Ekblom B. Effects of dietary nitrate on oxygen cost during exercise. Acta Physiol 2007;191(1):59-66.

6. Webb AJ, Patel N, Loukogeorgakis S, Okorie M, Aboud Z, Misra S, Rashid R, Miall P, Deanfield J, Benjamin $\mathrm{N}$, et al. Acute blood pressure lowering, vasoprotective, and antiplatelet properties of dietary nitrate via bioconversion to nitrite. Hypertension 2008;51:784-90.

7. Larsen FJ, Ekblom B, Sahlin K, Lundberg JO, Weitzberg E. Effects of dietary nitrate on blood pressure in healthy volunteers. N Engl J Med 2006;355:2792-3.

8. Hobbs DA, Kaffa N, George TW, Methven L, Lovegrove JA. Blood pressure-lowering effects of beetroot juice and novel beetroot-enriched bread products in normotensive male subjects. $\mathrm{Br} J \mathrm{Nutr}$ 2012;108:2066-74.

9. Stamler JS, Meissner G. Physiology of nitric oxide in skeletal muscle. Physiol Rev 2001;81(1):209-37.

10. Lundberg JO, Weitzberg E, Lundberg JM, Alving K. Intragastric nitric oxide production in humans: measurements in expelled air. Gut 1994;35(11):1543-6.

11. Benjamin N, O'Driscoll F, Dougall H, Duncan C, Smith L, Golden M, McKenzie H. Stomach NO synthesis. Nature 1994;368(6471):502-.

12. Duncan C, Dougall H, Johnston P, Green S, Brogan R, Leifert C, Smith L, Golden M, Benjamin N. Chemical generation of nitric oxide in the mouth from the enterosalivary circulation of dietary nitrate. Nature medicine 1995;1(6):546-51.

13. Zhang Z, Naughton D, Winyard PG, Benjamin N, Blake DR, Symons MC. Generation of nitric oxide by a nitrite reductase activity of xanthine oxidase: a potential pathway for nitric oxide formation in the absence of nitric oxide synthase activity. Biochem Biophys Res Commun 1998;249(3):767-72.

14. Govoni $\mathrm{M}$, Jansson $\mathrm{E}$, Weitzberg $\mathrm{E}$, Lundberg J. The increase in plasma nitrite after a dietary nitrate load is markedly attenuated by an antibacterial mouthwash. Nitric Oxide 2008;19:333-7.

15. Larsen FJ, Weitzberg E, Lundberg JO, Ekblom B. Dietary nitrate reduces maximal oxygen consumption while maintaining work performance in maximal exercise. Free Radic Biol Med 2010;48:342-7.

16. Bescos RI, Ferrer-Roca V, Galilea PA, Roig A, Drobnic F, Sureda A, Martorell M, Cordova A, Tur JA, Pons A. Sodium nitrate supplementation does not enhance performance of endurance athletes. Med Sci Sports Exerc 2012;44(12):2400-9.

17. Larsen FJ, Schiffer TA, Ekblom B, Mattsson MP, Checa A, Wheelock CE, Nystrom T, Lundberg JO, Weitzberg E. Dietary nitrate reduces resting metabolic rate: a randomized, crossover study in humans. Am J Clin Nutr 2014;99(4):843-50.

18. Wylie L, Kelly J, Bailey SJ, Blackwell JR, Skiba PF, Winyard PG, Jeukendrup AE, Vanhatalo A, Jones AM. Beetroot juice and exercise: pharmacodynamic and dose-response relationships. J Appl Physiol 2013;115:325-36.

19. Kelly J, Vanhatalo A, Wilkerson DP, Wylie L, Jones AM. Effects of Nitrate on the Power-Duration Relationship for Severe-Intensity Exercise. Med Sci Sports Exerc 2013;45:1798-1806.

20. Lansley KE, Winyard PG, Bailey SJ, Vanhatalo A, Wilkerson DP, Blackwell JR, Gilchrist M, Benjamin N, Jones AM. Acute dietary nitrate supplementation improves cycling time trial performance. Med Sci Sports Exerc 2011;43:1125-31.

21. Lansley KE, Winyard P, Fulford J, Vanhatalo A, Bailey S, Blackwell JR, DiMenna F, Gilchrist M, Benjamin $\mathrm{N}$, Jones AM. Dietary nitrate supplementation reduces the $\mathrm{O} 2$ cost of walking and running: a placebocontrolled study. J Appl Physiol 2011;110:591-600. 


\section{Chapter 4}

22. Wylie LJ, Mohr M, Krustrup P, Jackman SR, Ermiotadis G, Kelly J, Black MI, Bailey SJ, Vanhatalo A, Jones AM. Dietary nitrate supplementation improves team sport-specific intense intermittent exercise performance. Eur J Appl Physiol 2013;113:1673-84.

23. Vanhatalo A, Bailey S, Blackwell J, DiMenna F, Pavey TG, Wilkerson DP, Benjamin N, Winyard P, Jones AM. Acute and chronic effects of dietary nitrate supplementation on blood pressure and the physiological responses to moderate-intensity and incremental exercise. Am J Physiol Regul Integr Comp Physiol 2010;299:1121-31.

24. Ysart G, Miller P, Barrett G, Farrington D, Lawrance $P$, Harrison N. Dietary exposures to nitrate in the UK. Food Addit Contam 1999;16(12):521-32.

25. Kapil V, Milsom AB, Okorie M, Maleki-Toyserkani S, Akram F, Rehman F, Arghandawi S, Pearl V, Benjamin $\mathrm{N}$, Loukogeorgakis $\mathrm{S}$, et al. Inorganic nitrate supplementation lowers blood pressure in humans: role for nitrite-derived NO. Hypertension 2010;56:274-81.

26. James PE, Willis GR, Allen JD, Winyard PG, Jones AM. Nitrate pharmacokinetics: Taking note of the difference. Nitric Oxide 2015;48:44-50.

27. Millar-Craig MW, Bishop CN, Raftery EB. Circadian variation of blood-pressure. Lancet 1978;1(8068):7957.

28. Bahra M, Kapil V, Pearl V, Ghosh S, Ahluwalia A. Inorganic nitrate ingestion improves vascular compliance but does not alter flow-mediated dilatation in healthy volunteers. Nitric Oxide 2012;26(4):197-202.

29. Coles LT, Clifton PM. Effect of beetroot juice on lowering blood pressure in free-living, disease-free adults: a randomized, placebo-controlled trial. Nutrition Journal 2012;11(1):106-11.

30. Hord NG, Tang Y, Bryan NS. Food sources of nitrates and nitrites: the physiologic context for potential health benefits. Am J Clin Nutr 2009;90:1-10.

31. Salomez J, Hofman G. Nitrate extraction from fresh plant material by means of a methanol:water extraction solution. Commun Soil Sci Plant Anal 2002;33(15-18):3397.

32. Lundberg JO, Govoni M. Inorganic nitrate is a possible source for systemic generation of nitric oxide. Free Radic Biol Med 2004;37:395-400.

33. van Velzen AG, Sips AJ, Schothorst RC, Lambers AC, Meulenbelt J. The oral bioavailability of nitrate from nitrate-rich vegetables in humans. Toxicol Lett 2008;181:177-81.

34. Spiller RC. Pharmacology of dietary fibre. Pharmacol Therapeut 1994;62(3):407-27.

35. Petersen A, Stoltze S. Nitrate and nitrite in vegetables on the Danish market: content and intake. Food Addit Contam 1999;16(7):291-9.

36. Jovanovski E, Bosco L, Khan K, Au-Yeung F, Ho H, Zurbau A, Jenkins AL, Vuksan V. Effect of Spinach, a High Dietary Nitrate Source, on Arterial Stiffness and Related Hemodynamic Measures: A Randomized, Controlled Trial in Healthy Adults. Clinical Nutrition Research 2015;4(3):160-7.

37. Bondonno CP, Yang X, Croft KD, Considine MJ, Ward NC, Rich L, Puddey IB, Swinny E, Mubarak A, Hodgson JM. Flavonoid-rich apples and nitrate-rich spinach augment nitric oxide status and improve endothelial function in healthy men and women: a randomized controlled trial. Free Radic Biol Med 2012;52(1):95-102.

38. Weitzberg E, Lundberg JO. Nonenzymatic nitric oxide production in humans. Nitric Oxide 1998;2(1):1-7.

39. Gago B, Lundberg JO, Barbosa RM, Laranjinha Jo. Original Contribution: Red wine-dependent reduction of nitrite to nitric oxide in the stomach. Free Radic Biol Med 2007;43:1233-42.

40. Cermak NM, Res P, Stinkens R, Lundberg JO, Gibala MJ, van Loon LJ. No improvement in endurance performance after a single dose of beetroot juice. Int J Sport Nutr Exerc Metab 2012;22:470-8.

41. Wilkerson DP, Hayward GM, Bailey SJ, Vanhatalo A, Blackwell JR, Jones AM. Influence of acute dietary nitrate supplementation on 50 mile time trial performance in well-trained cyclists. Eur J Appl Physiol 2012;112:4127-34.

42. Velmurugan S, Kapil V, Ghosh SM, Davies S, McKnight A, Aboud Z, Khambata RS, Webb AJ, Poole A, Ahluwalia A. Original Contribution: Antiplatelet effects of dietary nitrate in healthy volunteers: Involvement of cGMP and influence of sex. Free Radic Biol Med 2013;65:1521-32.

43. Bryan NS, Ivy JL. Inorganic nitrite and nitrate: evidence to support consideration as dietary nutrients. Nutr Res 2015;35(8):643-54. 


\section{Chapter}

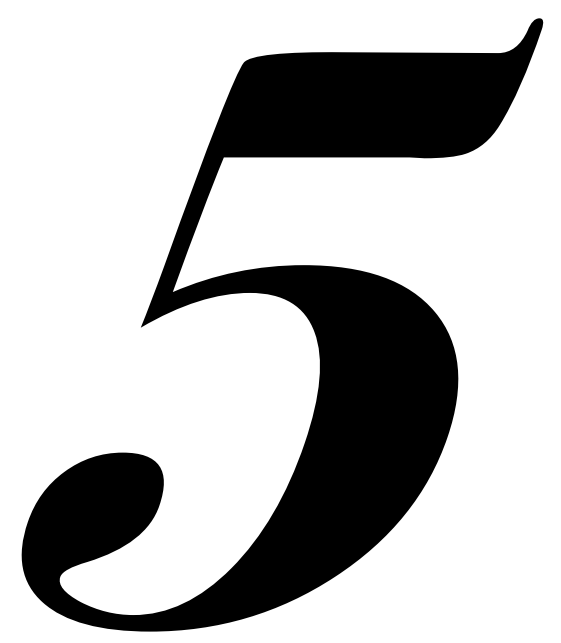

Habitual dietary nitrate intake in highly trained athletes

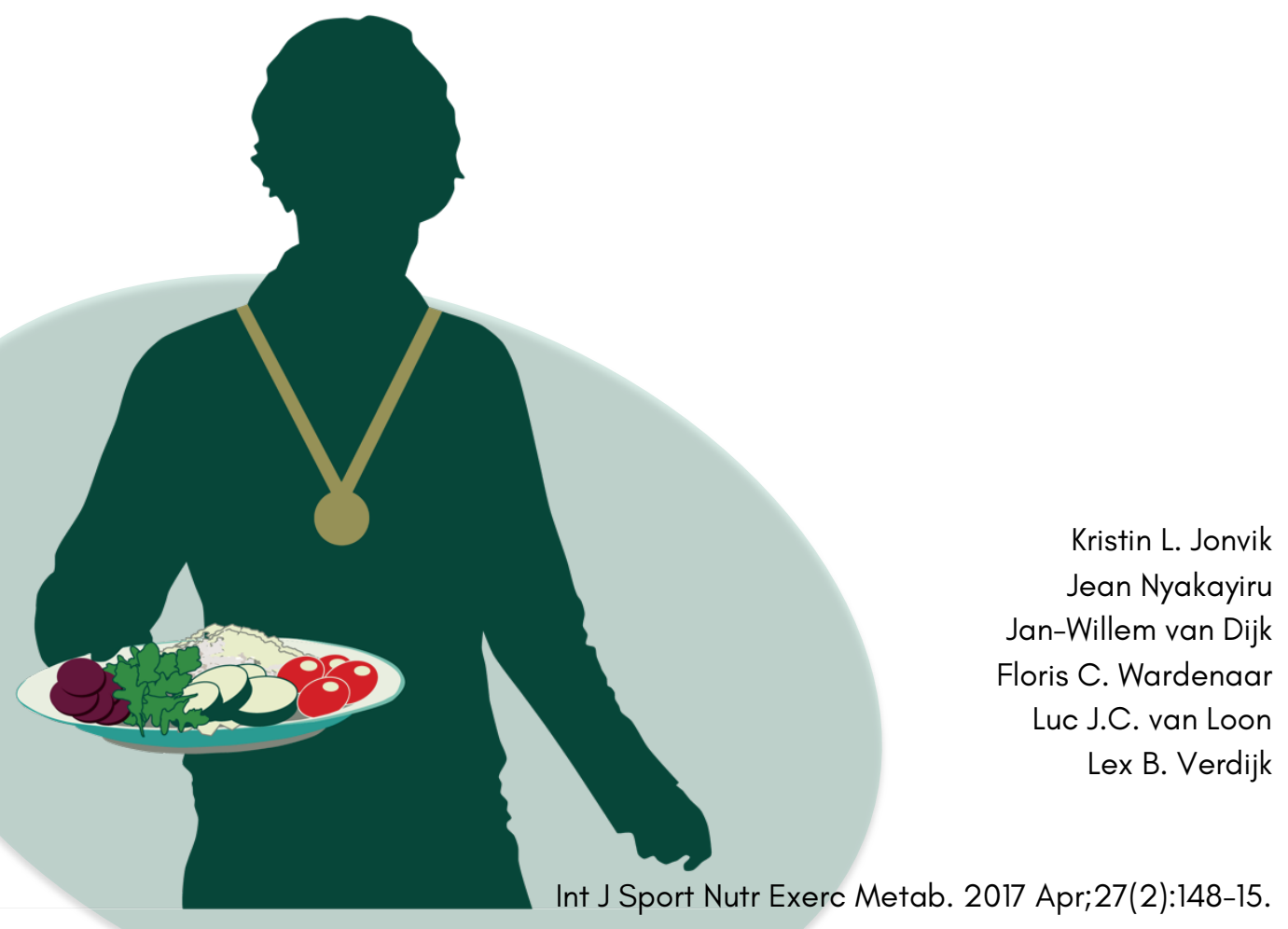




\section{ABSTRACT}

Background: Although beetroot juice, as a nitrate carrier, is a popular ergogenic supplement amongst athletes, nitrate is consumed through the regular diet as well. We aimed to assess the habitual dietary nitrate intake and identify the main contributing food sources in a large group of highly trained athletes.

Methods: Dutch highly trained athletes (226 women and 327 men) completed 24 web-based 24-h dietary recalls and questionnaires within a 2-4 week period. The nitrate content of food products and food groups was determined systematically based on values found in regulatory reports and scientific literature. These were then used to calculate each athlete's dietary nitrate intake from the web-based recalls.

Results: The median[IOR] habitual nitrate intake was 106[75-170] mg/d (range 19$525 \mathrm{mg} / \mathrm{d})$. Nitrate intake correlated with energy intake $(\rho=0.28, P<0.001)$, and strongly correlated with vegetable intake $(\rho=0.78, P<0.001)$. In accordance, most of the dietary nitrate was consumed through vegetables, potatoes and fruit, accounting for $74 \%$ of total nitrate intake, with lettuce and spinach contributing most. When corrected for energy intake, nitrate intake was substantially higher in female vs male athletes $(12.8[9.2-20.0]$ vs $9.4[6.2-13.8] \mathrm{mg} / \mathrm{MJ} ; \quad P<0.001)$. This difference was attributed to the higher vegetable intake in female vs male athletes (150[88-236] vs 114[61-183] g/d; $P<0.001$ ).

Conclusion: Median daily intake of dietary nitrate in highly trained athletes was $106 \mathrm{mg}$, with large inter-individual variation. Dietary nitrate intake was strongly associated with the intake of vegetables. Increasing the intake of nitrate-rich vegetables in the diet might serve as an alternative strategy for nitrate supplementation. 


\section{Introduction}

Beetroot juice, used as a carrier of dietary nitrate, has become a popular supplement due to the reported ergogenic and cardioprotective properties (1). Dietary nitrate can increase the bioavailability of nitric oxide (NO) through the nitrate-nitrite-NO pathway (2), which modulates many processes that are essential to exercise performance (e.g, blood flow and muscle contractility) (3). Previous studies have suggested that at least $300-600 \mathrm{mg}(4.8-9.7 \mathrm{mmol})$ of nitrate is needed to enhance exercise performance in various athlete populations (4-6). As a result, many athletes who use nitrate-containing supplements consume concentrated beetroot juice shots containing $400 \mathrm{mg}(\sim 6.5 \mathrm{mmol})$ nitrate per dose. Despite the popularity of beetroot juice, many other nitrate-rich vegetables exist, such as spinach, rocket salad (arugula), and other green leafy vegetables. We have recently shown that ingestion of such vegetables increases nitrate and nitrite bioavailability just as effectively as beetroot juice (7). Also, improved performance following a short-term high-nitrate diet (i.e., not based on beetroot juice) has been reported (8). Arguably, high nitrate intakes can be reached through regular consumption of nitrate-rich vegetables, and this may limit the effect of additional nitrate supplementation. For example, when following the recommendations of the DASH diet (including 4-5 servings of both vegetables and fruit), nitrate intake is estimated to range from 175 to $1,200 \mathrm{mg}$ (9). Thus, when studying the effects of nitrate supplementation, habitual intake through (nitrate-rich) vegetables should be taken into account.

It has been suggested that highly trained athletes are less responsive to the ergogenic properties of nitrate when compared with recreational athletes (10). These authors also reported higher baseline concentrations, followed by a lower rise in plasma nitrate and nitrite after nitrate supplementation, in well-trained versus less trained athletes. One possible explanation for the higher baseline plasma nitrate and nitrite concentrations, and the suggested blunted responsiveness to nitrate supplementation in well-trained athletes could be a greater habitual nitrate intake. This can potentially be caused by a greater energy intake (11), and/or different (more healthy) eating patterns, including (nitrate-rich) vegetable consumption. In the general population, the average dietary nitrate intake is estimated to be $\sim 31-185 \mathrm{mg} / \mathrm{d}(\sim 0.5-3.0 \mathrm{mmol} / \mathrm{d})$ in Europe (12) and $40-100 \mathrm{mg} / \mathrm{d}$ $(\sim 0.6-1.6 \mathrm{mmol} / \mathrm{d})$ in the United States $(13)$, of which $50-85 \%$ is derived from vegetables (12). So far, there are no specific data on the habitual dietary nitrate intake in athletes. 
Therefore, in the present study we assessed dietary nitrate intake in a large cohort of highly trained athletes. The aim of this study was to determine the habitual dietary nitrate intake in highly trained athletes of different sport disciplines, and identify the main sources of nitrate consumption through the diet.

\section{Methods}

\section{Participants}

A total of 759 Dutch highly trained athletes were included in the study. Due to incomplete data, 206 athletes were excluded and the data of the remaining 553 athletes were analyzed. All athletes 1) held an elite athlete status of the Dutch Olympic Committee (NOC*NSF) ( $n=195$ ); or 2) had participated in a European League (soccer) or European/World Championship ( $n=60$ ); or 3 ) had proven to be top level in their discipline or age group on a (inter)national level ( $n=298)$. Based on their particular discipline, participants were classified into one of three sport categories, similar to those used in other surveys of athletic groups (14): 1) strength

and/or sprint sports; 2) team-sports; or 3) endurance sports. A detailed overview of all disciplines within each sport category is provided in Supplemental Table 5.1. The survey was conducted according to the Declaration of Helsinki and was approved by the Medical Ethics Committee of Wageningen University. After being informed of the purpose and the burden of the study, all participants provided written informed consent. For participants under the age of eighteen, informed consent was also obtained from their parents or guardian.

\section{Study design}

Data were collected as part of the Dutch Sport Nutrition and Supplement Study (DSSS) that was performed between February 2012 and June 2015 (15). In short, participants were asked to complete 2-4 unannounced web-based (Compl-eat ${ }^{T M}$ ) 24-h dietary recalls and dietary supplement questionnaires during the conditioning phase of their training program. Data collection days were selected to include 1-3 week days and one weekend day for each participant and were scheduled over a 2-4 week period (at least four days apart). The output of the 24-h dietary recalls was sorted in 21 food groups. 


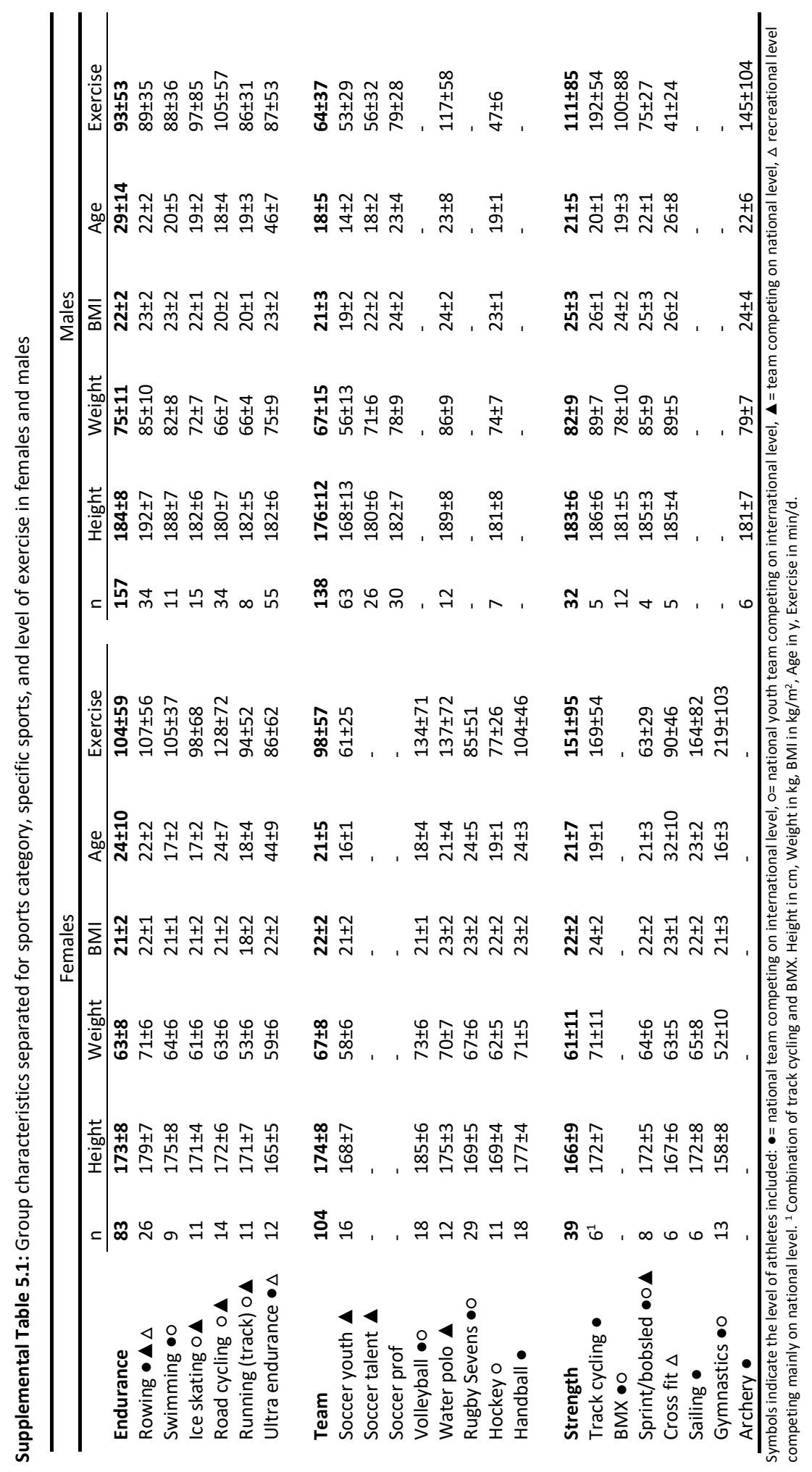




\section{Chapter 5}

The current study focused on determination of nitrate content in the diet of the athletes, and was performed between September and December 2015. We used the method previously described by Griesenbeck et al. (16) including 1) a thorough review of reports and scientific literature, 2) creating a database by categorizing relevant nitrate values for food groups and vegetables, and 3) generating summary estimates of nitrate values to calculate average daily nitrate intakes per individual. In case multiple analyses were available for a single food item within one reference source (e.g., 25 different analyses for spinach available in one database), all available analyses were used to generate an average nitrate value. Nitrate content (reported as $\mathrm{mg}$ nitrate/100 $\mathrm{g}$ food item) as determined for the food groups and vegetables used in this study are presented in Table 5.2 and Table 5.3, respectively. For all 21 food groups, and for all vegetables separately, each athlete's average daily intake (in grams) was calculated and multiplied by the respective nitrate content, yielding individual data on daily nitrate intake and contribution from the different sources. See Figure 5.1 for a flow-chart of the method used to determine nitrate content.

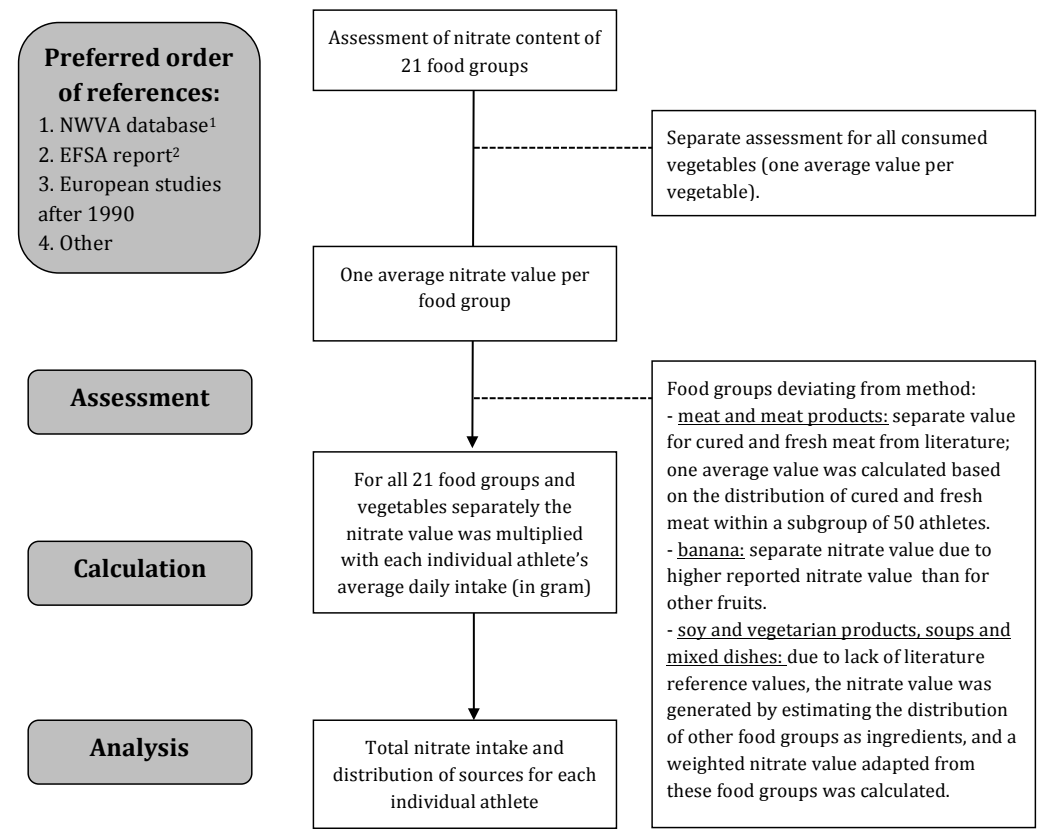

Figure 5.1: Flow chart of the method used to determine nitrate content. The nitrate values used are found in Table 5.2 and 5.3. ' Netherlands Food and Consumer Product Safety Authority, 2015 (32), ${ }^{2}$ Alexander et al., 2008 (28). 
Table 5.2: Nitrate content of food groups

\begin{tabular}{|c|c|}
\hline & Nitrate $\mathrm{mg} / 100 \mathrm{~g}$ (range) \\
\hline Potatoes & $17.5(0-35.0)^{1}$ \\
\hline Beverages & $1.0(0.1-3.7)^{2,3, *}$ \\
\hline Bread & $1.5(0.7-2.5)^{4,5}$ \\
\hline Diverse $^{a}$ & 0 \\
\hline Eggs & $0.7(0.5-1.0)^{4,5}$ \\
\hline Fruit & $2.0(1.3-2.7)^{2,4,5}$ \\
\hline Bananas & $5.5(2.0-10.7)^{3,6,7}$ \\
\hline Pastry, cake and biscuits & $2.0(1.9-2.5)^{4,8}$ \\
\hline Cereal and grain ${ }^{b}$ & $1.5(0.1-2.5)^{2,4,5,6}$ \\
\hline Savory spreads & $0.6^{5}$ \\
\hline Cheese & $1.0(0.1-1.7)^{4}$ \\
\hline Spices and herbs & $97.5(7.8-218.5)^{1}$ \\
\hline Milk and milk products & $0.2(0.1-0.5)^{2,4,5}$ \\
\hline Soy and vegetarian products ${ }^{\circ}$ & 3.0 \\
\hline Nuts, seeds and snacks & $2.0(0.6-3.7)^{5,7,9}$ \\
\hline Legumes & $6.0(0-14.8)^{1}$ \\
\hline Mixed dishes ${ }^{d}$ & 2.5 \\
\hline Soup & 3.0 \\
\hline Sugar, sweets, sweet spreads/sauces & $0^{4}$ \\
\hline Fats, oils and savory sauces & $0.22,4$ \\
\hline Fish & $2.0(1.0-5.5)^{2,4,5,6}$ \\
\hline Meat, meat products and poultry ${ }^{f}$ & $5.5(0.4-15.7)^{2,4,5,6,6,10}$ \\
\hline
\end{tabular}

ancludes cacao powder, Marmite and salt. 'b ncludes muesli, pasta, rice ect. 'Based calculations using

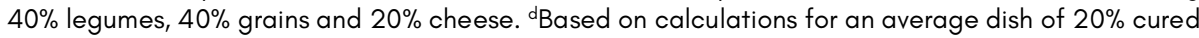
meat, $55 \%$ cereal and grain, $10 \%$ milk and milk products, $10 \%$ fats, oils and savory sauces, and $5 \%$

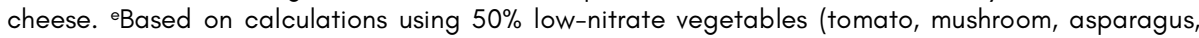
pea; Table 5.3) and $50 \%$ beverages. ${ }^{f}$ Based on analyses from a sub-selection of the athletes using a distribution of $35 \%$ fresh $(8 \mathrm{mg} / \mathrm{kg})$ and $65 \%$ cured $(80 \mathrm{mg} / \mathrm{kg})$ meat.

1 Netherlands Food and Consumer Product Safety Authority, 2015 (32), 2 Schuddeboom, 1993 (33), 3 Food Standards, 2010 (34), ${ }^{4}$ Pobel et al., 1995 (35), 5 FoodStandardsAgency, London; 1998 (36), 6 Cornee, 1992 (37), 7 Hord et al., 2009 (9), ${ }^{8}$ Howe, 1986 38), 9 Siciliano et al., 1975 (39), 10 Saccani et al., 2006 (40), * own analysis (Maastricht University, the Netherlands). 
Table 5.3: Nitrate content of vegetables

\begin{tabular}{|c|c|}
\hline & Nitrate $\mathrm{mg} / 100 \mathrm{~g}$ (range) \\
\hline Alfalfa sprouts & $5.5^{1}$ \\
\hline Asparagus & $4.0(0-10.0)^{2}$ \\
\hline Bean sprouts & $0^{2}$ \\
\hline Beans green & $52.5(21.0-100.0)^{2}$ \\
\hline Beans string & $37.5(0-61.0)^{2}$ \\
\hline Beetroot & $125.0(35.0-258.0)^{2}$ \\
\hline Broccoli & $27.5(6.0-100.0)^{2}$ \\
\hline Cabbage Chinese & $92.5(23.0-149.3)^{2}$ \\
\hline Cabbage oxheart & $70.0(15.0-89.7)^{2}$ \\
\hline Cabbage red & $25.0(5.5-49.0)^{2}$ \\
\hline Cabbage white & $27.5(9.4-59.0)^{2}$ \\
\hline Carrots & $15.0(0-43.0)^{2}$ \\
\hline Cauliflower & $15.0(0-38.7)^{2}$ \\
\hline Celeriac & $30.0(14.0-44.0)^{2}$ \\
\hline Celery & $90.0(51.5-119.3)^{2}$ \\
\hline Chicory & $30.0(10.0-50.3)^{2}$ \\
\hline Corn & $3.5(0-10.0)^{2}$ \\
\hline Cucumber & $20.0(2.0-47.6)^{2}$ \\
\hline Eggplant & $27.5(0-64.0)^{2}$ \\
\hline Endive & $125.0(0-328.1)^{2}$ \\
\hline Fennel & $130.0(22.0-229.0)^{2}$ \\
\hline Kale curly & $20.0(0-108.0)^{2}$ \\
\hline Kohlrabi & $170.0(126.0-214.0)^{2}$ \\
\hline Leek & $57.5(25.0-105.0)^{2}$ \\
\hline Lettuce various $^{a}$ & $200.0(151.1-275.8)^{2}$ \\
\hline Lettuce iceberg & $80.0(26.0-186.0)^{2}$ \\
\hline Mushrooms & $10.0^{2}$ \\
\hline Onion & $20.0(0-95.0)^{2}$ \\
\hline Pak choi & $325.0(229.0-490.0)^{2}$ \\
\hline Peas & $2.5(0-10.0)^{2}$ \\
\hline Pepper sweet & $7.0(0-19.0)^{2}$ \\
\hline Pickles & $10.0^{2}$ \\
\hline Pumpkin & $3.5(0-11.0)^{2}$ \\
\hline Radish & $210.0(172.0-251.0)^{2}$ \\
\hline Rocket salad (arugula) & $420.0(78.0-629.0)^{2}$ \\
\hline Rutabaga/turnip & $25.0(0-48.0)^{2}$ \\
\hline Sauerkraut & $10.0^{2}$ \\
\hline Spinach & $180.0(22.7-336.0)^{2}$ \\
\hline Sprouts & $4.0(0-10.0)^{2}$ \\
\hline Tomato & $9.5(0-37.0)^{2}$ \\
\hline Zucchini & $67.5(13.0-137.0)^{2}$ \\
\hline Mixed vegetables ${ }^{b}$ & $52.5(10.0-100.0)^{2}$ \\
\hline
\end{tabular}

a Lettuce various include average nitrate values for oakleaf, butterhead, leaf, lollo rossa, looseleaved, and lamb's lettuce.

b If not specified; mixed vegetables raw/boiled - value for mixed vegetable from NVWA is used.

'Chung et al., 2003 (41), ${ }^{2}$ Netherlands Food and Consumer Product Safety Authority, 2015 (32). 


\section{Statistical analysis}

Statistical analyses were carried out on data of all 553 participants delivering 2-4 complete 24-h dietary recalls, using SPSS (version 22.0, IBM Corp., Armonk, NY, USA). For each individual athlete, average daily intake of nitrate (mg), energy (MJ), nitrate corrected for energy (mg/MJ), vegetables $(\mathrm{g})$ and nitrate from vegetables (mg) were calculated. Data were checked for normality using Shapiro-Wilk tests. Based on non-normal distribution of all main variables, Mann-Whitney $U$ tests were used to test for differences between men and women. Subsequently, Kruskal Wallis $\mathrm{H}$ test was used for comparison of sports categories, with Bonferroni-corrected post-hoc testing when appropriate. Spearman correlation coefficients were calculated to determine relations between different main variables. Statistical significance was set at $P \leq 0.05$. All data are presented as median[IOR].

\section{Results}

A total of 553 athletes ( $n=226$ females: $172 \pm 8 \mathrm{~cm}, 65 \pm 9 \mathrm{~kg}, \mathrm{BMI} 22 \pm 2 \mathrm{~kg} / \mathrm{m}^{2} ; n=327$ males: $181 \pm 11 \mathrm{~cm}, 72 \pm 14 \mathrm{~kg}, \mathrm{BMl} 22 \pm 3 \mathrm{~kg} / \mathrm{m}^{2}$ ) completed the study. Of the total group of athletes, $122(22.1 \%)$ completed two recalls, 401 (72.5\%) completed three recalls and $30(5.4 \%)$ completed four recalls. The athletes were classified as strength $(n=71)$, team-sports $(n=242)$ or endurance $(n=240)$ athletes.

\section{Nitrate and vegetable intakes}

Median nitrate intake of the total group of athletes was 106[75-170] mg/d, ranging from 19 to $525 \mathrm{mg} / \mathrm{d}$. Only 10 of the 553 athletes (2\%) had a habitual nitrate intake exceeding the 'standard' supplement dose of $400 \mathrm{mg}$. There was a positive correlation between energy intake and nitrate intake for the total group $(\rho=0.28$, $P<0.001)$, and also for female $(\rho=0.36, P<0.001)$ and male athletes $(\rho=0.32, P<0.001)$ separately (Figure 5.2A). However, much stronger positive correlations were found between vegetable intake and nitrate intake for the total group $(\rho=0.78, P<0.001)$, and also for female $(\rho=0.80, P<0.001)$ and male athletes $(\rho=0.76, P<0.001)$ separately (Figure 5.2B). Median vegetable intake for the total group of athletes was 132[71-207] g/d, ranging from 0 to $858 \mathrm{~g} / \mathrm{d}$. 
A

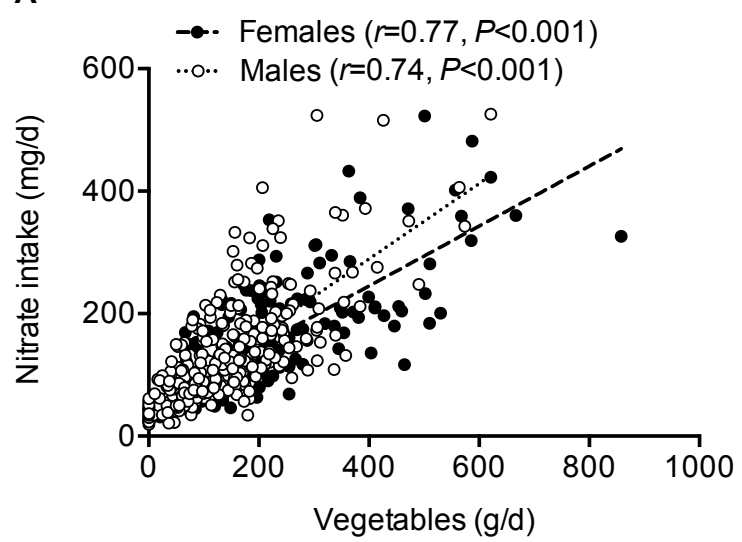

B

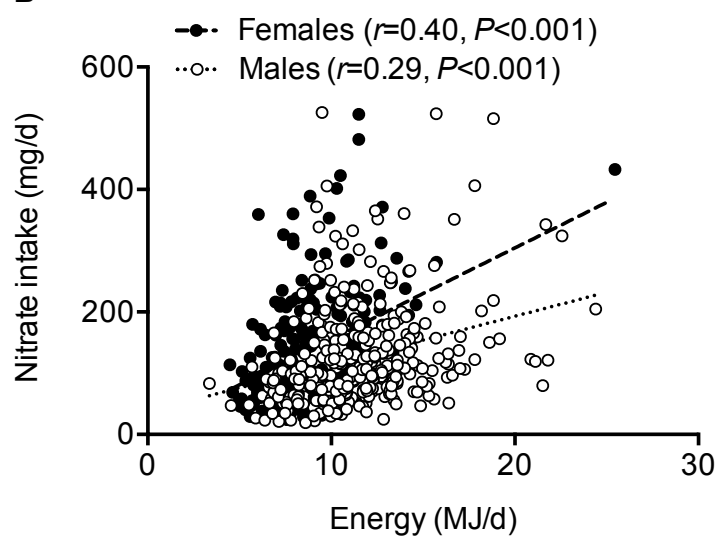

Figure 5.2: Correlations between dietary nitrate and vegetable intakes $(A)$ and dietary nitrate and energy intakes (B) in female (black circles) and male athletes (white circles). Significant correlation for female $(n=226)$ and male athletes $(n=327)$ separately, $P<0.05$.

The intake of dietary nitrate classified by sex and sport disciplines is shown in Table 5.1. Nitrate intake was higher in female vs male athletes (109[80-184] vs 104[72-158] $\mathrm{mg} / \mathrm{d}$, respectively; $P=0.046)$. Energy intake was lower in female vs male athletes (8.6[7.5-10.3] vs 11.1[9.5-13.2] MJ/d, respectively; $P<0.001)$. When corrected for total energy intake, nitrate intake was substantially higher in female vs male athletes (12.8[9.2-20.0] vs 9.4[6.2-13.8] mg/MJ, respectively; $P<0.001)$. In accordance, vegetable consumption was higher in female vs male athletes (150[88-236] vs $114[61-183] \mathrm{g} / \mathrm{d}$, respectively; $P<0.001)$. 
Habitual intake

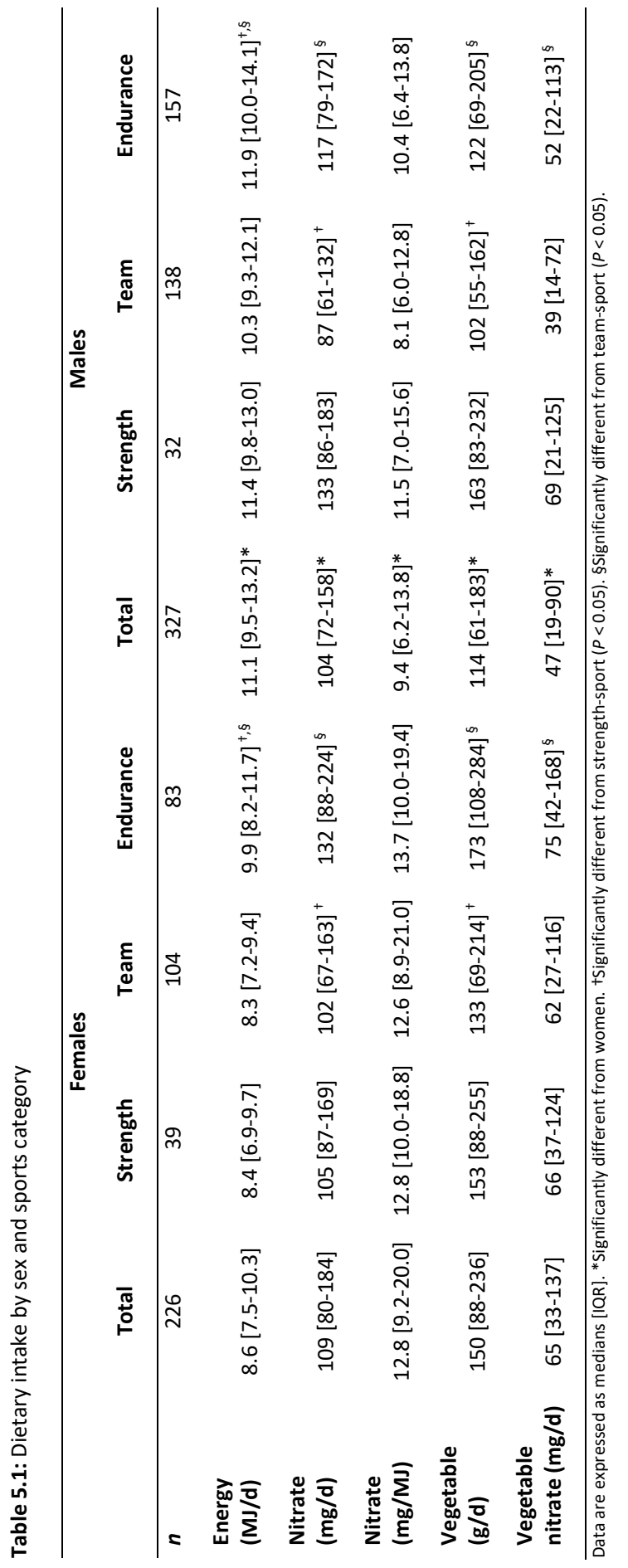


Nitrate intake was different between athletes from the three sport categories (Table 5.1; group-effect $P<0.001$ ). Post-hoc analysis revealed that the nitrate intake was lower for team-sport athletes compared with both endurance $(P<0.001)$, and strength athletes $(P=0.024)$. No differences were observed for nitrate intake between strength and endurance athletes. When corrected for energy intake, nitrate intake was different between the three sport categories ( $P=0.037)$, with post-hoc analyses showing a trend for lower intake in team-sport vs strength athletes $(P=0.069 ;$ Table 5.1). In line, vegetable intake was different between athletes from the three sport categories (Table 5.1; group-effect $P<0.001$ ). Post-hoc analysis showed that vegetable intake was lower for team-sport athletes compared with both endurance $(P=0.002)$, and strength athletes $(P=0.001)$. Vegetable intake was not different between strength and endurance athletes.

\section{Nitrate sources}

For the total group of athletes, the food sources contributing most to the nitrate intake were vegetables $(60 \%)$, potatoes $(9 \%)$, fruit $(5 \%)$, beverages $(11 \%)$, meat $(5 \%)$, and bread (2\%). Small differences were observed between female and male athletes (Figure 5.3A and 3B). When taken together, vegetables, potatoes and fruit accounted for $74 \%$ of the nitrate intake (77\% for female and $71 \%$ for male athletes). The relative contribution of different vegetables to total vegetable nitrate intake is shown in Figure 5.3C. Lettuce (20\%) and spinach (18\%) were clearly the greatest contributors to the nitrate intake from vegetables. 

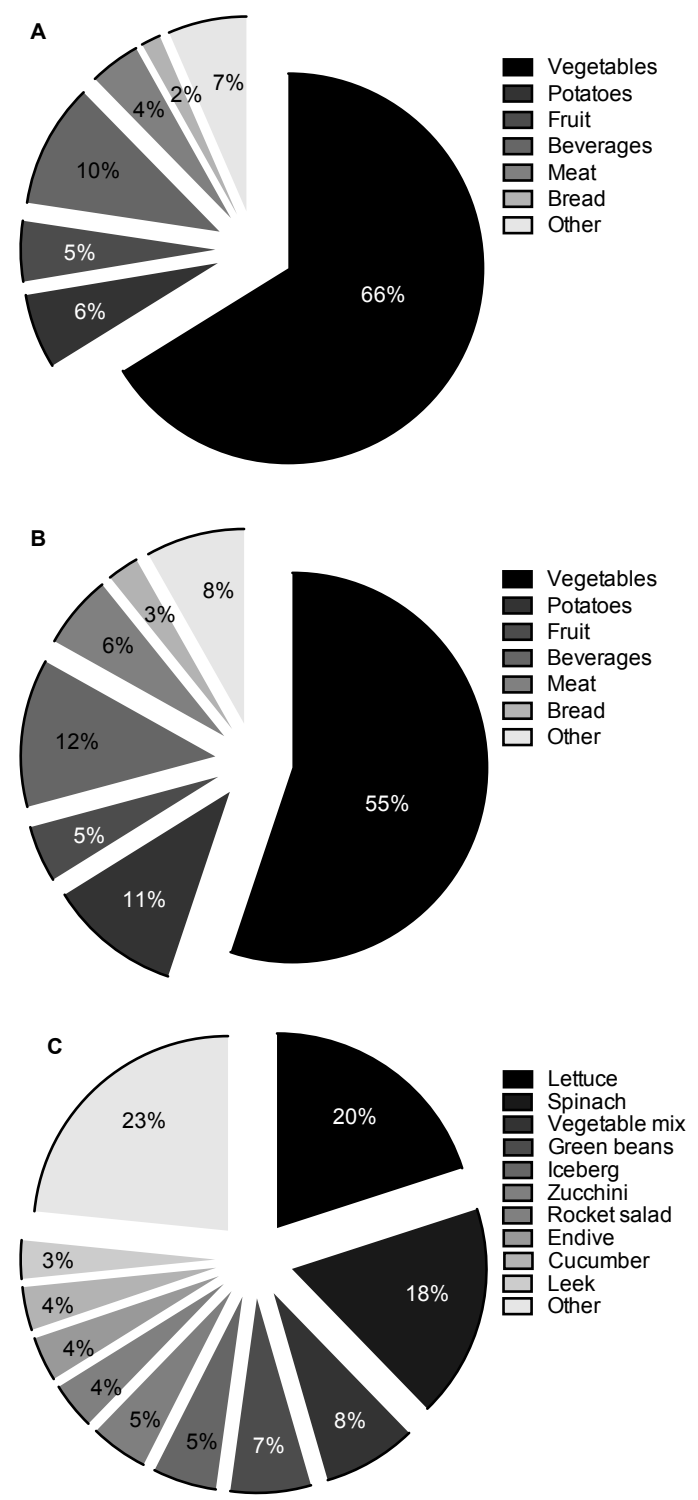

Figure 5.3: Distribution of total dietary nitrate in 226 female $(A)$ and 327 male athletes $(B)$, and dietary nitrate from vegetables in the total group of 553 athletes (C). Values are mean percentages. Lettuce include average nitrate values for oakleaf, butterhead, leaf, lollo rossa, loose-leaved, and lamb's lettuce. 


\section{Chapter 5}

\section{Beetroot juice}

Data on supplement use were available for 327 of the 553 athletes (59\%). In this subgroup, 68 athletes $(21 \%)$ reported the use of beetroot juice at some time in the past. This included 10 out of 53 strength athletes (19\%); 8 out of 84 team-sport athletes (10\%); and 50 out of 190 endurance athletes (26\%). Only 2 athletes reported the use of beetroot juice during at least one of the 24-h recall days. Nonetheless, median dietary nitrate intake (i.e., without taking beetroot juice supplements on these days) tended to be higher in the beetroot juice 'users' than the 'non-users' (140[88-199] vs 108[77-172] mg/d, respectively; $P=0.051$ ). Energy intake was not different between 'users' and 'non-users' (10.6[8.6-13.2] vs 10.2[8.3$12.4] \mathrm{MJ} / \mathrm{d}$, respectively; $P=0.18$ ), but athletes reporting to have never used beetroot juice in the past typically consumed less vegetables than the 'users' (133[69-204] vs $147[88-301] \mathrm{g} / \mathrm{d}$, respectively; $P=0.035)$.

\section{Discussion}

The present work demonstrated that median habitual dietary nitrate intake in a large group of highly trained Dutch athletes was $106 \mathrm{mg} / \mathrm{d}$, with a range of 19 to $525 \mathrm{mg} / \mathrm{d}$ between individuals. Total nitrate intake was positively correlated with total daily energy as well as daily vegetable intake. Vegetables, potatoes and fruit accounted for $75 \%$ of total nitrate intake, with lettuce and spinach representing the greatest contributors to daily nitrate intake.

Despite the increased interest in dietary nitrate as a potential cardioprotective and ergogenic substance, very little is known on nitrate intake in the habitual diet. Based on 20 -year-old reports within the general population, estimated daily dietary nitrate intake ranges from $\sim 31-185 \mathrm{mg}(\sim 0.5-3.0 \mathrm{mmol})$ across various European countries (12), and from $40-100 \mathrm{mg}(\sim 0.6-1.6 \mathrm{mmol})$ in the United States (13). In agreement, a prospective cohort study in the Netherlands reported a mean nitrate intake of $99 \mathrm{mg} / \mathrm{d}$ (17). However, at present there are no data on nitrate intake in different subpopulations. Given the proposed ergogenic effects of nitrate for different sport disciplines (18), we specifically aimed to assess dietary nitrate intake in a diverse group of highly trained athletes. The median nitrate intake of the athletes in the present study $(106 \mathrm{mg} / \mathrm{d})$ falls within the upper range of previous findings in the general population. Furthermore, similar to what has been reported for the general population $(19,20)$, we found great interindividual variation in the nitrate intake of athletes (19-525 mg/d).

Most of the variation in nitrate intake in the present study can be explained by the vegetable consumption, which ranged from 0 to $858 \mathrm{~g} / \mathrm{d}$ between individuals. The cumulative intake of vegetables, potatoes and fruit accounted for 
$75 \%$ of the total nitrate intake. This is in line with the previous Dutch report in which $68 \%$ of nitrate intake came from vegetables and $9 \%$ from potato (17). Similarly, for the general European population, vegetables have been estimated to account for $50-85 \%$ of nitrate intake (12). In the Dutch National Food Consumption Survey conducted between 2007 and 2010 (21), median vegetable intake in young women and men (19-30 y) were reported to be 95 and $107 \mathrm{~g} / \mathrm{d}$, respectively. Compared to the general population, the Dutch athletes in the present study had higher vegetable intakes. However, only $38 \%$ (212 out of 553 athletes) met the WHO recommendations of $400 \mathrm{~g}$ fruit and vegetables per day (22). The vegetable intake was higher in the female athletes: 150[88-236] in female compared with 114[61-183] $\mathrm{g} / \mathrm{d}$ in male athletes. A possible explanation could be higher nutrition knowledge and dietary quality, which previously has been reported in female compared with male elite athletes (23). The higher vegetable and associated nitrate intake in females could possibly explain the higher plasma nitrate values previously found in females compared to men, both by our research group (7) as well as by others (24, 25). In addition to sex differences, the team-sport athletes had lower nitrate and vegetable intakes than both endurance and strength athletes. In line, Burke et al. (26) also found lower vegetable intakes in football players compared with marathon runners, triathletes and weight lifters. This finding was suggested to be associated with lower nutrition interest and knowledge in the football players.

In addition to the strong association between nitrate and vegetable intake, this study also reports a positive correlation between nitrate and energy intake. It has previously been hypothesized that highly trained athletes respond less to nitrate supplementation than recreational athletes (10). One of the suggested explanations is that athletes with a higher training load also have a greater energy intake, and/or a different (more healthy) eating pattern, including the consumption of (nitraterich) vegetables. As such, highly trained athletes may have a greater nitrate intake in their habitual diet, potentially rendering additional nitrate supplementation ineffective (11). However, in the current study only $2 \%$ (10 out of 553 athletes) reached a daily nitrate intake above the 'standard' supplement dose of $400 \mathrm{mg}$ $(\sim 6.5 \mathrm{mmol})$. Thus despite large inter-individual differences in nitrate intake (range $19-525 \mathrm{mg} / \mathrm{d}$ ), the intake level for most athletes is substantially lower than the 300 $600 \mathrm{mg}$ (4.8-9.7 mmol) of nitrate representing the suggested minimal dose needed to enhance exercise performance (4-6). As such, we propose that greater habitual nitrate consumption in highly trained athletes is not a likely explanation for the suggested ineffectiveness of nitrate supplementation in this population. Nonetheless, as the dietary nitrate intake varies greatly between individuals, it seems relevant to assess habitual dietary nitrate intake when studying the physiological effects of nitrate supplementation. 


\section{Chapter 5}

The present study used a systematic approach to determine nitrate content in various food groups and vegetables. Determination of nitrate content of foods has certain limitations, such as variation in nitrate content of foods by season and environment (e.g. soil, use of nitrate-rich fertilizers in non-organic vs organic foods), and insufficient analytical data of nitrate content of certain foods. In addition, nitrate content can be reduced by food preparation such as heating, in which the reduction in general is greater after boiling than steaming and microwaving (27). Thus, we are aware that the dietary nitrate intakes of the present study may be slightly overestimated by the use of raw product values. However, the approach used provides the best possible estimate and represents the commonly accepted method to determine nitrate content of foods (28). While the habitual nitrate intake of most athletes is substantially lower than the suggested minimal dose needed to enhance performance (i.e., 300-600 mg), some athletes actually reach this intake level on a daily basis. In line, Hord et al. (9) reported that a dietary nitrate intake up to $1,200 \mathrm{mg}$ can be achieved when following the DASH-guidelines. We have recently shown that nitrate-rich vegetables are just as effective as beetroot juice in increasing plasma nitrate/nitrite and reducing blood pressure, when providing the same nitrate dose (7). In line, there is current speculation that the cardioprotective effects of the Mediterranean Diet may be, at least partly, attributed to the high nitrate intake from vegetable consumption $(9,29)$. Furthermore, Porcelli et al. (8) reported improved performance following a shortterm high-nitrate diet. As such, we propose that increasing habitual dietary nitrate intake through vegetables may represent a feasible alternative to nitrate supplementation when aiming for health and/or ergogenic effects of nitrate. Furthermore, this approach has the potential to provide a greater diversity of nutrients, which might be beneficial. Clearly, for various vegetable sources, the ingestion of $400 \mathrm{mg}$ nitrate can be achieved by consuming feasible amounts of these vegetables (e.g.; $200 \mathrm{~g}$ lettuce, $222 \mathrm{~g}$ spinach, $123 \mathrm{~g}$ pak choi, or $95 \mathrm{~g}$ rocket salad/arugula), or combinations of these products (Table 5.3).

Due to the use of a web-based approach for the current study, unannounced 24-h dietary recalls and questionnaires were possible to perform for such a large athlete population. Though the dietary habits of athletes are notoriously constant, we cannot exclude the possibility that a slight change in dietary habits and nitrate intake may have occurred throughout the 3-year collection period (e.g. due to changing food trends). Furthermore, there are several limitations of dietary assessments in athletes (30) such as self-reported estimation of portion sizes, frequency of snacking, and underreporting, which have previously been described for a sub-selection of the current dataset (15). However, the inclusion of 2-4 dietary registration days per person and verification of food intake 
by certified dietitians, strongly improves the validity for food consumption surveys to evaluate dietary intake (31). Based on the large inter-individual variation, it would be of interest to link habitual nitrate intake to basal saliva, plasma or tissue nitrate and nitrite concentrations in future studies. In addition, future work should assess the effectiveness of dietary advice and/or other strategies to increase dietary nitrate intake, thereby evaluating whether similar ergogenic and cardioprotective effects can be obtained as previously shown for nitrate supplements.

\section{Conclusions}

Dutch highly trained athletes have a median daily nitrate intake of $106 \mathrm{mg}$, with large inter-individual variation (19-525 mg). Most of the variation in nitrate intake can be explained by the athletes' vegetable intake. Increasing the intake of nitraterich vegetables in the habitual diet could potentially be used as an alternative strategy for nitrate supplementation. 


\section{References}

1. Clements, W.T., S.-R. Lee, and R.J. Bloomer, Nitrate ingestion: a review of the health and physical performance effects. Nutrients, 2014. 6(11): p. 5224-5264.

2. Lundberg, J.O., et al., Intragastric nitric oxide production in humans: measurements in expelled air. Gut, 1994. 35(11): p. 1543-1546.

3. Stamler, J.S. and G. Meissner, Physiology of nitric oxide in skeletal muscle. Physiol Rev, 2001. 81(1): p. 209-237.

4. Bryan, N.S. and J.L. Ivy, Inorganic nitrite and nitrate: evidence to support consideration as dietary nutrients. Nutr Res, 2015. 35(8): p. 643-54.

5. Hoon, M.W., et al., The Effect of Nitrate Supplementation on Exercise Performance in Healthy Individuals: A Systematic Review and Meta-Analysis. Int J Sport Nutr Exerc Metab, 2013, 23, 522-532.

6. Wylie, L.J., et al., Beetroot juice and exercise: pharmacodynamic and dose-response relationships. J Appl Physiol (1985), 2013. 115: p. 325-336.

7. Jonvik, K.L., et al., Nitrate-Rich Vegetables Increase Plasma Nitrate and Nitrite Concentrations and Lower Blood Pressure in Healthy Adults. J Nutr, 2016, 146(5), 986-93.

8. Porcelli, S., et al., Effects of a Short-Term High-Nitrate Diet on Exercise Performance. Nutrients, 2016. 8(9).

9. Hord, N.G., Y. Tang, and N.S. Bryan, Food sources of nitrates and nitrites: the physiologic context for potential health benefits. Am J Clin Nutr, 2009. 90: p. 1-10.

10. Porcelli, S., et al., Aerobic Fitness Affects the Exercise Performance Responses to Nitrate Supplementation. Med Sci Sports Exerc, 2015, 47(8), 1643-51.

11. Jonvik, K.L., et al., Can elite athletes benefit from dietary nitrate supplementation? J Appl Physiol (1985), 2015. 119(6): p. 759-61.

12. Gangolli, S.D., et al., Nitrate, nitrite and N-nitroso compounds. Eur J Pharmacol, 1994. 292(1): p. 1-38.

13. Mensinga, T.T., G.J. Speijers, and J. Meulenbelt, Health implications of exposure to environmental nitrogenous compounds. Toxicol Rev, 2003. 22(1): p. 41-51.

14. Burke, L.M., et al., Eating patterns and meal frequency of elite Australian athletes. Int J Sport Nutr Exerc Metab, 2003. 13(4): p. 521-38.

15. Wardenaar, F.C., et al., Validation of web-based, multiple 24- $h$ recalls combined with nutritional supplement intake questionnaires against nitrogen excretions to determine protein intake in Dutch elite athletes. Br J Nutr, 2015. 114(12): p. 2083-92.

16. Griesenbeck, J.S., et al., Development of estimates of dietary nitrates, nitrites, and nitrosamines for use with the Short Willet Food Frequency Questionnaire. Nutr J, 2009. 8: p. 16.

17. van Loon, A.J., et al., Intake of nitrate and nitrite and the risk of gastric cancer: a prospective cohort study. Br J Cancer, 1998. 78(1): p. 129-35.

18. Jones, A.M., Influence of dietary nitrate on the physiological determinants of exercise performance: $a$ critical review. Appl Physiol Nutr Metab, 2014. 39(9): p. 1019-28.

19. Petersen, A. and S. Stoltze, Nitrate and nitrite in vegetables on the Danish market: content and intake. Food Addit Contam, 1999, 16(7), 291-299.

20. Ysart, G., et al., Dietary exposures to nitrate in the UK. Food Addit Contam, 1999, 16(12), 521-532.

21. van Rossum, C.T.M.F., H.P.; Verkaik-Kloosterman, J.; Buurma-Rethans, E.J.M.; Ocke, M.C., Dutch National Food Consumption Survey 2007-2010 : Diet of children and adults aged 7 to 69 years. 2011. National Institute for Public Health and the Environment, Ministry of Health, Welfare and Sport.

22. WHO (2006). Comparative analysis of nutrition policies in the WHO European Region: a comparative analysis of nutrition policies and plans of action in WHO European Region, May 2006.

23. Spronk, I., et al., Relationship Between General Nutrition Knowledge and Dietary Quality in Elite Athletes. Int J Sport Nutr Exerc Metab, 2015. 25(3): p. 243-51.

24. Kapil, V., et al., Inorganic nitrate supplementation lowers blood pressure in humans: role for nitritederived NO. Hypertension, 2010. 56: p. 274-281.

25. Velmurugan, S., et al., Original Contribution: Antiplatelet effects of dietary nitrate in healthy volunteers: Involvement of cGMP and influence of sex. Free Radical Bio Med, 2013. 65: p. 1521-1532.

26. Burke, L.M., R.A. Gollan, and R.S. Read, Dietary intakes and food use of groups of elite Australian male athletes. Int J Sport Nutr, 1991. 1(4): p. 378-94. 
27. Boari, F., Cefola, M., Di Gioia, F., Pace, B., Serio, F., \& Cantore, V. (2013). Effect of cooking methods on antioxidant activity and nitrate content of selected wild Mediterranean plants. Int J Food Sci Nutr, 64(7), 870-876. doi:10.31019/09637486.2013.799125

28. Alexander, J., Benford, D., Cockburn, A., Cravedi, J. P., Dogliotti, E., Di Domenico, A., ... Verger, P.. Nitrate in vegetables Scientific Opinion of the Panel on Contaminants in the Food chain. The EFSA Journal, 2008 Vol. 689, 1-79.

29. Lundberg, J.O., et al., Cardioprotective effects of vegetables: is nitrate the answer? Nitric Oxide, 2006. 15(4): p. 359-62.

30. Magkos, F. and M. Yannakoulia, Methodology of dietary assessment in athletes: concepts and pitfalls. Curr Opin Clin Nutr Metab Care, 2003. 6(5): p. 539-49.

31. Brussaard, J.H., et al., A European food consumption survey method--conclusions and recommendations. Eur J Clin Nutr, 2002. 56 Suppl 2: p. S89-94.

32. Netherlands Food and Consumer Product Safety Authority, 2015, NVWA analysen 20151002-Nitraat KAP-databank 2006-2014. From National Institute of Public Health and the Environment (RIVM), the Netherlands.

33. Schuddeboom, L.J., Nitrate and nitrite in foodstuffs. 63 ed. 1993, Counsil of Europe Press. 125.

34. Food Standards, A.N.Z., Survey of nitrates and nitrites in food and beverages in Australia. 2010. Retrieved from http://www.foodstandards.gov.au/consumer/ additives/nitrate/Pages/default.aspx on November $15,2015$.

35. Pobel, D., et al., Nitrosamine, nitrate and nitrite in relation to gastric cancer: a case-control study in Marseille, France. Eur J Epidemiol, 1995. 11(1): p. 67-73.

36. FoodStandardsAgency, Total diet study, nitrate and nitrite. Total diet study, nitrate and nitrite. Food Surveillance Information Sheet, No. 163. London; 1998.

37. Cornee, J., An estimate of nitrate, nitrite and $\mathrm{N}$-nitrosodimethylamine concentrations in French food products or food groups. Sci. Aliments, 1992(12): p. 115-197.

38. Howe, G.R., Harrison, L., Jain, M., A short diet history for assessing dietary exposure to $N$-nitrosamines in epidemiologic studies. Am J Epidemiol, 1986(124): p. 595-602.

39. Siciliano, J., et al., Nitrate and nitrite content of some fresh and processed market vegetables. J Agric Food Chem, 1975. 23(3): p. 461-4.

40. Saccani, G., et al., Determination of nitrite, nitrate, and glucose-6-phosphate in muscle tissues and cured meat by IC/MS. J AOAC Int, 2006. 89(3): p. 712-9.

41. Chung, S.Y., et al., Survey of nitrate and nitrite contents of vegetables grown in Korea. Food Addit Contam, 2003. 20(7): p. 621-8. 



\section{Chapter}

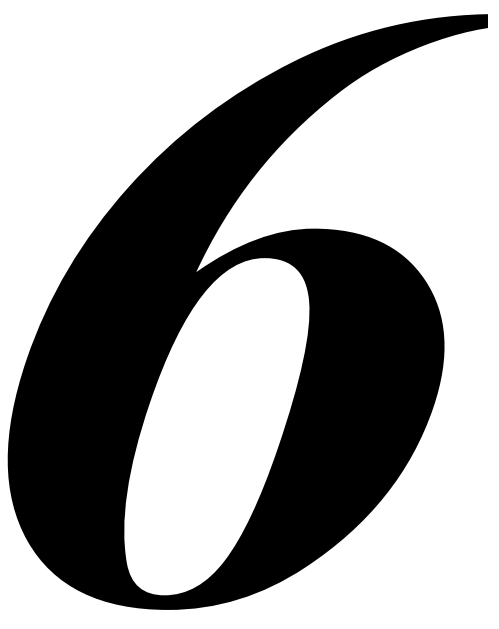

Repeated-sprint performance and plasma responses following beetroot juice supplementation do not differ between recreational, competitive and elite sprint athletes

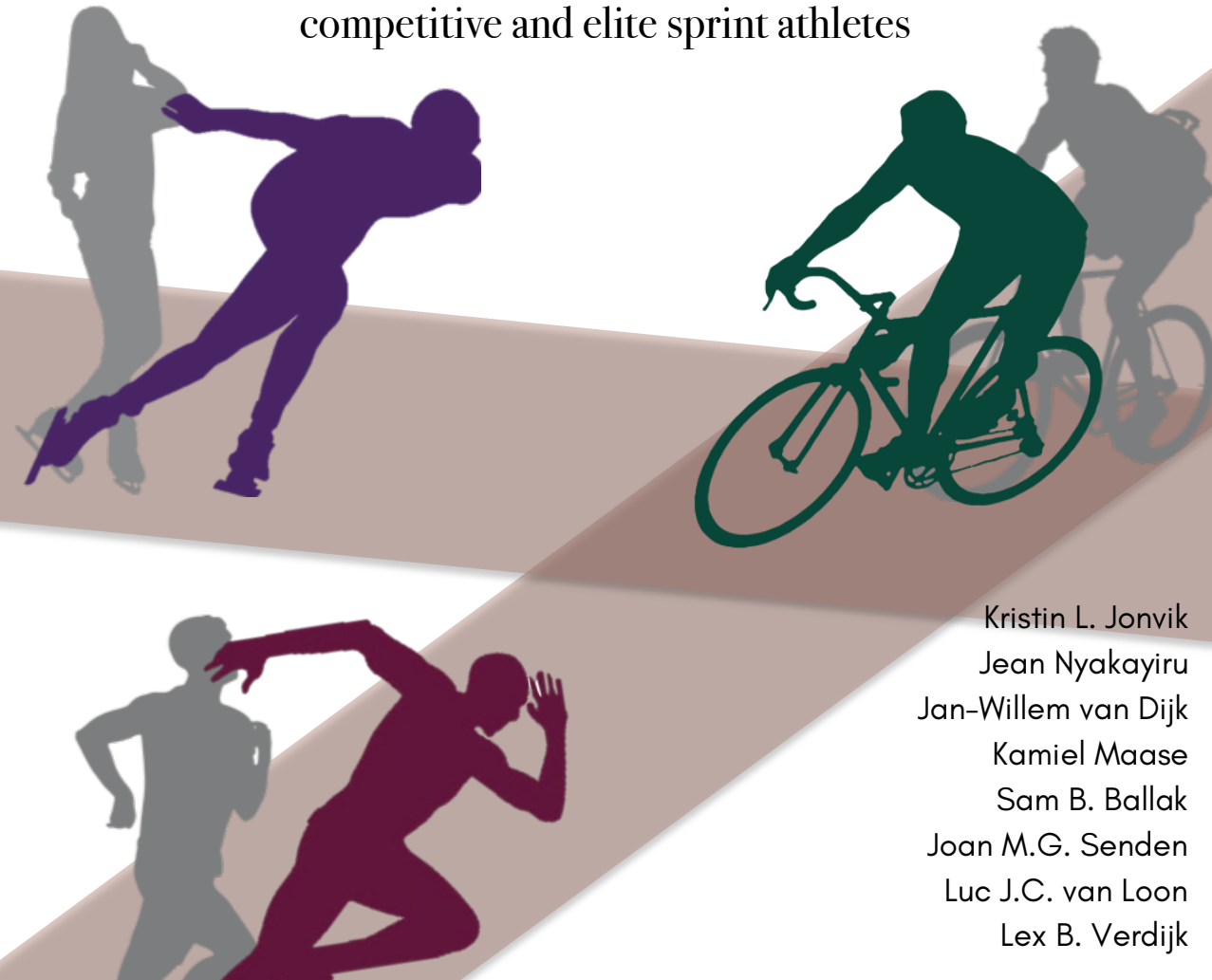

Eur J Sport Sci. 2018 Feb;7:1-10. 


\section{ABSTRACT}

Background: There is an ongoing debate whether highly trained athletes are less responsive to the ergogenic properties of nitrate. We assessed the effects of nitrate supplementation on plasma nitrate and nitrite concentrations and repeated sprint performance in recreational, competitive, and elite sprint athletes.

Methods: In a randomized double-blinded cross-over design, recreational cyclists $(n=20)$, national talent speed-skaters $(n=22)$ and Olympic level track cyclists $(n=10)$ underwent two 6-day supplementation periods; $140 \mathrm{~mL} / \mathrm{d}$ nitrate-rich (BR; 800 $\mathrm{mg} / \mathrm{d}$ ) and nitrate-depleted (PLA; $0.5 \mathrm{mg} / \mathrm{d}$ ) beetroot juice. Blood samples were collected and three 30-s Wingate tests were performed.

Results: Plasma nitrate and nitrite concentrations were higher following BR vs PLA $(P<0.001)$, with no differences between sport levels (all $P>0.10)$. Peak power over the three Wingates was not different between BR and PLA ( $1338 \pm 30$ vs $1333 \pm 30$ W; $P=0.62$ ), and there was no interaction between treatment (BR-PLA) and Wingate number (1-2-3; $P=0.48)$. Likewise, mean power did not differ between BR and PLA $(P=0.86)$. In contrast, time to peak power improved by $2.8 \%$ following BR vs PLA $(P=0.007)$. This improvement in BR vs PLA was not different between Wingate 1, 2 and 3. Moreover, the effects of BR vs PLA did not differ between sport levels for any Wingate parameter (all P>0.30).

Conclusion: The plasma and repeated-sprint performance responses to beetroot juice supplementation do not differ between recreational, competitive and elite sprint athletes. Beetroot juice supplementation reduces time to reach peak power, which may improve the capacity to accelerate during high-intensity and sprint tasks in recreational as well as elite athletes. 


\section{Introduction}

Due to the proposed effects of dietary nitrate on exercise performance, nitraterich supplements and foods currently receive considerable attention as ergogenic aids. The effects of dietary nitrate have been attributed to its reduction to nitrite by oral bacteria, which in turn enters the circulation after swallowing, and is then further reduced to nitric oxide (NO), particularly in environments of low oxygen availability and low pH (1). $\mathrm{NO}$ is important for several physiological processes associated with exercise, including the regulation of blood flow and skeletal muscle contraction (2). Over the past decade, dietary nitrate supplementation has been shown to improve oxygen efficiency during submaximal exercise (3-5), increase time to exhaustion of high-intensity exercise $(3,6,7)$ and improve exercise time-trial performance $(8,9)$ in recreational to well-trained athletes. Whereas most research on performance effects of dietary nitrate has been on endurance sports, the focus is currently shifting towards intermittent and very high-intensity sports. During highintensity exercise metabolic by-products accumulate and cause acidosis (10), creating an environment that promotes nitrite to NO conversion (1). It has been suggested that under such circumstances, nitrate supplementation may be more effective in eliciting its ergogenic potential $(11,12)$. In this respect, improvements in intermittent and repeated-sprint performance following beetroot juice supplementation have been observed in recreational athletes (11, 13-16), although this has not been confirmed by all studies $(17,18)$. A potential mechanism for improvement of repeated-sprint performance following beetroot juice supplementation is a decreased fatigue development between sprints associated with reduced PCr cost of force production (11). Given that short rest periods normally lead to an incomplete recovery of muscle PCr and force production, beetroot juice may be most effective for repeated-sprints interspersed by short recovery periods. However, power production per se has also been shown to improve following nitrate ingestion $(19,20)$, which could be caused by improved rate of force production (21) and speed of contraction (20). As such, both a more generalized effect of nitrate ingestion on (peak) power output, as well as more prominent effect in the later sprints of a repeated-sprint protocol could be expected.

It has been suggested that differences in the efficacy of dietary nitrate to improve exercise performance may be related to training status, with highly trained athletes potentially being less responsive to the ergogenic properties of nitrate than recreational athletes (22). Such unresponsiveness may be explained by higher endogenous NO synthesis, higher habitual dietary nitrate intakes, and optimized exercise training adaptations in highly trained athletes (23). Recent work by Porcelli et al. (22) suggests that highly trained endurance athletes have higher baseline plasma nitrate and nitrite concentrations and show less of an increase in plasma 


\section{Chapter 6}

concentrations following nitrate ingestion. In contrast, we have shown substantial increases in plasma nitrate and nitrite concentrations after nitrate supplementation in highly trained endurance athletes (24). As such, it remains to be determined what the potential effect of training status is on (changes in) plasma nitrate and nitrite concentrations.

Apart from differences in plasma nitrate or nitrite concentrations, the benefits of nitrate supplementation may also depend on genetic or training effects on muscle oxygenation, mitochondrial function, and on muscle fiber type composition (11). It has been suggested that nitrate supplementation may be particularly effective at improving physiological and functional responses in type II (fast-twitch) muscle fibers (25). This could be relevant for short, high-intensity events with greater type II muscle fiber recruitment (26), further explaining the shifted attention in nitrate research towards these activities. Importantly, the suggested blunted performance effect of nitrate in highly trained compared to recreational athletes has only been described for endurance athletes (22), and the effects of nitrate for elite athletes of sprint disciplines remain unknown.

The current study aimed to assess and compare plasma nitrate and nitrite concentrations and repeated-sprint performance following beetroot juice supplementation between recreational, competitive and elite athletes of sprint disciplines. We hypothesized that plasma nitrate and nitrite concentrations would not differ between sport levels, but that only the recreational athletes would improve repeated-sprint performance, showing an increase in power output in all sprints.

\section{Methods}

\section{Subjects}

Out of a total of 53 athletes that participated in this study, 52 completed the entire protocol: 10 elite ( 5 male and 5 female), 22 competitive ( 14 male and 8 female) and 20 recreational ( 10 male and 10 female) athletes (Table 6.1). One male subject from the competitive group dropped out during the trial. We included the Dutch Olympic track cycling sprint selection. They were tested in the preparation phase leading up to the European Championship 2015, where five athletes won a medal and two won a medal at the 2016 Olympics. Due to their competitive level these athletes could be classified as absolute elite sprinters. The second group consisted of regional talent level speed-skaters of sprint distances (mainly $1500 \mathrm{~m}$ ), competing at national level (senior or youth), and were tested off-season in May-June 2016. These speedskaters were cycling the whole off-season and used Wingate tests as main 
performance test in daily practice. Due to their competitive level and test cycling sprint experience these athletes could be classified as competitive sprinters. The final group comprised healthy individuals cycling 1-5 h per week, who were tested in September-November 2016. They had no experience with Wingate testing and were classified as recreational athletes.

After being informed about the purpose and potential risks of the study, all subjects provided written informed consent. The experimental protocol and procedures were approved by the HAN University of Applied Sciences ethical advisory board and the local ethical committee of the Arnhem and Nijmegen region, The Netherlands, and followed the principles of the Declaration of Helsinki (27).

\section{Study design}

In a randomized, double-blinded, placebo-controlled crossover design, subjects underwent two supplementation periods. Over two 6-day periods, they were provided $140 \mathrm{~mL}$ nitrate-rich (BR; $800 \mathrm{mg} / \mathrm{d}$ ) and $140 \mathrm{~mL}$ nitrate-depleted (PLA; $\sim 0.5 \mathrm{mg} / \mathrm{d}$ ) beetroot juice per day, both provided by Beet it, James White Drinks Ltd., Ipswich, UK. Randomization was performed in blocks of 4 within each sport level, and resulted in supplementation order BR-PLA for 26 athletes and PLA-BR for the other 26 athletes. The study included three visits over a 4-week period, consisting of a screening and familiarization session (visit 1) and two experimental test days (visits 2-3). The two experimental test days were performed at the same day of the week and time of day for each individual $( \pm 1 \mathrm{~h})$. The supplementation periods were interspaced by a l-week washout.

\section{Experimental protocol}

Baseline characteristics were obtained, and DEXA scans were performed to determine whole body and regional fat free mass (Table 6.1). DEXA scans were not performed in 8 of the 52 subjects due to time constraints. During visit 1 subjects were familiarized to the triple Wingate test. Firstly, they underwent a 15-17 min warming up at $1.5 \mathrm{~W} \cdot \mathrm{kg}^{-1}$ including two 3 -s sprints. Then, a series of three all-out Wingate tests was performed, interspersed by $4 \mathrm{~min}$ recovery periods. During the recovery periods the subjects kept pedalling against a resistance of $50 \mathrm{~W}$. For each subsequent 30-s Wingate, they were notified at the $15 \mathrm{~s}$ mark followed by a countdown during the final $5 \mathrm{~s}$. All tests were performed on calibrated Lode Excalibur Sport ergometer bikes (Lode, Groningen, Netherlands) with a standstill start, and applying a fixed load of $8.5 \%$ bodyweight $\left(0.83 \mathrm{Nm} \cdot \mathrm{kg}^{-1}\right)(28)$. Load, bike set up and verbal encouragements were kept similar over all test days. Lode Ergometer Manager was used to extract the raw power data measured at $5 \mathrm{~Hz}$. 
Following the familiarization visit, subjects started a 6-day beetroot juice supplementation period during which $140 \mathrm{~mL}$ of either BR or PLA was ingested each day at breakfast. Two $h$ after ingestion of the last supplemental dose (on the 6th supplementation day), subjects arrived at the sports facility for the first test day. Prior to the warm-up, a single blood sample was obtained and a gastrointestinal tolerance questionnaire (29) was administered. Subjects then performed the same warm-up as during the familiarization visit, and the Wingate test was initiated $3 \mathrm{~h}$ after ingestion of the supplement. Heart rate was monitored continuously from the last 7 min of the warm-up until the end of the Wingate tests. The rate of perceived exertion was obtained immediately after individual termination of the triple Wingate test. Subjects were allowed to drink water ad libitum during test days. After a 1week washout, the second supplementation period was started and on day 6 of supplementation, the exact same procedures were followed as during the first test day.

\section{Physical activity and dietary standardization}

Subjects recorded their dietary intake $36 \mathrm{~h}$ prior to the first test day (visit 2). They were subsequently instructed to replicate their dietary intake $36 \mathrm{~h}$ prior to the second test day (visit 3). Subjects were asked to avoid caffeine and alcohol for 12 and $24 \mathrm{~h}$ prior to each test day, respectively. No restrictions were set for the intake of nitrate-rich foods during the intervention period, to allow for the determination of the additional effect of nitrate supplementation on plasma nitrate and nitrite concentrations and performance outcomes on top of the normal diet (4). However, to prevent any attenuation in the reduction of nitrate to nitrite in the oral cavity by commensal bacteria, subjects were asked to refrain from using any antibacterial mouthwash/toothpaste, chewing gum and tongue-scraping during each day of supplementation (30). Supplement logs and training diaries were kept for both intervention periods, to verify compliance and monitor potential period differences.

\section{Plasma analyses}

Blood samples were collected in Lithium-Heparin containing tubes for nitrate and nitrite determination, and centrifuged immediately at $1,000 \mathrm{~g}$ for $5 \mathrm{~min}$, at $20 \pm 1^{\circ} \mathrm{C}$. Aliquots of the plasma were transferred to $2 \mathrm{~mL}$ Eppendorf tubes and immediately frozen with dry ice, $5 \mathrm{~h}$ prior to being stored in a $-80^{\circ} \mathrm{C}$ freezer for subsequent analysis. Plasma nitrate and nitrite concentrations were determined after reduction to NO using the chemiluminescence technique (NOA; Sievers NOA 280;; Analytix, Durham, UK) as described previously (31). 


\section{Statistical analysis}

Power calculations were based on previously reported differences in plasma nitrate responses between moderately and highly trained endurance athletes (22), and a $\sim 4 \%$ improvement of sprint performance in recreational athletes $(13,15)$, with a CV of $\sim 3 \%$ (32). This resulted in an effect size of 2.75 for plasma nitrate and an effect size of 1.33 for peak and mean power. Taking into account a power of $80 \%$, and an alpha level of 0.025 (enabling post-hoc comparisons between recreational and elite athletes), a minimum of 10 athletes should be included per sport level. Although we did not power for potential sex differences within sport levels, we included more athletes in the recreational and competitive groups to provide some insight into potential sex differences. Normality of all data was assessed using KolmogorovSmirnov tests. Peak power was defined as the maximum power achieved over $1 \mathrm{~s}$ (i.e., average of the 5 highest consecutive $0.2 \mathrm{~s}$ values). Mean power was defined as the average power during the entire $30 \mathrm{~s}$ of a Wingate. Time to peak power was defined as the time (closest $0.2 \mathrm{~s}$ ) from start to reach peak power. Baseline characteristics were analysed using univariate ANOVA with 'sex' and 'sport level' as factors. Peak and mean power were analysed using repeated measures ANOVA, with 'Wingate' (first, second and third Wingate) and 'treatment' (BR vs PLA) as within-subjects factors. This approach enabled us to assess a potential generalized effect of BR on peak and mean power, as well as a more specific effect towards the later sprints of the repeated sprint protocol (i.e., 'Wingate $x$ treatment' interaction). 'Sport level' and 'sex' were included as between-subjects factors to assess whether potential treatment effects were different between sport levels or between men and women. Time to peak was analysed non-parametrically. To enable similar analysis as for peak and mean power, difference in time to peak power between BR and PLA was calculated for each participant and each Wingate, and these data were analysed by Wilcoxon signed-rank, Kruskal-Wallis and Friedman tests. Plasma nitrate was also analysed using non-parametric testing (Wilcoxon signed-rank, Kruskal-Wallis and Mann-Whitney U tests). Plasma nitrite, heart rate (mean and maximum per Wingate) and rate of perceived exertion, were analysed using repeated-measures ANOVA, with 'treatment' as within-subjects factor, and 'sex' and 'sport level' as between-subjects factors. Statistical significance was set at $P<0.05$ and any interaction or main effect was subsequently analysed using a Bonferroni post-hoc test in SPSS 22.0 (IBM Corp., Armonk, USA). Data are presented as means \pm SDs, or medians $[I Q R]$ where appropriate. For data on group total, estimated marginal means \pm SEMs are presented, due to the uneven number of athletes per sport level. 


\section{Results}

Subject characteristics are reported in Table 6.1. Independent of sex, lower limb fat free mass (FFM) was higher in elite vs competitive vs recreational athletes (all $P<0.05)$. Independent of sport level, lower limb FFM was higher in male vs female athletes $(P<0.001)$. Supplement logs showed $100 \%$ compliance by all subjects, and training diaries showed no difference in activity between the two periods. 


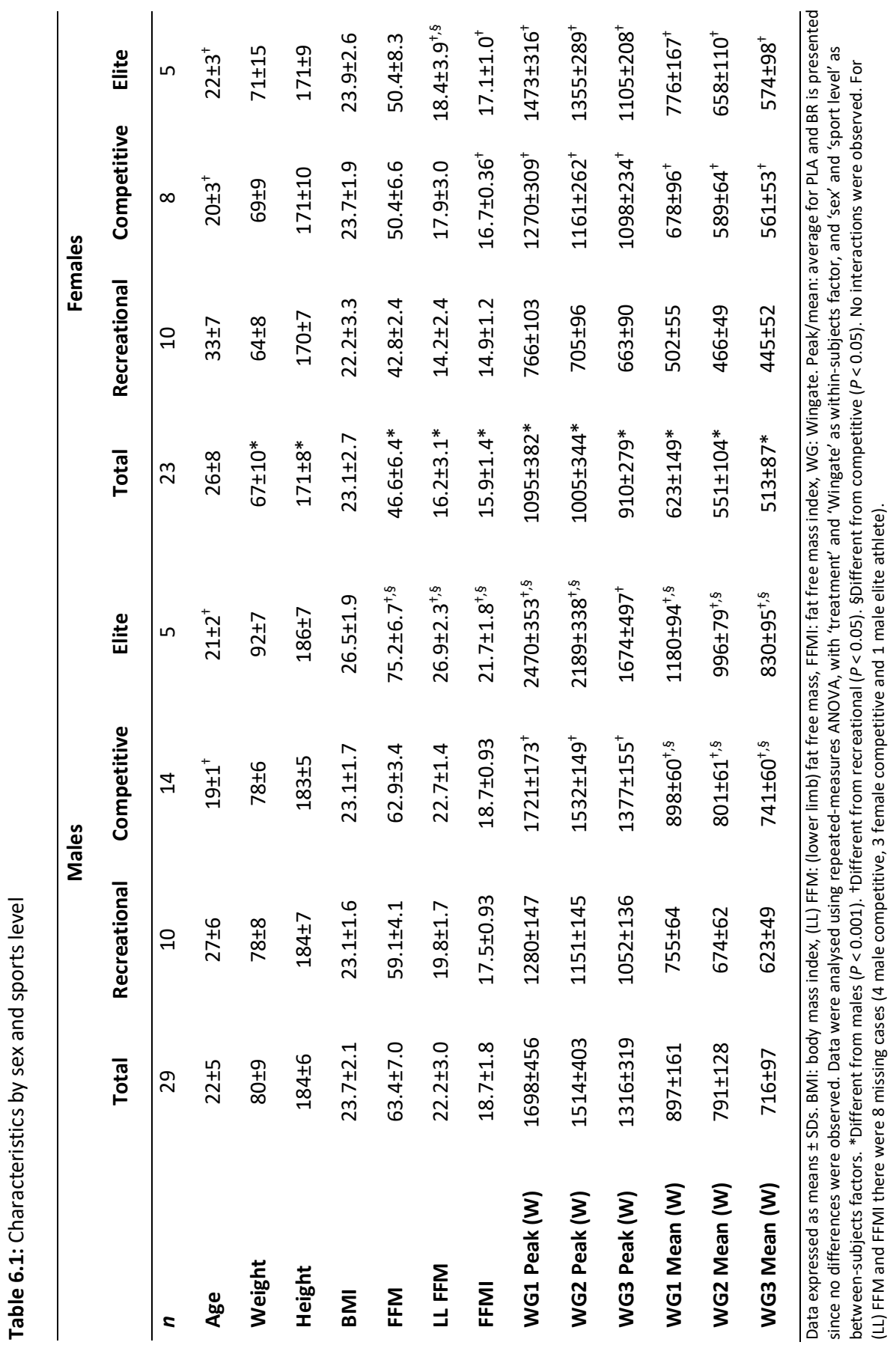




\section{Chapter 6}

\section{Plasma nitrate and nitrite concentrations}

No differences in plasma nitrate concentrations were observed between sport levels following PLA (recreational: 44[28-68], competitive: 42[32-56], elite athletes: $\left.35[26-40] \mu \mathrm{mol} \cdot \mathrm{L}^{-1} ; P=0.33\right)$. For all groups, plasma nitrate concentrations were significantly higher following BR vs PLA ( 16 fold, $P<0.001)$, but this difference was not dependent on sport level (Figure 6.1A; $P=0.13$ ). However, despite similar baseline nitrate concentrations (female: 37[27-50] vs male: $44[32-64] \mu \mathrm{mol} \cdot \mathrm{L}^{-1}$, $P=0.13$ ), the difference in plasma nitrate following BR vs PLA was higher in female vs male athletes (717[557-775] vs 569[495-611] $\left.\mu \mathrm{mol} \cdot \mathrm{L}^{-1}, P=0.007\right)$.

Similarly, plasma nitrite concentrations following PLA were not different between recreational $\left(197 \pm 97 \mathrm{nmol} \cdot \mathrm{L}^{-1}\right)$, competitive $\left(145 \pm 60 \mathrm{nmol} \cdot \mathrm{L}^{-1}\right)$ and elite athletes $\left(105 \pm 35 \mathrm{nmol} \cdot \mathrm{L}^{-1}\right)$. Plasma nitrite was 4 -fold higher following BR vs PLA $(P<0.001$, Figure 6.1B), with no differences between sport levels $(P=0.62)$. In line with plasma nitrate, an effect of sex was observed for plasma nitrite, with post-hoc analyses showing that for all athletes together, plasma nitrite concentrations were higher in female vs male athletes following BR $\left(756 \pm 275\right.$ vs $390 \pm 132 \mathrm{nmol} \cdot \mathrm{L}^{-1}$, $P<0.001)$. Following PLA, this sex difference was only apparent in the recreational athletes (256 \pm 98 vs $\left.137 \pm 51 \mathrm{nmol} \cdot \mathrm{L}^{-1} ; P=0.003\right)$, whereas no differences between females and males were observed in competitive (152 \pm 48 vs $\left.141 \pm 68 \mathrm{nmol} \cdot L^{-1} ; P=0.69\right)$ and elite athletes $\left(103 \pm 43\right.$ vs $\left.107 \pm 31 \mathrm{nmol} \cdot \mathrm{L}^{-1} ; P=0.85\right)$. Furthermore, within the female athletes, plasma nitrite concentrations were similar between all sport levels in both PLA and BR. In contrast, within male athletes, plasma nitrite concentrations were higher in competitive athletes compared with both recreational and elite athletes, which was most pronounced following BR supplementation ( $460 \pm 135$ vs $325 \pm 113$ and $325 \pm 23 \mathrm{nmol} \cdot \mathrm{L}^{-1}$, respectively; $P=0.015$ ). 

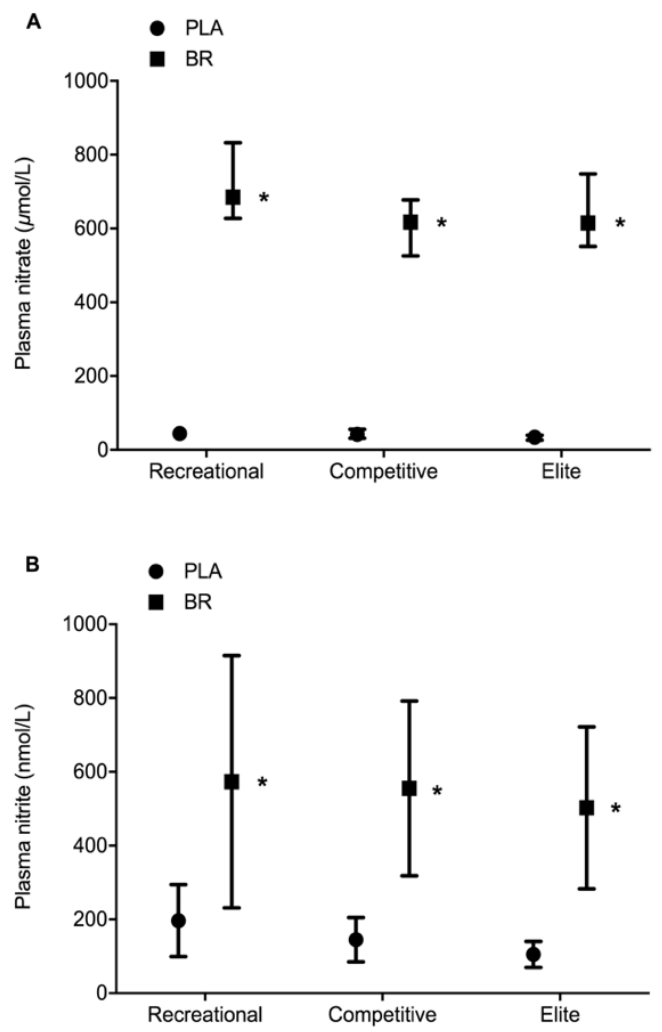

Figure 6.1: Plasma nitrate $(A)$ and nitrite $(B)$ concentrations for recreational $(n=20)$, competitive $(n=22)$ and elite athletes $(n=10)$ following 6 days of placebo (PLA) or beetroot juice (BR). Plasma nitrate was analysed by Wilcoxon signed-rank, Kruskal-Wallis and Mann-Whitney $U$ tests. Values are medians [IORs]. Plasma nitrite was analysed using repeated-measures ANOVA, with 'treatment' as within-subjects factor, and 'sex' and 'sport level' as betweensubjects factors. Values are means \pm SDs. *Significantly different from PLA, $P<0.001$. See text for interaction effects.

\section{Wingate performance}

The peak and mean power per Wingate for male and female athletes of recreational, competitive and elite sport levels are presented in Table 6.1. Both the peak and mean power significantly declined over the three consecutive Wingates $(P<0.001)$. Peak and mean power were higher in male vs female athletes, and higher in elite vs competitive vs recreational athletes $(P<0.001)$. The peak and mean power of Wingate 1 (average for PLA and BR) for male and female athletes are shown as a scatter plot in Figure 6.2A and 6.2B, respectively, to visualize the differences in power between the different sport levels. 

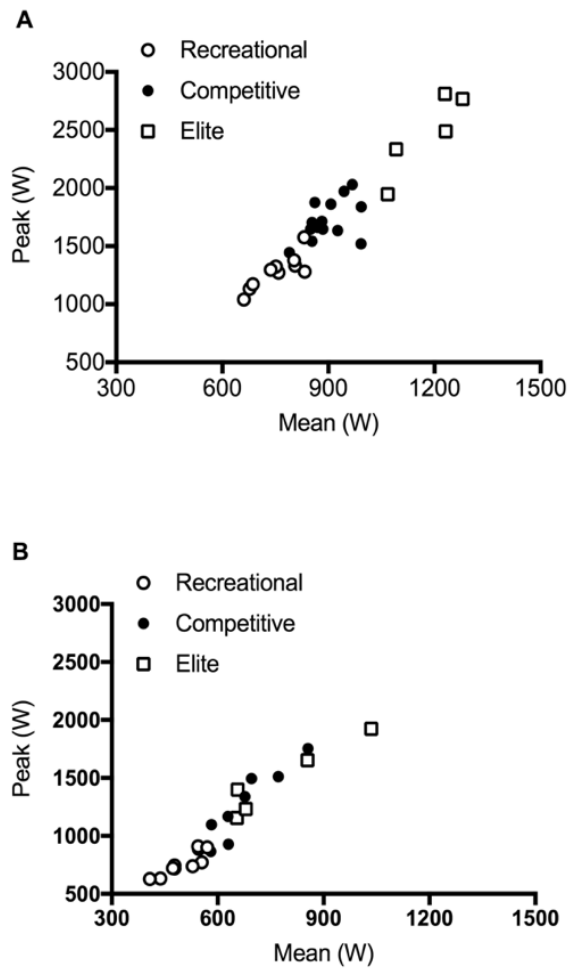

Figure 6.2: Scatter plot for peak and mean power output of the first Wingate for male $(A, n=29)$ and female $(B, n=23)$ athletes. Output represents each individual's average values for PLA and BR. Markers indicate the recreational, competitive, and elite athletes.

No differences were observed between BR and PLA for peak power over the three Wingates ( $1338 \pm 30$ vs $1333 \pm 30 \mathrm{~W} ; P=0.62$, Figure 6.3A), and there was no interaction between treatment (BR vs PLA) and Wingate number (1-2-3; $P=0.48$ ). No effects of sport level $(P=0.70)$ or sex $(P=0.21)$ were observed. Likewise, mean power did not differ between BR and PLA over the three Wingates ( $P=0.86$, Figure 6.3B), and there was no interaction between treatment (BR vs PLA) and Wingate number (1-2-3; $P=0.55)$. No effects of sport level $(P=0.81)$ or sex $(P=0.27)$ were observed. In contrast, time to peak power improved by $\sim 2.8 \%$ following BR vs PLA, with a median difference of $-0.2[-1.0$ to 0.4$] \mathrm{s}(P=0.007$, Figure $6.3 \mathrm{C})$. This effect of BR was not dependent on sport level $(P=0.82)$ or sex $(P=0.39)$, and was not different between the three consecutive Wingates $(P=0.80)$. 

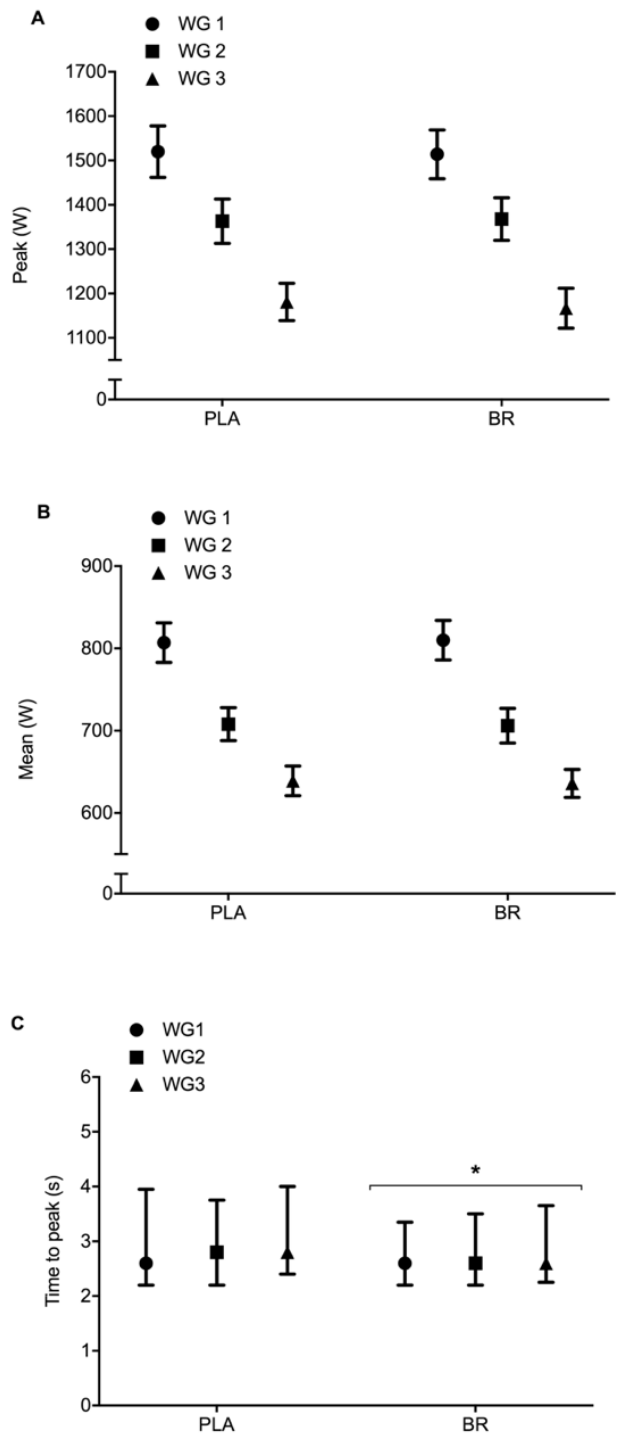

Figure 6.3: Peak power (A), mean power (B) and time to peak power (C) of the three consecutive Wingates for the total group of 52 athletes following 6 days of placebo (PLA) or beetroot juice (BR). Peak and mean power were analysed using repeated-measures ANOVA, with 'treatment' and 'Wingate' as within-subjects factor, and 'sex' and 'sport level' as between-subjects factors. Values are estimated marginal means \pm SEMs. Time to peak was analysed by Wilcoxon signed-rank, Kruskal-Wallis and Friedman tests. Values are medians [IQRs]. *Significantly different from PLA, $P=0.007$. No interactions were observed. 


\section{Chapter 6}

\section{RPE, heart rate, Gl discomfort}

No differences were found for the rate of perceived exertion between BR and PLA (17.4 \pm 1.8 vs $17.7 \pm 1.8, P=0.13$ ). For 41 of the 52 athletes heart rates were successfully recorded for all Wingates. No differences between BR and PLA were observed for the mean or maximum heart rate during the consecutive Wingates ( $P=0.56$ and $P=0.46$, respectively). No serious adverse effects were reported. One male athlete from the competitive group was excluded prior to testing due to an allergic reaction to beetroot juice. Gastrointestinal complaints $2 \mathrm{~h}$ after supplement ingestion on the test day were only reported by 1 athlete following the PLA trial (diarrhoea) and 1 athlete following the BR trial (fullness and headache).

\section{Discussion}

We show that six days of nitrate-rich beetroot juice supplementation substantially increases plasma nitrate and nitrite concentrations, with no differences between recreational, competitive and elite athletes. BR did not affect peak and mean power during repeated Wingate tests. However, time to peak power over the consecutive Wingates was significantly improved by beetroot juice supplementation, independent of sport level.

Given the current discussion whether dietary nitrate may or may not induce similar ergogenic benefits for athletes of different fitness level, we aimed to compare both the plasma and repeated-sprint performance responses to beetroot juice supplementation between recreational, competitive, and elite athletes. The three groups were selected based on their very different level of competition in sprint disciplines, and not on their cycling test performance. The elite comprised Olympic sprinters, the competitive comprised national talent level sprinters and the recreational comprised inexperienced non-competitive athletes. The differences observed in peak power output and lower limb fat free mass (Table 6.1) between the three groups further support this differentiation into recreational, competitive and elite athletes. In the only study that previously compared athletes of low, moderate, and high fitness level, Porcelli, Ramaglia (22) reported slightly higher baseline levels as well as an attenuated increase in plasma nitrate concentrations following dietary nitrate ingestion in the highly trained subjects, but no differences in plasma nitrite concentrations. In contrast, we show no differences in plasma nitrate or nitrite concentrations between recreational, competitive and elite athletes both following PLA and BR supplementation. Notably, in the current study we used the gold-standard methodology for determining plasma nitrate and nitrite concentrations and included a much larger group of athletes when compared with previous work (22). Overall, we report baseline values (i.e., following PLA ingestion) 
as well as substantial increases in plasma nitrate and nitrite concentrations that are in line with recent literature $(3,9,31,33,34)$, and that are independent of athletes' training status. Based on these findings, the proposed unresponsiveness to nitrate supplementation in elite athletes is unlikely due to basal or post-ingestion differences in plasma nitrate and nitrite concentrations between athletes of different training status. On the contrary, we did observe higher plasma nitrate and nitrite concentrations in female vs male athletes, especially following BR supplementation. This is in line with our previous findings in healthy individuals (31). For now it remains unknown what may cause this sex difference and whether it also could translate to functional differences in the response to nitrate supplementation between men and women.

Despite a substantial increase in plasma nitrate and nitrite concentrations for athletes of all sport levels, BR did not affect peak or mean power during the Wingate tests. It has been suggested that nitrate supplementation may be most beneficial during exercise protocols likely to involve high type II muscle fibre recruitment (25), as may be expected during a repeated Wingate sprint test. However, inconsistent findings have been reported on the effects of beetroot juice on sprint performance. An improved peak power of a single Wingate test has been observed in cross-fit athletes (19), while others found no effect on 7x 30-s sprints in recreational athletes (11). In the same study however, mean power of $24 \times 6$-s sprints improved following beetroot juice. Apart from differences in the training background of the participants, it was argued that the specific test used may be of relevance, and that beetroot juice could particularly improve performance of repeated-sprints with short rests, when muscle PCr and force production is not fully recovered (11). In line, other studies using shorter sprints and shorter recovery periods have found ergogenic effects of beetroot juice $(14,35)$. Interestingly, Haider and Folland (21) recently reported an enhanced force production during twitch contractions evoked by supra-maximal nerve stimulation following nitrate supplementation in humans, especially during the rising phase of contraction. Likewise, nitrate supplementation was shown to enhance peak twitch force and early-phase explosive force production but not peak force of high-frequency stimulation in mouse fast-twitch muscle (36). As such, it could be speculated that the faster recruitment of type II muscle fibres following beetroot juice supplementation mainly affects the initial force production during sprint activities. This would be in line with our observation of a faster time to reach peak power following beetroot juice. Such a benefit during the initial phase of contraction would also fit with the observation that nitrate can improve muscle calcium handling (11), as this would likely elicit the greatest impact during the initial phase of contraction where the calcium saturation normally is incomplete. Alternatively, the 


\section{Chapter 6}

improved time to peak power following beetroot juice may also be (partly) explained by an improved reaction time, as was recently reported during repeated sprints in recreational athletes (14).

One of the main findings of the current study is the similar effect of beetroot juice on all Wingate parameters for recreational, competitive and elite athletes. Indeed, the improved time to peak power was not dependent on the training status of the athletes. This finding contradicts the suggested reduced response to nitrate in highly trained compared with less trained athletes (22). However, this study investigated endurance athletes, as opposed to the sprint athletes of the current study. Since elite athletes of sprint disciplines have higher proportions of type II muscle fibres compared to elite endurance athletes (37), we suggest that the sprinters might have a greater response to nitrate supplementation and that even elite athletes of high-intensity and/or sprint disciplines could experience positive effects of beetroot juice supplementation. In line, improved high-intensity short distance performance following beetroot juice supplementation has previously been reported for elite kayak athletes (38). However, more studies in elite athletes of high-intensity or sprint disciplines are needed to establish the ergogenic potential of nitrate supplementation for specific sports, and specify the conditions under which nitrate may be most beneficial.

Clearly there are limitations to the testing of athletes in simulated real-life settings. Due to practical reasons, in the current study athletes from different sport levels were tested during different time periods. Furthermore, detection of small but potentially relevant performance benefits is complicated by the normal day-to-day variations in performance. This was kept to a minimum by using a familiar test setting for the elite and competitive athletes (i.e., Wingate tests on Lode ergometers), as well as including a familiarization trial before the actual test days. Furthermore, by including a relatively large number of subjects, we feel confident that the current findings are representative and truly indicate no effects of BR on peak and mean power during repeated Wingate tests, but an improvement in the time to reach peak power. Obviously, it could be questioned to what extent the improved time to peak power represents an actual performance benefit, as it did not lead to an increase in peak or mean power. Importantly though, for many athletes of high-intensity and sprint disciplines, a faster acceleration can be of great relevance. In sprint disciplines, such as short distance running (100, 200 and $400 \mathrm{~m}$ ), speed-skating (500, 1000 and $1500 \mathrm{~m}$ ), short track speed skating, BMX and track cycling, the ability to produce a great(er) concentric power and to generate high(er) velocity during acceleration is key to success (39). Furthermore, speed and acceleration are essential for high-intensity field sports (40). Potentially, beetroot juice supplementation could result in reaching the top speed faster, which may 
prove relevant to various sports where a quick acceleration is important. For instance, in track cycling a faster acceleration can improve positioning, whereupon fewer meters have to be made. Furthermore, elite BMX riders continuously search for the optimal strategy to improve time to reach peak power (41), as the athlete first at the curve very often is the winner.

\section{Conclusion}

In conclusion, the plasma and repeated-sprint performance responses to beetroot juice supplementation do not differ between recreational, competitive and elite athletes. Beetroot juice reduces the time to reach peak power, which may improve the capacity to accelerate during high-intensity and sprint tasks in recreational as well as elite athletes. 


\section{References}

1. Lundberg JO, Weitzberg E, Gladwin MT. The nitrate-nitrite-nitric oxide pathway in physiology and therapeutics. Nat Rev Drug Discov. 2008;7:156-67.

2. Stamler JS, Meissner G. Physiology of nitric oxide in skeletal muscle. Physiol Rev. 2001;81(1):209-37.

3. Bailey SJ, Winyard P, Vanhatalo A, Blackwell JR, Dimenna FJ, Wilkerson DP, et al. Dietary nitrate supplementation reduces the $\mathrm{O} 2$ cost of low-intensity exercise and enhances tolerance to high-intensity exercise in humans. J Appl Physiol. 2009;107:1144-55.

4. Vanhatalo A, Bailey S, Blackwell J, DiMenna F, Pavey TG, Wilkerson DP, et al. Acute and chronic effects of dietary nitrate supplementation on blood pressure and the physiological responses to moderateintensity and incremental exercise. Am J Physiol Regul Integr Comp Physiol. 2010;299:1121-31.

5. Larsen FJ, Weitzberg E, Lundberg JO, Ekblom B. Effects of dietary nitrate on oxygen cost during exercise. Acta Physiologica. 2007;191(1):59-66.

6. Breese BC, McNarry MA, Marwood S, Blackwell JR, Bailey SJ, Jones AM. Beetroot juice supplementation speeds $\mathrm{O} 2$ uptake kinetics and improves exercise tolerance during severe-intensity exercise initiated from an elevated baseline. Am J Physiol Regul Integr Comp Physiol. 2013;305(12):R1441-R1450.

7. Kelly J, Vanhatalo A, Wilkerson DP, Wylie LJ, Jones AM. Effects of Nitrate on the Power-Duration Relationship for Severe-Intensity Exercise. Med Sci Sports Exerc. 2013;45(9):1798-1806.

8. Cermak NM, Gibala MJ, van Loon LIC. Nitrate Supplementation's Improvement of 10-km Time-Trial Performance in Trained Cyclists. Int J Sport Nutr Exerc Metab. 2012;22(1):64-71.

9. Lansley KE, Winyard PG, Bailey SJ, Vanhatalo A, Wilkerson DP, Blackwell JR, et al. Acute dietary nitrate supplementation improves cycling time trial performance. Med Sci Sports Exerc. 2011;43:1125-31.

10. Robergs RA, Ghiasvand F, Parker D. Biochemistry of exercise-induced metabolic acidosis. Am J Physiol Regul Integr Comp Physiol. 2004;287(3):R502-16.

11. Wylie LJ, Bailey SJ, Kelly J, Blackwell JR, Vanhatalo A, Jones AM. Influence of beetroot juice supplementation on intermittent exercise performance. Eur J Appl Physiol. 2016;116(2):415-25.

12. Callahan MJ, Parr EB, Hawley JA, Burke LM. Single and Combined Effects of Beetroot Crystals and Sodium Bicarbonate on 4-km Cycling Time Trial Performance. Int J Sport Nutr Exerc Metab. 2017;27(3):271-8.

13. Thompson C, Wylie LJ, Fulford J, Kelly J, Black MI, McDonagh STJ, et al. Dietary nitrate improves sprint performance and cognitive function during prolonged intermittent exercise. Eur J Appl Physiol. 2015;115(9):1825-34.

14. Thompson C, Vanhatalo A, Jell H, Fulford J, Carter J, Nyman L, et al. Dietary nitrate supplementation improves sprint and high-intensity intermittent running performance. Nitric Oxide. 2016;61:55-61.

15. Wylie LJ, Mohr M, Krustrup P, Jackman SR, Ermiotadis G, Kelly J, et al. Dietary nitrate supplementation improves team sport-specific intense intermittent exercise performance. Eur J Appl Physiol. 2013;113:1673-84.

16. Muggeridge DJ, Sculthorpe N, James PE, Easton C. The effects of dietary nitrate supplementation on the adaptations to sprint interval training in previously untrained males. J Sci Med Sport. 2016;20(1):92-97.

17. Clifford T, Berntzen B, Davison GW, West DJ, Howatson G, Stevenson EJ. Effects of Beetroot Juice on Recovery of Muscle Function and Performance between Bouts of Repeated Sprint Exercise. Nutrients. 2016;8(8).

18. Martin K, Smee D, Thompson KG, Rattray B. No improvement of repeated-sprint performance with dietary nitrate. Int J Sports Physiol Perform. 2014;9:845-50.

19. Kramer SJ, Baur DA, Spicer MT, Vukovich MD, Ormsbee MJ. The effect of six days of dietary nitrate supplementation on performance in trained CrossFit athletes. J Int Soc Sports Nutr. 2016;13:39.

20. Coggan AR, Leibowitz JL, Kadkhodayan A, Thomas DP, Ramamurthy S, Spearie CA, et al. Effect of acute dietary nitrate intake on maximal knee extensor speed and power in healthy men and women. Nitric Oxide. 2015;48:16-21.

21. Haider G, Folland JP. Nitrate supplementation enhances the contractile properties of human skeletal muscle. Med Sci Sports Exerc. 2014;46(12):2234-43.

22. Porcelli S, Ramaglia M, Bellistri G, Pavei G, Pugliese L, Montorsi M, et al. Aerobic Fitness Affects the Exercise Performance Responses to Nitrate Supplementation. Med Sci Sports Exerc. 2015;47(8):164351.

23. Jonvik KL, Nyakayiru J, van Loon L, Verdijk LB. Can elite athletes benefit from dietary nitrate supplementation? J Appl Physiol (1985). 2015;119(6):759-61. 
24. Nyakayiru J, Jonvik KL, Pinckaers PJ, Senden J, Van Loon LJ, Verdijk LB. No Effect of Acute and 6-Day Nitrate Supplementation on VO2 and Time-Trial Performance in Highly-Trained Cyclists. Int J Sport Nutr Exerc Metab. 2017;27(1):11-17.

25. Bailey SJ, Varnham RL, DiMenna FJ, Breese BC, Wylie LJ, Jones AM. Inorganic nitrate supplementation improves muscle oxygenation, $\mathrm{O}(2)$ uptake kinetics, and exercise tolerance at high but not low pedal rates. J Appl Physiol (1985). 2015;118(11):1396-405.

26. Burke LM. Practical Issues in Evidence-Based Use of Performance Supplements: Supplement Interactions, Repeated Use and Individual Responses. Sports Med. 2017;47(Suppl 1):79-100.

27. World Medical A. World Medical Association Declaration of Helsinki: ethical principles for medical research involving human subjects. JAMA. 2013;310(20):2191-4.

28. Vargas NT, Robergs RA, Klopp DM. Optimal loads for a 30-s maximal power cycle ergometer test using a stationary start. Eur J Appl Physiol. 2014;115(5):1087-94.

29. Trommelen J, Fuchs CJ, Beelen M, Lenaerts K, Jeukendrup AE, Cermak NM, et al. Fructose and Sucrose Intake Increase Exogenous Carbohydrate Oxidation during Exercise. Nutrients. 2017;9(2).

30. Govoni M, Jansson E, Weitzberg E, Lundberg J. The increase in plasma nitrite after a dietary nitrate load is markedly attenuated by an antibacterial mouthwash. Nitric Oxide. 2008;19:333-7.

31. Jonvik KL, Nyakayiru J, Pinckaers PJ, Senden JM, van Loon LJ, Verdijk LB. Nitrate-Rich Vegetables Increase Plasma Nitrate and Nitrite Concentrations and Lower Blood Pressure in Healthy Adults. J Nutr. 2016;146(5):986-93.

32. Jaafar $H$, Rouis $M$, Coudrat L, Attiog be $E$, Vandewalle $H$, Driss $T$. Effects of load on wingate test performances and reliability. J Strength Cond Res. 2014;28(12):3462-8.

33. Wylie LJ, Kelly J, Bailey SJ, Blackwell JR, Skiba PF, Winyard PG, et al. Beetroot juice and exercise: pharmacodynamic and dose-response relationships. J Appl Physiol (1985). 2013;115:325-36.

34. Lansley KE, Winyard P, Fulford J, Vanhatalo A, Bailey S, Blackwell JR, et al. Dietary nitrate supplementation reduces the $\mathrm{O} 2$ cost of walking and running: a placebo-controlled study. J Appl Physiol (1985). 2011;110:591-600.

35. Porcelli S, Pugliese L, Rejc E, Pavei G, Bonato M, Montorsi M, et al. Effects of a Short-Term High-Nitrate Diet on Exercise Performance. Nutrients. 2016;8(9).

36. Hernandez A, Schiffer TA, Ivarsson N, Cheng AJ, Bruton JD, Lundberg JO, et al. Dietary nitrate increases tetanic [Ca2+]i and contractile force in mouse fast-twitch muscle. J Appl Physiol (1985). 2012;590(15):3575-83.

37. Tesch PA, Thorsson A, Kaiser P. Muscle capillary supply and fiber type characteristics in weight and power lifters. J Appl Physiol Respir Environ Exerc Physiol. 1984;56(1):35-8.

38. Peeling P, Cox GR, Bullock N, Burke LM. Beetroot Juice Improves on-Water $500 \mathrm{~m}$ Time-Trial Performance, and Laboratory-Based Paddling Economy in National and International-Level Kayak Athletes. Int J Sport Nutr Exerc Metab. 2014;25(3):278-84.

39. Mero A, Komi PV, Gregor RJ. Biomechanics of sprint running. A review. Sports Med. 1992;13(6):376-92.

40. Lockie RG, Murphy AJ, Knight TJ, Janse de Jonge XA. Factors that differentiate acceleration ability in field sport athletes. J Strength Cond Res. 2011;25(10):2704-14.

41. Rylands LP, Roberts SJ, Hurst HT, Bentley I. Effect of cadence selection on peak power and time of power production in elite BMX riders: A laboratory based study. J Sports Sci. 2017;35(14):1372-6. 



\section{Chapter}

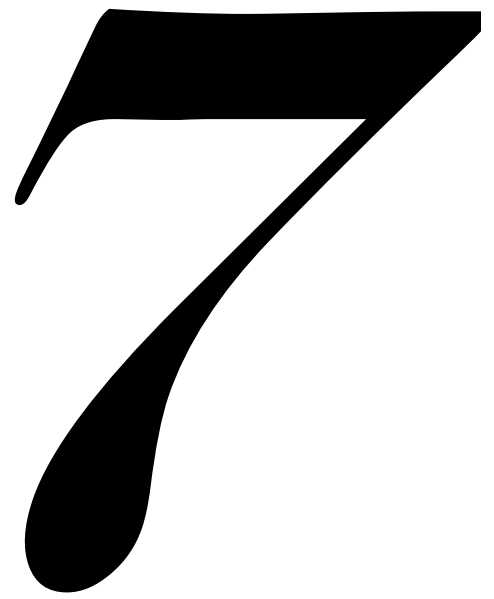

The effect of beetroot juice supplementation on dynamic apnea and intermittent sprint performance in elite female water polo players

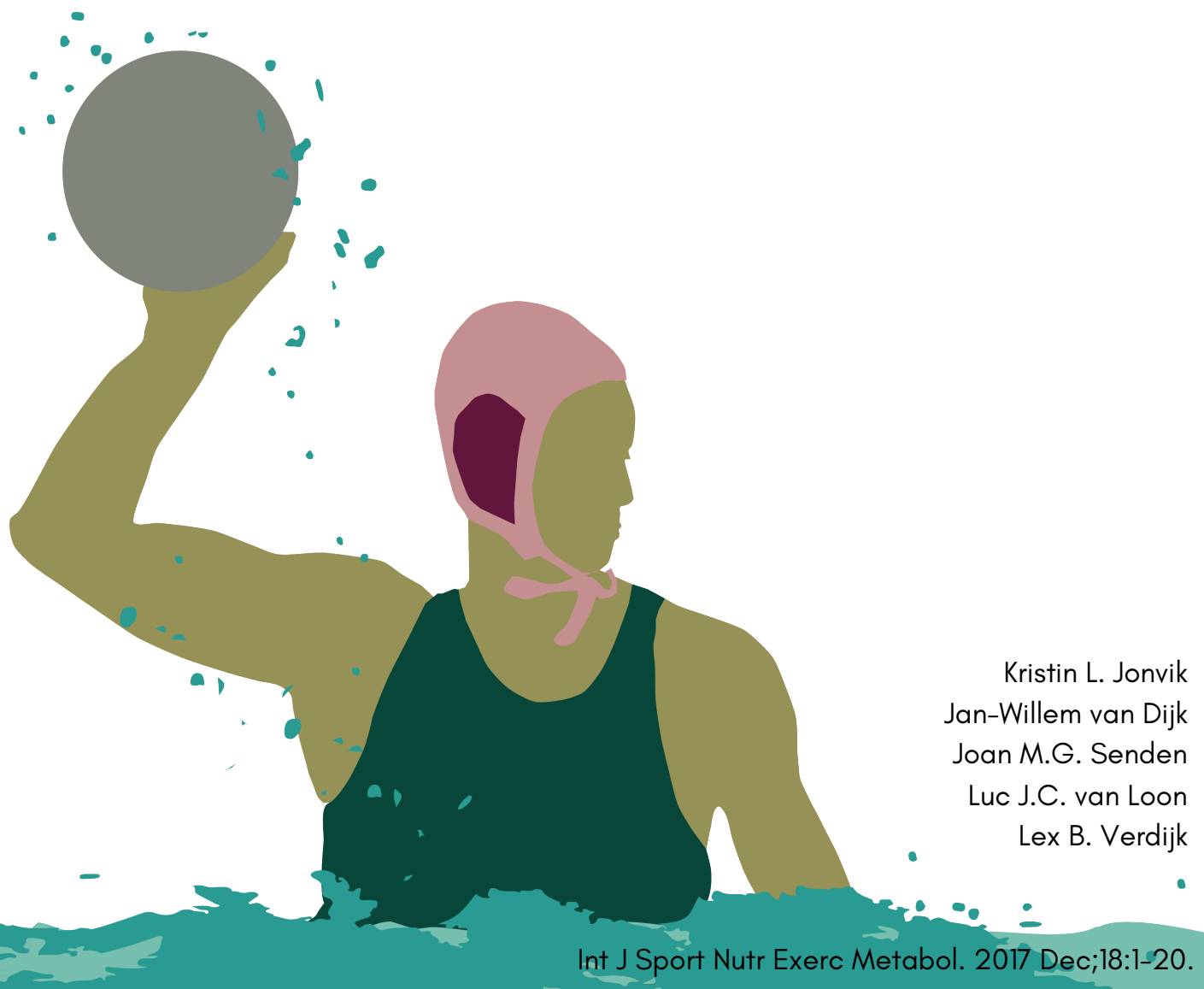




\section{ABSTRACT}

Background: Nitrate-rich beetroot juice is thought to have ergogenic effects, particularly in conditions where oxygen availability is limited. Whether these effects also apply to elite athletes is currently unknown. The aim of this study was to assess the effects of beetroot juice supplementation on dynamic apnea and intermittent sprint performance in elite female water polo players.

Methods: In a double-blind, randomized crossover manner the Dutch National female water polo team $(n=14)$ was subjected to two 6-day supplementation periods (I and II), with either $140 \mathrm{~mL} / \mathrm{d}$ nitrate-rich (BR; $800 \mathrm{mg} / \mathrm{d}$ nitrate) or nitratedepleted (PLA) beetroot juice. Following blood sampling on day six the athletes performed a maximal distance front crawl swimming-test without breathing (dynamic apnea test). In addition, intermittent sprint performance was assessed by performing 16 swim sprints of $15 \mathrm{~m}$, in a $4 \times 4$ block with 30 -s recovery between blocks (intermittent test).

Results: Distance covered during the dynamic apnea test did not differ between $\operatorname{BR}(49.5 \pm 7.8 \mathrm{~m})$ and PLA (46.9 $\pm 9.1 \mathrm{~m}, P=0.178)$. However, when correcting for testorder, distance covered was significantly larger in BR vs PLA when BR was ingested in period II (50.1 \pm 8.5 vs $42.8 \pm 5.7 \mathrm{~m} ; P=0.002)$ whereas no difference was observed when $B R$ was ingested in period I $(48.8 \pm 7.4$ vs $52.3 \pm 10.4 \mathrm{~m} ; P=0.10)$. The time to complete the intermittent test was not different between BR and PLA (316.0 \pm 7.9 vs $316.3 \pm 6.9 \mathrm{~s}, P=0.73)$.

Conclusion: Beetroot juice supplementation does not improve intermittent performance in elite female water polo players, but there may be a potential for ergogenic effects during dynamic apnea. 


\section{Introduction}

Over the past decade, the use of dietary nitrate to enhance performance has received increased attention, with possible ergogenic effects being caused by the reduction of dietary nitrate into nitrite and nitric oxide (NO) (1). NO plays a key role in skeletal muscle function, e.g. by regulating blood flow and muscle contractility (2). Hypoxic conditions with low oxygen availability and low $\mathrm{pH}$ environment can stimulate the nitrate-nitrite-NO pathway (3).

Several studies have found ergogenic effects of nitrate supplementation when exercising under hypoxic conditions. This could be 'local' tissue hypoxia such as during anaerobic, high-intensity intermittent exercise (4-6), or 'systemic' normobaric/hypobaric hypoxia $(7,8)$. Although 'systemic hypoxia' has also been used with respect to maximal under-water exercise (9), the term 'dynamic apnea' more appropriately reflects the different physiological characteristics associated with these breath-hold activities. Interestingly, recent work suggests that dietary nitrate may also prove beneficial under conditions of dynamic apnea (10).

Water polo represents a high-intensity intermittent-type sport performed in and under water. Similar to the intermittent-type activity in soccer players (11), recruitment of type II muscle fibers is likely of key importance for water polo. Considering their relatively low oxygen tension, nitrate supplementation may be particularly effective in these type II muscle fibers (12). Additionally, the sequence of short periods of under-water (breath-hold) activities in water polo could represent a condition in which dietary nitrate may prove beneficial (10). Furthermore, although it has been postulated that the ergogenic properties of nitrate may be reduced in well-trained endurance athletes vs untrained individuals (13), the effect of nitrate supplementation has not been investigated in elite teamsport athletes. Therefore, the aim of the current study was to assess the effects of dietary nitrate supplementation on dynamic apnea and intermittent-type sprint performance in elite female water polo players.

\section{Methods}

\section{Subjects}

We recruited the female Dutch National water polo selection $(n=18)$, whereof two athletes could not participate due to injuries. Out of 16 athletes, one was excluded due to illness, and one due to lack of compliance with study protocol; 14 athletes completed the study (Table 7.1). The team was in preparation for the 2016 Olympic Games qualification, three months after winning World Championship silver, training $7 \pm 1$ sessions $(\sim 12 \mathrm{~h})$ per week. All athletes provided written informed consent 
to participate in the study that was approved by the local ethical committee $\mathrm{CMO}$, Arnhem and Nijmegen, The Netherlands and was conducted in accordance with the Declaration of Helsinki (2013).

Table 7.1: Participants' characteristics ${ }^{1}$

\begin{tabular}{ll}
\hline$n$ & 14 \\
Age, $\mathrm{y}$ & $22 \pm 4$ \\
Height, $\mathrm{cm}$ & $178 \pm 5$ \\
Weight, $\mathrm{kg}$ & $74 \pm 9$ \\
$\mathrm{BMl}, \mathrm{kg} / \mathrm{m}^{2}$ & $23 \pm 2$ \\
\hline IValues are means \pm SDs &
\end{tabular}

Study design

In a randomized, double-blinded crossover design, subjects underwent two 6-d supplementation periods (I and II), with either $140 \mathrm{~mL} / \mathrm{d}$ nitrate-rich (BR; 800 mg/d nitrate) or nitrate-depleted (PLA; placebo) beetroot juice (Beet It, James White Drinks Ltd., Ipswich, UK). Over a 4-week period, subjects underwent a screening and familiarization session (visit 1 ) and two experimental test days identical to visit 1 , except for the 6-d supplementation periods (test days I and II). Intervention periods were interspaced by a l-week washout. The exercise tests were performed at the same time of day $( \pm 10 \mathrm{~min})$.

\section{Experimental protocol}

The athletes had practiced both the dynamic apnea and the intermittent test several times in training settings. On visit 1 , they performed a standardized familiarization of both exercise tests. Testing was performed in a $25 \times 30 \mathrm{~m}$ swimming pool at $28^{\circ} \mathrm{C}$. The dynamic apnea test was adapted from apnea diving, which includes maximal distance swimming in shallow water (9). To create a setting more relevant to water polo, continuous front-crawl swimming was performed with the head kept under water, until exhaustion. Hyperventilation preceding the test was not allowed as this can affect performance and is difficult to standardize (10). The test was performed individually and the pace, floating distance, start and turning technique were standardized. The main outcome was the completed distance when the athlete came to the surface to breath, measured to the closest $0.5 \mathrm{~m}$ using video recording. Secondary outcomes were apnea time and speed. The intermittent test consisted of $4 \times 4$ 15-m swim sprints in the middle of the pool, interspersed with $5 \mathrm{~s}$ active rest (arms stretched above the head) between each sprint and $30 \mathrm{~s}$ semi-active rest (wrists above water) between each block of 4 sprints. This time-trial is adapted from water polo-specific performance tests previously validated in elite female water polo players (14), and was frequently used 
as performance test during regular training sessions. The intermittent test was performed in heats of 5-6 athletes, using the same heats and starting lanes during both test days. Each athlete had an individual supervisor clocking her in and out of the rest periods, and providing her a 'go' signal by lowering the arm.

Supplements were ingested for five days at home and the sixth dose was provided on the test day at the sports facility. Subjects underwent baseline and 2.5-h post-ingestion measurements of plasma, saliva and $\mathrm{Gl}$ tolerance questionnaires. Plasma and saliva were collected and analyzed for nitrate and nitrite using chemiluminescence (Sievers NOA 280i; Analytix) as previously described (15). Following a standardized warm-up protocol, the dynamic apnea test started $3 \mathrm{~h}$ post-ingestion. Each athlete had 30-35 min rest between the dynamic apnea and the intermittent test. The rate of perceived exertion (RPE) was obtained twice; immediately after termination of both exercise tests.

\section{Physical activity and dietary standardization}

Subjects were instructed to: record their dietary intake $30 \mathrm{~h}$ prior to test day l, and replicate their intake prior to test day II which was checked by a dietitian; avoid caffeine and alcohol for 12 and $24 \mathrm{~h}$ prior to each test day, respectively; refrain from using any antibacterial mouthwash/toothpaste and tongue-scraping during each supplementation day (16). Supplement logs and training diaries were kept for both intervention periods.

\section{Statistical analysis}

Dynamic apnea and intermittent test results, and plasma and salivary nitrate and nitrite concentrations were analyzed using paired samples t-tests or one-way repeated measures ANOVA where appropriate, with treatment (BR vs PLA) as within-subjects factor. After these pre-planned initial analyses, test-order was added as a between-subjects factor (in view of a potential period effect). In case of a significant treatment $x$ test-order interaction, separate paired t-tests were performed. Statistical significance was set at $P<0.05$. All data were analyzed using SPSS 22.0 (IBM Corp., Armonk, NY), and are presented as means=SD.

\section{Results}

\section{Plasma and saliva}

Baseline plasma nitrate concentrations on the test day were significantly higher following five days of BR vs PLA ( $127 \pm 98$ vs $56 \pm 22 \mu \mathrm{mol} / L ; P=0.016$; Figure 7.1A), and further increased at 2.5-h post-ingestion for BR on the test day $(751 \pm 118 \mu \mathrm{mol} / \mathrm{L})$, 
remaining significantly higher than PLA ( $P<0.001$; Figure 7.1A). In line, plasma nitrite concentrations for BR increased from baseline to 2.5 -h post-ingestion ( $227 \pm 246 \mathrm{vs}$ $516 \pm 268 \mathrm{nmol} / \mathrm{L} ; \quad P<0.001$ vs PLA; Figure 7.1B). Salivary nitrate and nitrite concentrations were significantly higher following five days of BR vs PLA (1078 \pm 1202 vs $260 \pm 241 \mu \mathrm{mol} / \mathrm{L}$, and $746 \pm 1221$ vs $286 \pm 148 \mu \mathrm{mol} / \mathrm{L}$, respectively) and further increased at 2.5-h post-ingestion for BR $(13795 \pm 5365$ and $3852 \pm 2541 \mu \mathrm{mol} / \mathrm{L}$, respectively, all $P<0.001)$.
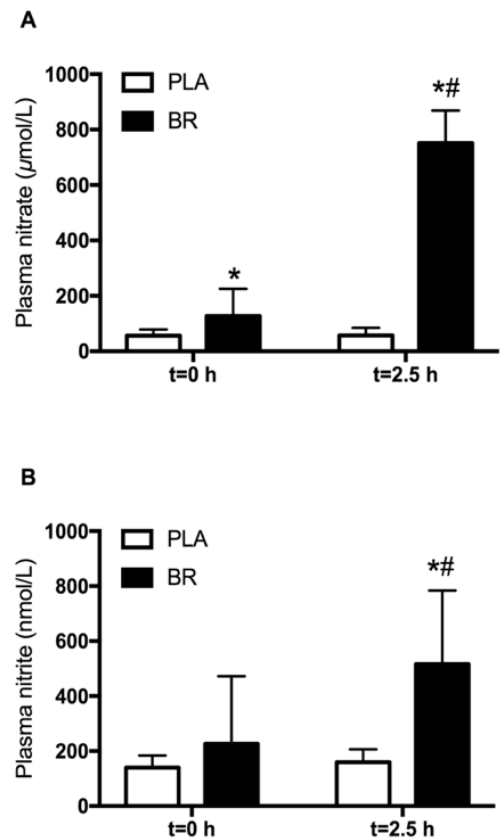

Figure 7.1: Plasma nitrate $(A)$ and nitrite $(B)$ concentrations at baseline $(0 \mathrm{~h})$ and 2.5-h post-ingestion on the test day $(n=14)$. PLA: placebo, BR: beetroot juice, t: time point in hours. Values are means \pm SDs. *Significantly different from PLA, \#significantly different from BR baseline $\mathrm{P}<0.001$.

\section{Performance}

With the pre-planned primary analyses, distance covered during the dynamic apnea test did not significantly differ between BR and PLA (49.5 \pm 7.8 vs $46.9 \pm 9.1 \mathrm{~m}, P=0.18$, Figure 7.2A). However, when test-order was added as a between-subjects factor, a significant treatment $x$ test-order interaction was observed $(P=0.001)$. Separate analyses showed no difference in the distance covered between BR and PLA (and no difference between test I and II) when BR was ingested in period I (48.8 \pm 7.4 vs 
$52.3 \pm 10.4 \mathrm{~m}$, respectively, $P=0.10$, Figure 7.2B). In contrast, distance covered was significantly larger in BR vs PLA (and thus in test II vs I) when BR was ingested in period II (50.1 \pm 8.5 vs $42.8 \pm 5.7 \mathrm{~m}$, respectively, $P=0.002$, Figure $7.2 \mathrm{C})$. Likewise, time-to-exhaustion during dynamic apnea did not differ between BR and PLA (30.6 \pm 6.3 vs $28.1 \pm 5.9 \mathrm{~s}, P=0.14)$, but a significant treatment $\mathrm{x}$ test-order interaction was observed $(P=0.01)$. Separate analyses revealed no difference when BR was ingested in period I $(P=0.14)$, but an increased time-to-exhaustion when BR was ingested in period II ( $P=0.023)$. The average swim speed was not different between BR and PLA $(1.63 \pm 0.11$ vs $1.67 \pm 0.069 \mathrm{~m} / \mathrm{s}, P=0.28)$, and no treatment $\mathrm{x}$ test-order interaction was observed $(P=0.40)$.

A

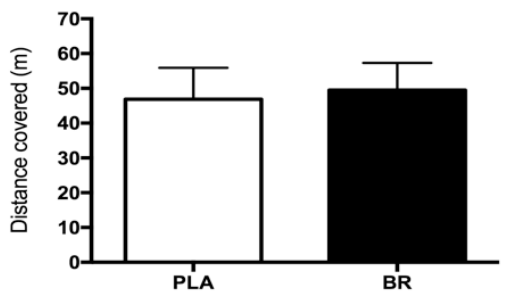

B

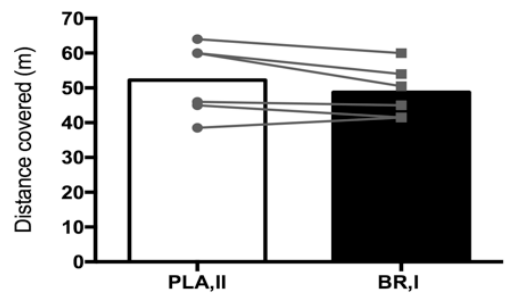

C

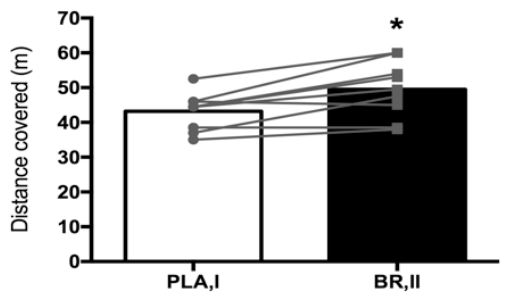

Figure 7.2: Dynamic apnea test performance for the total group $(A ; n=14)$, and separated by test order; BRPLA $(B ; n=6)$ and PLA-BR ( $C ; n=8)$. PLA: placebo, BR: beetroot juice. I: test I, II: test II. Values are means $\pm S D$. B: *Significantly different from PLA, $\mathrm{P}=0.002$. 


\section{Chapter 7}

Time to complete the intermittent test was not different between BR and PLA $(316.0 \pm 7.9 \mathrm{~s}$ vs $316.3 \pm 6.9 \mathrm{~s}, P=0.73$, Figure 7.3). Time to complete separate blocks $(4 \times 15 \mathrm{~m})$ also did not differ between BR and PLA (data not shown). Adding testorder as a between-subjects factor did not alter these findings. However, a small improvement (independent of test-order) was observed from test-day I to test-day II $(-1.3 \pm 2.1 \mathrm{~s}, P=0.034)$.

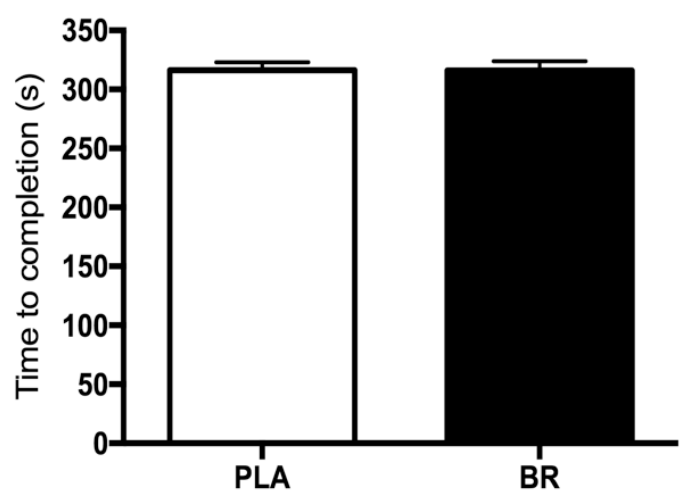

Figure 7.3: Intermittent test performance for the total group $(n=14)$. Values are means \pm SD.

\section{Secondary parameters}

No serious adverse effects were reported. Four athletes (two following BR and two following PLA) reported mild GI complaints (belching, bloating or windiness) 2.5-h post-ingestion. RPE was not different between BR and PLA for the dynamic apnea $(15.3 \pm 2.1$ vs $16.1 \pm 2.0, P=0.16)$ or the intermittent test $(19.1 \pm 0.9$ vs $18.9 \pm 1.1, P=0.58)$, with no interaction of test-order (both $P>0.70)$. However, the fatigue scores of training were $28 \pm 19 \%$ higher in period I than period II ( $P<0.0001)$.

\section{Discussion}

Six days of beetroot juice supplementation substantially increased plasma and salivary nitrate and nitrite concentrations, but did not improve intermittent sprint performance in elite female water polo players. Overall, no difference in dynamic apnea performance could be detected between BR and PLA. However, a significant interaction with test-order showed that a performance benefit was attained when BR was ingested during period II.

We specifically aimed to assess the effects of dietary nitrate supplementation in elite athletes. Baseline values and increases in plasma nitrate 
and nitrite concentrations of our elite athletes were comparable to those observed in female recreational and well-trained athletes $(17,18)$. This argues against the proposed attenuated plasma response in elite vs recreational athletes (13). Previous studies reported benefits of nitrate for intermittent team-sport performance in recreational $(4,6)$ and trained athletes (5). Despite effective increases in plasma nitrate/nitrite however, we observed no beneficial effects on intermittent sprint performance in the water. Although high-intensity exercise may lower plasma nitrite concentrations (19), it seems unlikely that the $30 \mathrm{~s}$ apnea test would render the remaining BR-derived nitrite insufficient to also affect intermittent performance. Furthermore, distance covered in the dynamic apnea test was similar for BR vs PLA. This suggests that nitrate does not improve exercise performance in elite water polo players, in line with most studies in elite athletes of high-intensity sports (20-22). Advanced physiological adaptations through extensive training, such as higher muscular capillarization and optimized oxygen transport, may render nitrate supplementation less effective in elite athletes (3). Moreover, since by definition there are not many elite athletes, and there are likely only small benefits to be attained, it is difficult to establish potential ergogenic effects. On the other hand, by recruiting a homogenous group of Olympic level athletes, and testing them in a sport-specific environment, we minimized day-to-day variations and optimized the power for the small sample size. This particularly applies to the intermittent sprinttest, as it was adapted from a previously validated test (14), subjects were highly familiarized, and it closely resembles physical performance during water polo. Since absolutely no effect of BR was observed for intermittent performance, nitrate does not seem to be ergogenic for elite water polo players. However, despite great test-familiarization, a significant improvement was observed from the first to the second test day, independent of BR supplementation. Though we aimed to set up two identical test periods, standardizing training programs between test periods is challenging in elite athletes (23). Higher fatigue scores of training were reported in period l, which likely caused the 'improvement' in intermittent performance.

The differences in training intensity/fatigue also appeared to have an effect on dynamic apnea performance. For this test however, there was an interaction of this 'period effect' with the effect of BR supplementation. Separate analyses showed a significant improvement in distance covered when BR was ingested during period II, whereas no difference in distance covered was found when BR was administered during period I. As such, the effect of BR was likely confounded by training periodization. In contrast to the lack of ergogenic effects for intermittent performance, our findings suggest minor ergogenic effects of BR for front crawl swimming without breathing. This is further supported when using the alternative analytical approach of magnitude-based inferences, which has been 
suggested to be of added value in (small scale) exercise performance studies (24). Using this approach, here was a 'possibly small increase' $(6.2 \%$ [90\% Cl: -0.5 to $13.3 \%]$ ) in dynamic apnea performance in BR vs PLA, which even turned into a 'likely small increase' when including treatment order as a covariate. For the intermittent test, there was a 'very) likely trivial effect' of BR vs PLA, thus supporting a potential benefit of BR only for the dynamic apnea test.

Exhaustion testing like the dynamic apnea test is much more sensitive to changes than sport-specific performance testing like the intermittent test (25). Furthermore, despite rehearsal and standardization, subjects were less 'trained' in performing dynamic apnea exercise, which may have further increased the window of opportunity to detect beneficial effects of BR. Previously, Patrician and Schagatay (10) found improved arterial oxygen saturation following beetroot juice supplementation for sub-maximal $75 \mathrm{~m}$ underwater swimming. They suggested that total distance would likely be increased during a maximal attempt, due to increased remaining oxygen stores. This is in line with our observation of increased distance covered during the dynamic apnea test. The test was adapted from maximal distance swimming in shallow water in apnea divers (9), using front crawl highintensity swimming to increase the relevance to water polo. However, the dynamic apnea test simulates an extreme breath-hold situation of much longer duration than the intermittent underwater phases of a water polo game, and can therefore not be considered a water polo-specific test. It has been suggested that nitrate supplementation could be applied to sports with limited oxygen availability such as underwater rugby and hockey (10), in which longer under-water phases are prevalent. Clearly though, we can only speculate whether an improved maximal distance of the dynamic apnea test could also translate to actual performance enhancement for water polo. Since there was absolutely no improvement of the intermittent water polo-specific performance test, a substantial performance enhancement of nitrate supplementation in elite water polo players is unlikely. Yet, it is obvious that even minor benefits could be very relevant in highly trained individuals, and future work should further examine which specific athlete populations may or may not benefit from nitrate supplementation.

\section{Conclusion}

Six days of beetroot juice supplementation does not improve intermittent sprint performance in elite female water polo players, but there may be a potential for beneficial effects during dynamic apnea. 


\section{References}

1. Lundberg JO, Weitzberg E, Gladwin MT. The nitrate-nitrite-nitric oxide pathway in physiology and therapeutics. Nat Rev Drug Discov. 2008;7:156-67.

2. Stamler JS, Meissner G. Physiology of nitric oxide in skeletal muscle. Physiol Rev. 2001;81(1):209-37.

3. Jones A. Dietary Nitrate Supplementation and Exercise Performance. Sports Med. 2014;44:35-45.

4. Wylie L, Mohr M, Krustrup P, Jackman SR, Ermiotadis G, Kelly J, et al. Dietary nitrate supplementation improves team sport-specific intense intermittent exercise performance. Eur J Appl Physiol. 2013;113:1673-84.

5. Nyakayiru J, Jonvik KL, Trommelen J, Pinckaers PJ, Senden JM, van Loon LJ, et al. Beetroot Juice Supplementation Improves High-Intensity Intermittent Type Exercise Performance in Trained Soccer Players. Nutrients. 2017;9(3).

6. Thompson C, Vanhatalo A, Jell H, Fulford J, Carter J, Nyman L, et al. Dietary nitrate supplementation improves sprint and high-intensity intermittent running performance. Nitric Oxide. 2016;61:55-61.

7. Carriker CR, Mermier CM, Van Dusseldorp TA, Johnson KE, Beltz NM, Vaughan RA, et al. Effect of Acute Dietary Nitrate Consumption on Oxygen Consumption During Submaximal Exercise in Hypobaric Hypoxia. Int J Sport Nutr Exerc Metab. 2016;26(4):315-22.

8. Vanhatalo A, Bailey S, Blackwell J, DiMenna F, Pavey TG, Wilkerson DP, et al. Acute and chronic effects of dietary nitrate supplementation on blood pressure and the physiological responses to moderateintensity and incremental exercise. Am J Physiol Regul Integr Comp Physiol. 2010;299:1121-31.

9. Schagatay E. Predicting performance in competitive apnea diving, part II: dynamic apnoea. Diving Hyperb Med. 2010;40(1):11-22.

10. Patrician A, Schagatay E. Dietary nitrate enhances arterial oxygen saturation after dynamic apnea. Scand J Med Sci Sports. 2017;27(6), 622-26.

11. Krustrup P, Mohr M, Steensberg A, Bencke J, Kjaer M, Bangsbo J. Muscle and blood metabolites during a soccer game: implications for sprint performance. Med Sci Sports Exerc. 2006;38(6):1165-74.

12. Bailey SJ, Varnham RL, DiMenna FJ, Breese BC, Wylie LJ, Jones AM. Inorganic nitrate supplementation improves muscle oxygenation, $\mathrm{O}(2)$ uptake kinetics, and exercise tolerance at high but not low pedal rates. J Appl Physiol (1985). 2015;118(11):1396-405.

13. Porcelli S, Ramaglia M, Bellistri G, Pavei G, Pugliese L, Montorsi M, et al. Aerobic Fitness Affects the Exercise Performance Responses to Nitrate Supplementation. Med Sci Sports Exerc. 2015;47(8), 16431651.

14. Tan FH, Polglaze T, Dawson B. Comparison of progressive maximal swimming tests in elite female water polo players. Int J Sports Physiol Perform. 2009;4(2):206-17.

15. Jonvik KL, Nyakayiru J, Pinckaers PJ, Senden JM, van Loon LJ, Verdijk LB. Nitrate-Rich Vegetables Increase Plasma Nitrate and Nitrite Concentrations and Lower Blood Pressure in Healthy Adults. J Nutr. 2016;146(5), 986-93.

16. Govoni M, Jansson E, Weitzberg E, Lundberg J. The increase in plasma nitrite after a dietary nitrate load is markedly attenuated by an antibacterial mouthwash. Nitric Oxide. 2008;19:333-7.

17. Glaister M, Pattison JR, Muniz-Pumares D, Patterson SD, Foley P. Effects of dietary nitrate, caffeine, and their combination on 20-km cycling time trial performance. J Strength Cond Res. 2015;29(1):165-74.

18. Buck CL, Henry T, Guelfi K, Dawson B, McNaughton LR, Wallman K. Effects of sodium phosphate and beetroot juice supplementation on repeated-sprint ability in females. Eur J Appl Physiol. 2015;115(10):2205-13.

19. Bescos R, Rodriguez FA, Iglesias X, Ferrer MD, Iborra E, Pons A. Acute administration of inorganic nitrate reduces VO(2peak) in endurance athletes. Med Sci Sports Exerc. 2011;43:1979-86.

20. Sandbakk SB, Sandbakk O, Peacock O, James P, Welde B, Stokes K, et al. Effects of acute supplementation of $\mathrm{L}$-arginine and nitrate on endurance and sprint performance in elite athletes. Nitric Oxide. 2015;48:10-5.

21. Boorsma RK, Whitfield J, Spriet LL. Beetroot Juice Supplementation Does Not Improve Performance in Elite 1500-m Runners. Med Sci Sports Exerc. 2014;46(12), 2326-34.

22. Peacock $O$, Tjonna $A E$, James $P$, Wisloff $U$, Welde $B$, Bohlke $N$, et al. Dietary nitrate does not enhance running performance in elite cross-country skiers. Med Sci Sports Exerc. 2012;44:2213-9.

23. Tanner RK, Gore, C.J. Physiological Tests for Elite Athletes. 2nd ed. Human Kinetics: Australian Institute of Sports; 2013. 
Chapter 7

24. Batterham AM, Hopkins WG. Making meaningful inferences about magnitudes. Int J Sports Physiol Perform. 2006;1(1):50-7.

25. Hopkins WG, Hawley JA, Burke LM. Design and analysis of research on sport performance enhancement. Med Sci Sports Exerc. 1999;31(3):472-85. 


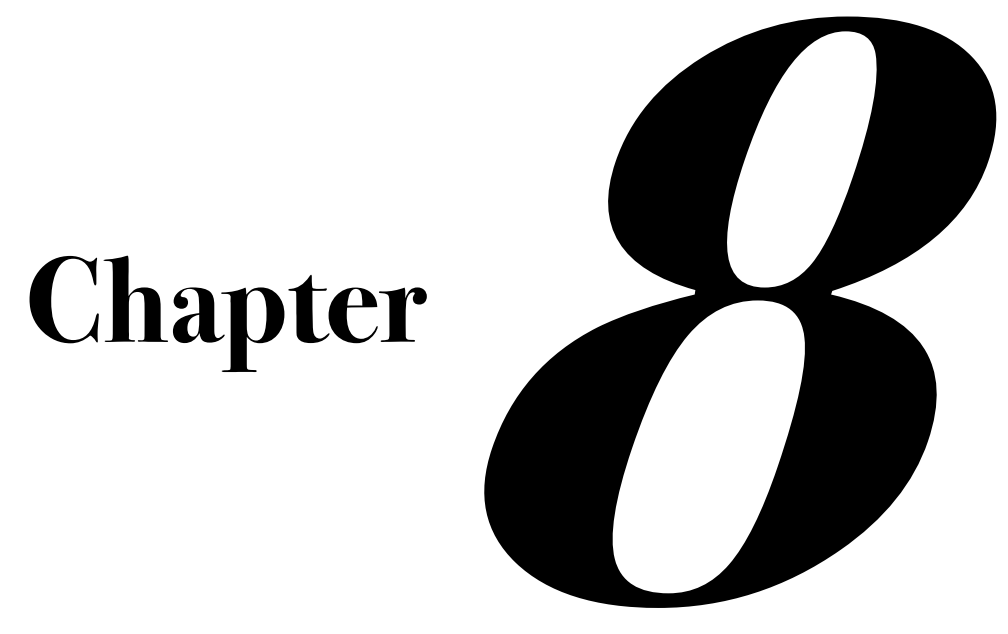

Sucrose but not nitrate ingestion reduces high-intensity exerciseinduced gut injury

Kristin L. Jonvik

Kaatje Lenaerts Joey S.J. Smeets Jeroen J. Kolkman Luc J.C. van Loon Lex B. Verdijk

Submitted. 


\section{ABSTRACT}

Background: During high-intensity exercise many athletes suffer from gastrointestinal (GI) complaints, which are likely related to splanchnic hypoperfusion, resulting in intestinal injury. Increasing circulating nitric oxide (NO) levels or inducing postprandial hyperemia may improve splanchnic perfusion, thereby attenuating intestinal injury during exercise. Therefore, we investigated the effects of both dietary nitrate ingestion and sucrose ingestion on splanchnic perfusion and intestinal injury induced by high-intensity exercise.

Methods: In a randomized cross-over manner, 16 well-trained male athletes (age: $28 \pm 7$ y; $\left.W_{\max }: 5.0 \pm 0.3 \mathrm{~W} \cdot \mathrm{kg}^{-1}\right)$ cycled $60 \mathrm{~min}$ at $70 \% \mathrm{~W}_{\max }$ following acute ingestion of: sodium nitrate (NIT; $800 \mathrm{mg} \mathrm{NO} 3$ ), sucrose (SUC; $40 \mathrm{~g}$ ) or a water placebo (PLA). Splanchnic perfusion was assessed by determining the gap between gastric and arterial $\mathrm{pCO}_{2}\left(\right.$ gap $_{\mathrm{g}-\mathrm{a}} \mathrm{pCO}_{2}$ ) using gastric air tonometry. Plasma intestinal fatty-acid binding protein (I-FABP) concentrations, reflecting enterocyte damage, were assessed every $20 \mathrm{~min}$ during and up to $60 \mathrm{~min}$ of post-exercise recovery.

Results: The exercise protocol resulted in splanchnic hypoperfusion, as gapg${ }_{a} \mathrm{pCO}_{2}$ levels increased during exercise $(P<0.001)$, with no differences between treatments $(P=0.47)$. Although plasma I-FABP concentrations increased during exercise and post-exercise recovery for all treatments $(P<0.0001)$, the increase was different between treatments $(P<0.0001)$. Post-hoc comparisons showed an attenuated increase in I-FABP in SUC vs PLA ( $P=0.020)$. In accordance, I-FABP area under the curve (AUC) was significantly lower in SUC vs PLA $(4,622 \pm 6,291 \%$ vs $10,099 \pm 6,783 \%, P=0.004)$. No differences were observed between NIT and PLA $(P=0.78)$.

Conclusion: Sucrose but not nitrate ingestion lowers gut injury evoked during highintensity exercise. These results suggest that sucrose ingestion, but not nitrate, prevents hypoperfusion-induced $G$ l damage during exercise and, as such, may help to lower exercise-related $\mathrm{Gl}$ complaints. 


\section{Introduction}

The gastrointestinal $(\mathrm{Gl})$ tract plays an important role in exercise, delivering nutrients and fluid to facilitate endurance performance and promote early recovery (1). However, during high-intensity exercise the intestinal epithelial lining is prone to injury, impairing its integrity. This will likely hamper performance and subsequent recovery, and may lead to serious $G$ l problems such as nausea, vomiting, and diarrhea (2), experienced by $30-90 \%$ of endurance athletes (3). During highintensity exercise there is a redistribution of blood from the splanchnic (GI) organs to serve the working muscle (4). The consequence of this exercise-induced splanchnic vasoconstriction is splanchnic ischemia, which can lead to mucosal injury, impaired nutrient uptake and loss of Gl barrier functions (2). Previous work has demonstrated that splanchnic hypoperfusion is associated with small intestinal injury, shown as increased plasma intestinal fatty acid binding protein (I-FABP) concentrations (5). Strategies that improve splanchnic blood flow and attenuate gut injury will likely reduce $\mathrm{Gl}$ symptoms and benefit exercise performance and recovery (3).

It has been suggested that splanchnic blood flow can be manipulated by increasing the local availability of nitric oxide (NO) (6). NO is an important vasodilator, regulating microvascular tone, leucocyte adhesion, thrombocyte aggregation and microvascular permeability (7). Being a short-lived gas, NO cannot readily be applied to the gut, but several NO donors can be used to increase the bioavailability of NO. One NO donor that has been studied is L-citrulline, which is converted into L-arginine, and further oxidized upon activation of endothelial NO synthase (eNOS) to produce NO (8). Interestingly, van Wijck et al. (9) showed that ingestion of L-citrulline prior to exercise preserves splanchnic perfusion and attenuates gut injury during high-intensity cycling. In line with the recent interest in nitrate as a potent $\mathrm{NO}$ donor it has been suggested that dietary nitrate can also modulate splanchnic perfusion (2). Circulating nitrate is actively taken up by the salivary glands and concentrated in the saliva, where it can be reduced to nitrite by facultative anaerobic bacteria in the oral cavity. Upon swallowing the saliva, nitrite enters the circulation and can be further reduced to NO via various pathways (10-12). In a study in rats, oral nitrate supplementation was shown to increase gastric mucosal blood flow (13). The role of dietary nitrate for $\mathrm{Gl}$ function during exercise in humans has never been investigated. Therefore, our first aim was to assess the effects of dietary nitrate ingestion on splanchnic perfusion and gut injury during high-intensity exercise.

It is generally accepted that oral meal ingestion (14), and glucose ingestion in particular (15) increases splanchnic blood flow, a phenomenon referred to as postprandial splanchnic hyperemia. One possible explanation is the $\mathrm{NO}$ and 
adenosine Al receptor mediated microvascular vasodilation during intestinal glucose absorption. A study in rats showed that NOS inhibition significantly blunts the glucose-induced vasodilation of the premucosal arterioles (16). Furthermore, carbohydrate ingestion was recently shown to attenuate the increase in I-FABP levels following $2 \mathrm{~h}$ of running at moderate intensity in the heat (17). Consequently, the second aim of this study was to investigate the effects of carbohydrate ingestion on splanchnic perfusion and gut injury during high-intensity exercise.

We hypothesized that both nitrate and carbohydrate improve splanchnic perfusion and attenuate gut injury evoked during high-intensity exercise. Therefore, 16 well-trained male athletes performed a 60 min high-intensity cycling protocol $\left(70 \% W_{\text {max }}\right)$ after ingestion of sodium nitrate, sucrose or placebo. During exercise and upon 60 min post-exercise recovery, splanchnic perfusion was measured by gastric tonometry and gut injury was measured by plasma I-FABP concentrations.

\section{Methods}

\section{Subject's characteristics}

Sixteen male cyclists $\left(28 \pm 7 \mathrm{y}, \mathrm{BMI} 23.0 \pm 2.2 \mathrm{~kg} \cdot \mathrm{m}^{-2}\right)$ were included in the present study. Prior to the experiments, individual maximal workload capacity $\left(W_{\max }\right)$ was assessed on a stationary cycle ergometer (Lode Excalibur Sport, Groningen, The Netherlands), by completing an incremental exercise test starting with a 5 min warm-up at $150 \mathrm{~W}$ and increasing with $50 \mathrm{~W}$ every $2.5 \mathrm{~min}$ until volitional exhaustion; subjects were excluded when $W_{\max }$ was $<4.5 \mathrm{~W} \cdot \mathrm{kg}^{-1}$. All subjects were well-trained (9.4 $\pm 3.3 \mathrm{~h}$ of weekly endurance training) and had an average $W_{\max }$ of $5.0 \pm 0.3$ $\mathrm{W} \cdot \mathrm{kg}^{-1}$. Furthermore, they had no abdominal complaints during daily activities, had no history of $\mathrm{Gl}$ disease or abdominal surgery, did not take any medication interfering with test outcomes, and were nonsmokers. After being informed about the purpose and potential risks of the study, all subjects provided written informed consent. The experimental protocol and procedures were approved by the medical ethics committee of Maastricht University Medical Centre+, and conducted in accordance with the Declaration of Helsinki (2013).

\section{Study design and nutritional interventions}

In this randomized, controlled crossover study, all subjects performed $60 \mathrm{~min}$ of cycling exercise at $70 \% \mathrm{~W}_{\max }$ on three test days. During these test days subjects ingested $200 \mathrm{~mL}$ of a test beverage before and during exercise. On a test day the subject was provided either sodium nitrate (NIT), sucrose (SUC) and placebo (PLA) interventions. Intestinal injury was assessed by the rise in plasma I-FABP 
concentrations and splanchnic perfusion was assessed by gastric tonometry. For each subject, testing was performed on the same day, at the same time, with 1-2 weeks between test days.

\section{Test beverages}

Each subject ingested one 'salty' beverage dissolved in $200 \mathrm{~mL}$ tap water $150 \mathrm{~min}$ prior to cycling ( $t=-150)$. The beverage contained either sodium nitrate in NIT (1.1 g $\mathrm{NaNO}_{3}$, Food grade, F.C.C. Brentag, the Netherlands) or an equal amount of $\mathrm{NaCl}$ in SUC and PLA (ESCO Steen-Consumptiezout, the Netherlands), with similar taste, smell and appearance. Furthermore, subjects ingested one beverage of $200 \mathrm{~mL} 15$ min prior to ( $t=-15)$ as well as 30 min into cycling $(t=30)$. The beverages contained either $20 \mathrm{~g}$ sucrose in SUC (Granulated sugar, Sundale, Breda, the Netherlands) or tap water in NIT and PLA. The test beverages were identical in appearance and smell, but since no additives or sweeteners were used, a difference in taste was unavoidable between sucrose and water placebo. However, the subject's knowledge of the intervention was unlikely to impact the main outcomes.

\section{Physical activity and dietary standardization}

Subjects maintained normal activities of daily living and recorded their activity pattern the $48 \mathrm{~h}$ prior to a test day, but refrained from strenuous physical activity for $24 \mathrm{~h}$ before each test day. Diet was standardized by use of a 48-h food intake diary before the first test day, which was repeated prior to the following test days, and a standard evening meal was provided prior to each test day. Subjects were not allowed to consume alcohol and caffeine 24 and $12 \mathrm{~h}$ prior to testing, respectively. On the evening before each test day, the subjects ingested ranitidine (150 mg; Accord Healthcare Limited, UK) to inhibit gastric acid production and secretion. The latter is necessary to enable gastric tonometry measurements because the presence of acid in the stomach during tonometry can buffer carbon dioxide molecules, thereby interfering with the outcome of the tonometry measurements (18). An additional $150 \mathrm{mg}$ of ranitidine was consumed on the test days at 07:00am, 2-3 h prior to start of tonometry measurements. Furthermore, to prevent any attenuation in the reduction of nitrate to nitrite in the oral cavity by commensal bacteria, subjects were asked to refrain from using any antibacterial mouthwash/toothpaste, and tongue-scraping during the test period (12). 


\section{Chapter 8}

\section{Experiments and sampling}

All subjects reported to the sports laboratory at 08:00 by car or public transport in an overnight fasted state. After seated rest for $5 \mathrm{~min}$, a Teflon catheter was inserted in a dorsal hand vein of the subject, and the hand was placed in a hot box set at $60^{\circ} \mathrm{C}$ to enable collection of arterialized blood for analysis of arterial $\mathrm{pCO}_{2}$ levels (19). For practical reasons, no hotbox was used during exercise, but blood oxygen saturation never dropped below 95\%, confirming sustained arterialized blood (20). To measure gastric $\mathrm{pCO}_{2}$, an 8 French tonometrics catheter (MEDI-LINE s.a., Liege, Belgium) was introduced via the nose into the stomach of the subject and fixed to the nasal flares. Gastric $\mathrm{pCO}_{2}$ was measured at 10-min intervals before, during, and up to $60 \mathrm{~min}$ post-exercise using an automated capnograph (Tonocap TC-200; Datex-Ohmeda Oy, Helsinki, Finland). Arterialized blood samples were collected at baseline $(t=-150)$, before exercise $(t=-50, t=-30$ and $t=-10)$ and every 20 min during and post-exercise in heparin syringes (safePICOTM aspirator; Radiometer Benelux $\mathrm{BV}$, Zoetemeer, Netherlands), for determination of arterial $\mathrm{pCO}_{2}$. By subtracting the gastric and arterial $\mathrm{pCO}_{2}$ values, the gap $\mathrm{p}_{-\mathrm{p}} \mathrm{pCO}_{2}$ per 20 min time point was calculated as a measure of splanchnic perfusion (9). Tonometry data were obtained from 14 subjects because of inability to introduce the nasogastric catheter into the stomach of one of the subjects and measurement errors in one other subject. At each time point, a second blood sample was collected into Lithium-Heparine tubes and centrifuged immediately at $1,000 \mathrm{~g}$ for $5 \mathrm{~min}$, at $\pm 4^{\circ} \mathrm{C}$. Aliquots of plasma were stored at $-80^{\circ} \mathrm{C}$ for subsequent analysis of plasma I-FABP, nitrate, nitrite, and glucose concentrations.

Following a 5 -min warm-up at $50 \%$ of the individual's pre-assessed $\mathrm{W}_{\text {max }}$ subjects continued cycling at $70 \% \mathrm{~W}_{\max }(262 \pm 33 \mathrm{~W})$ for $60 \mathrm{~min}(t=0-60)$. Subjects were free to cycle according to their own comfortable pace, with a minimum of 50 rpm. Workload was decreased in steps of $25 \mathrm{~W}$ if the subject was unable to maintain $50 \mathrm{rpm}$. Performance per test day was estimated by calculating the average workload throughout the 60 min exercise. Subjects consumed water ad libitum, with a maximum of $200 \mathrm{~mL}$ every $20 \mathrm{~min}$ (including the interventional beverages). Since gastric $\mathrm{pCO}_{2}$ levels drop directly after fluid or meal ingestion due to dilution rather than an actual change in $\mathrm{pCO}_{2}(21)$, the gastric $\mathrm{pCO}_{2}$ value directly after ingestion of a beverage was substituted for the previous gastric $\mathrm{pCO}_{2}$ value (e.g. $t=30$ was used instead of $\mathrm{t}=40$ ) when calculating the gap $\mathrm{g}_{\mathrm{a}} \mathrm{pCO}_{2}$. Gastric $\mathrm{pCO}_{2}$ is shown to stabilize within 15-20 min after fluid ingestion (22) and the values used for analysis are all extending this period after fluid ingestion. Secondary measurements included heart rate during exercise (Polar Electro Oy, Kempele, Finland), rate of perceived exertion after completion of the exercise (23), and a multiple factor $G$ distress questionnaire using a VAS scale as previously described (24). The GI 
questionnaire was filled in before exercise, immediately after exercise, 60 min after exercise and the day after the test day.

\section{Plasma analysis}

To evaluate the extent of small intestinal injury during and post-exercise, plasma concentrations of intestinal fatty acid binding protein (I-FABP) were determined. Plasma I-FABP levels were measured by an in-house developed enzyme-linked immunosorbent assay (25). The assay is specific for the detection of the I-FABP isoform, with a lower limit of detection of $12.5 \mathrm{pg} \cdot \mathrm{mL}^{-1}$. Baseline I-FABP concentrations tend to vary substantially between individuals and even within individuals between subsequent test days. In addition, I-FABP values are highly variable between different ELISA kits and comparison of absolute I-FABP values between studies is not recommended (26). Therefore, changes in plasma I-FABP concentrations were calculated as percentage from baseline. Plasma nitrate and nitrite concentrations were analyzed using the chemiluminescence technique (NOA; Sievers NOA 280i; Analytix, Durham, UK) as described previously (27). Plasma glucose was analyzed using Uni Kit III (Roche, Basel, Switzerland).

\section{Statistical analysis}

Power calculations were based on previously reported percentage changes in IFABP AUC following L-citrulline vs placebo supplementation during high-intensity exercise (9). This resulted in an effect size of 1.19. Taking into account a power of $95 \%$ and an alpha level of 0.025 (for pre-planned post-hoc comparisons for PLA vs NIT and PLA vs SUC), a minimum of 14 subjects should be included. Normality of all data was verified by the Kolmogorov-Smirnov test. The primary outcome parameters were area under the curve (AUC) for I-FABP and for gap g-a $\mathrm{PCO}_{2}$, and were analyzed using repeated measures ANOVA with 'treatment' (NIT, SUC or PLA) as withinsubjects factor. Continuous data for I-FABP (increase from baseline in \%), gap ${ }_{a} \mathrm{PCO}_{2}$, plasma nitrate, plasma nitrite and plasma glucose were analyzed using repeated measures ANOVA, with 'time' and 'treatment' as within-subjects factors. Other secondary parameters were analyzed using repeated measures ANOVA, with 'treatment' as within-subjects factor. Statistical significance was set at $P<0.05$, and any interaction or main effect was subsequently analyzed using a Bonferroni corrected post hoc test for pre-planned comparisons (i.e., SUC vs PLA and NIT vs PLA). All data were analyzed using SPSS 22.0 (IBM Corp., Armonk, NY), and are presented as means \pm SDs. 


\section{Results}

\section{Plasma nitrate/nitrite and glucose}

There were no baseline differences between treatments for plasma nitrate ( $P=0.144$; Figure 8.1A) or nitrite $(P=0.694$; Figure 8.1B) concentrations. A significant time $x$ treatment interaction was observed for both plasma nitrate and nitrite concentrations (both $P<0.0001)$. Post hoc analysis showed significantly higher plasma nitrate and nitrite concentrations following NIT vs PLA throughout the test day (both $P<0.0001$ ), with no differences between SUC and PLA. Following NIT, plasma nitrate and nitrite concentrations were increased at all time points when compared to baseline $(P<0.0001)$. Subtle changes in plasma nitrate and nitrite concentrations were also observed within SUC and PLA (Figure 8.1A and 8.1B).

For plasma glucose concentrations there were no baseline differences between treatments $(P=0.181$; Figure $8.1 C)$. There was a significant time effect $(P<0.0001)$, and a trend for a time $x$ treatment interaction $(P=0.088)$. Plasma glucose concentrations increased compared to baseline at $\mathrm{t}=20$ and $\mathrm{t}=40(P<0.01)$, tended to be increased at $\mathrm{t}=60(P=0.063)$ and decreased at $\mathrm{t}=120(P<0.01)$. Furthermore, plasma glucose was higher in SUC vs PLA at $t=-10(P=0.008)$ and tended to be higher in SUC vs PLA at $\mathrm{t}=60(P=0.076)$. 

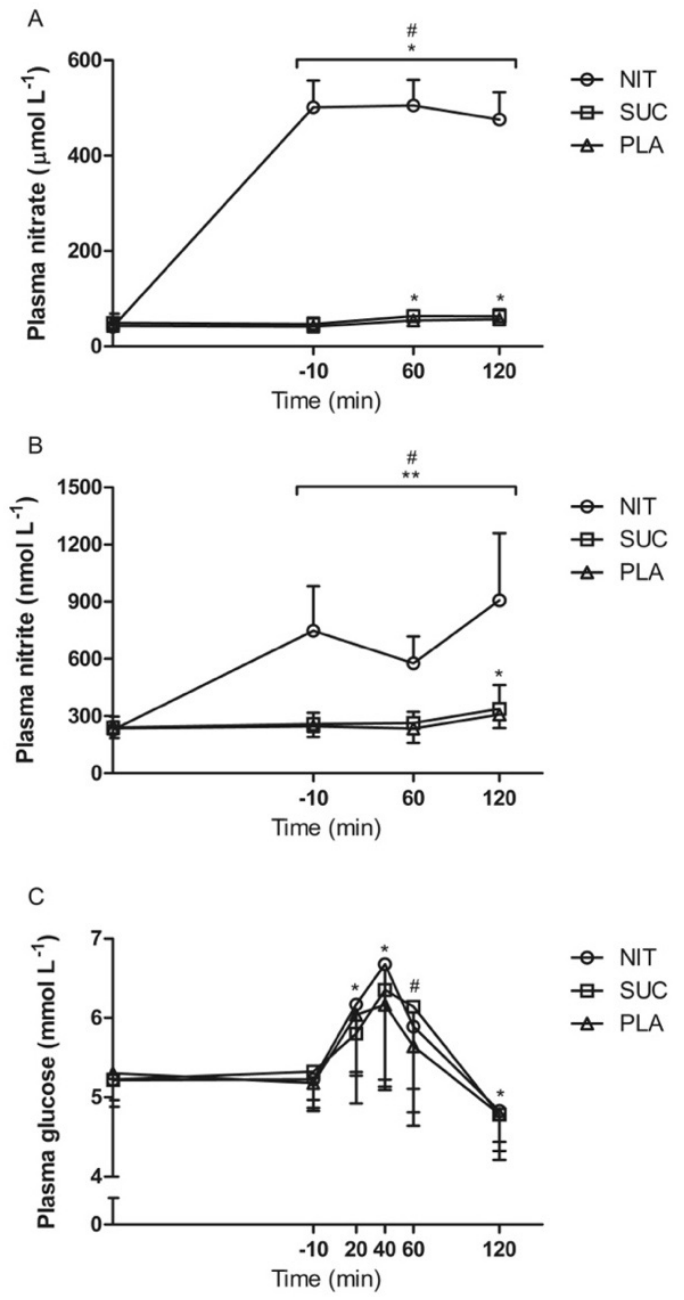

Figure 8.1: Mean $( \pm S D)$ plasma concentrations of nitrate $(A)$, nitrite $(B)$, and glucose (C) after oral bolus of sodium nitrate (NIT), sucrose (SUC) or placebo (PLA) in healthy young men $(n=16)$. Data were analyzed with repeated measures ANOVA. Plasma nitrate (A): *Significantly different from baseline (main effect for all treatments; all $P<0.001$ ). "Significantly different in the NIT vs PLA treatment $(P<0.0001)$. Plasma nitrite $(B)$ : * ${ }^{*}$ ignificantly different from baseline at $P<0.05$, only in the SUC and PLA treatment, and ${ }^{* *} P<0.0001$ only in the NIT treatment. "Significantly different in the NIT vs PLA treatment $(P<0.0001)$. Plasma glucose $(C)$ : * Significantly different from baseline (main effect for all treatments; all $P<0.01)$. "Significantly different in the SUC vs PLA treatment $(P<0.01)$. 


\section{Splanchnic perfusion}

For gap $\mathrm{g}_{\mathrm{a}} \mathrm{p} \mathrm{CO}_{2}$ levels, no differences were observed at baseline and no time $\mathrm{x}$ treatment interaction $(P=0.47)$ or overall effect of treatment $(P=0.53)$ were observed. However, there was a significant time effect $(P<0.001)$, with post hoc analyses showing that for all treatments gap ${ }_{\text {-a }} \mathrm{PCO}_{2}$ levels significantly increased compared to baseline at all time points during cycling $(P<0.01)$, returning to baseline levels following exercise cessation (Figure 8.2A). In accordance, AUC for gap ${ }_{a} \mathrm{pCO}_{2}$ during exercise was significantly higher than zero, with no differences between treatments $(P=0.64$; Figure 8.2B). Likewise, peak values for gapg-apCO $(P=0.87)$ were not different between treatments.
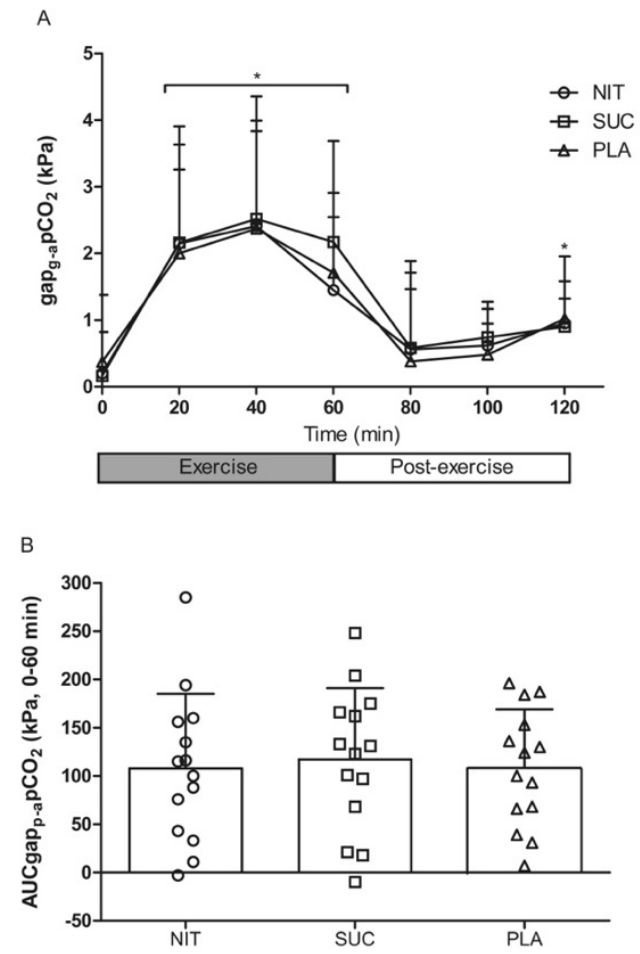

Figure 8.2: Mean $( \pm S D)$ gapg-apCO 2 levels at baseline, during and postexercise (A) and $\mathrm{AUC}$ of gapg-apCO 2 levels during exercise (B) after consumption of sodium nitrate (NIT), sucrose (SUC) or placebo (PLA) in healthy young men $(n=14)$. The data over time were analyzed with repeated measures ANOVA. *Significantly different from baseline (main effect for all treatments; all $P<0.01$ ). AUC data $(B)$ were analyzed with a one-way ANOVA; no differences were observed between treatments. 


\section{Gut injury}

Baseline plasma I-FABP concentrations (at $\mathrm{t}=-150$, prior to the first supplement) were not different between treatments (NIT: 1037 \pm 309 , SUC: $1213 \pm 385$ and PLA: $\left.1171 \pm 384 \mathrm{pg} \cdot \mathrm{mL}^{-1} ; P=0.26\right)$, and remained stable until the onset of exercise.

A significant time $x$ treatment interaction was observed for the percentage change in I-FABP concentrations throughout the exercise and post-exercise period $(P<0.0001$; Figure 8.3A). Plasma I-FABP concentrations increased over time with all three treatments $(P<0.0001)$, but the increase was attenuated following sucrose ingestion when compared with placebo $(P=0.020)$. Post hoc analysis showed that the percentage increase over time was significantly lower in SUC vs PLA from $t=40$ through $\mathrm{t}=120$ (all $P<0.05$ ). In contrast, no differences were observed between NIT and PLA. Following SUC, plasma I-FABP was increased from baseline at $t=20, t=40$, $t=60$ and $t=80$, but not at $t=100$ and $t=120$. Following NIT and PLA, plasma I-FABP remained elevated above baseline at all time points during and post-exercise. Peak values for the increase in plasma I-FABP from baseline were significantly different between treatments (NIT: $299 \pm 120 \%$, SUC: $179 \pm 60 \%$, PLA: $249 \pm 88 \%, P=0.001$ ), with significantly lower peak values observed in SUC vs PLA $(P=0.004)$, but no difference between NIT and PLA ( $P=0.31)$. In accordance, AUC for percentage change in IFABP concentrations during and post-exercise was significantly different between treatments ( $P=0.001$; Figure 8.3B). Post hoc analysis showed lower I-FABP AUC following SUC vs PLA $(4,622 \pm 6,291 \%$ vs $10,099 \pm 6,783 \% ; P=0.004)$, with no differences between NIT and PLA $(P=0.78)$. No correlations between gapg-apCO 2 and I-FABP levels were found. 
A

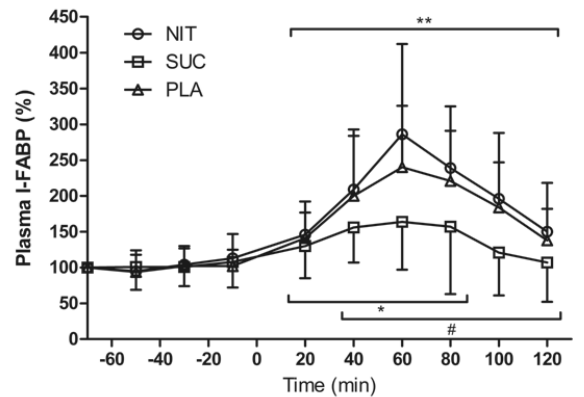

B

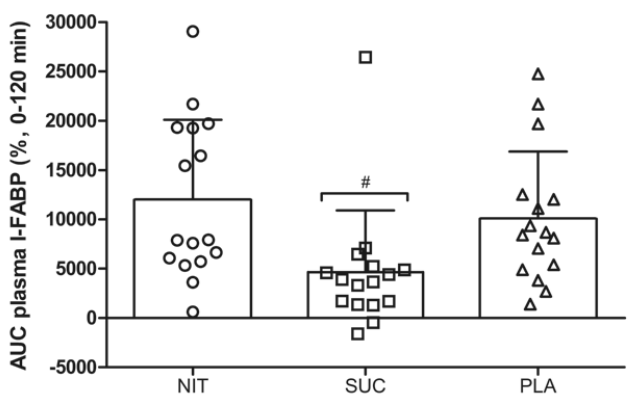

Figure 8.3: Mean (SD) percentage changes from baseline in plasma I-FABP concentrations pre-, during and post-exercise $(A)$ and $A \cup C$ of percentage IFABP change (B) after consumption of sodium nitrate (NIT), sucrose (SUC) or placebo (PLA) in young healthy men ( $n=16)$. Data were analyzed with repeated measures ANOVA. * Significantly different from baseline at $P<0.05$, only in the SUC treatment, and ${ }^{*} P<0.01$ only in the NIT and PLA treatment. "Significantly different in the SUC vs PLA treatment $(P<0.01)$. AUC data $(B)$ were analyzed using one-way ANOVA. "Significantly different compared with PLA $(P<0.01)$.

\section{Gl complaints and exercise performance}

For 15 of the 16 subjects only minor Gl complaints were reported on the test day and the day after the test day, and there were no differences between treatments $(P=0.57)$. One subject experienced $\mathrm{Gl}$ complaints during cycling on all three test days, likely related to the exercise intensity, but was able to complete the test protocol each test day. Average cycling power output did not differ between treatments (NIT; $247 \pm 34 \mathrm{~W}$, SUC; $250 \pm 35 \mathrm{~W}$, and PLA; $249 \pm 32 \mathrm{~W}, P=0.22$ ). A tendency was observed towards reduced rate of perceived exertion in the SUC treatment (NIT; 17.4 \pm 1.3 , SUC; 16.5 \pm 1.9 , PLA; 17.4 $\pm 1.5, P=0.082$ ). The highest 1-min heart rate during cycling did not differ between treatments (NIT; 178 \pm 12 , SUC; $\left.178 \pm 13, \mathrm{PLA} ; 180 \pm 13 \mathrm{bts} \cdot \mathrm{min}^{-1}, P=0.278\right)$. 


\section{Discussion}

Cycling for $60 \mathrm{~min}$ at $70 \% \mathrm{~W}_{\max }$ resulted in splanchnic hypoperfusion and gut injury in well-trained cyclists. We observed no differences in splanchnic perfusion between treatments, and dietary nitrate did not affect gut injury. However, sucrose ingestion strongly attenuated the increase in plasma I-FABP levels, indicative of a substantial reduction in exercise-induced gut injury.

High-intensity exercise has been associated with splanchnic hypoperfusion and gut injury (5), which is likely to hamper GI function, exercise performance, and post-exercise recovery. In line, following placebo ingestion, the high-intensity exercise protocol of the current study led to a clear $\sim 2 \mathrm{kPa}$ increase in gapg-apCO levels within the first $20 \mathrm{~min}$ of exercise. This reflects a rapid development of profound splanchnic hypoperfusion, where blood flow is reduced to less than 30$40 \%$ of baseline levels $(28,29)$. Furthermore, a clear increase in plasma I-FABP levels throughout the exercise until $60 \mathrm{~min}$ post-exercise was seen, reflecting the development of gut injury at this intensity and duration of cycling. The increase in plasma I-FABP levels at the end of exercise following placebo ingestion $(\sim 250 \%)$ is in line with previous studies using the same exercise protocol $(5,9)$. In an attempt to attenuate the exercise-induced splanchnic hypoperfusion and marked enterocyte damage, we studied the impact of dietary intervention strategies in the form of dietary nitrate and carbohydrate (sucrose) ingestion.

Dietary nitrate ingestion increased plasma nitrate and nitrite concentrations by $\sim 12$ and $\sim 3$ fold, respectively, in line with a previous study from our group supplementing the same dose of sodium nitrate in well-trained cyclists (30). However, the effective uptake of dietary nitrate in the circulation and its endogenous conversion into nitrite did not result in an improvement in splanchnic perfusion or gut injury when compared to the placebo treatment. This contradicts previous results following supplementation of another NO donor L-citrulline. Using the same exercise protocol as in the current study, van Wijck et al. (9) reported an attenuated rise in plasma I-FABP concentrations and a tendency for preservation of splanchnic perfusion following acute L-citrulline ingestion. The proposed mechanism was increased arginine-induced intracellular NO production leading to improved perfusion, as demonstrated in a mice model (31) where L-citrulline supplementation indeed reduced intestinal microcirculatory dysfunction and increased intracellular NO production. L-citrulline induces NO production through the L-citrulline-L-arginine-NOS pathway, which is highly oxygen dependent. In contrast, NO production through the nitrate-nitrite-NO pathway is gradually activated as oxygen tension and $\mathrm{pH}$ decrease (32). Indeed, since the oxygendependent NOS pathway can still be stimulated under conditions of splanchnic hypoperfusion (9), such conditions may be suboptimal for the nitrate-nitrite-NO 


\section{Chapter 8}

pathway to be stimulated. Perhaps a total blockage of the splanchnic blood flow resulting in a highly hypoxic state would have been necessary to see an effect of nitrate. Furthermore, the suppression of gastric acid secretion by ranitidine ingestion increases gastric $\mathrm{pH}$ to allow for an accurate gastric $\mathrm{pCO}_{2}$ measurement (18). As a potential side-effect though, the increased gastric $\mathrm{pH}$ could have attenuated the gastric reduction of nitrite to $\mathrm{NO}$ (32). This may partly explain our findings of a lack of effect of dietary nitrate ingestion on exercise-induced intestinal hypoperfusion and damage.

Splanchnic hypoperfusion during high-intensity exercise is caused by increased activity of the sympathetic nervous system to redistribute blood flow from the splanchnic organs to the working muscle (4). This centrally acting mechanism can be counteracted by providing macronutrients during exercise to stimulate local vasodilation, which could be an effective strategy to prevent gut injury. It is well known that oral meal ingestion (14), and glucose in particular (15), can improve intestinal blood flow in non-exercise conditions. It has been shown that glucoseinduced vasodilation of premucosal jejunal arterioles is mediated through adenosine $\mathrm{Al}$ receptors, and that $\mathrm{NO}$ at least partially mediates the adenosine $\mathrm{Al}$ receptor-induced vasodilation (16). Since many athletes consume sports drinks containing multiple transportable carbohydrates (1) during exercise, we investigated the effect of sucrose ingestion (i.e., providing both glucose and fructose) on splanchnic blood flow and gut injury during high-intensity exercise. Plasma glucose levels were elevated in the 10-30 min following sucrose ingestion compared to placebo, indicating an effect of exogenous ingestion on top of the endogenous glucose production during exercise (Figure 8.1C). In contrast to dietary nitrate, sucrose ingestion strongly attenuated the increase in plasma I-FABP levels throughout both the exercise and post-exercise period when compared to placebo. Peak I-FABP concentrations were only increased from baseline by $185 \%$ following sucrose, compared to $250 \%$ following placebo. Total AUC for the increase in IFABP during and after exercise was even decreased by more than $50 \%$ following sucrose ingestion. Attenuation of the exercise-induced increase in plasma I-FABP levels has previously been seen following glucose, and also whey protein ingestion during $2 \mathrm{~h}$ of running at $60 \% \mathrm{VO}_{2 \max }(17)$. The authors suggested using carbohydrates rather than protein during exercise, since carbohydrates can support endotoxin clearance and reduce stress markers, while protein seems to increase Gl symptoms. We extend on these findings by showing the effectiveness of carbohydrate ingestion at high-intensity exercise (i.e., $70 \%$ vs $~ 50 \% \mathrm{~W}_{\max }$ ) and by measuring an attenuated rise in I-FABP concentrations throughout exercise and in the postexercise period. Furthermore, we observed splanchnic hypoperfusion, which likely caused the observed exercise-induced gut injury. 
Despite the attenuation of gut injury, sucrose ingestion did not preserve splanchnic perfusion during exercise. In line, a previous study found that glucose ingestion increased portal vein flow at rest, but did not lead to a significant attenuation of the exercise-induced reduction in blood flow (33). However, the expected mechanism for the attenuated gut injury following sucrose ingestion would be an improved splanchnic perfusion, potentially through the NO-mediated glucoseinduced vasodilation (16). The lack of change in $\mathrm{gap}_{\mathrm{g}-\mathrm{a}} \mathrm{pCO}_{2}$ levels following the sucrose intervention compared with placebo could be attributed to a local stimulation of perfusion at the site of intestinal villi tips, and that the measured gastric blood flow thereby remained unaffected. Gastric $\mathrm{pCO}_{2}$ has been shown to correlate well with jejunal $\mathrm{pCO}_{2}$ at rest (34), but is not a direct marker of total intestinal blood flow. A correlation between gastric $\mathrm{pCO}_{2}$ and plasma I-FABP levels has been reported using the same exercise protocol as the current study (5). However, the profound exercise-induced hypoperfusion might limit the possibility for the tonometry method to detect perfusion changes corresponding with the reduction in systemic I-FABP appearance as seen for the sucrose intervention in the current study. Moreover, it is recommended to use gastric tonometry in a fasted state, and a rise in gastric $\mathrm{pCO}_{2}$ after feeding can be caused by a buffer effect of meal-induced gastric acid secretion (21). We aimed to suppress basal gastric acid production by providing ranitidine. Yet, we cannot rule out the possibility that gastric acid secretion evoked by sucrose ingestion was not sufficiently inhibited by ranitidine (21), which is a limitation of this study. As such gastric $\mathrm{pCO}_{2}$ values might have been elevated following sucrose ingestion, overshadowing a potential effect of sucrose on attenuation of the exercise-induced hypoperfusion. This could explain why the attenuated increase in I-FABP levels was not accompanied by a reduction in gap $_{\mathrm{g}-\mathrm{a}} \mathrm{pCO}_{2}$ levels following sucrose ingestion.

GI complaints are very common among endurance athletes and may have a negative impact on performance and subsequent recovery. Reduced splanchnic blood flow could lead to compromised GI function in athletes, however this has not yet been casually linked to the prevalence of Gl symptoms (3). Although increased I-FABP levels following high-intensity exercise are commonly observed, a firm association with the existence of $\mathrm{Gl}$ complaints remains to be established $(5,9,35$ 38). Importantly, the difficulties of obtaining objective measures of $\mathrm{Gl}$ complaints may to some extent explain the lack of association with gut injury. Furthermore, a transient increase in systemic I-FABP levels does not represent a direct marker for $\mathrm{Gl}$ complaints, but rather reflects acute enterocyte damage being indicative of temporary loss of intestinal integrity and absorptive capacity. Indeed, reduced dietary protein digestion and absorption rates have been shown during post- 
exercise recovery when I-FABP levels were increased during exercise (25), supporting the relevance of this marker for enterocyte damage.

Consuming carbohydrates frequently and consistently during exercise may represent a feasible protective strategy against exercise-induced $\mathrm{Gl}$ malfunction (39). Of course carbohydrate intake during exercise should be practiced sensibly as highly concentrated carbohydrate intakes can also increase $G$ injury (40). The current study shows that ingesting small amounts of carbohydrates (2x $20 \mathrm{~g}$ ) shortly prior to and during exercise is sufficient to strongly attenuate exercise-induced gut injury. We propose that athletes suffering from ischemia-related $\mathrm{Gl}$ symptoms during exercise of high-intensity and/or long duration could benefit from practicing carbohydrate ingestion during exercise to limit gut injury. Future work should further establish whether this also would result in reduced $\mathrm{Gl}$ symptoms. Furthermore, it would be interesting to investigate whether asymptomatic athletes can use carbohydrates during exercise to improve nutrient uptake and early recovery.

\section{Conclusion}

Sucrose but not nitrate ingestion lowers gut injury evoked during high-intensity exercise. These results suggest that sucrose ingestion, but not nitrate, prevents hypoperfusion-induced GI damage during exercise and, as such, may help to lower exercise-related $\mathrm{Gl}$ complaints. 


\section{References}

1. Jeukendrup AE. Training the Gut for Athletes. Sports Med. 2017;47(Suppl 1):101-10.

2. van Wijck K, Lenaerts K, Grootjans J, et al. Physiology and pathophysiology of splanchnic hypoperfusion and intestinal injury during exercise: strategies for evaluation and prevention. Am J Physiol Gastrointest Liver Physiol. 2012;303(2):G155-68.

3. de Oliveira EP, Burini RC, Jeukendrup A. Gastrointestinal complaints during exercise: prevalence, etiology, and nutritional recommendations. Sports Med. 2014;44 Suppl 1:S79-85.

4. ter Steege RW, Kolkman JJ. Review article: the pathophysiology and management of gastrointestinal symptoms during physical exercise, and the role of splanchnic blood flow. Aliment Pharmacol Ther. 2012;35(5):516-28.

5. van Wijck K, Lenaerts K, van Loon LJ, Peters WH, Buurman WA, Dejong CH. Exercise-induced splanchnic hypoperfusion results in gut dysfunction in healthy men. PLoS One. 2011;6(7):e22366.

6. Luiking YC, Engelen MP, Deutz NE. Regulation of nitric oxide production in health and disease. Curr Opin Clin Nutr Metab Care. 2010;13(1):97-104.

7. Ince C. The microcirculation is the motor of sepsis. Crit Care. 2005;9 Suppl 4:S13-9.

8. Martin MJ, Jimenez MD, Motilva V. New issues about nitric oxide and its effects on the gastrointestinal tract. Curr Pharm Des. 2001;7(10):881-908.

9. van Wijck K, Wijnands KA, Meesters DM, et al. L-citrulline improves splanchnic perfusion and reduces gut injury during exercise. Med Sci Sports Exerc. 2014;46(11):2039-46.

10. Duncan $C$, Dougall $H$, Johnston $P$, et al. Chemical generation of nitric oxide in the mouth from the enterosalivary circulation of dietary nitrate. Nat Med. 1995;1(6):546-51.

11. Zhang Z, Naughton D, Winyard PG, Benjamin N, Blake DR, Symons MC. Generation of nitric oxide by a nitrite reductase activity of xanthine oxidase: a potential pathway for nitric oxide formation in the absence of nitric oxide synthase activity. Biochem Biophys Res Commun. 1998;249(3):767-72.

12. Govoni $M$, Jansson $E$, Weitzberg $E$, Lundberg J. The increase in plasma nitrite after a dietary nitrate load is markedly attenuated by an antibacterial mouthwash. Nitric Oxide. 2008;19:333-7.

13. Petersson J, Phillipson M, Jansson EA, Patzak A, Lundberg JO, Holm L. Dietary nitrate increases gastric mucosal blood flow and mucosal defense. Am J Physiol Gastrointest Liver Physiol. 2007;292(3):G718-24.

14. Moneta GL, Taylor DC, Helton WS, Mulholland MW, Strandness DE, Jr. Duplex ultrasound measurement of postprandial intestinal blood flow: effect of meal composition. Gastroenterology. 1988;95(5):1294301.

15. Gentilcore D, Hausken T, Meyer JH, Chapman IM, Horowitz M, Jones KL. Effects of intraduodenal glucose, fat, and protein on blood pressure, heart rate, and splanchnic blood flow in healthy older subjects. Am J Clin Nutr. 2008;87(1):156-61.

16. Matheson PJ, Li N, Harris PD, Zakaria el R, Garrison RN. Glucose-induced intestinal vasodilation via adenosine A1 receptors requires nitric oxide but not K(+)(ATP) channels. J Surg Res. 2011;168(2):17987.

17. Snipe RMJ, Khoo A, Kitic CM, Gibson P, Costa RJS. Carbohydrate and protein intake during exertionalheat stress ameliorates intestinal epithelial injury and small intestine permeability. Appl Physiol Nutr Metab. 2017;42(12):1283-92.

18. Kolkman JJ, Groeneveld AB, Meuwissen SG. Effect of ranitidine on basal and bicarbonate enhanced intragastric PCO2: a tonometric study. Gut. 1994;35(6):737-41.

19. Knowles TP, Mullin RA, Hunter JA, Douce FH. Effects of syringe material, sample storage time, and temperature on blood gases and oxygen saturation in arterialized human blood samples. Respir Care. 2006;51(7):732-6.

20. Nauck M, Liess H, Siegel E, Niedmann P, Creutzfeldt W. Critical evaluation of the "heated-handtechnique'for obtaining 'arterialized'venous blood: incomplete arterialization and alterations in glucagon responses. Clin Physiol. 1992;12(5):537-52.

21. Kolkman JJ, Groeneveld AB, Meuwissen SG. Effect of gastric feeding on intragastric $\mathrm{P}(\mathrm{CO} 2)$ tonometry in healthy volunteers. J Crit Care. 1999;14(1):34-8.

22. Hamilton JD, Dawson AM, Webb PW. Observations upon small gut "mucosal" pO2 and pCO2 in anesthetized dogs. Gastroenterology. 1968;55(1):52-60.

23. Borg GA. Psychophysical bases of perceived exertion. Med Sci Sports Exerc. 1982;14(5):377-81. 


\section{Chapter 8}

24. Trommelen J, Fuchs CJ, Beelen M, et al. Fructose and Sucrose Intake Increase Exogenous Carbohydrate Oxidation during Exercise. Nutrients. 2017;9(2).

25. van Wijck $K$, Pennings $B$, van Bijnen AA, et al. Dietary protein digestion and absorption are impaired during acute postexercise recovery in young men. Am J Physiol Regul Integr Comp Physiol. 2013;304(5):R356-61.

26. Peoc'h K, Nuzzo A, Guedj K, Paugam C, Corcos O. Diagnosis biomarkers in acute intestinal ischemic injury: so close, yet so far. Clin Chem Lab Med. 2018;56(3):373-85.

27. Jonvik KL, Nyakayiru J, Pinckaers PJ, Senden JM, van Loon LJ, Verdijk LB. Nitrate-Rich Vegetables Increase Plasma Nitrate and Nitrite Concentrations and Lower Blood Pressure in Healthy Adults. J Nutr. 2016;146(5):986-93.

28. Knichwitz G, Rotker J, Mollhoff T, Richter KD, Brussel T. Continuous intramucosal PCO2 measurement allows the early detection of intestinal malperfusion. Crit Care Med. 1998;26(9):1550-7.

29. Otte JA, Oostveen E, Geelkerken RH, Groeneveld AB, Kolkman JJ. Exercise induces gastric ischemia in healthy volunteers: a tonometry study. J Appl Physiol (1985). 2001;91(2):866-71.

30. Nyakayiru J, Jonvik KL, Pinckaers PJ, Senden J, Van Loon LJ, Verdijk LB. No Effect of Acute and 6-Day Nitrate Supplementation on VO2 and Time-Trial Performance in Highly-Trained Cyclists. Int J Sport Nutr Exerc Metab. 2017;27(1):11-17.

31. Wijnands KA, Vink H, Briede JJ, et al. Citrulline a more suitable substrate than arginine to restore NO production and the microcirculation during endotoxemia. PLoS One. 2012;7(5):e37439.

32. Lundberg JO, Weitzberg E, Gladwin MT. The nitrate-nitrite-nitric oxide pathway in physiology and therapeutics. Nat Rev Drug Discov. 2008;7:156-67.

33. Rehrer NJ, Goes E, DuGardeyn C, Reynaert H, DeMeirleir K. Effect of carbohydrate on portal vein blood flow during exercise. Int J Sports Med. 2005;26(3):171-6.

34. Otte JA, Huisman AB, Geelkerken RH, Kolkman JJ. Jejunal tonometry for the diagnosis of gastrointestinal ischemia. Feasibility, normal values and comparison of jejunal with gastric tonometry exercise testing. Eur J Gastroenterol Hepatol. 2008;20(1):62-7.

35. Smetanka RD, Lambert GP, Murray R, Eddy D, Horn M, Gisolfi CV. Intestinal permeability in runners in the 1996 Chicago marathon. Int J Sport Nutr. 1999;9(4):426-33.

36. Pals KL, Chang RT, Ryan AJ, Gisolfi CV. Effect of running intensity on intestinal permeability. J App/ Physiol (1985). 1997;82(2):571-6.

37. Ryan AJ, Chang RT, Gisolfi CV. Gastrointestinal permeability following aspirin intake and prolonged running. Med Sci Sports Exerc. 1996;28(6):698-705.

38. Nieman DC, Henson DA, Dumke CL, et al. Ibuprofen use, endotoxemia, inflammation, and plasma cytokines during ultramarathon competition. Brain Behav Immun. 2006;20(6):578-84.

39. Costa RJS, Snipe RMJ, Kitic CM, Gibson PR. Systematic review: exercise-induced gastrointestinal syndrome-implications for health and intestinal disease. Aliment Pharmacol Ther. 2017;46(3):246-65.

40. Sessions J, Bourbeau K, Rosinski M, et al. Carbohydrate gel ingestion during running in the heat on markers of gastrointestinal distress. Eur J Sport Sci. 2016;16(8):1064-72. 


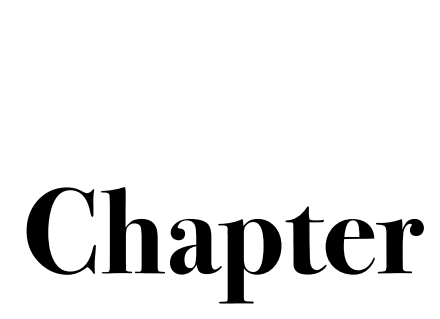

General discussion
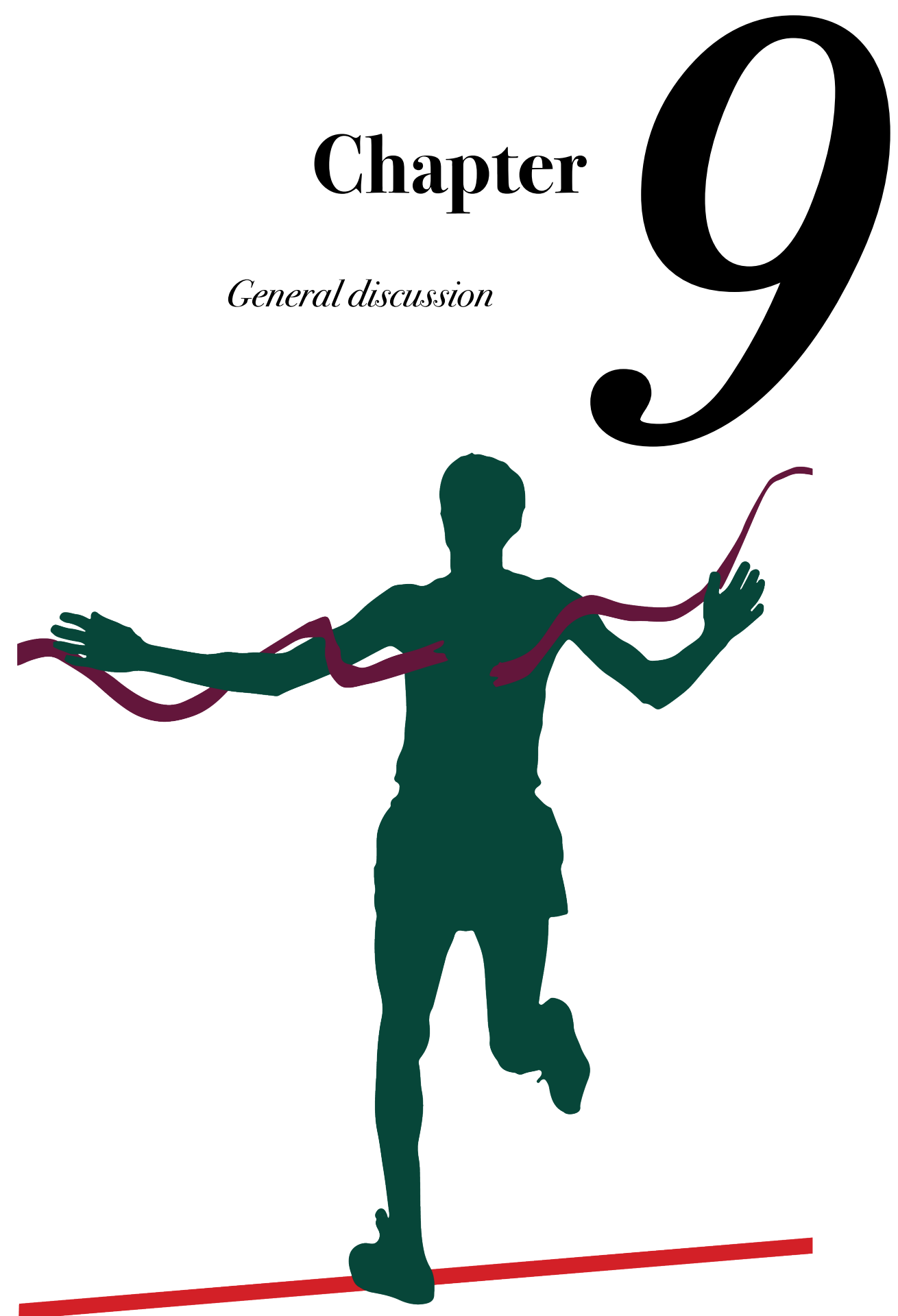


\section{Chapter 9}

Nitrate-rich beetroot juice is a popular supplement used by many athletes, including elite athletes. Even though beetroot juice is mentioned as one of the top-5 supplements to enhance exercise performance (1), its ergogenic potential still remains to be fully established. This thesis aimed to gain further insight into dietary nitrate supplementation as a means to enhance sports performance. The main topics addressed were the 'how', 'when', and 'for whom' in terms of supplementation protocol, specific exercise conditions and the training status of the athletes, with due attention for the pertaining question to what extent elite athletes can benefit from dietary nitrate supplementation. This final chapter elaborates on the primary findings of the studies described in the previous chapters and discusses them in a broader perspective. Practical implications and directions for future research are presented at the end of this chapter.

\section{Supplementation protocol}

One of the complicating factors in the nitrate research, which undoubtedly contributed to the contradictory findings observed in different studies, is the use of various supplementation protocols. In the first meta-analysis on nitrate and sports performance in 2013 (2), 300-600 mg of nitrate over a minimum of 3 days was suggested as the best strategy. This meta-analysis, however, based its conclusions on the few studies between 2007 and 2012, and since then the research on nitrate supplementation and sports performance has greatly expanded. Based on recent literature, including the results of this thesis, an updated view on the duration of nitrate supplementation, timing of the final dose, as well as the amount and source of nitrate that are most likely to enhance sports performance seems appropriate.

\section{Duration and timing of supplementation}

Several studies in healthy individuals have reported a reduction in blood pressure following a single bolus of nitrate ingestion (3-7). In chapter 4, we show that ingestion of $800 \mathrm{mg}$ of nitrate, provided from various sources, reduces blood pressure 2.5-5 hafter ingestion. This supports the idea that the vasodilatory effects of nitrate are acutely triggered by the ingestion of a single bolus of dietary nitrate. A prolonged benefit of nitrate supplementation on blood pressure has also been suggested, as persisting decreases in blood pressure have been reported after 3 15 days of nitrate supplementation (8-12). However, these studies provided a daily dose of nitrate, and it could be speculated that the overall decline in blood pressure is simply attributed to the acute response to each successive dose of nitrate administered. It has yet to be determined whether actual structural tissue adaptations may also take place that could sustain the vasodilatory effects of 
nitrate and, as such, structurally improve blood flow and oxygen availability throughout the body.

Next to the acute vasodilatory effects, a multiple day nitrate supplementation protocol may be required to permit certain myocellular adaptations that could help to improve performance $(13,14)$. Yet, there is very limited research that compares the effects of acute versus multiple day supplementation protocols. In chapter 3, we compared the effects of acute and 6 days of sodium nitrate supplementation on oxygen consumption during submaximal exercise, and subsequent $10 \mathrm{~km}$ time-trial performance. However, no effects of nitrate supplementation were observed on oxygen consumption or time-trial performance in this group of highly trained male athletes. The lack of effect might be explained by the high training status of the athletes included in the study, in line with previous nitrate studies in more highly trained endurance athletes (15-18). Interestingly, in less trained subjects, Vanhatalo et al. (9) reported that despite decreased oxygen consumption during submaximal exercise following acute, 5 days and 15 days of nitrate supplementation, peak power output was only improved after 15 days of nitrate supplementation. In accordance, a recent review (19) included 40 trials using acute supplementation and 36 trials using 2-15 days of nitrate supplementation, and reported a trend towards a better performance outcome for time to exhaustion testing using a 'chronic' versus an 'acute' supplementation protocol. With myocellular adaptations likely taking more time to develop $(13,14)$, a more prolonged supplementation protocol would allow for both cardiovascular and muscular systems to be triggered, thus representing the best approach to maximize the effects on overall performance. Although future work should further establish optimal supplementation duration in different exercise contexts, based on current knowledge we recommend a protocol of at least 5 days fitting with the individual competition schedule, for those athletes that seek to use nitrate supplementation to induce performance benefits.

The timing of the last nitrate dose in a supplementation protocol is in most literature set to 2-3 $\mathrm{h}$ prior to the exercise test. Similarly, for all studies in the current thesis, we provided the last nitrate dose 2.5-3 h prior to the exercise tests (chapters $3,6,7$ and 8). This seems adequate since peak values for plasma nitrate are reached within this time, and half-life of plasma nitrate is 5-8 h (20-22). In support, when analyzing plasma nitrate and nitrite concentrations every 30 min following ingestion of four different nitrate sources (chapter 4), peak nitrate concentrations were reached after $\sim 2-2.5 \mathrm{~h}$ for beetroot juice, $\sim 2.5-3 \mathrm{~h}$ for sodium nitrate and $\sim 3 \mathrm{~h}$ for the vegetables spinach and rocket salad. This implies that ingesting concentrated beetroot juice 2-3 $\mathrm{h}$ prior to the event may be the preferred strategy, whereas for the vegetable-based beverages a minimum of $3 \mathrm{~h}$ prior to the event might be 
required to maximize nitrate availability. As plasma nitrate and nitrite concentrations plateaued until at least $5 \mathrm{~h}$ after ingestion, it could even be suggested that the time between intake and peak exercise performance can be increased up to 4-5 h, without strongly affecting plasma nitrate and nitrite concentrations. As such, based on individual experience and preference, an athlete can take practicality, competition schedule, and possible risk of gastrointestinal complaints into account when timing the intake of nitrate.

\section{Effective nitrate dose}

As with the duration and timing of supplementation, the optimal daily dose of nitrate has also been under discussion. Effective dosing may depend on several factors, such as 1) habitual dietary nitrate intake, 2) the purpose of supplementation (cardiovascular benefits or performance effects), and 3) characteristics of the athlete (e.g., training status, type of sport, sex, and body weight). With respect to the first factor, we assessed the habitual dietary nitrate intake in highly trained athletes in chapter 5 . Vegetables clearly provided most of the dietary nitrate, but the majority of the athletes had habitual nitrate intakes substantially below a standard supplemental dose. We concluded that high habitual dietary nitrate intakes are unlikely to explain the less evident effects of nitrate supplementation on performance in highly trained athletes. However, a few athletes exceeded daily nitrate intakes of a standard dose of beetroot juice concentrate $(400 \mathrm{mg}$ of nitrate), which could render additional nitrate supplementation ineffective in these individuals. Although it thus seems important to account for the habitual dietary nitrate intake of an individual athlete when recommending a dose for supplementation, the actual effect of habitual nitrate intake on the performance response to nitrate supplementation has not yet been investigated.

Secondly, the purpose of nitrate supplementation is an important factor to consider. For cardiovascular benefits, a dose above $300 \mathrm{mg}$ nitrate is suggested to be sufficient to lower blood pressure. A dose-response study (4) found similar reductions in systolic and diastolic blood pressure following both $350 \mathrm{mg}$ and 700 $\mathrm{mg}$, but to a less extent following $140 \mathrm{mg}$. Considering performance effects, Wylie et al. (6) found a reduction in oxygen consumption during submaximal exercise and improved time-to-task failure following both 521 and $1042 \mathrm{mg}$, but not following $260 \mathrm{mg}$ of nitrate supplementation. Based on this single report of the doseresponse relationship, most studies on nitrate supplementation and sports performance apply daily nitrate doses above $500 \mathrm{mg}$, which seems to be sufficient in recreationally trained athletes to allow performance benefits to occur. This 'effective dose' may however vary between different athletes, which leads us to the third factor: the characteristics of the athlete, such as training status and 
type of sport performed. It has been suggested that highly trained athletes may require a different nitrate supplementation strategy (i.e., higher dose and/or for a longer period) to elicit performance effects in comparison to more recreationally trained athletes $(15,23,24)$. Notably, these suggestions are based on studies in endurance-trained athletes, for whom it has become increasingly apparent that they may not benefit from nitrate supplementation (i.e., independent of the dose provided). In chapter 6, we are the first to compare the effects of nitrate supplementation between athletes of different training status specifically for highintensity sports. There were absolutely no differences in the plasma nitrate and nitrite concentrations at baseline or following beetroot juice supplementation between recreational, competitive, and elite sprint athletes. In Table 9.1 we extend on this information by reporting plasma nitrate and nitrite concentrations at baseline and following $800 \mathrm{mg}$ nitrate supplementation for all athletes of different training status and sports disciplines as included in the current thesis.

Table 9.1: Plasma nitrate and nitrite concentrations of male and female athletes

\begin{tabular}{|c|c|c|c|c|c|c|}
\hline Chapter & $\begin{array}{l}\text { Sport and } \\
\text { level }\end{array}$ & $\begin{array}{l}\text { Sample } \\
\text { size and } \\
\text { sex }\end{array}$ & $\begin{array}{l}\text { Baseline } \\
\text { plasma } \\
\text { nitrate } \\
(\mu \mathrm{mol} / \mathrm{L})\end{array}$ & $\begin{array}{c}\text { Plasma } \\
\text { nitrate } \\
2.5 \mathrm{~h} \\
\text { after BR } \\
(\mu \mathrm{mol} / \mathrm{L})\end{array}$ & $\begin{array}{c}\text { Baseline } \\
\text { plasma } \\
\text { nitrite } \\
(\mathrm{nmol} / \mathrm{L})\end{array}$ & $\begin{array}{c}\text { Plasma } \\
\text { nitrite } 2.5 \\
\text { h after BR } \\
\text { (nmol/L) }\end{array}$ \\
\hline 3 & $\begin{array}{l}\text { Highly } \\
\text { trained } \\
\text { cycling }\end{array}$ & 17 males & $65 \pm 16$ & $509 \pm 70$ & $235 \pm 82$ & $508 \pm 212$ \\
\hline 4 & $\begin{array}{l}\text { Recreational } \\
\text { active }\end{array}$ & $\begin{array}{l}11 \text { males } \\
7 \text { females }\end{array}$ & $\begin{array}{l}57 \pm 19 \\
69 \pm 20\end{array}$ & $\begin{array}{l}503 \pm 83 \\
636 \pm 100\end{array}$ & $\begin{array}{c}160 \pm 92 \\
96 \pm 54\end{array}$ & $\begin{array}{c}436 \pm 234 \\
498 \pm 164\end{array}$ \\
\hline 6 & $\begin{array}{l}\text { Recreational } \\
\text { active }\end{array}$ & $\begin{array}{l}10 \text { males } \\
10 \text { females }\end{array}$ & $\begin{array}{c}45 \pm 20 \\
50 \pm 19\end{array}$ & $\begin{array}{l}590 \pm 105 \\
642 \pm 144\end{array}$ & $\begin{array}{c}114 \pm 61 \\
168 \pm 55\end{array}$ & $\begin{array}{l}456 \pm 156 \\
654 \pm 291\end{array}$ \\
\hline & $\begin{array}{l}\text { Competitive } \\
\text { sprint/HI }\end{array}$ & $\begin{array}{l}14 \text { males } \\
8 \text { females }\end{array}$ & $\begin{array}{c}48 \pm 20 \\
43 \pm 14\end{array}$ & $\begin{array}{l}602 \pm 96 \\
671 \pm 149\end{array}$ & $\begin{array}{r}141 \pm 68 \\
152 \pm 48\end{array}$ & $\begin{array}{l}460 \pm 135 \\
722 \pm 291\end{array}$ \\
\hline & Elite sprint & $\begin{array}{l}5 \text { males } \\
5 \text { females }\end{array}$ & $\begin{array}{c}46 \pm 24 \\
28 \pm 8\end{array}$ & $\begin{array}{l}564 \pm 54 \\
743 \pm 165\end{array}$ & $\begin{array}{r}107 \pm 31 \\
103 \pm 43\end{array}$ & $\begin{array}{l}325 \pm 23 \\
680 \pm 268\end{array}$ \\
\hline 7 & $\begin{array}{l}\text { Elite water } \\
\text { polo }\end{array}$ & 14 females & $57 \pm 28$ & $751 \pm 118$ & $160 \pm 47$ & $516 \pm 268$ \\
\hline 8 & $\begin{array}{l}\text { Highly } \\
\text { trained } \\
\text { cycling }\end{array}$ & 16 males & $41 \pm 15$ & $502 \pm 57$ & $228 \pm 45$ & $749 \pm 241$ \\
\hline TOTAL & & $\begin{array}{l}73 \text { males } \\
44 \\
\text { females }\end{array}$ & $\begin{array}{c}51 \pm 20 \\
51 \pm 23 \\
(P=1.00)\end{array}$ & $\begin{array}{c}539 \pm 88 \\
692 \pm 137 \\
(P<0.001)\end{array}$ & $\begin{array}{c}179 \pm 84 \\
144 \pm 55 \\
(P=0.007)\end{array}$ & $\begin{array}{c}521 \pm 230 \\
601 \pm 261 \\
(P=0.087)\end{array}$ \\
\hline
\end{tabular}




\section{Chapter 9}

For all studies we reported substantial increases (8-13-fold) in plasma nitrate concentrations following dietary nitrate supplementation, which is in line with (or higher than) what has been reported in other studies using similar dietary nitrate doses. Furthermore, we report an efficient bioconversion into nitrite, as 2-5-fold increases in plasma nitrite concentrations were seen following dietary nitrate supplementation, also in line with other literature $(5,6,8,12)$. Thus, in contrast to the previously reported blunted plasma response to beetroot juice supplementation in highly trained compared with less trained subjects (15), we found absolutely no differences in plasma nitrate or nitrite concentrations both at baseline and following nitrate supplementation between athletes of different training status (Table 9.1). Including a substantial number of 117 athletes and using the gold standard methodology for determination of plasma nitrate and nitrite, we argue that there is no reason to differentiate on training status when choosing the nitrate supplementation protocol to effectively increase plasma nitrate and nitrite concentrations. Furthermore, with the substantial increases in plasma nitrate and nitrite concentrations observed following nitrate ingestion (Table 9.1), the $800 \mathrm{mg}$ nitrate dose provided in this thesis has been ample sufficient to elicit beneficial effects.

Importantly, in their recent review on nitrate supplementation and performance studies, McMahon et al. (19) report that although increased plasma nitrate and nitrite concentrations provide evidence for effective uptake and bioconversion of dietary nitrate, the extent of the post-prandial rise in plasma nitrate or nitrite concentrations does not relate to effect size on performance. There are many factors that likely determine the individual response to nitrate supplementation, including effective uptake (gut dependent), effective bioconversion (dependent on oral microbiome), and most importantly local conversion and utilization of NO. Currently there are very limited data on how these issues differ between individuals based on training status, genetic background, habitual dietary nitrate intake, etc. Interestingly though, sex has been shown to be a relevant factor. When combining all our data, we noticed that plasma nitrate concentrations increase to a greater extent following nitrate supplementation in females compared with their male counterparts. A lower bodyweight could be suggested as an explanation for the greater increase in women. However, also when correcting for body weight, increases in plasma nitrate concentrations following nitrate ingestion were higher in the women (chapter 4). Despite the larger increases in plasma nitrate concentrations in women, the increase in plasma nitrite concentrations did not differ between women and men. Thus, the higher or faster uptake of the supplement does not seem to translate into a higher bioconversion. And most importantly, women apparently do not have an improved local conversion 
and utilization of NO, as the impact on blood pressure (chapter 4) and performance (chapter 7) appear similar in women and men. In line, higher plasma nitrate responses to nitrate supplementation have previously been reported for women compared to men, without any differences in the physiological response (25). A possible explanation for the absence of such physiological differences could be the existence of a plateau for the functional effects of nitrate supplementation. This was also observed in the dose-response studies where plasma nitrate concentrations continued to increase in a dose-dependent manner, whereas the impact on performance (6) and blood pressure (4) plateaued at the higher dietary nitrate doses. Whether this plateau is similar for women and men remains unknown, but it could be speculated that women may need lower dietary nitrate doses than men to reach this plateau. To increase knowledge on the potential sex-dependent differences in the response to nitrate, more studies including male and female subjects within the same study population are needed.

Another factor that may explain some of the differences observed in the response to nitrate supplementation between individuals may be the ability to locally store nitrate for later use as a NO donor. In this light, our group has recently shown that basal nitrate concentrations are greater in skeletal muscle tissue when compared with plasma concentrations (26). Furthermore, dietary nitrate ingestion does not only increase plasma nitrate, but also muscle nitrate contents. Differences in such a 'reserve storage capacity' of nitrate, and in its increase through nitrate intake, likely affect the nitrate dose needed to induce beneficial effects. Given our current lack of understanding of all the factors that play a role in 'how much nitrate is needed', it is very difficult to come up with a general or even individualized advice on the preferred supplementation dose. When aiming for ergogenic effects of nitrate in athletes, it seems that fairly large doses are well tolerated, especially when provided in the form of a beetroot juice concentrate. For now, a daily dose of 600-800 $\mathrm{mg}$ of nitrate seems to serve as an effective strategy to increase plasma nitrate/nitrite concentrations and induce performance benefits in male and female athletes.

\section{Effective nitrate source}

The final aspect to consider regarding the nitrate supplementation protocol is the source of nitrate. Considering the absence of any performance effects following acute or 6 days of nitrate supplementation (chapter 3), we discussed whether the use of sodium nitrate as opposed to e.g. beetroot juice may explain our findings. Relative to the provided nitrate dose, similar increases in plasma nitrate and nitrite concentrations following sodium nitrate $(27,28)$ and beetroot juice ingestion $(6,8$, 12) were previously reported. In chapter 4 , we extend on these findings by 


\section{Chapter 9}

presenting the first study comparing the acute responses to the exact same dose of nitrate from different sources. We found similar increases in plasma nitrate and nitrite concentrations following the ingestion of $800 \mathrm{mg}$ nitrate from sodium nitrate, beetroot juice, spinach smoothie and rocket salad smoothie. However, the further reduction from nitrite to $\mathrm{NO}$ is greatly enhanced by reducing compounds such as vitamin C and polyphenols (29-31). As such, it could be speculated that nitrate from natural vegetable sources (with high levels of vitamin $C$ and polyphenols) may be more effective than sodium nitrate in eliciting the effects of NO. Again, this would corroborate with previous indications that plasma nitrate/nitrite concentrations per se do not predict the extent of functional effects. Indeed, in chapter 4 a more pronounced effect on blood pressure was found when nitrate was provided from beetroot juice and vegetables when compared with the ingestion of sodium nitrate. Our findings are supported by previous work in healthy populations showing reductions in systolic and diastolic blood pressure following acute beetroot juice $(3-5,7,32)$, several days beetroot juice $(8,9,33)$ or acute spinach $(34,35)$ ingestion, whereas sodium nitrate ingestion only decreased diastolic blood pressure $(10,28)$. These findings can be further extended to athletes, as Flueck et al. (36) recently showed small but significant decreases in oxygen consumption during severe intensity exercise following beetroot juice when compared with placebo, but also when compared with sodium nitrate ingestion. In addition, Clifford et al. (37) found that beetroot juice attenuated muscle pain after exercise when compared with both placebo and sodium nitrate. Yet, both studies did not observe any differences between the nitrate sources for several other performance outcomes, such as oxygen consumption during moderate intensity exercise (36) and performance in maximal voluntary contractions or countermovement jumps (37). Future research should further establish whether beetroot juice or vegetable sources are more ergogenic than sodium nitrate, including the assessment of potential underlying mechanisms, i.e., which factors determine the efficacy of endogenous nitratenitrite-NO conversion and, as such, of a nitrate source. At present though, it is obvious that various nitrate-rich natural food sources can be used effectively as NO donors and, if provided in sufficient amounts, elicit ergogenic effects.

\section{Training status and exercise conditions}

The search for the optimal nitrate supplementation protocol is pointless if it is not applied under exercise conditions where NO availability may be limiting and, as such, dietary nitrate may act beneficial. The sports-related nitrate research started with studies reporting improvements in oxygen consumption and exercise capacity during endurance-type activities $(8,38)$. These studies, however, were conducted 
in recreationally trained athletes. As research on nitrate supplementation and endurance sports expanded, it appeared rather difficult to induce ergogenic effects of nitrate in more highly trained endurance athletes. In a study comparing groups of different endurance training status, it was finally concluded that nitrate supplementation was only beneficial for recreational and not for highly trained athletes (15), a standpoint that was quickly adopted by many researchers. At the same time though, new insights into the mechanisms behind the effects of nitrate supplementation on exercise performance led to a shift in attention towards more high-intensity exercise protocols, creating a situation that we believe could completely alter current views on the potential of nitrate supplementation to improve performance in elite athletes.

The nitrate-nitrite-NO pathway is particularly stimulated under conditions of low pH and low oxygen availability (39), and therefore nitrate supplementation is suggested to be most beneficial under conditions of relative hypoxia. This could be environmental 'systemic hypoxia', such as at high altitude, or 'local hypoxia' within the muscle, such as during (partly anaerobic) high-intensity and intermittent exercise. The relatively low oxygen tension surrounding type II (fast-twitch) muscle fibers, creates optimal circumstances for reduction of nitrite to NO (40), and animal work has shown that nitrate may largely convey its effect on exercise performance through type II muscle fibers $(14,41)$. Well-trained athletes of high-intensity sports likely have a high proportion of type II muscle fibers (1), theoretically increasing the ergogenic potential of nitrate. Well-trained endurance athletes however, typically have a low proportion of type II fibers in the trained musculature (42), and may therefore experience a lesser physiological response to nitrate supplementation. In line, several studies in highly trained endurance athletes have reported no effect of nitrate supplementation on performance (16-18, chapter 3 ). We conclude that highly trained and/or elite endurance athletes do not derive the same performance enhancing effects from dietary nitrate ingestion than those commonly reported in less trained populations.

Given the predominant effect of nitrate on type II muscle fibers, research attention has partly shifted to studies investigating the effects of nitrate supplementation on high-intensity intermittent-type sprint performance. Although repeated-sprint performance in moderately trained subjects has been shown to improve after several days of nitrate supplementation $(6,43-45)$, repeated-sprint performance remained unaltered when an acute nitrate dose was used $(46,47)$ and in elite endurance-trained athletes (18). Based on these studies, there is currently not enough knowledge on whether the training status of the athlete could affect the ergogenic potential of nitrate for sprint and/or power type activities, i.e., similar to what is observed for endurance-type activities. Therefore, in chapter 6 of 


\section{Chapter 9}

the current thesis, we compared the repeated-sprint performance following beetroot juice supplementation between recreational, competitive, and elite sprint athletes. Our main finding was that the lack of effect on peak power and mean power, and the improvement of time to reach peak power following beetroot juice supplementation were not dependent on athletes' sport level. To our knowledge, this is the first study to show that beetroot juice supplementation can improve the capacity to accelerate during sprints in recreational as well as elite athletes of high-intensity sports. We extended on these findings by investigating the effects of beetroot juice on high-intensity intermittent-type performance in elite female water polo players (chapter 7). The intermittent performance test aimed to create local hypoxia' due to the high-intensity and intermittent character of the repeated sprints. However, beetroot juice did not lead to an improved performance on this test, and possibly these elite athletes still managed to oxygenate their muscle sufficiently under such conditions, resulting in insufficient stimulation of the nitratenitrite-NO pathway. An elite athlete has probably developed a greater capacity to increase oxygen availability and will likely only experience beneficial effects of nitrate supplementation under extreme oxygen deprived conditions (48), which may not have been the case for this intermittent test lasting $\sim 5 \mathrm{~min}$. In contrast, we did find indications for a small improvement of the dynamic apnea test in elite water polo players. This test likely created an extreme hypoxic setting with a potential for ergogenic effects of nitrate supplementation even in an elite athlete. However, the test is neither sport-specific nor a direct performance test, representing an important limitation. Small sample sizes and a narrow window of opportunity for performance enhancement make it extremely challenging to detect a potential ergogenic effect of any intervention. The use of highly validated sport-specific performance tests with minor day-to-day variation is essential to establish the ergogenic potential of nitrate supplementation, especially in elite athletes. Unfortunately, such performance tests are not readily available for many sports. Therefore, we have to base our advice to the daily sports practice on the current scientific knowledge, while at the same time aiming to improve our testing abilities to resemble the actual competitive situation.

The repeated Wingate sprint test used in chapter 6 is an extensively validated and reproducible performance test for athletes of high-intensity and sprint disciplines on the bike (49). We observed improvements in time to reach peak power following beetroot juice supplementation, but no effects on peak power itself. Similar to our findings, Wylie et al. (45) found no improved power of repeated Wingate tests in recreational athletes, while performance on shorter sprints was improved following beetroot juice supplementation. These observations may be explained by a predominant effect of nitrate on the initial force production of 
fast-twitch muscle fibers. In support, an enhanced early-phase explosive force production was seen following nitrate supplementation in mouse fast-twitch muscle (14). Also in humans, nitrate supplementation has been reported to enhance force production during the initial phase of muscle contractions (50). Furthermore, nitrate supplementation can improve muscle calcium handling (14), which may elicit a greater impact during the initial phase of contraction where the calcium saturation normally is incomplete. The Olympic level track cyclists included in chapter 6 of this thesis all showed extremely high power outputs, up to $2800 \mathrm{~W}$ representing almost four horse power. Obviously, for such very-high-intensity sport disciplines, a high proportion of and ability to recruit type II muscle fibers is the key to success $(51,52)$. The differences in muscle fiber type composition and recruitment between elite athletes of endurance sports and those of sprint/high-intensity type sports, could very well explain the ergogenic effects of nitrate observed even in the elite sprint athletes in this thesis. Indeed, for elite athletes of sprint/high-intensity sports, nitrate supplementation could result in reaching top speed faster and improving actual sports performance in very short bursts of maximal activity.

\section{Elite athletes}

Due to various reasons, most sports nutrition studies include recreational to welltrained athletes, while very few studies are undertaken on world-class elite athletes (1). Busy schedules and conflicting priorities are possible arguments against intervention studies on elite athletes. In the current thesis however, we took on the challenge of recruiting and studying elite athletes of various sports disciplines, aiming to give answer to the question "can elite athletes benefit from dietary nitrate supplementation?" We dwelled on this question in the viewpoint paper in chapter 2. It is clear that this topic is of high interest, as 16 commentaries from other authors were published in response to our viewpoint (53). Until now, only five studies have investigated the impact of nitrate supplementation in elite, professional athletes, four of which found no effect on performance $(16-18,54)$. Only one study observed a small but significant decline in oxygen consumption during exercise, accompanied by an improvement in time-trial performance in elite kayak athletes (55). In the current thesis, we are the first to investigate the ergogenic effects of nitrate supplementation on different types of athletes from highly trained and even absolute world-class level, including World and Olympic champions. In line with the above-mentioned studies in elite athletes, the effects of beetroot juice on performance that we observed in highly trained and elite athletes were relatively minor (chapters 3, 6 and 7). Even though we standardized testing in the best possible way, used sport-specific performance tests where possible, and included 
the maximal number of elite athletes available nationally (10 in chapter 6 and 14 in chapter 7), it proved difficult to detect possible small performance benefits of nitrate supplementation. It is obvious though, that even minor benefits could be very relevant to elite athletes. A performance enhancement of less than $1 \%$ generally represents the difference between gold and not even reaching the podium, but such small differences in performance may indeed be difficult to detect (56). In Box 1, we summarize this and other issues addressed above, and provide an updated insight to why less effects of nitrate supplementation may be observed in elite athletes.

Box 1: Possible reasons why nitrate supplementation may not be as ergogenic in elite athletes

\section{1) Greater habitual nitrate intake in elite athletes?}

In chapter 5 the habitual dietary nitrate intake of most highly trained athletes was substantially lower than a supplemental dose of nitrate, and a blunted effect of nitrate supplementation in elite athletes is unlikely to be caused by high habitual dietary nitrate intakes.

\section{2) Higher baseline concentrations and attenuated increase in plasma nitrate/nitrite in elite athletes?}

As visualized in Table 9.1, there appear to be absolutely no differences in plasma nitrate and nitrite concentrations between athletes of different training status from multiple disciplines. We argue that any attenuated effect of nitrate supplementation in elite athletes is unlikely due to differences in basal or post-prandial plasma nitrate and/or nitrite concentrations between athletes of different training status.

\section{3) Extensive exercise training reconditioning in elite $\square$} athletes?

The extensive adaptive reconditioning in elite athletes ensures a greater metabolic and mechanical efficiency (57), reducing the window of opportunity for any ergogenic supplement. Since nitrate supplementation is most effective on type II muscle fibers and under conditions of low oxygen availability and low $\mathrm{pH}$, elite endurance athletes may not benefit from nitrate supplementation. On the other side, very high intensity (anaerobic) exercise and high dependency of type II muscle fibers go hand in hand. Consequently, nitrate supplementation may still have an ergogenic potential in elite athletes when assessed under such conditions.

\section{4) Methodological limitations in elite athlete research?}

Small sample size and very subtle expected differences are inherent to studying elite athletes. Furthermore, minor improvements may be overshadowed by possible period effects, due to difficulty in standardization of training periods, busy schedules and conflicting priorities, and potential improvements in performance measures may be difficult to translate to actual sports performance due to lack of sport-specific tests. A possible future approach would be to assess the reproducibility of the impact of nitrate supplementation on performance in competitive events within the same athlete. This may also provide information on the existence of potential responders or non-responders to nitrate supplementation, allowing more individualized nutritional counselling for the elite athlete. 
While in general, we should strive for excellent sport-specific research in elite athletes, it is not likely that all the (methodological) limitations mentioned in Box 1 will be resolved within a short timeframe. As such, for now we will have to provide the best possible advice to elite athletes based on available evidence from research on recreational athletes and try to translate these findings into what may be realistic for the elite athlete.

\section{Practical advice}

Based on the available literature including the work presented in this thesis, the following recommendations can be made (Figure 9.1), bearing in mind that we are still far from a consensus.

- Dose amount: A supplement of $-600-800 \mathrm{mg}$ of nitrate per day on top of a normal diet should be used.

- Dose duration: A minimum of 5 days of supplementation should be applied.

- Timing: To optimize benefits, beetroot juice should be ingested 2-3 $\mathrm{h}$ prior to the event and nitrate-rich vegetables a minimum of $3 \mathrm{~h}$ prior to the event.

- Source: A vegetable source is preferred over nitrate salts, taken as a supplement (e.g. 1.5-2 shots of concentrated beetroot juice) or through 300$400 \mathrm{~g}$ nitrate-rich vegetables per day. A few studies have shown that the effects of nitrate can be reached by meal ingestion $(4,58)$. However, whether such large vegetable intakes are practically achievable still needs to be investigated, and for most athletes consuming a beetroot juice concentrate would be the more practical and feasible strategy.

- Type of athletes: Nitrate is likely more beneficial under oxygen-limited conditions. This could be 'local hypoxia' in the muscle or 'systemic hypoxia' in the environment. Oxygen will more often be limiting for less trained athletes, who could benefit from nitrate at several types of events, including endurance type sports. Based on current evidence, nitrate supplementation may not be of much benefit to elite endurance athletes, while elite athletes partaking in sprint/power type and high-intensity intermittent type exercise tasks may still benefit from nitrate. 


\section{PRACTICAL ADVICE}

\section{$>5$ day}

supplementation

Normal diet contains

$\sim 100 \mathrm{mg}$ of nitrate per day

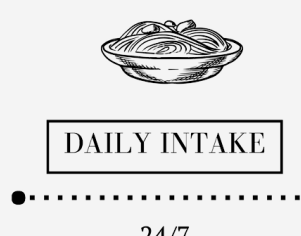

$24 / 7$

A supplement of $600-800 \mathrm{mg}$ of nitrate per day on top of a normal diet.

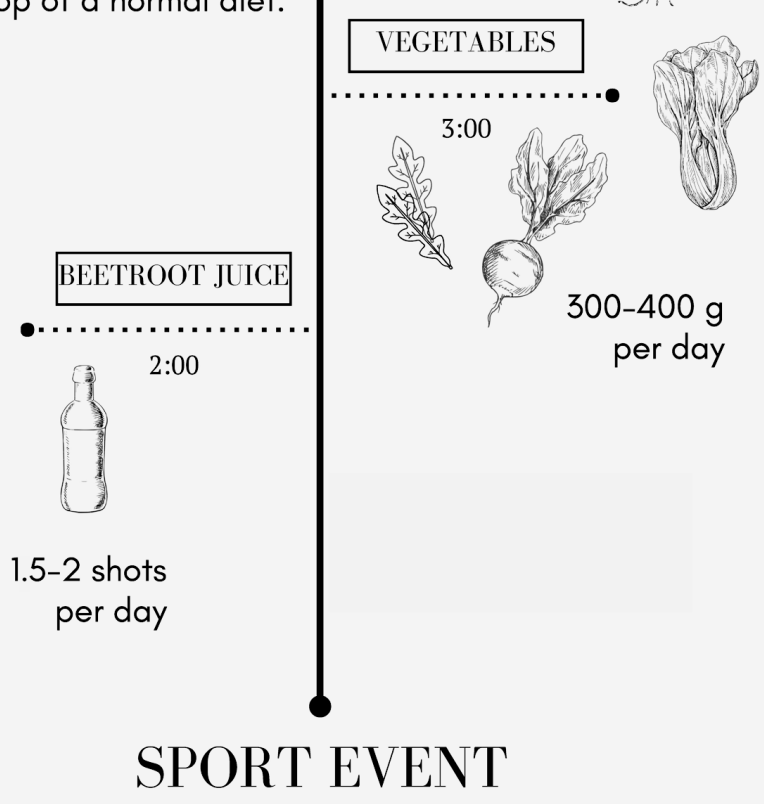

Figure 9.1: Recommendations for the use of nitrate supplementation in athletes 


\section{Clinical relevance}

Next to the effects of nitrate on performance, nitrate supplementation has a great potential for improvement of health. This broadens its impact towards the entire population and society in general. Several studies (3-7, 34, 35, chapter 4) have reported reductions in blood pressure following ingestion of beetroot juice and nitrate-rich vegetables in healthy, normotensive subjects. The effects of nitrate on blood pressure are likely even more substantial in the treatment of hypertension (59). In fact, dietary nitrate supplementation has been shown to decrease blood pressure in hypertensive patients to a similar extent as any anti-hypertensive drug (60). Furthermore, there are epidemiological and clinical data supporting the idea that nitrate from vegetables could represent an effective dietary intervention to lower blood pressure and improve cardiovascular health (61).

Just like for the athlete, it could be expected that patient groups experiencing low oxygen availability would benefit from nitrate supplementation. For instance, improved performance and reduced blood pressure have been reported following beetroot juice supplementation in COPD patients $(62,63)$. Currently though, the vascular effects of nitrate supplementation, including improvements in blood pressure, measures of arterial stiffness and platelet activity, have been more extensively established (64). In general, nitrate supplementation could be utilized for therapeutic benefit in those cardiovascular disease states where reduced bioavailable $\mathrm{NO}$ is thought to contribute to the pathogenesis, including hypertension and stroke or myocardial infarction caused by arterial occlusion or stiffness (59). Unfortunately, so far there have been no studies investigating the cardiovascular effects of nitrate supplementation in humans beyond four weeks (65). As such, long-term clinical studies are needed before we can recommend the use of nitrate supplementation for any clinical indication. The same is of course the case for athletes, where the longest duration of nitrate supplementation also has been four weeks (66). It remains to be established whether beyond this period, nitrate supplementation may continue to improve performance and/or health, or potentially even cause deleterious physiological adaptations.

\section{Future research}

Nitrate supplementation for exercise performance has become a hot topic, but as a research field it is still in its infancy with the first study being published just over a decade ago in 2007 (38). Since then, the research on the ergogenic effects of nitrate has provided relevant insight in several aspects of nitrate supplementation. However, there are still a number of important topics to address, some of which are listed below: 
- Women vs men: There are various indications that plasma nitrate and nitrite concentrations (both baseline and in response to nitrate intake) may differ between women and men. The potential sex-dependent differences in the response to nitrate supplementation should be further investigated.

- Repeated testing within individual (elite) athletes of high-intensity sports: With the limited number of 'small sample size' studies in elite athletes, future research focusing on repeated testing of elite athletes of high-intensity sports would be an important yet challenging next step to determine whether there are reproducible performance effects of nitrate supplementation in elite athletes.

- Multiple events: Most nitrate research has investigated the effect of nitrate supplementation on performance during a subsequent bout of exercise. However, recommendations for the repeated use of nitrate in sports involving two or more events within a 24-h period or a tournament over several days may be more relevant to many athletes. The optimal strategy for nitrate supplementation around multiple bouts of exercise still needs to be investigated.

- Combinations of supplements: Limited knowledge exists for the total effect on performance when using combinations of supplements, for which performance benefits have been observed (1). Studies on the ergogenic properties of nitrate supplementation in combination with other supplements (67) will be of value for athletes in the choice of which supplements to use or rather not to use.

- Long-term use of nitrate: Until recently, nitrate and nitrite were considered inert byproducts of $\mathrm{NO}$ metabolism and unfavorable dietary constituents. Public perception has been that these are harmful substances in our food and water supply (68). Ironically, most people would not argue that a vegetable-rich, and thus nitrate-rich, diet is unhealthy. However, no study has investigated the effects of nitrate supplementation in humans beyond four weeks $(65,66)$. Studies on long-term effects of high nitrate intakes through supplementation are needed to investigate long-term benefits as well as potential harmful effects on both performance and health.

- Nitrate at altitude: The 'systemic hypoxia' of high altitude is an interesting setting for nitrate research. At simulated altitude, nitrate supplementation has been shown to improve oxygen efficiency and exercise capacity/performance, but not performance-related adaptations over time (69). Future studies should investigate whether the effects of nitrate supplementation that have been demonstrated at simulated altitude also manifest at actual high altitude. 


\section{References}

1. Burke LM. Practical Issues in Evidence-Based Use of Performance Supplements: Supplement Interactions, Repeated Use and Individual Responses. Sports Med. 2017;47(Suppl 1):79-100.

2. Hoon MW, Johnson NA, Chapman PG, Burke LM. The effect of nitrate supplementation on exercise performance in healthy individuals: a systematic review and meta-analysis. Int J Sport Nutr Exerc Metab. 2013;23:522-32.

3. Webb AJ, Patel N, Loukogeorgakis S, Okorie M, Aboud Z, Misra S, et al. Acute blood pressure lowering, vasoprotective, and antiplatelet properties of dietary nitrate via bioconversion to nitrite. Hypertension. 2008;51:784-90.

4. Hobbs DA, Kaffa N, George TW, Methven L, Lovegrove JA. Blood pressure-lowering effects of beetroot juice and novel beetroot-enriched bread products in normotensive male subjects. $\mathrm{Br} \mathrm{J}$ Nutr. 2012;108:2066-74.

5. Lansley KE, Winyard PG, Bailey SJ, Vanhatalo A, Wilkerson DP, Blackwell JR, et al. Acute dietary nitrate supplementation improves cycling time trial performance. Med Sci Sports Exerc. 2011;43:1125-31.

6. Wylie LJ, Kelly J, Bailey SJ, Blackwell JR, Skiba PF, Winyard PG, et al. Beetroot juice and exercise: pharmacodynamic and dose-response relationships. J Appl Physiol (1985). 2013;115:325-36.

7. Coles LT, Clifton PM. Effect of beetroot juice on lowering blood pressure in free-living, disease-free adults: a randomized, placebo-controlled trial. Nutrition Journal. 2012;11(1):106-11.

8. Bailey SJ, Winyard P, Vanhatalo A, Blackwell JR, Dimenna FJ, Wilkerson DP, et al. Dietary nitrate supplementation reduces the $\mathrm{O} 2$ cost of low-intensity exercise and enhances tolerance to high-intensity exercise in humans. J Appl Physiol. 2009;107:1144-55.

9. Vanhatalo A, Bailey S, Blackwell J, DiMenna F, Pavey TG, Wilkerson DP, Benjamin N, Winyard P, Jones AM. Acute and chronic effects of dietary nitrate supplementation on blood pressure and the physiological responses to moderate-intensity and incremental exercise. Am J Physiol Regul Integr Comp Physiol 2010;299:1121-31.

10. Larsen FJ, Ekblom B, Sahlin K, Lundberg JO, Weitzberg E. Effects of dietary nitrate on blood pressure in healthy volunteers. N Engl J Med. 2006;355:2792-3.

11. Porcelli S, Pugliese L, Rejc E, Pavei G, Bonato M, Montorsi M, et al. Effects of a Short-Term High-Nitrate Diet on Exercise Performance. Nutrients. 2016;8(9).

12. Lansley KE, Winyard P, Fulford J, Vanhatalo A, Bailey S, Blackwell JR, DiMenna F, Gilchrist M, Benjamin $\mathrm{N}$, Jones AM. Dietary nitrate supplementation reduces the $\mathrm{O} 2$ cost of walking and running: a placebocontrolled study. J Appl Physiol 2011;110:591-600.

13. Larsen FJ, Schiffer TA, Borniquel S, Sahlin K, Ekblom B, Lundberg JO, et al. Dietary inorganic nitrate improves mitochondrial efficiency in humans. Cell Metab. 2011;13:149-59.

14. Hernandez A, Schiffer TA, Ivarsson N, Cheng AJ, Bruton JD, Lundberg JO, et al. Dietary nitrate increases tetanic [Ca2+]i and contractile force in mouse fast-twitch muscle. J Physiol. 2012;590(15):3575-83.

15. Porcelli S, Ramaglia M, Bellistri G, Pavei G, Pugliese L, Montorsi M, et al. Aerobic Fitness Affects the Exercise Performance Responses to Nitrate Supplementation. Med Sci Sports Exerc. 2015;47(8):164351.

16. Peacock O, Tjonna AE, James P, Wisloff U, Welde B, Bohlke N, et al. Dietary nitrate does not enhance running performance in elite cross-country skiers. Med Sci Sports Exerc. 2012;44:2213-9.

17. Sandbakk SB, Sandbakk O, Peacock O, James P, Welde B, Stokes K, et al. Effects of acute supplementation of L-arginine and nitrate on endurance and sprint performance in elite athletes. Nitric Oxide. 2015; 48:10-5.

18. Christensen PM, Nyberg M, Bangsbo J. Influence of nitrate supplementation on VO(2) kinetics and endurance of elite cyclists. Scand J Med Sci Sports. 2013;23:e21-31.

19. McMahon NF, Leveritt MD, Pavey TG. The Effect of Dietary Nitrate Supplementation on Endurance Exercise Performance in Healthy Adults: A Systematic Review and Meta-Analysis. Sports Med. 2017;47(4):735-56.

20. McKnight GM, Smith LM, Drummond RS, Duncan CW, Golden M, Benjamin N. Chemical synthesis of nitric oxide in the stomach from dietary nitrate in humans. Gut. 1997;40(2):211-4.

21. Dejam A, Hunter CJ, Tremonti C, Pluta RM, Hon YY, Grimes G, et al. Nitrite infusion in humans and nonhuman primates: endocrine effects, pharmacokinetics, and tolerance formation. Circulation. 2007;116(16):1821-31. 


\section{Chapter 9}

22. Hunault CC, van Velzen AG, Sips AJ, Schothorst RC, Meulenbelt J. Bioavailability of sodium nitrite from an aqueous solution in healthy adults. Toxicol Lett. 2009;190(1):48-53.

23. Wilkerson DP, Hayward GM, Bailey SJ, Vanhatalo A, Blackwell JR, Jones AM. Influence of acute dietary nitrate supplementation on 50 mile time trial performance in well-trained cyclists. Eur J Appl Physiol. 2012;112:4127-34.

24. Cermak NM, Res $P$, Stinkens R, Lundberg JO, Gibala MJ, van Loon $L$. No improvement in endurance performance after a single dose of beetroot juice. Int J Sport Nutr Exerc Metab. 2012;22:470-8.

25. Kapil V, Milsom AB, Okorie M, Maleki-Toyserkani S, Akram F, Rehman F, et al. Inorganic nitrate supplementation lowers blood pressure in humans: role for nitrite-derived NO. Hypertension. 2010;56:274-81.

26. Nyakayiru J, Kouw IWK, Cermak NM, Senden JM, van Loon LC, Verdijk LB. Sodium nitrate ingestion increases skeletal muscle nitrate content in humans. J Appl Physiol (1985). 2017;123(3):637-44.

27. Lundberg JO, Govoni M. Inorganic nitrate is a possible source for systemic generation of nitric oxide. Free Radic Biol Med. 2004;37:395-400.

28. Larsen FJ, Weitzberg E, Lundberg JO and Ekblom B. Dietary nitrate reduces maximal oxygen consumption while maintaining work performance in maximal exercise. Free Radic Biol Med. 2010;48: 342-347.

29. Peri L, Pietraforte D, Scorza G, Napolitano A, Fogliano V, Minetti M. Original Contribution: Apples increase nitric oxide production by human saliva at the acidic $\mathrm{pH}$ of the stomach: $\mathrm{A}$ new biological function for polyphenols with a catechol group? Free Radic Biol Med. 2005;39:668-81.

30. Gago B, Lundberg JO, Barbosa RM, Laranjinha Jo. Original Contribution: Red wine-dependent reduction of nitrite to nitric oxide in the stomach. Free Radic Biol Med 2007;43:1233-42.

31. Weitzberg E, Lundberg JO. Nonenzymatic nitric oxide production in humans. Nitric Oxide 1998;2(1):1-7.

32. Wylie LJ, Mohr M, Krustrup P, Jackman SR, Ermiotadis G, Kelly J, et al. Dietary nitrate supplementation improves team sport-specific intense intermittent exercise performance. Eur J Appl Physiol. 2013;113:1673-84.

33. Bailey SJ, Fulford J, Vanhatalo A, Winyard PG, Blackwell JR, DiMenna FJ, et al. Dietary nitrate supplementation enhances muscle contractile efficiency during knee-extensor exercise in humans. J Appl Physiol. 2010;109:135-48.

34. Jovanovski E, Bosco L, Khan K, Au-Yeung F, Ho H, Zurbau A, Jenkins AL, Vuksan V. Effect of Spinach, a High Dietary Nitrate Source, on Arterial Stiffness and Related Hemodynamic Measures: A Randomized, Controlled Trial in Healthy Adults. Clinical Nutrition Research 2015;4(3):160-7.

35. Bondonno CP, Yang X, Croft KD, Considine MJ, Ward NC, Rich L, Puddey IB, Swinny E, Mubarak A, Hodgson JM. Flavonoid-rich apples and nitrate-rich spinach augment nitric oxide status and improve endothelial function in healthy men and women: a randomized controlled trial. Free Radic Biol Med 2012;52(1):95-102.

36. Flueck JL, Bogdanova A, Mettler S, Perret C. Is beetroot juice more effective than sodium nitrate? The effects of equimolar nitrate dosages of nitrate-rich beetroot juice and sodium nitrate on oxygen consumption during exercise. Appl Physiol Nutr Metab. 2016;41(4):421-9.

37. Clifford T, Howatson G, West DJ, Stevenson EJ. Beetroot juice is more beneficial than sodium nitrate for attenuating muscle pain after strenuous eccentric-bias exercise. Appl Physiol Nutr Metab. 2017; 42(11):1185-1191.

38. Larsen FJ, Weitzberg E, Lundberg JO, Ekblom B. Effects of dietary nitrate on oxygen cost during exercise. Acta Physiol. 2007;191(1):59-66.

39. Lundberg JO, Weitzberg E, Gladwin MT. The nitrate-nitrite-nitric oxide pathway in physiology and therapeutics. Nat Rev Drug Discov. 2008;7:156-67.

40. Jones AM, Ferguson SK, Bailey SJ, Vanhatalo A, Poole DC. Fiber Type-Specific Effects of Dietary Nitrate. Exerc Sport Sci Rev. 2016;44(2):53-60.

41. Ferguson SK, Holdsworth CT, Wright JL, Fees AJ, Allen JD, Jones AM, et al. Microvascular oxygen pressures in muscles comprised of different fiber types: Impact of dietary nitrate supplementation. Nitric Oxide. 2015; 48:38-43.

42. Tesch PA, Karlsson J. Muscle fiber types and size in trained and untrained muscles of elite athletes. J Appl Physiol (1985). 1985;59(6):1716-20.

43. Thompson C, Vanhatalo A, Jell H, Fulford J, Carter J, Nyman L, et al. Dietary nitrate supplementation improves sprint and high-intensity intermittent running performance. Nitric Oxide. 2016;61:55-61. 
44. Thompson C, Wylie LJ, Fulford J, Kelly J, Black MI, McDonagh STJ, et al. Dietary nitrate improves sprint performance and cognitive function during prolonged intermittent exercise. Eur J Appl Physiol. 2015;115(9):1825-34.

45. Wylie LJ, Bailey SJ, Kelly J, Blackwell JR, Vanhatalo A, Jones AM. Influence of beetroot juice supplementation on intermittent exercise performance. Eur J Appl Physiol. 2016;116(2):415-25.

46. Muggeridge DJ, Howe CC, Spendiff O, Pedlar C, James PE, Easton C. The effects of a single dose of concentrated beetroot juice on performance in trained flatwater kayakers. Int J Sport Nutr Exerc Metab. 2013;23:498-506.

47. Martin K, Smee D, Thompson KG, Rattray B. No improvement of repeated-sprint performance with dietary nitrate. Int J Sports Physiol Perform. 2014;9:845-50.

48. Jones AM. Influence of dietary nitrate on the physiological determinants of exercise performance: a critical review. Appl Physiol Nutr Metab. 2014;39(9):1019-28.

49. Jaafar H, Rouis $M$, Coudrat L, Attiogbe E, Vandewalle H, Driss T. Effects of load on wingate test performances and reliability. J Strength Cond Res. 2014;28(12):3462-8.

50. Haider G, Folland JP. Nitrate supplementation enhances the contractile properties of human skeletal muscle. Med Sci Sports Exerc. 2014;46(12):2234-43.

51. Mero A, Komi PV, Gregor RJ. Biomechanics of sprint running. A review. Sports Med. 1992;13(6):376-92.

52. Lockie RG, Murphy AJ, Knight TJ, Janse de Jonge XA. Factors that differentiate acceleration ability in field sport athletes. J Strength Cond Res. 2011;25(10):2704-14.

53. Hultstrom M, Amorim de Paula C, Antonio Peliky Fontes M, Porcelli S, Bellistri G, Pugliese L, et al. Commentaries on Viewpoint: Can elite athletes benefit from dietary nitrate supplementation? J Appl Physiol (1985). 2015;119(6):762-9.

54. Boorsma RK, Whitfield J, Spriet LL. Beetroot juice supplementation does not improve performance of elite 1500-m runners. Med Sci Sports Exerc. 2014;46(12):2326-34.

55. Peeling P, Cox GR, Bullock N, Burke LM. Beetroot Juice Improves On-Water 500 M Time-Trial Performance, and Laboratory-Based Paddling Economy in National and International-Level Kayak Athletes. Int J Sport Nutr Exerc Metabol. 2015;25(3):278-84.

56. Hopkins WG, Schabort EJ, Hawley JA. Reliability of power in physical performance tests. Sports Med. 2001;31(3):211-34.

57. Jensen L, Bangsbo J, Hellsten Y. Effect of high intensity training on capillarization and presence of angiogenic factors in human skeletal muscle. J Physiol. 2004;557:571-82.

58. Liu AH, Bondonno CP, Croft KD, Puddey IB, Woodman RJ, Rich L, et al. Effects of a nitrate-rich meal on arterial stiffness and blood pressure in healthy volunteers. Nitric Oxide. 2013;35:123-30.

59. Kapil V, Weitzberg E, Lundberg JO, Ahluwalia A. Clinical evidence demonstrating the utility of inorganic nitrate in cardiovascular health. Nitric Oxide. 2014;38:45-57.

60. Ghosh SM, Kapil V, Fuentes-Calvo I, Bubb KJ, Pearl V, Milsom AB, et al. Enhanced vasodilator activity of nitrite in hypertension: critical role for erythrocytic xanthine oxidoreductase and translational potential. Hypertension. 2013;61(5):1091-102.

61. Gee LC, Ahluwalia A. Dietary Nitrate Lowers Blood Pressure: Epidemiological, Pre-clinical Experimental and Clinical Trial Evidence. Curr Hypertens Rep. 2016;18(2):17.

62. Berry MJ, Justus NW, Hauser JI, Case AH, Helms CC, Basu S, et al. Dietary nitrate supplementation improves exercise performance and decreases blood pressure in COPD patients. Nitric Oxide. 2015;48:22-30.

63. Kerley CP, Cahill K, Bolger K, McGowan A, Burke C, Faul J, et al. Dietary nitrate supplementation in COPD: an acute, double-blind, randomized, placebo-controlled, crossover trial. Nitric Oxide. 2015;44:105-11.

64. Rathod KS, Velmurugan S, Ahluwalia A. A 'green' diet-based approach to cardiovascular health? Is inorganic nitrate the answer? Mol Nutr Food Res. 2016;60(1):185-202.

65. Kapil V, Khambata RS, Robertson A, Caulfield MJ, Ahluwalia A. Dietary Nitrate Provides Sustained Blood Pressure Lowering in Hypertensive Patients: A Randomized, Phase 2, Double-Blind, Placebo-Controlled Study. Hypertension. 2015;65(2):320-7.

66. Thompson C, Wylie LJ, Blackwell JR, Fulford J, Black MI, Kelly J, et al. Influence of dietary nitrate supplementation on physiological and muscle metabolic adaptations to sprint interval training. J Appl Physiol (1985). 2017;122(3):642-52. 


\section{Chapter 9}

67. Lane SC, Hawley JA, Desbrow B, Jones AM, Blackwell JR, Ross ML, et al. Single and combined effects of beetroot juice and caffeine supplementation on cycling time trial performance. Appl Physiol Nutr Metab. 2014;39:1050-7.

68. Lundberg JO, Gladwin MT, Ahluwalia A, Benjamin N, Bryan NS, Butler A, et al. Nitrate and nitrite in biology, nutrition and therapeutics. Nat Chem Biol. 2009;5(12):865-9.

69. Shannon OM, McGawley K, Nyback L, Duckworth L, Barlow MJ, Woods D, et al. "Beet-ing" the Mountain: A Review of the Physiological and Performance Effects of Dietary Nitrate Supplementation at Simulated and Terrestrial Altitude. Sports Med. 2017;47(11):2155-6. 


\section{Summary}

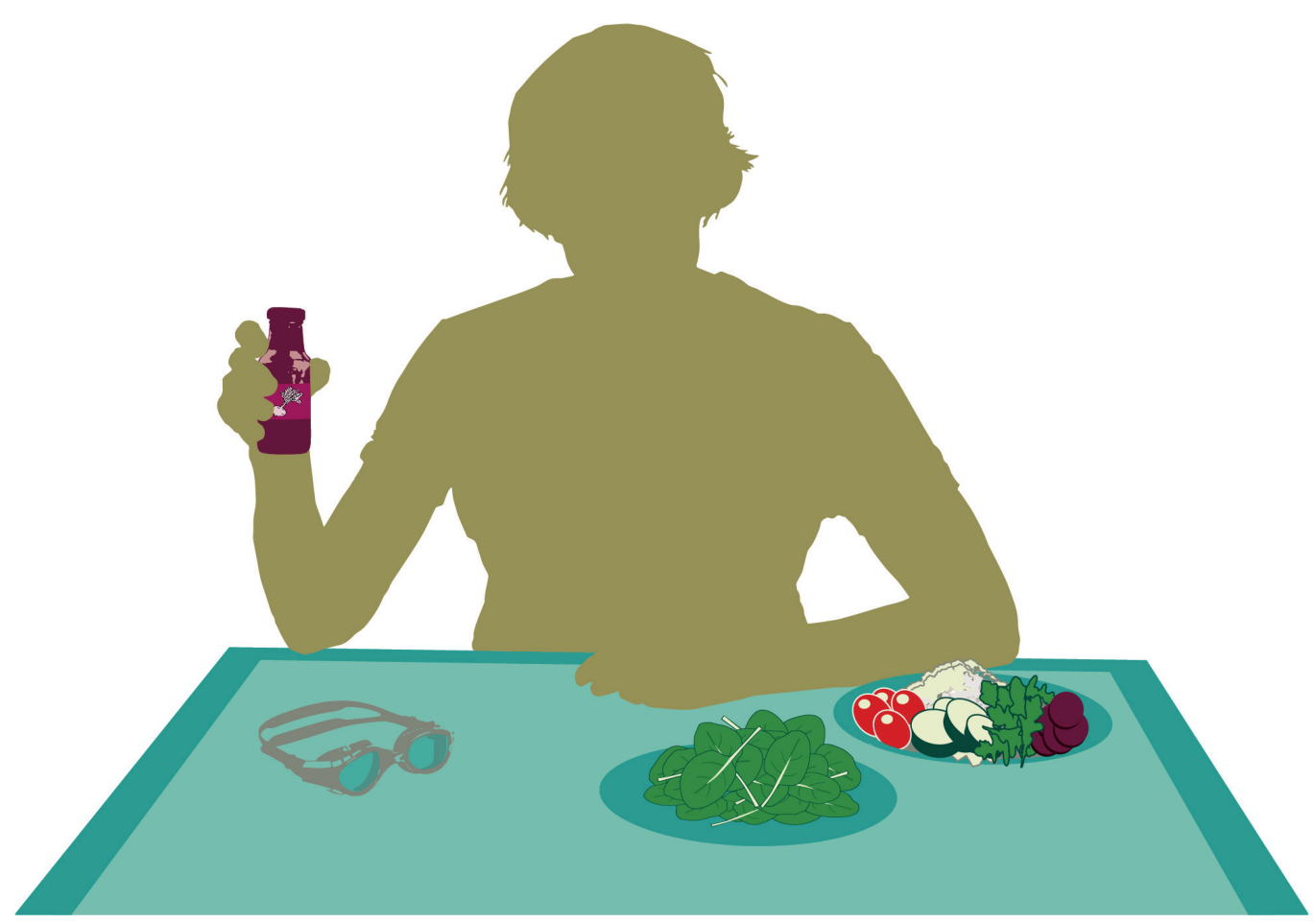




\section{Summary}

Dietary nitrate supplementation is used by many athletes to enhance sports performance. The potential ergogenic effects of nitrate are attributed to its endogenous reduction into nitrite and, subsequently, nitric oxide (NO), thereby increasing the bioavailability of this highly bioactive compound, which regulates several processes such as blood flow and muscle contraction. Nitrate supplementation seems to be more effective under conditions where oxygen is a limiting factor. Acute effects of nitrate include vasodilation and thereby increased systemic blood flow and oxygen supply, while the more 'adaptive' effects seem to concern improvements at the myocellular level, such as enhanced contractility and decreased oxygen cost of ATP production. In this thesis, we aimed to provide further insight into how nitrate supplementation can be used to enhance sports performance, under which conditions and in which athletes. One of the focus areas of this thesis was to investigate whether elite athletes can benefit from dietary nitrate supplementation.

In chapter 2, we present a viewpoint entitled Can elite athletes benefit from dietary nitrate supplementation?, in which we address the key questions concerning the proposed ergogenic effects of nitrate supplementation in elite athletes, providing a foundation for the various studies described in this thesis. As there is little known about the preferred duration of supplementation, the daily nitrate dose needed, and the nitrate source to maximize the ergogenic potential of nitrate supplementation, we next studied some of these aspects. In chapter 3 we compared the effects of acute and 6 days of sodium nitrate supplementation on oxygen consumption during submaximal exercise and subsequent $10 \mathrm{~km}$ time-trial performance. However, no effects of nitrate supplementation were observed following both the acute and the 6-day intervention. We propose that this is most likely caused by the high training level of the endurance athletes included in this study, and/or by the choice for sodium nitrate as the nitrate carrier, which may be less effective than vegetable nitrate sources. Indeed in chapter 4, we showed that the effects of nitrate supplementation may be dependent on the NO donor chosen. Here, we provided an acute dose of nitrate from sodium nitrate, concentrated beetroot juice, spinach, and rocket salad, and investigated the increase in plasma nitrate and nitrite concentrations and the subsequent effects on resting blood pressure in a group of healthy young men and women. All four nitrate sources resulted in similar increases in plasma nitrate and nitrite concentrations, indicating an efficient absorption and endogenous bioconversion of the supplement. However, the three vegetable sources reduced resting blood pressure to a greater extent than sodium nitrate. We concluded that nitrate-rich vegetables can effectively be used as dietary nitrate supplements and may actually be more effective than socalled nitrate salts. Based on this finding we next investigated whether a high(er) 
habitual vegetable and nitrate intake could explain why highly trained athletes seem to benefit less from nitrate supplementation (chapter 5). Based on multiple 24-h dietary recalls, we estimated the dietary nitrate intake of 553 Dutch athletes, ranging from well-trained to Olympic level. For the vast majority of athletes, nitrate intake from their habitual diet was substantially lower than any supplemental dose that would be deemed effective to induce ergogenic effects. Hence, we concluded that for most athletes the habitual dietary nitrate intake is not a sufficient substitute for nitrate supplementation and certainly does not explain why highly trained athletes seem to benefit less from nitrate supplementation.

In view of the suggestions that nitrate supplementation may be more effective for recreational athletes and during high-intensity exercise, we compared the metabolic and functional responses to beetroot juice between recreational, competitive and elite athletes, completing the exact same repeated-sprint exercise protocol (i.e., repeated Wingate tests). In chapter 6, we show that the plasma nitrate and nitrite concentrations at baseline and following beetroot juice supplementation did not differ between athletes with these different training levels. This is in stark contrast to previous suggestions that elite athletes might have higher baseline plasma nitrate and nitrite concentrations and/or an attenuated plasma response to nitrate supplementation. Furthermore, the lack of effect on peak power and mean power, and, perhaps more striking, the improvement in time to reach peak power following beetroot juice supplementation were not dependent on athletes' sport level. Our results indicate that beetroot juice supplementation can improve the capacity to accelerate during sprints, with no differences in the responsiveness between recreational, competitive and elite athletes performing in sports characterized by high-intensity, intermittent type exercise.

Since nitrate supplementation is more effective under conditions of low oxygen availability and low $\mathrm{pH}$, we further investigated the effects of beetroot juice supplementation in elite athletes using two hypoxic settings in water polo players; the 'local hypoxia' of an intermittent performance test and the 'systemic hypoxia' of a dynamic apnea test (chapter 7). No effect of beetroot juice supplementation was seen for the intermittent test, that may not have created a sufficient oxygen deprivation in this group of elite athletes. For the dynamic apnea test, however, we observed a performance benefit following beetroot juice supplementation, indicating a potential benefit of nitrate supplementation for hypoxic exhaustive exercise in elite athletes.

Besides direct performance enhancements, the vasodilatory properties of nitrate may provide other beneficial effects during exercise. In the final study described in chapter 8, we hypothesized that nitrate ingestion could improve splanchnic blood flow and attenuate the gut injury induced by high-intensity 


\section{Summary}

exercise. In contrast to what was previously shown for a different NO donor (Lcitrulline), we observed no beneficial effects of nitrate supplementation, which might be related to the different NO pathway stimulated by nitrate compared to Lcitrulline supplementation. We also investigated the effects of sucrose ingestion, as macronutrients are known to increase splanchnic blood flow at rest. In agreement, sucrose ingestion attenuated gut injury during and post-exercise as shown by an attenuated increase in plasma intestinal fatty acid binding protein (I-FABP) levels. We concluded that sucrose but not nitrate intake, prior to and during

high-intensity exercise can be used as a strategy to reduce gastrointestinal injury and may lower the risk of gastrointestinal complaints.

The final chapter encompasses the primary findings of this thesis and practical advises for the use of nitrate supplementation by athletes. In this relatively new field of research there are still several questions to be answered before reaching a definite consensus on how nitrate supplementation can best be used to induce its proposed ergogenic effects. However, this thesis shows that there is a potential for beneficial effects of nitrate supplementation when taking the supplementation protocol, exercise conditions, and characteristics of the athlete into account. 


\section{Valorization}

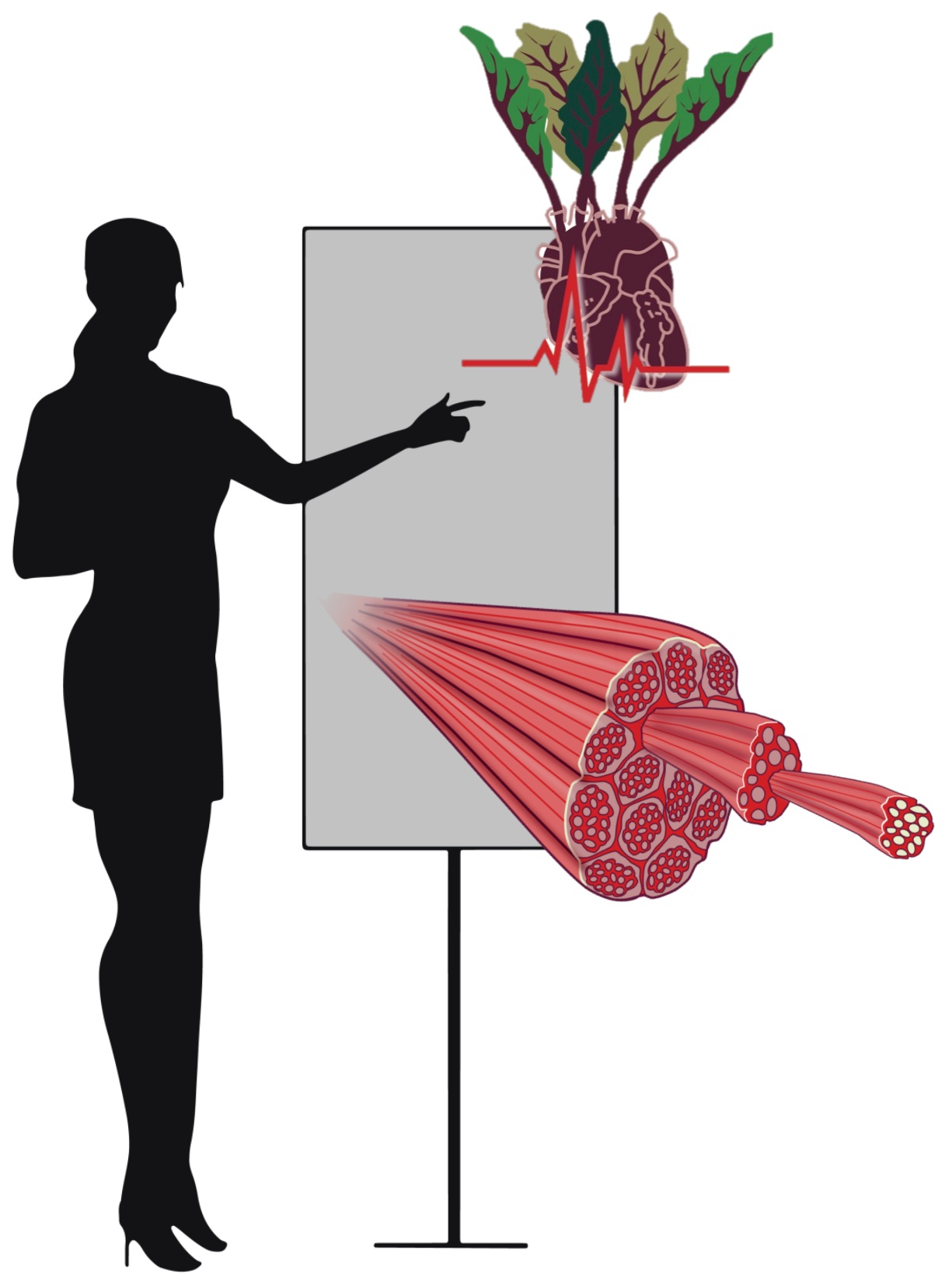




\section{Relevance}

Worldwide there is a high prevalence of dietary supplement use among athletes, and particularly in elite athletes [1]. Beetroot juice is one of the supplements that has been increasingly used over the past decade and which has also received plentiful research attention, generally aimed at establishing robust evidence for the enhancement of sports performance by nitrate supplementation. However, it is difficult to translate research results directly to sport-specific performance, as most research is performed in laboratory situations that are in many ways different from real-life issues in everyday sports practice [2]. Furthermore, only a handful studies have investigated the effect of beetroot juice supplementation in elite athletes, and the translation of research findings in less trained athletes to elite sports performance is highly questionable. The current thesis included both well-trained and elite athletes who were tested in applied settings, using sport-specific tests, and simulating actual competitive settings as much as possible. As such, we aimed to gain knowledge about the effects of beetroot juice on sport performance that can readily be implemented in a practical (top)sport setting.

\section{Recommendations to athletes}

Apart from gaining further scientific insight into the ergogenic properties of nitrate, as described in this thesis, one of the key aims of the entire project was to provide practical recommendations for the use of beetroot juice in the Dutch top-sports sector. To achieve this, direct top-sport performance was tested when possible, by including Dutch national selections that were willing to go through the effort and time strain of an intervention study. Furthermore, the effects of nitrate supplementation on exercise performance and functional mechanisms were investigated in highly trained recreational individuals, and different dietary nitrate sources were tested in less trained subjects to determine the optimal supplementation protocol.

Based on the findings of the current thesis and other relevant recent literature, information for the efficient use of nitrate as an ergogenic aid can and will be provided to the Dutch top-sport sector. This information will be differentiated on type of sports and sport level of the athletes, and will be presented to sport dietitians, medical professionals, and other staff in (professional) sports. The translation of valid and reliable scientific information into practicebased guidelines is a step that is too often missing, resulting in inadequate and inconsistent advices to athletes and staff. The close collaboration with the Dutch Olympic committee (NOC*NSF), Sports Centre Papendal, and the top-sports practice has been important for the practical relevance of the studies of the current thesis. Dissemination of the acquired scientific knowledge toward the top-sports 
sector (using these same stakeholders) forms an essential asset to ensure the relevance in terms of actual implementation of performance-enhancing strategies in daily sports practice. Apart from this thesis, several newsletter publications, factsheets, seminars, workshops and master classes have been and will be organized in collaboration with NOC*NSF and Sports Centre Papendal to increase the knowledge on dietary nitrate and sports performance within sport professionals and athletes. For instance, we are currently updating the NOC*NSF factsheet on beetroot juice, based on our findings and current literature. We will implement upto-date knowledge on the type of athletes and sports that are either more or less likely to benefit from nitrate supplementation. The setup and content of the factsheet has been discussed within the sports nutrition team of NOC*NSF and a consensus was made around the use of beetroot juice and recommendations for implementation per sports federation. Furthermore, nitrate-rich menus have been implemented in the Topsport restaurant at Sports Centre Papendal (the training center for many of the Dutch national selection teams) including information about the benefits of a vegetable- and nitrate-rich diet for athletes. Moreover, an infographic 'thesis for dummies' and a promotion movie have been developed to be used in the education of sport and nutrition students and to inform the general public about the results of this thesis, all in order to further facilitate knowledge development as well as decision making in terms of when and when not to use dietary nitrate as an ergogenic aid.

\section{Societal relevance}

Apart from the direct relevance for the Dutch top-sports sector, the results of the current thesis may also be of interest to the general population as a means to improve individual performance, but also to improve general health by means of the cardioprotective and blood pressure reducing properties of dietary nitrate. Potentially of even greater importance, is the use of dietary nitrate supplementation in more compromised (clinical) populations [3, 4]. By improving exercise tolerance, nitrate supplementation could serve as a nutritional strategy to facilitate the general health benefits of regular exercise in, for example, the elderly and/or patients with type 2 diabetes, cardiovascular diseases, and COPD. Furthermore, the results from chapter 4 concerning the effects of different nitrate-rich vegetables on blood pressure reduction could be highly relevant for patients with hypertension, and potentially even overcome the need of anti-hypertensive drugs [5]. Based on the findings of the current thesis, information can be provided to the general population about the possible beneficial effects of a vegetable- and nitrate-rich diet. This could be through the use of factsheets about the health effects of increasing the intake of nitrate-rich vegetables and practical guidelines 
on how to increase habitual vegetable intake and which vegetables are the most nitrate-rich. The factsheets and guidelines could be implemented in different settings, such as for high schools to increase vegetable intake in adolescents and reduce the risk of future health complications. Alternatively, and likely more realistic for the short(er)-term, information should be communicated to dietitians involved in advising patients with cardiovascular disease and/or hypertension. Furthermore, a currently ongoing $\mathrm{PhD}$ project in our lab extends on the findings from the current thesis by investigating clinical and health benefits of increased nitrate consumption through the habitual diet, and strategies to increase the feasibility of a more vegetable- and nitrate-rich diet.

\section{Personal perspective}

Over the past 4 years, I have combined my research as a $\mathrm{PhD}$ student with my role as a sport dietitian at NOC*NSF. Being a part of both worlds, I have experienced the differences of the relatively slow but very thorough process of gaining answers in research compared to the black-and-white need for 'quick fix' answers in the practical approach of the top-sport setting. It has been a great challenge trying to bridge the two worlds and to make sure to incorporate the best of both without creating conflicts. Furthermore, I have realized that involving elite athletes in research solely developed by a research group is a rather challenging approach. Involving coaches and staff in the setup of a scientific study and base the research question (partly) on practical issues of the specific team, is crucial for the success of a research project in top-sports, as it creates the commitment and enthusiasm necessary for the completion of a time consuming and burdensome intervention study.

My personal goal is to further extend my involvement in high quality research to gain (top)sport nutrition knowledge that can be directly translated into practical advice and guidelines to enhance (top)sport performance. In this respect, I believe that it is crucial to focus on strategies that facilitate practical implementation of available sport nutrition research findings. On the other hand, further collaboration between academia and (top)sport institutes is necessary to address research questions that are directely relevant to the professional sports practice. Increased emphasis on these aspects can bring the fields of research and sport practice closer together, optimizing the support of nutrition to enhance sports performance. 


\section{References}

1. Knapik, J.J., et al., Prevalence of Dietary Supplement Use by Athletes: Systematic Review and MetaAnalysis. Sports Med. 2016;46(1):103-23.

2. Burke, L.M., Practical Issues in Evidence-Based Use of Performance Supplements: Supplement Interactions, Repeated Use and Individual Responses. Sports Med. 2017;47(Suppl 1):79-100.

3. Machha, A. and A.N. Schechter, Dietary nitrite and nitrate: a review of potential mechanisms of cardiovascular benefits. Eur J Nutr. 2011;50(5):293-303.

4. Kenjale, A.A., et al., Dietary nitrate supplementation enhances exercise performance in peripheral arterial disease. J Appl Physiol (1985). 2011;110(6):1582-91.

5. Ghosh, S.M., et al., Enhanced vasodilator activity of nitrite in hypertension: critical role for erythrocytic xanthine oxidoreductase and translational potential. Hypertension. 2013;61(5):1091-102. 



\section{Dankwoord \\ Curriculum Vitae \\ List of publications}

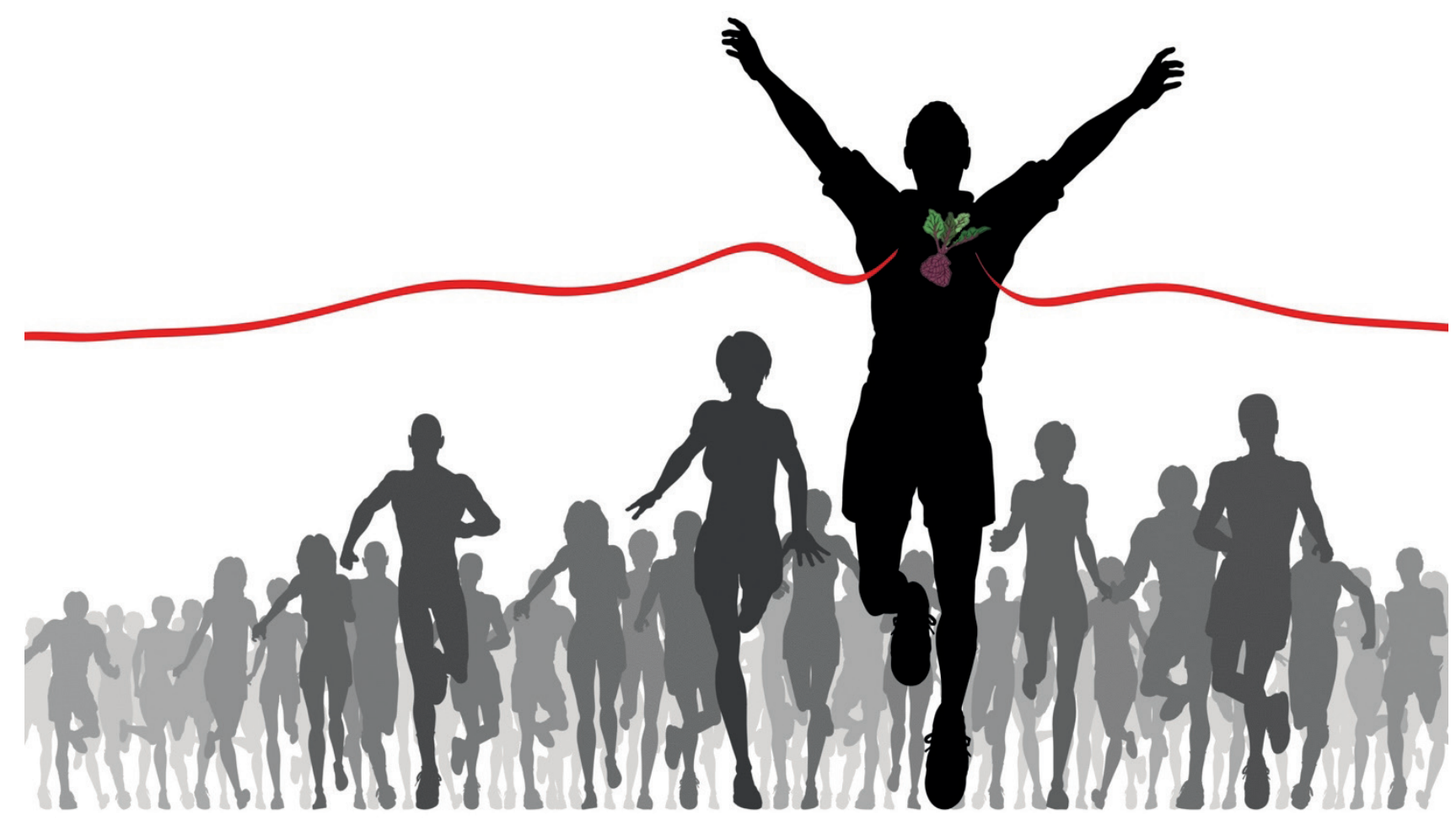




\section{Dankwoord}

\section{Dankwoord}

Promoveren kan en wil je niet alleen doen, en wil daarom graag iedereen bedanken die bijgedragen heeft aan mijn ontwikkeling en de tot stand komen van dit proefschrift. Met jullie steun heb ik deze mijlpaal kunnen bereiken. Een aantal mensen wil ik in het bijzonder bedanken.

Lex, bedankt voor al je steun, feedback en leuke discussies. Jouw deur staat altijd open en je bent altijd erg betrokken bij alle aspecten van mijn PhD traject. Dankzij jouw heb ik enorm veel geleerd over het analyseren van data en het schrijven van goede manuscripten. Gelukkig reken je geen uurtarief, dan was ik nu zo arm als een kerkrat. Verder ben ik heel dankzaam dat je me vrij hebt durven laten in het zelfstandig uitvoeren van een aantal veldstudies, waardoor ik als wetenschapper veel gegroeid ben.

Luc, wat heb je me enthousiast gemaakt voor de wetenschap! Ik kwam binnen als een sportdiëtiste die wat met onderzoek wilde gaan doen, en nu voel ik me als een wetenschapper die de wereld van sportdiëtetiek wil verbeteren. Jouw passie, zowel voor de wetenschap als voor je M3 familie, is zeer belangrijk geweest voor mijn $\mathrm{PhD}$. Ik voelde me gelijk deel van het team en dat ik mezelf kon zijn. Ik bewonder jouw manier om moeilijke onderwerpen simpel te maken en je duidelijke statements in presentaties en artikelen. En elke keer dat ik nu iets schrijf hoor ik jouw stem zeggen; "één zin, één boodschap".

Cindy, wat hebben wij een leuke PhD-tijd samen gehad! Bedankt voor alle praatjes samen in de auto op weg naar Maastricht, bij de B\&B tijdens het half jaar "samenwonen", op de fiets, tijdens het rennen. Als dé praktische wetenschappers, ofdewel de HANers in de M3 groep hebben we samen neergezet dat praktisch onderzoek ook erg goed kan zijn. Beet us if you can!

Joan, jij bent mijn schutsengel geweest al deze jaren. Wat een interesse je hebt getoond in mijn projecten, veel meer dan de analyses die je moest doen. Met een grote rugzak vol droogijs naar Amsterdam, drie uur's nachts prikken op Texel en al onze lunchloopjes; ik ga het nooit vergeten. Tusen takk for hjelpen med alle studiene og spørsmålene mine.

Astrid, bedankt voor alle uren luisteren naar mijn frustraties of successen. Zowel op kantoor in het eerste PhD jaar als tijdens al onze duurlopen. En mijn Nederlands was nooit zo goed zonder jouw opmerkingen. En wat hebben we ook gelachen over 
mijn foute uitdrukkingen; "waar een wil is, wil ik weg." Desalniettemin heb je vast wat vooruitgang bij mij gezien en zou ik het op prijs stellen als je me wil helpen om mijn Nederlands scherp te houden in de toekomst.

Antoine, je gaat nogsteeds "als een stier". Bedankt voor een leuke tijd op kantoor samen en voor al hulp met analyses, prikken en Nederlandse uitspraken. Jouw Noorse uitspraak ga ik hier maar niet benoemen.

Jean, bedankt voor de erg fijne samenwerking. De eerste studies samen uitvoeren en vervolgens ons eigen pad bewandelen werkte voor mij heel goed. En van jou heb ik veel geleerd over nauwkeuring werken, geduld hebben en niet te druk maken over zaken waar je geen controle over hebt.

Philippe, wat heb jij me vaak geholpen de laatste jaren. Je toont altijd interesse en biedt altijd je hulp aan, dat stel ik ontzettend op prijs. Ook veel leuke gesprekken op kantoor, mooie fietstochten en leuke ervaringen met testen zowel op Papendal als op Texel.

Kaatje, bedankt voor al steun tijdens het laatste jaar van het project. Het was leuk om een nieuw vakgebied in te duiken en ik stel je inzet en interesse om een mooi samenwerkingsproject te realiseren heel erg op prijs.

M3 collega's, wat zijn we een goed team. Bedankt Andy, Cas, Evelien, Fleur, Imre, Joey, Jorn, Joy, Jeanneu, Lisanne Maarten, Marlou, Michelle, Milou, Rachel, Rinske, Stefan, Tim en Tyler voor de fijne samenwerking in de afgelopen jaren. Het is niet van zelfsprekend dat iedereen in een onderzoeksgroep elkaar steunt waar nodig, interesse toont voor elkaars projecten en gezellige uitjes en congressen samen meemaken.

Jan-Willem, eerst even in Maastricht en vervolgens collega en teamleider op de HAN. Bedankt voor je grote interesse in mijn projecten, je denkt altijd mee, stelt de juiste vragen en hebt een enorme inzet. Vooral in het koppelen van wetenschap en praktijk heb ik veel aan jou kennis en ideeën gehad.

Joris, bedankt voor het in mij geloven en het geven van ruimte voor mijn projecten op de HAN. Als directeur ben je erg goed in het je 'zien en horen' van je medewerkers, daar heb ik zelf veel aan gehad. Bedankt voor je enthousiasme en interesse zowel in mijn onderzoeken als in mijn persoonlijke ontwikkeling.

Floris, jij hebt me als "buitenlandse potentiaal" binnengehaald en vanaf het begin in me geloofd, ik wil je daar ontzettend voor bedanken. Als teamleider gaf je me de ruimte te ontwikkelen en mijn idëeen uit te voeren. Van jouw passie en out-ofthe-box manier van denken heb ik heel veel geleerd.

Kevin, bedankt voor de supergoede samenwerking afgelopen jaar. De promotie moeten afronden en tegelijkertijd de trainingsstudie op de HAN draaien was nooit 


\section{Dankwoord}

zonder jou gelukt. Al het harde werken, de frustratiemomenten, de slappe lachen en genieten van mooie resultaten samen was het moeite waard.

Karin, wat hebben we een mooie proefschrift samen opgesteld. Ik ben er erg trots op en dankzij jouw creatieviteit, passie en inzet is het allemaal gelukt.

Team SEN, wat zijn wij een dream team. Passie, samenwerken, 'elkaars rug dekken', creativiteit, toffe projecten en een vertrouwelijke werkomgeving, allemaal dankzij jullie. Bedankt Tjieu, Nick, Gert, Heleen, Ingrid, Naomi, Joline, Luuk, Luuk, Rob en Shiannah.

Kamiel, bedankt voor al steun vanuit het NOC*NSF al deze jaren. In mij geloven terwijl ik drie zinnen Nederlands sprak tijdens het sollicitatiegesprek bij NOC*NSF team voeding. Ook bedankt voor onze leuke discussies en projecten zowel bij NOC*NSF team voeding als binnen het PhD project. Dankzij jouw inzet en netwerk hebben we hele unieke topsport-studies kunnen uitvoeren.

Sigrid, Line, Majuri, Annette, Ane, Ria, gode venner har du for livet. Det er virkelig sant når det gjelder dere. Etter 7,5 år i Nederland er det fremdeles det samme når jeg kommer hjem, og dere har vært der for meg hele tiden. Tusen takk for all støtte, veldig glad for at jeg har dere i livet mitt. Blir fint å komme hjem igjen og ses mye oftere.

Lena, min eneste norske venninne i Nederland. Takk for alle gode samtaler i løpet av årene og for støtten som landskvinne.

Mamma, Pappa, Erik, tusen takk for all støtte hele veien. At jeg bestemte meg for å dra til Nederland og bli værende i så mange år kan ikke ha vært enkelt. Men dere har backet meg opp hele veien og hjulpet meg i å nå målene jeg har satt meg på veien. Mamma, alle de timene med gjennomlesning av mine tekster og alle spørsmålene jeg har hatt, takk for tålmodigheten og at du alltid hjelper meg. Pappa, for noen gode diskusjoner vi har hatt rundt diverse temaer i løpet av min PhD. Tusen takk for at du alltid er interessert og stiller spørsmål ved det jeg gjør. Erik, tusen takk for de gode samtalene. Du setter ting i et annet perspektiv og får meg til å tenke mer helhetlig rundt det jeg gjør. Gleder meg til å få mer kvalitetstid med dere alle sammen. 


\section{Curriculum Vitae}

Kristin Lundanes Jonvik was born on September 24, 1987 in Oslo, Norway. She completed secondary school at Wang Toppidrettsgymnas in Oslo in 2006. In the same year, she started her Bachelor program of Nutrition at the University of Oslo, obtaining her BSc diploma in 2009. Immediately after that, she started her Master's degree in Clinical nutrition at the University of Oslo, and conducted her Master thesis at the Norwegian Olympic Committee entitled 'Vitamin D status among female handball and football elite athletes in Norway at latitude $60^{\circ} \mathrm{N}^{\prime}$, which entitled her Master of Sciences in 2011. At the end of the writing period of the Master thesis, she had moved to the Netherlands and worked as a dietitian in 2011, both in hospital and private clinic. From 2012, she was hired as part-time sport dietitian at the Dutch Olympic Committee (NOC*NSF), which also developed into a fulltime position as lecturer, sport dietitian, and researcher at HAN University of Applied Sciences in Nijmegen. In cooperation with the HAN, Kristin started her PhD at the Department of Human Biology at Maastricht University within the NUTRIM School of Nutrition and Translational Research in Metabolism under the supervision of Associate Professor Lex Verdijk and Professor Luc van Loon. Kristin conducted a project funded by the Dutch Technology Foundation STW titled 'Beet-ing your competitors: Dietary nitrate to enhance sports performance' together with PhD student Jean Nyakayiru. Kristin's part of the project focused on dietary nitrate to enhance elite sports performance, resulting in this thesis. During her PhD, Kristin attended several national and international conferences and was awarded top-5 finalist for the GSSI Sport Nutrition Award at the European College of Sports Sciences congress both in Malmø, Sweden in 2015 and in Essen, Germany in 2017. Throughout the PhD trajectory, Kristin continued working part-time as a sport dietitian at NOC*NSF, counselling the Dutch Olympic sailors and wind surfers. From August 2017 until August 2018, Kristin has worked as a researcher and project leader of a one-year training study on protein and endurance training at the HAN University of Applied Sciences, while finishing the PhD thesis. From September 2018 she will move back to Norway to continue her career as a researcher and dietitian in (elite) sports. 


\section{List of publications}

\section{Published}

Jonvik KL, Nyakayiru J, van Dijk JW, Maase K, Ballak SB, Senden JM, van Loon LJ, Verdijk LB. Repeated-sprint performance and plasma responses following beetroot juice supplementation do not differ between recreational, competitive and elite sprint athletes. Eur J Sport Sci. 2018 Feb 7:1-10.

Jonvik KL, Van Dijk JW, Senden JMG, Van Loon LJC, Verdijk LB. The Effect of Beetroot Juice Supplementation on Dynamic Apnea and Intermittent Sprint Performance in Elite Female Water Polo Players. Int J Sport Nutr Exerc Metab. 2017 Dec 18:1-20.

Jean Nyakayiru, Kristin L. Jonvik, Jorn Trommelen, Philippe J. M. Pinckaers, Joan M. Senden, Luc J. C. van Loon, Lex B. Verdijk. Beetroot Juice Supplementation Improves High-Intensity Intermittent Type Exercise Performance in Trained Soccer Players. Nutrients 2017, 9(3), 314.

Jonvik KL, Nyakayiru J, Van Dijk JW, Wardenaar FC, Van Loon LJ, Verdijk LB. Habitual Dietary Nitrate Intake in Highly Trained Athletes. Int J Sport Nutr Exerc Metab. 2016 Oct 21:1-25.

Jenna B. Gillen, Jorn Trommelen, Floris C. Wardenaar, Naomi Y.J. Brinkmans, Joline J. Versteegen, Kristin L. Jonvik, Christoph Kapp, Jeanne de Vries, Joost J.G.C. van den Borne, Martin J. Gibala, Luc J.C. van Loon. Trained athletes typically consume well above $1.2 \mathrm{~g}$ dietary protein per kg body weight per day. Int J Sport Nutr Exerc Metab. 2016 Oct 6:1-23.

Nyakayiru J*, Jonvik KL*, Pinckaers PJ, Senden J, Van Loon LJ, Verdijk LB. No Effect of Acute and 6-Day Nitrate Supplementation on VO2 and Time-Trial Performance in Highly-Trained Cyclists. Int J Sport Nutr Exerc Metab. 2016 Sep 6:1-25. * Shared $\beta^{t}$ authorship.

Jonvik KL, Nyakayiru J, Pinckaers PJ, Senden JM, van Loon LJ, Verdijk LB. NitrateRich Vegetables Increase Plasma Nitrate and Nitrite Concentrations and Lower Blood Pressure in Healthy Adults. J Nutr. 2016 May;146(5):986-93.

Jonvik KL, Nyakayiru J, van Loon LJ, Verdijk LB. Last Word on Viewpoint: Can elite athletes benefit from dietary nitrate supplementation? J Appl Physiol (1985). 2015 Sep 15;119(6):770.

Jonvik KL, Nyakayiru J, van Loon LJ, Verdijk LB. Can elite athletes benefit from dietary nitrate supplementation? J Appl Physiol (1985). 2015 Sep 15;119(6):759-61. 
Submitted for publication:

Jonvik KL, Lenaerts K, Smeets JSJ, Kolkman J, van Loon LJC, Verdijk LB. Sucrose but not nitrate ingestion reduces strenuous cycling-induced intestinal injury. Submitted. 
Financial support for the printing of this thesis was kindly provided by:
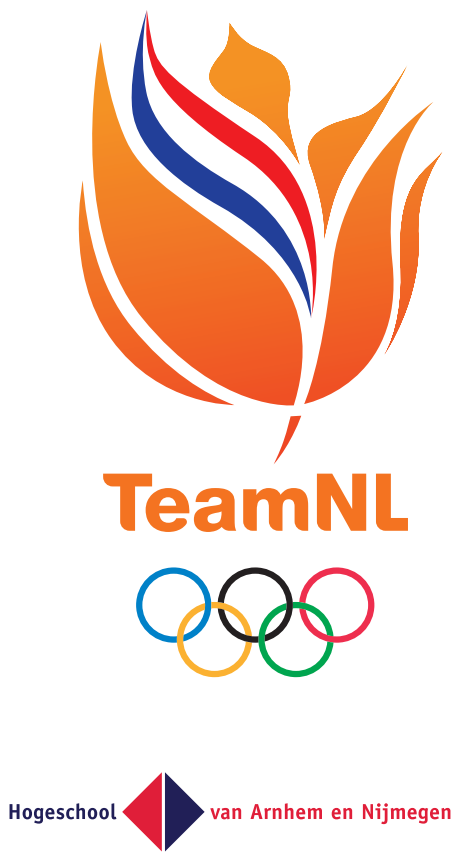

\section{H A N \\ SENECA}

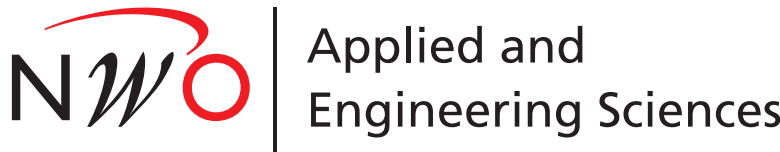

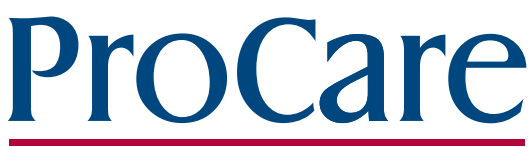

We take intensive Care

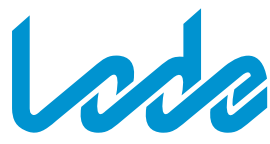

FOR LIFE/MOVERSTANDING 